\title{
Review of Resolution of \\ Known Problems in Engine \\ Components for Transamerica \\ Delaval Inc. Emergency Diesel \\ Generators
}

December 1985

Prepared for

the U.S. Nuclear Regulatory Commission

under Contract DE-AC06-76RLO 1830

NRC FIN B2952

Pacific Northwest Laboratory

Operated for the U.S. Department of Energy

by Battelle Memorial Institute 


\title{
DISCLAIMER
}

This report was prepared as an account of work sponsored by an agency of the United States Government. Neither the United States Government nor any agency thereof, nor any of their employees, makes any warranty, express or implied, or assumes any legal liability or responsibility for the accuracy, completeness, or usefuiness of any information, apparatus, product, or process disclosed, or represents that its use would not infringe privately owned rights. Reference herein to any specific commercial product, process, or service by trade name, trademark, manufacturer, or otherwise, does not necessarily constitute or imply its endorsement, recommendation, or favoring by the United States Government or any agency thereof. The views and opinions of authors expressed herein do not necessarily state or reflect those of the United States Government or any agency thereof.

\author{
PACIFIC NORTHWEST LABORATORY \\ operated by \\ BATTELLE \\ for the \\ UNITED STATES DEPARTMENT OF ENERGY \\ under Contract DE-AC06-76RLO 1830
}




\author{
Technical Evaluation Report \\ REVIEW OF \\ RESOLUTION OF KNOWN PROBLEMS \\ IN ENGINE COMPONENTS \\ FOR TRANSAMERICA DELAVAL INC. \\ EMERGENCY DIESEL GENERATORS
}

Decenter 1985

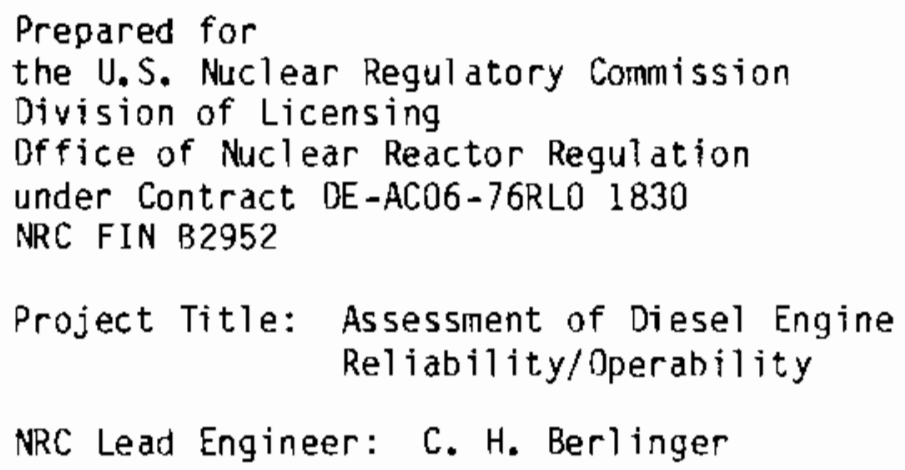





\section{PACIFIC NORTHWEST LABORATORY}

PROJECT APPROVALS

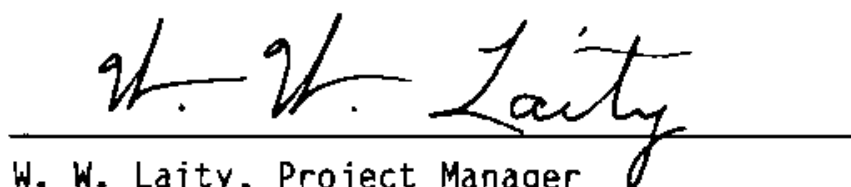

Date December 12,1985

Pacific Northwest Laboratory

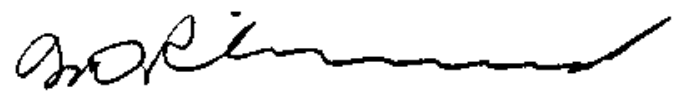

Date $62-13-95$

W. D. Richmond, Chairman Senior Review Panel

Pacific Northwest Laboratory 



\section{FOREWORD}

This report is supplied as part of the Technical Assistance Project, Assessment of Diesel Engine Reliability/Operability being conducted for the U.S. Nuclear Regulatory Commission, Office of Nuclear Reactor Regulation, Division of Licensing, by the Pacific Northwest Laboratory. The U.S. Nuclear Regulatory Commission funded this work under authorization B\&R 20-19-40-42-1 FIN No. B2952. 



\section{ACKNOWLEDGMENTS}

The expertise and energies of many people were applied to the technical evaluation documented in this report. In addition to the PNL project team members, participants in this effort included consultants from both the U.S. and abroad as well as other PNL scientists and engineers. The contributions of the following individuals are gratefully acknowledged:

\section{CONSULTANTS}

- S. H. Bush, Review and Synthesis Associates

- H. Engja, Norwegian Marine Technology Research Institute

- H. M. Hardy, P.E.

- A. J. Henriksen, A. J. Henriksen, Inc.

- J. E. Horner, Seaworthy Systems, Inc.

- B. J. Kirkwood, Covenant Engineering

- E. Loftus, Kaiser Engineers Hanford

- P. J. Louzecky, Engineered Applications Corporation

- H. R. McSpadden, Ph.D.

- N. N. Rivera, Designers and Planners, Inc.

- E. Sandberg, Det Norske Veritas

- the late A. Sarsten, Norwegian Institute of Technology

- T. W. Spaetgens, P.E.

- H. Valland, Norwegian Marine Technology Research Institute

- J. V. Webber, Ricardo Consulting Engineers

- L. Hechsler, Tracor Hydronautics

PNL STAFF

- M. C. C. Bampton

- S. J. Foreman

- K. I. Johnson

- S. G. Pitman

- J. C. Spanner

- C. L. Wilson 
PNL PROJECT TEAM

- J. M. Alzheimer

- M. Clenent

- A. J. Currie

- S. D. Dahigren

- D. A. Dingee

- R. E. Dadge

- W. W. Laity

- J. F. Nesbitt

- F. R. Zaloudek 


\section{CONTENTS}

PACIFIC NORTHWEST LABORATORY PROJECT APPROVALS $\ldots \ldots \ldots \ldots \ldots \ldots \ldots \ldots$

FOREWORD

ACKNOWLEDGMENTS

ABBREVIATIONS

xvi i

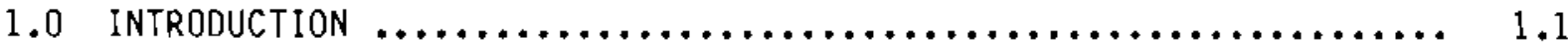

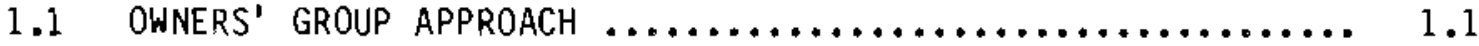

1.2 PACIFIC NORTHWEST LABORATORY APPROACH $\ldots \ldots \ldots \ldots \ldots \ldots \ldots \ldots \ldots . \ldots \ldots$

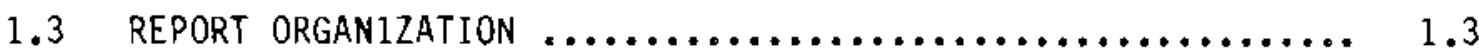

2.0 OVERALL CONCLUSIONS AND RECOMMENDATIONS $\ldots \ldots \ldots \ldots \ldots \ldots \ldots \ldots \ldots . . \ldots \ldots$

2.1 COMPONENTS ADEQUATE FOR NUCLEAR SERVICE TO RATED

ENGINE POWER

2.2 COMPONENTS THAT WARRANT SPECIAL EMPHASIS $\ldots \ldots \ldots \ldots \ldots \ldots \ldots .2 .3$

2.2.1 Connecting Rods for V-Block Engines ........... 2.3

2.2.2 Crankshaft: 8-Cy1inder, DSR-4 Series Engines ..... 2.4

2.2.3 Crankshaft: 20-Cylinder, DSRV-4 Series Engines ... 2.4

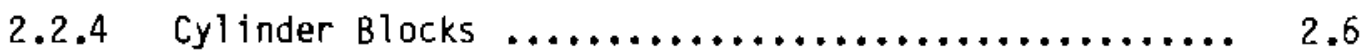

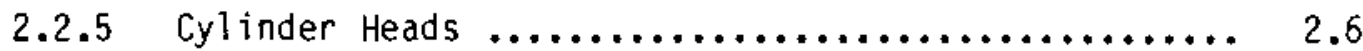

2.2.6 Modified Type AF Piston Skirts $\ldots . . \ldots \ldots \ldots . . . . . .2 .7$

2.2 .7 Turbochargers $\ldots \ldots \ldots \ldots \ldots \ldots \ldots \ldots \ldots \ldots \ldots \ldots \ldots . \ldots . \ldots$

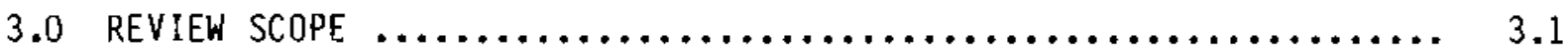

4.0 COMPONENT REVIEWS $\ldots \ldots \ldots \ldots \ldots \ldots \ldots \ldots \ldots \ldots \ldots \ldots \ldots \ldots \ldots \ldots \ldots \ldots$

4.1 AIR START VALVE CAPSCREWS $\ldots \ldots \ldots \ldots \ldots \ldots \ldots \ldots \ldots \ldots \ldots \ldots \ldots . \ldots \ldots$

4.1 .1 Component Description ..................... 4.3

4.1 .2 Failure History $\ldots \ldots \ldots \ldots \ldots \ldots \ldots \ldots \ldots \ldots \ldots \ldots . \ldots . . \ldots \ldots$

4.1 .3 Owners' Group Evaluation $\ldots \ldots \ldots \ldots \ldots \ldots \ldots \ldots \ldots . . \ldots . . . \ldots$ 
4.1 .4 PNL's Review $\ldots \ldots \ldots \ldots \ldots \ldots \ldots \ldots \ldots \ldots \ldots \ldots \ldots, 4.5$

4.1.5 References $\ldots \ldots \ldots \ldots \ldots \ldots \ldots \ldots \ldots \ldots \ldots \ldots \ldots, 4.6$

4.2 AUXILIARY MODULE WIRING AND TERMINATIONS $\ldots \ldots \ldots \ldots \ldots \ldots, 4.7$

4.2.1 Component Description $. \ldots \ldots \ldots \ldots \ldots \ldots \ldots \ldots \ldots, 4.7$

4.2 .2 Failure History $\ldots \ldots \ldots \ldots \ldots \ldots \ldots \ldots \ldots \ldots \ldots, 4.7$

4.2.3 Owners' Group Evaluation $\ldots \ldots \ldots \ldots \ldots \ldots \ldots \ldots \ldots . .6 .6$

4.2.4 PNL's Review ........................... 4.10

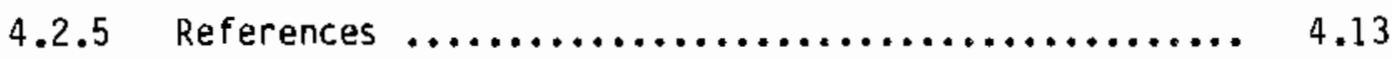

4.3 CDNNECTING RODS: 8-CYLINDER, DSR-4 SERIES ENGINES $\ldots \ldots \ldots .4 .15$

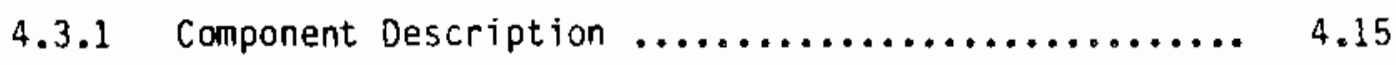

4.3.2 Failure History $\ldots \ldots \ldots \ldots \ldots \ldots \ldots \ldots \ldots \ldots, 4.15$

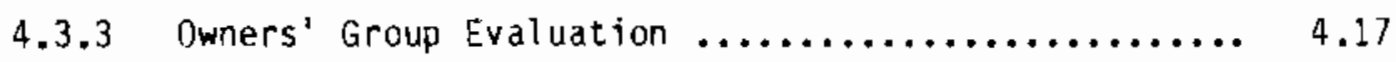

4.3 .4 PNL's Review $\ldots \ldots \ldots \ldots \ldots \ldots \ldots \ldots \ldots \ldots \ldots \ldots, 4.20$

4.3.5 References $\ldots \ldots \ldots \ldots \ldots \ldots \ldots \ldots \ldots \ldots \ldots \ldots \ldots, 4.21$

4.4 CONNECTING RODS: DSRV-4 SERIES ENGINES $\ldots \ldots \ldots \ldots \ldots \ldots \ldots, 4.23$

4.4.1 Component Description $\ldots \ldots \ldots \ldots \ldots \ldots \ldots \ldots \ldots, 4.23$

4.4 .2 Failure History $\ldots \ldots \ldots \ldots \ldots \ldots \ldots \ldots \ldots \ldots \ldots, 4.23$

4.4.3 Owners' Group Evaluation $\ldots \ldots \ldots \ldots \ldots \ldots \ldots \ldots \ldots . .4 .26$

$4.4 .4 \quad$ PNL's Review $. \ldots \ldots \ldots \ldots \ldots \ldots \ldots \ldots \ldots \ldots \ldots, 4.32$

4.4.5 References $\ldots \ldots \ldots \ldots \ldots \ldots \ldots \ldots \ldots \ldots \ldots \ldots \ldots \ldots, 4.39$

4.5 CONNECTING ROD BEARING SHELLS $\ldots \ldots \ldots \ldots \ldots \ldots \ldots \ldots \ldots, 4.41$

4.5.1 Component Description $\ldots \ldots \ldots \ldots \ldots \ldots \ldots \ldots \ldots \ldots, 4.41$

4.5 .2 Failure History $\ldots \ldots \ldots \ldots \ldots \ldots \ldots \ldots \ldots \ldots \ldots, 4.41$

4.5 .3 Owners' Group Evaluation $\ldots \ldots \ldots \ldots \ldots \ldots \ldots \ldots \ldots .6 .4 .42$

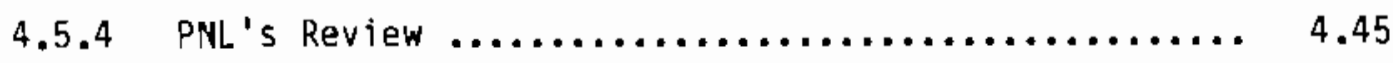

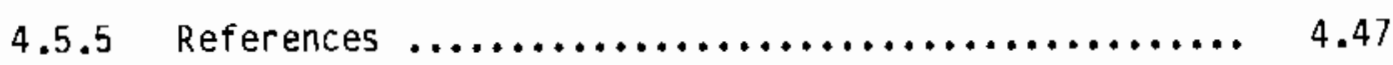


4.6 CRANKSHAFT: 8-CYLINDER, DSR-4 SERIES ENGINES $\ldots \ldots \ldots \ldots \ldots \ldots 4.49$

4.6.1 Component Description ................... 4.49

4.6.2 Design Guidelines ........................ 4.49

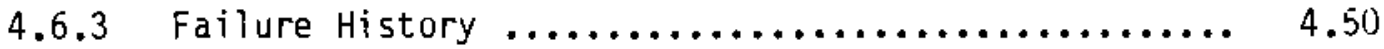

4.6.4 Owners' Group Evaluation: Shoreham Engines ....... 4.51

4.6.5 PNL's Review: Shoreham Engines ............. 4.55

4.6.6 Owners' Group Evaluation: River Bend Engines ..... 4.61

4.6.7 PNL's Review: River Bend Engines ............. 4.69

4.6.8 Extension of Conclusions to Other 8-Cyitinder

TDI Engines ............................ 4.73

4.6 .9 References $\ldots \ldots \ldots \ldots \ldots \ldots \ldots \ldots \ldots \ldots \ldots \ldots \ldots \ldots \ldots \ldots .74$

4.7 CRANKSHAFT: 16 -CYLINDER, DSRV-4 SERIES ENGINES $\ldots \ldots \ldots \ldots \ldots \quad 4.77$

4.7 .1 Component Description .................. 4.77

4.7 .2 Design Guidelines $\ldots \ldots \ldots \ldots \ldots \ldots \ldots \ldots \ldots \ldots \ldots \ldots . . \ldots \ldots$

4.7 .3 Failure History $\ldots \ldots \ldots \ldots \ldots \ldots \ldots \ldots \ldots \ldots \ldots \ldots .4 .78$

4.7.4 Owners' Group Evaluation: Grand Gulf Engines ...... 4.78

4.7.5 Owners' Group Evaluation: Perry Engines ......... 4.84

4.7.6 Owners' Group Evaluation: Catawba Engines ....... 4.86

4.7.7 Owners' Group Evaluation: Comanche Peak Engines ... 4.87

$4.7 .8 \quad$ PNL's Review $\ldots \ldots \ldots \ldots \ldots \ldots \ldots \ldots \ldots \ldots \ldots \ldots \ldots \ldots . . .48$

4.7.9 Extension of Conclusions to Other 16-Cylinder

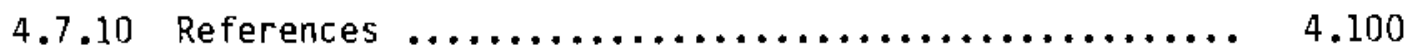

4.8 CRANKSHAFT: 20 -CYLINDER, DSRV -4 SERIES ENGINES $\ldots \ldots \ldots \ldots \ldots .4 .103$

4.8.1 Component Description .................... 4.103

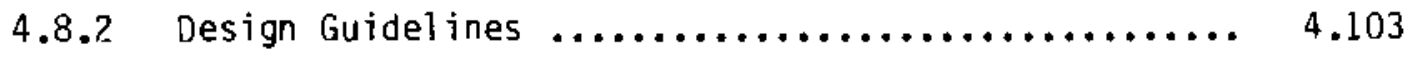

4.8 .3 Operating History ...................... 4.104 
4.8.4 Owners' Group Evaluation .................... 4.105

4.8.5 PNL's Review ............................. 4.116

4.8.6 References $\ldots \ldots \ldots \ldots \ldots \ldots \ldots \ldots \ldots \ldots \ldots \ldots \ldots, 4.135$

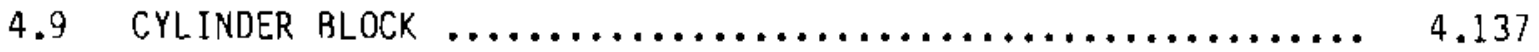

4.9.1 Component Description ........................ 4.137

4.9.2 Service History ............................. 4.137

4.9.3 Owners' Group Evaluation ...................... 4.139

4.9.4 Atomic Safety and Licensing Board Hearing on

4.9.5 PNL's Review ............................. 4.145

4.9.6 References ................................ 4.149

4.10 CYLINDER HEADS $\ldots \ldots \ldots \ldots \ldots \ldots \ldots \ldots \ldots \ldots \ldots \ldots \ldots \ldots \ldots \ldots \ldots \ldots, 4.151$

4.10.1 Component Description $. . . \ldots \ldots \ldots \ldots \ldots \ldots \ldots \ldots, 4.151$

4.10 .2 Failure History $\ldots \ldots \ldots \ldots \ldots \ldots \ldots \ldots \ldots \ldots \ldots, 4.152$

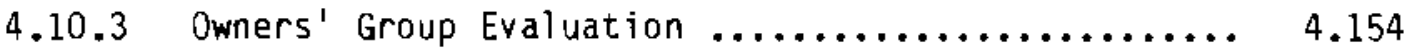

4.10 .4 PNL's Review .............................. 4.156

4.10.5 References $. \ldots \ldots \ldots \ldots \ldots \ldots \ldots \ldots \ldots \ldots \ldots \ldots, 4.160$

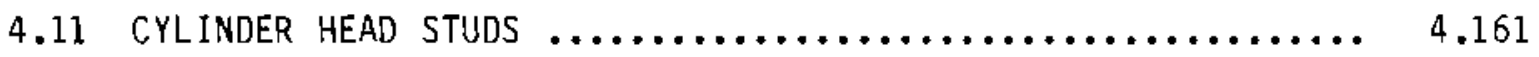

4.11.1 Component Description ....................... 4.161

4.11 .2 Failure History $\ldots \ldots \ldots \ldots \ldots \ldots \ldots \ldots, \ldots, \ldots, 4.161$

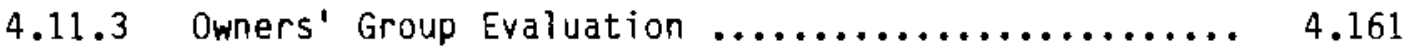

4.11.4 PNL's Review .............................. 4.163

4.11.5 References ............................... 4.164

4.12 ENGINE BASE AND BEARING CAPS: 8 -CYLINDER, DSR -4
SERIES ENGINES $\ldots \ldots \ldots \ldots \ldots \ldots \ldots \ldots \ldots \ldots \ldots \ldots \ldots \ldots \ldots \ldots \ldots \ldots \ldots \ldots$

4.12.1 Component Description $. \ldots \ldots \ldots \ldots \ldots \ldots \ldots \ldots \ldots . .4 .165$

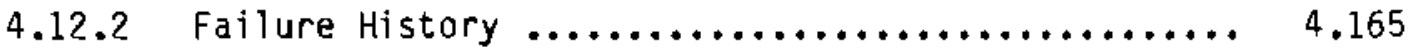


4.12 .3 Owners' Group Evaluation ................. 4.166

$4.12 .4 \quad$ PNL's Review $\ldots \ldots \ldots \ldots \ldots \ldots \ldots \ldots \ldots \ldots \ldots \ldots \ldots \ldots . \ldots . \ldots \ldots$

4.12 .5 References $\ldots \ldots \ldots \ldots \ldots \ldots \ldots \ldots \ldots \ldots \ldots \ldots \ldots \ldots . \ldots . \ldots \ldots 17$

4.13 ENGINE BASE AND BEARING CAPS: DSRV-4 SERIES ENGINES ..... 4.173

4.13 .1 Component Description .................. 4.173

4.13 .2 Failure History $\ldots \ldots \ldots \ldots \ldots \ldots \ldots \ldots \ldots \ldots \ldots \ldots . \ldots \ldots .173$

4.13 .3 Owners' Group Evaluation $\ldots \ldots \ldots \ldots \ldots \ldots \ldots \ldots \ldots .4 .173$

4.13 .4 PNL's Review .......................... 4.175

4.13 .5 References $\ldots \ldots \ldots \ldots \ldots \ldots \ldots \ldots \ldots \ldots \ldots \ldots \ldots \ldots . \ldots \ldots . \ldots \ldots$

4.14 FUEL OIL INJECTION TUBING $\ldots \ldots \ldots \ldots \ldots \ldots \ldots \ldots \ldots \ldots \ldots \ldots . \ldots \ldots$

4.14.1 Component Description ................... 4.179

4.14 .2 Failure history $\ldots \ldots \ldots \ldots \ldots \ldots \ldots \ldots \ldots \ldots \ldots . \ldots . \ldots \ldots$

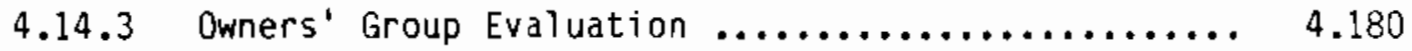

4.14 .4 PNL's Review $\ldots \ldots \ldots \ldots \ldots \ldots \ldots \ldots \ldots \ldots \ldots \ldots \ldots \ldots . . \ldots \ldots 3$

$4.14 .5 \quad$ References $\ldots \ldots \ldots \ldots \ldots \ldots \ldots \ldots \ldots \ldots \ldots \ldots \ldots \ldots . \ldots \ldots$. 4.185

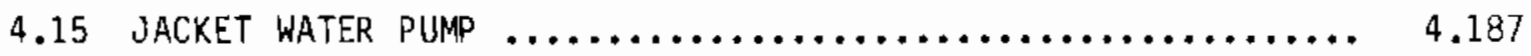

4.15 .1 Component Description ................... 4.187

4.15 .2 Failure History $\ldots \ldots \ldots \ldots \ldots \ldots \ldots \ldots \ldots \ldots \ldots \ldots . \ldots \ldots . \ldots \ldots$

4.15.3 Owners' Group Evaluation ................... 4.189

4.15 .4 PNL's Review .......................... 4.192

$4.15 .5 \quad$ References $\ldots \ldots \ldots \ldots \ldots \ldots \ldots \ldots \ldots \ldots \ldots \ldots \ldots \ldots . \ldots \ldots . \ldots \ldots$

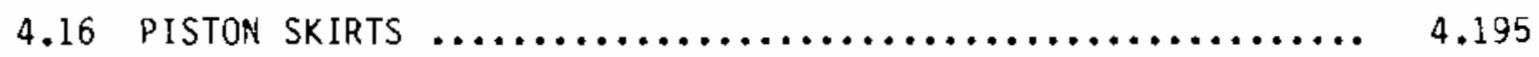

4.16 .1 Component Description .................... 4.195

4.16.2 Piston Skirt Evaluations ................... 4.195

4.16 .3 Type AE Skirt ........................ 4.196

4.16 .4 Modified Type AF Skirt .................. 4.200 
4.16 .5 Type AH Skirt $\ldots \ldots \ldots \ldots \ldots \ldots \ldots \ldots \ldots \ldots \ldots \ldots, 4.205$

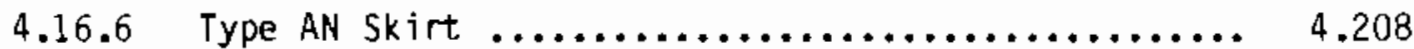

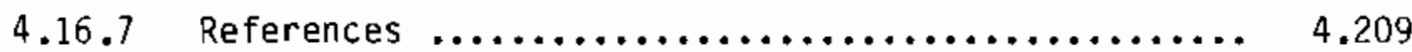

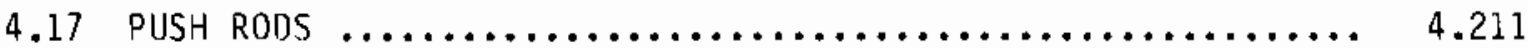

4.17.1 Component Description ...................... 4.211

4.17 .2 Operating History $\ldots \ldots \ldots \ldots \ldots \ldots \ldots \ldots \ldots \ldots, 4.212$

4.17.3 Owners' Group Evaluation .................... 4.212

4.17 .4 PNL's Review $. . \ldots \ldots \ldots \ldots \ldots \ldots \ldots \ldots \ldots \ldots \ldots, 4.215$

4.17 .5 References $\ldots \ldots \ldots \ldots \ldots \ldots \ldots \ldots \ldots \ldots \ldots \ldots \ldots, 4.218$

4.18 ROCKER ARM CAPSCREWS $\ldots \ldots \ldots \ldots \ldots \ldots \ldots \ldots \ldots \ldots \ldots \ldots \ldots \ldots . \ldots \ldots . \ldots \ldots, 4.219$

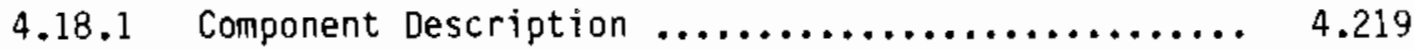

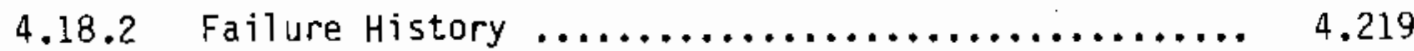

4.18.3 Owners' Group Evaluation $\ldots \ldots \ldots \ldots \ldots \ldots \ldots \ldots \ldots . . .24 .219$

4.18 .4 PNL's Review $. . \ldots \ldots \ldots \ldots \ldots \ldots \ldots \ldots \ldots \ldots \ldots ., 4.220$

4.18 .5 References $\ldots . \ldots \ldots \ldots \ldots \ldots \ldots \ldots \ldots \ldots \ldots \ldots, 4.222$

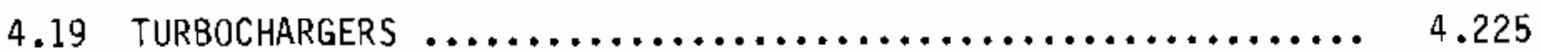

4.19.1 Component Description ....................... 4.225

4.19.2 Failure History $\ldots \ldots \ldots \ldots \ldots \ldots \ldots \ldots \ldots \ldots \ldots ., 4.226$

4.19.3 Owners' Group Evaluation ................... 4.227

4.19 .4 PNL's Review $\ldots \ldots \ldots \ldots \ldots \ldots \ldots \ldots \ldots \ldots \ldots \ldots, 4.232$

4.19 .5 References $\ldots \ldots \ldots \ldots \ldots \ldots \ldots \ldots \ldots \ldots \ldots \ldots \ldots, 4.236$ 


\section{FIGURES}

4.3.1 Connecting Rod, Model R-4 Int ine Engine $\ldots \ldots \ldots \ldots \ldots \ldots \ldots \ldots, 4.16$

4.4.1 Connecting Rod, Model RV-4 V-Engine $\ldots \ldots \ldots \ldots \ldots \ldots \ldots \ldots \ldots . . . . . .24$

4.7.1 Variation of Free-End Crankshaft Vibration with Engine RPM for Sum of 24 Orders in TDI DSRV-16-4 Crankshaft ............. 4.91

4.7.2 Torsional Vibratory Stresses for Single Drders in TOI DSRV-16-4 Crankshaft ............................... 4.92

4.7.3 Torsional Vibratory Stresses for the Sum of 24 Orders in TDI

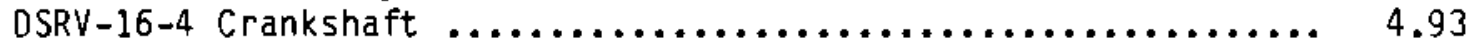

4.8.1 Torsional Vibratory Stresses for Single Orders in TDI DSRV-20-4 Crankshaft at Full Load

4.8.2 Torsional Vibratory Stresses for Sum of 24 Orders in TDI DSRV-20-4 Crankshaft at Full Load ........................ 4.119

4.8.3 Variation of Free-End Crankshaft Vibration with Engine RPM for Sum of 24 Orders in TDI DSRV-20-4 Crankshaft ............. 4.122

4.8.4 Torsional Vibratory Stresses Below Rated Speed for Single Orders in TDI DSRV-20-4 Crankshaft

4.8.5 Torsional Vibratory Stresses Below Rated Speed for Sum of 24 Orders in TDI DSRV-20-4 Crankshaft 



\section{ABBRE VIATIONS}

\begin{tabular}{|c|c|}
\hline ABS & American Bureau of Shipping \\
\hline ASLB & Atomic Safety and Licensing Board \\
\hline ASME & American Society of Mechanical Engineers \\
\hline B\&A & before and after \\
\hline BMEP & brake mean effective pressure \\
\hline CPSES & Comanche Peak Steam Electric Station \\
\hline DEMA & Diesel Engine Manufacturers Association \\
\hline$D G$ & diesel generator \\
\hline $\mathrm{DR} / \mathrm{QR}$ & design review/quality revalidation \\
\hline EDG & emergency diesel generator \\
\hline ESF & engineered safety feature \\
\hline ET & eddy current \\
\hline $\mathrm{FaAA}$ & Failure Analysis Associates \\
\hline FSAR & final safety analysis report \\
\hline GGNS & Grand Gulf Nuclear Station \\
\hline GSU & Gulf States Utilities Company \\
\hline IACS & International Association of Classification Societies \\
\hline IEEE & Institute of Electrical and Electronics Engineers \\
\hline LER & Licensee Event Report \\
\hline LILCO & Long Island Lighting Company \\
\hline LOCA & loss-of-coolant accident \\
\hline LOOP & loss of offsite power \\
\hline MP\&L & Mississippi Power \& Light Company \\
\hline MT & magnetic particle \\
\hline NDT & nondestructive testing \\
\hline NRC & U.S. Nuclear Regulatory Commission \\
\hline$O G$ & Owners' Group \\
\hline PNL & Pacific Northwest Laboratory \\
\hline PNPP & Perry Nuclear Power Plant \\
\hline PT & liquid penetrant \\
\hline RBS & River Bend Station \\
\hline SCE & Southern California Edison Company \\
\hline
\end{tabular}


SIM Service Information Memorandum

SONGS San Onofre Nuclear Generating Station

SNPS Shoreham Nuclear Power Station

SWEC Stone \& Webster Engineering Corporation

TDI Transamerica Delaval inc.

TER technical evaluation report

UTS ultimate tensile strength 


\author{
REVIEW OF \\ RESOLUTION OF KNOWN PROBLEMS \\ IN ENGINE COMPONENTS \\ FOR TRANSMERICA DELAVAL INC. EMERGENCY DIESEL GENERATORS
}

\title{
1.D INTRODUCTION
}

The Pacific Northwest Laboratory (PNL) has provided technical support to the U.S. Nuclear Regulatory Comission (NRC) staff in addressing questions regarding the adequacy of Transamerica Delaval Inc. (TDI) diesel generators used to provide standby power for safety-related systems in several nuclear power plants. These questions stemmed from a crankshaft failure in a TDI diesel engine at the Shoreham Nuclear Power Station in August 1983, and from less serious problems with TOI diesels at other nuclear power plants. The scope of PNL's effort encompassed reviews of TDI engine-related information submitted to NRC by the TDI Diesel Generator Owners' Group and by individual licensees, and reviews of disassemblies and inspections of TDI engines at nuclear power plants. Participants in this effort included consultants to PNL who have substantial experience in diesel engine technology.

This report documents PNL's reviews of the resolution of problems identified by the Owners' Group in 16 components of TDI engines. PNL also addressed these components in earlier technical evaluation reports on TDI engines at seven nuclear power plants, and in several reports on the components themselves. Because this report reflects PNL's evaluation of all of the information that became available on the 16 components during these reviews, the conclusions and recommendations documented herein supersede any conflicting conclusions and recommendations in the PNL reports issued earlier.

\subsection{OWNERS' GROUP APPROACH}

TDI diesel generators have been the subject of a coordinated effort by 13 utilities to address reliability and quality issues and to qualify the engines as emergency power sources for nuclear service. The Owners' Group 
formed by the utilities submitted a plan to NRC in March 1984 for "...a comprehensive program which, through a combination of design reviews, quality revalidations, engine tests and component inspections, will provide an in-depth assessment of the adequacy of the respective utilities' TDI engines to perform their intended safety-related functions."

Under Phase I of that program, the Owners' Group sought to resolve known problems in 16 engine components. These problems had been identified through a review of TDI diesel generator operating experience in both nuclear and nonnuclear installations. The Owners' Group had concluded that the problems were potentially generic to TDI engines. By focusing first on these components, the Owners' Group intended to establish a basis for several utility members to obtain near-term operating licenses in parallet with ongoing work on the second major element of the 0wners' Group program, the design review and quality revalidation $(D R / Q R)$ of other engine components.

For components with known problems that required plant-specific action (e.g., engine-mounted electrical cable), the Owners' Group issued a separate report on each plant addressed. Action taken to resolve the problems with the remaining components was documented by the Owners' Group in separate, enginespecific reports (e.g., connecting rods for $V$-type engines).

\subsection{PACIFIC NORTHWEST LABORATORY APPROACH}

Key considerations in PNL's reviews of the 16 components included design adequacy as addressed in the reports submitted by the Owners' Group, verification of design adequacy through known nuciear and non-nuclear operating experience and through engine tests and inspections performed by individual members of the Owners' Group, and surveillance and maintenance recommended by the Owners' Group to ensure continued satisfactory operation of the components.

PNL had planned initially to review the reports on known problems as they were issued by the Owners' Group and to prepare a separate technical evaluation report on each. However, as several power plants became candidates for operating licenses, the scope of PNL's reviews grew to encompass the additiona? information that became available from tests and inspections of the TDI engines 
at these installations. The results of these tests became a primary consideration in PNL's conclusions and recommendations regarding the 16 components. In the context of this broad base of information, PNL reached conclusions regarding component adequacy that are consistent with the conclusions reached by the Owners' Group in earlier reports on the 16 components.

PNL's reviews of the 16 components are documented in technical evaluation reports issued earlier on TOI engines at seven power plants that becane candidates for operating licenses. These plant-specific reports, which were issued over a 12-month period between July 1984 and July 1985, reflect the changes made in PNL's conclusions and recommendations on certain components as additional tests and inspections provided increased confidence that the components would operate successfully.

The expanded scope of PNL's reviews and the evolving process followed by PNL as new information became available are documented more appropriately in a single "capstone" report than in individual reports on each component. This report reflects information reviewed through September 1985 and presents PNL's final conclusions and recommendations on all 16 components.

\subsection{REPORT ORGANIZATION}

The overall conclusions and recommendations drawn from PNL's reviews of the 16 components are presented in Section 2. Next, the scope of the PNL reviews is discussed in more detail in Section 3 . Section 4 documents the reviews performed on each component. Actions taken by the owners' Group to resolve each known problem are described first, followed by a discussion of PNL's component-specific reviews and conclusions and recominendations. 



\subsection{OVERALL CONCLUSIONS AND RECOMMENDATIONS}

On the basis of the reviews performed by PNL staff and consultants as discussed in Section 4 of this report, PNL concludes that the Owners' Group accomplished the objectives of Phase I of the Owners' Group Program. Phase I involved the identification and resolution of known problems that had potentially generic applicability. Through a review of operating experience with TDI engines in both nuclear and non-nuclear installations, the Owners'Group identified 16 components with known problems. Consultants to the Owners' Group [primarily Failure Analysis Associates (FaAA) and Stone \& Webster Engineering Corporation (SWEC)] performed various analytical and experimental investigations to resolve the problems. These investigations formed the basis for recommendations made by the Owners' Group to individual utilities to ensure that the components will perform reliably in nuclear service.

Highlights of PNL's conclusions and recomnendations from the reviews discussed in Section 4 are presented in the two sections that follow. The components identified in Section 2.1 were found by both the Owners' Group and by PNL to be adequate for nuclear service at engine loads up to the ratings specified by the engine manufacturer. In PNL's opinion, the surveillance recommendations for several of these components warrant special emphasis. These recommendations are highlighted in section 2.2 for the components to which they apply.

Components that warrant special emphasis for other reasons are also highlighted in Section 2.2. These components include the crankshafts for 8- and 20-cylinder TDI engines, the turbochargers, and the modified type Af piston skirts used in the TDI engines at one nuclear power plant (San Onofre).

Any proposed changes to the load limits and/or to the surveillance recommendations discussed in Section 2.2 of this report should be subject to NRC review before they are implemented at nuclear power plants.

\subsection{COMPONENTS ADEQUATE FOR NUCLEAR SERVICE TO RATED ENGINE POWER}

Subject to implementation of the Owners' Group and PNL recomendations discussed on a component-by-component basis in Section 4 of this report, PNL 
concurs with the Owners' Group that the components listed below are adequate for nuclear service in TOI engines at any load within the ratings specified by the engine manufacturer. The DSR-4 (inline) and DSRV-4 (V-block) diesel engines purchased for nuclear service are rated by TOI for continuous operation at loads corresponding to a brake mean effective pressure (BMEP) of 225 psig at the design speed of $450 \mathrm{rpm}$. (The engine power level at rated BMEP varies with the number of cylinders.) These engines are also rated by TOI to operate for 2 hours out of every 24 operating hours at 10 percent in excess of full load rating at rated speed.

- air-start valve capscrews

- auxiliary module wiring and terminations

- connecting rods for inline, DSR-48 engines

- connecting rods for V-block, DSRV-4 series engines(a)

- connecting rod bearing shells

- crankshafts for 16-cylinder, DSRV-4 series engines at the Catawba, Comanche Peak, Grand Gulf, and Perry nuclear power stations (PNL's recommendations for evaluating crankshafts in $V-16$ engines in plants not yet licensed are included in Section 4.7 .8 .3$.

- cylinder blocks (a)

- cylinder heads(a)

- cylinder head studs

- engine bases and bearing caps

- fuel oil injection tubing

- jacket water pumps

- type AE piston skirts

- push rods

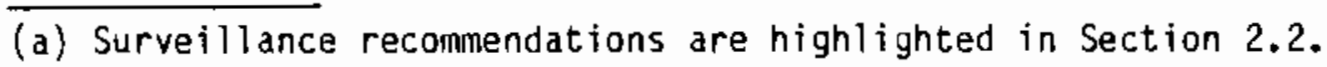


- rocker arm capscrews

- turbochargers. (a)

\subsection{COMPONENTS THAT WARRANT SPECIAL EMPHASIS}

In the opinion of PNL's reviewers, the surveillance recommendations for several components addressed during Phase I of the Owners' Group Program warrant special emphasis. These recommendations are highlighted in this section for the components to which they apply, and are discussed more fully in Section 4. In addition, the crankshafts for the 8- and 20-cylinder TDI engines and the modified type AF piston skirt warrant special emphasis because of 1) the plant-specific nature of the reviews of these components and 2) PNL's recommendations regarding load limitations for the engines in which these components are installed. Finally, PNL wishes to highlight a recomnendation for additional remedial action to prevent vane failures in turbocharger nozzle rings.

\subsubsection{Connecting Rods for V-Block Engines}

The connecting rods used in the DSRV-4 series engines (V-block configuration) are of an articulated design that links two pistons to each throw of the crankshaft. According to FaAA, TDI identified two failure mechanisins that resulted in cracking of components in lower connecting rod assemblies of $\checkmark$-engines in certain non-nuclear installations: 1) fatigue cracking of link rod bolts resulting from loss of bolt preload and 2) fatigue cracking of the connecting rod bolts and/or the link rod box in the mating threads.

As discussed in Section 4.4 of this report, PNL concurs with the Owners' Group that the OSRV-4 connecting rods are adequate for use in emergency diese1 generators for nuclear power plants. However, PNL recommends additional surveillance of the connecting rods to facilitate the timely identification of any problems that may develop in service. PNL's recommendations are discussed in Section 4.4.4.4. In PNL's opinion, the additional survejtlance is necessary in light of the mixed results of known non-nuclear service experience, the

(a) Surveillance recommendations are highlighted in Section 2.2. 
unknown level of conservatism of FaAA's stress analysis of the connecting rods, and the difficulties inherent in inspecting threaded bolt holes (in the link rod box) for small flaws.

\subsubsection{Crankshaft: 8-Cylinder, DSR-4 Series Engines}

PNL reviewed the evaluations performed by the Owners' Group of the crankshafts installed in 8-cylinder engines at two installations: Shoreham and River Bend. The crankshafts in both installations are of the same design and were made to the same material specifications. However, the generators and flywheels differ between the two installations, resulting in differences in crankshaft torsional stresses. Furthermore, the fillets of the Shoreham crankshafts are shotpeened while those of the River Bend crankshafts are not. These differences led to different conclusions regarding the power levels at which the crankshafts are qualified to operate in the two installations.

For reasons discussed in Section 4.6 of this report, PNL concludes that the crankshafts in the TDI engines at Shoreham are acceptable for nuclear service at loads up to the "qualified" load of $3300 \mathrm{~kW}$ (i.e., the load selected by the Long Island Lighting Company for a $10^{7}$-cycle confirmatory test of the EDG 103 engine at Shoreham). Also as discussed in Section 4.6, PNL concludes that the crankshafts in the TDI engines at River Bend are acceptable for nuclear service at loads up to $3130 \mathrm{kw}$.

PNL's recommendations for establishing whether or not the above-mentioned conclusions may be extended to crankshafts of the same design in TDI 8-cylinder engines at other nuclear installations are discussed in Section 4.6 .8 of this report.

\subsubsection{Crankshaft: $20-C y$ inder, DSRV-4 Series Engines}

As discussed in Section 4.8 of this report, the crankshaft in each of the two 20-cylinder TDI engines at San onofre Unit 1 is exposed to three closelyspaced resonant peaks during engine startup and coastdown. The vibratory conditions corresponding to these peaks fom a band of high stresses that induced cracks in certain main journal oil holes of both crankshafts. To remove the cracks in an oil hole surface, the hole diameter was increased until no 
recordable eddy-current indications remained. The fillets at the oil hole/journal intersections were then reestablished to complete the repair.

PNL concurs with the Owners' Group that the crankshafts in the San Onofre engines are adequate for continued service, subject to the PNL recommendations discussed in Section 4.8.5.6. Several of these recommendations warrant particular emphasis.

- Prompt action should be taken to modify the San Onofre engines as necessary to alleviate the crankshaft torsional stresses that have led to crack initiation and propagation under startup and coastdown transients. The parts necessary to modify the engines should be obtained and installed in a timely manner. On the basis of stresses computed by FaAA for engine starts and coastdowns, cracks may reinitiate in the crankshafts even if "slow" starts rather than "fast" starts are used during periodic engine tests. PNL concurs with FaAA that the number of start-stops at wich crack initiation will occur cannot be estimated with certainty. However, the likelihood of crack reinitiation leads PNL to conclude that the root cause of the cracking should be corrected to ensure long-term reliability of the engines. The modifications should be subject to NRC review.

- Pending implementation of the above-mentioned modifications, nondestructive examinations of certain critical crankshaft surfaces should be performed at each refueling outage (approximately every 50 start-stop cycles) as discussed in Section 4.8.5.6. PNL concurs with FaAA that the periodic examinations will provide adequate surveillance to detect new cracks before they propagate to a depth that would jeopardize engine reliability.

- If cracks reinitiate in the oil holes where they were previously discovered and removed, or if cracks initiate in other crankshaft surfaces, they should be removed and the adequacy of the repaired crankshafts should be reanalyzed as a prerequisite to additional service. The results should be subject to NRC review. 
- Because the depth at which a crack will propagate under steady-state stresses is inversely proportional to engine power level, the engine loading for periodic surveillance tests should continue to be limited to $4500 \mathrm{~kW}+5 \%$ rather than to the $6000-\mathrm{kW}$ rating of the generator on each engine. Southern California Edison initiated the 4500-kW limit, which bounds the maximum emergency service load for each engine. (PNL also recommends continuation of this limit for the modified type AF piston skirts installed in the San Onofre engines, as discussed later in this section.)

- "Slow" starts should be used for the monthly surveillance tests, to reduce the cumulative fatigue damage to the crankshafts. As shown in FaAA's transient torsiograph tests, crankshaft response during a slow start is similar to the response during a coastdown and is generally less severe than the response during a fast start. The only planned engine test for which $\mathrm{PNL}$ recommends a "fast" start is the one performed at 18-month intervals to demonstrate operation under simulated design-basis emergency power requirements.

\section{2 .4 cylinder Blocks}

Cracks have been reported in cylinder blocks of both DSR-4 (inline) and DSRV-4 (V) engines in nuclear and non-nuclear applications. Several types of cracks have occurred in cylinder block tops. Cracks have also occurred in the camshaft galleries of inline engines. FaAA's metallurgical and analytical investigations of these cracks are summarized in Section 4.9 of this report, together with PNL's review of various reports prepared by FaAA and the Owners' Group.

The periodic inspections discussed in Section 4.9.5.2 warrant careful attention for all TOI engine blocks in nuclear installations. These recommended inspections stem in large part from FaAA's stress and fatigue analyses of the various types of cracks.

\subsubsection{Cylinder Heads}

For reasons discussed in Section 4.10 of this report, problems experienced with cylinder heads in service are indicative of manufacturing defects rather 
than design deficiencies. PNL wishes to emphasize the following recomendations included in Section 4.10.4.3 that pertain to initial acceptance and subsequent survelllance of the cylinder heads:

- Cylinder heads with any through-wall weld repair of the fire deck should not be placed in nuclear standby service if the repair is performed from one side only (i.e., a "plug weld"). The coolant side of the fire deck is not readily accessible for weld repair. Thus, a repair from the combustion side might leave defects on the coolant side that would compromise the integrity of the head.

- The engine should be air-rolled with the cylinder cocks open prior to each,operation, as discussed in more detail in Section 4.10.4.3. This will facilitate the detection of cooling water leaks that could develop in the heads because of subsurface flaws or flaws that are otherwise not detectable through the nondestructive examinations recommended by the Owners' Group. Corrective action can then be taken before the leakage impairs the rapid-start capability of the engine.

\subsubsection{Modified Type AF Piston Skirts}

At the time this report was written, the only TDI engines equipped with modified type AF piston skirts in nuclear installations in the United States were the two 20-cylinder engines at San Onofre Unit 1. Piston skirts of this type had previously been installed in TDI engines at Shoreham and Grand Gulf, but were replaced with type $A E$ piston skirts when fatigue cracks were found in the AF skirts.

Subject to the recommendations discussed in Section 4.16 .4 .3 of this report, PNL concurs that the modified type AF skirts are adequate for continued service at San Onofre. This conclusion is based, in part, on the low brake mean effective pressure (BMEP) to which the pistons are exposed at the load limit of $4500 \mathrm{~kW}$ used in periodic surveillance tests of the San Onofre engines. The BMEP at this load limit is approximately $116 \mathrm{psig}$, which is well below the manufacturer's rated engine BMEP of 225 psig. 
Should modified type AF piston skirts be considered for service in nuclear standby engines that would be operated at loads greater than an engine BMEP of 116 psig, PNL recommends that the skirts be tested for $10^{7}$ power cycles ( 750 hours at $450 \mathrm{rpm}$ ) at the load that bounds the maximum energency service load of the engines. PNL also recommends that modified type AF piston skirts not be placed in nuclear standby service without NRC review at load levels where cracking is found to occur.

\subsubsection{Turbochargers}

The Owners' Group evaluated known problems in two elements of the turbochargers: 1) the thrust bearing and its lubrication system and 2) the nozzle ring assembly. Turbocharger thrust bearings in some nuclear installations had experienced excessive wear and failure due to lack of prelubrication before planned engine starts. Problems reported in nozzle rings included failures of vanes, capscrews, washers, and a hub. None of the known failures of nozzle ring components prevented continued operation of the turbocharger.

PNL's review of actions taken by the Owners' Group to resolve turbocharger problems is presented in Section 4.19 of this report. Two of the PNL recommendations concerning the nozzle ring assembly warrant emphasis in this summary:

- The nozzle ring as sembly should be redesigned to prevent nozzle vane failures. FaAA has identified the cause of the vane failures as high-cycle fatigue arising either from engine exhaust gas pulsations or from vibration during operation. Although the Owners' Group reported no instances of turbocharger failure due to missing nozzle vanes, PNL's consultants are of the opinion that a definite potential exists for severe turbine damage or performance degradation when vanes fail. Accordingly, PNL recommends that remedial action be taken expeditiously to correct the cause of the failures. Pending completion of this action, PNL recommends that the nozzle ring components and inlet guide vanes be inspected at each refueling outage and, if damaged parts are found, that the entire ring assembly be replaced. 
- The turbine inlet temperature should be monitored directly with appropriate instrumentation to ensure that it does not exceed the limit specified by the turbocharger manufacturer. As noted in Section 4.19.4.2.2, FaAA reported that cracks found in one hub of a nozzle ring removed from an engine at Grand Gulf were attributed by the turbocharger manufacturer (Elliott) to thermal fatigue. Also according to FaAA, Elliott concluded that the nozzle ring had been subjected to operating temperatures above the specified limit. 



\subsection{REVIEW SCOPE}

The PNL staff and consultants who participated in this effort reviewed over 30 reports submitted by the 0wners' Group on the 16 components with known problems, witnessed disassemblies and inspections of TDI engines at seven nuclear power plants, and testified in two Atomic Safety and Licensing Board hearings (Shoreham and Perry) on contentions concerning the components and the adequacy of the engines for nuclear service. These reviewers also evaluated the surveillance and maintenance recomendations included in certain $D R / Q R$ reports submitted as part of Phase II of the Owners' Group Program.

Although PNL's reviewers were authorized to perform calculations as appropriate for the review process, it was not the role of PNL to perform independent analyses of the components in question. However, PNL consultants did perform torsional stress analyses of crankshafts for certain engines, to provide a quantitative basis for comparison with the torsional analyses performed by consultants to the Owners' Group. These comparisons were necessary because the complexity of such analyses precluded alternative approaches for verifying the stresses reported by the Owners" Group.

Initially, PNL had planned to review the reports on known problems as they were issued by the 0wners' Group and to prepare a separate technical evaluation report on each. However, the scope of the reviews grew to encompass additional infomation on component performance because:

- The Owners' Group reports were not issued on the schedule originally planned. Meanwhile, several nuclear power plants equipped with TDI engines became candidates for licenses to meet fuel loading schedules, and another became a candidate for restart following extensive plant modifications. It became necessary for PNL's consultants to evaluate the engines in these plants on a case-by-case basis, taking into consideration the predicted loads for emergency operation, the results of engine tests and inspections, and applicable engine operating experience in nuclear and non-nuclear installations. To 
support schedules for licensing decisions, these plant-specific evaluations received priority over review of the reports on known problems.

- More important, however, PNL's reviewers concluded that the owners' Group reports on known problems generally did not, by themselves, provide a conclusive basis for determining the adequacy of the components for nuclear service. PNL's Review and Evaluation of TDL Diesel Generator Owners' Group Program Plan (PNL-5161, June 1984) emphasized the importance of engine tests and inspections for verifying design adequacy. Demonstrated satisfactory perfomance was particularly important for resolving the reservations of PNL's reviewers about two of the 16 components with known problems-piston skirts and crankshafts--because the condition of these components cannot be monitored without significant engine disassembly.

PNL recommended in the above-referenced report that TDI engines not be placed in nuclear service prior to the completion of certain actions as part of the Owners' Group Program, unless two conditions were met: 1) the engine brake inean effective pressure (BMEP) would be no higher than $185 \mathrm{psig}$ under the maximum postulated emergency service load (versus the manufacturer's rated BMEP of 225 psig at the maximum rated engine load for continuous operation), and 2) the engine would be operated with "type AE" piston skirts. Other types of piston skirts would need to be evaluated on a case-by-case basis. In the opinion of PNL's consultants, non-nuclear operating experience known at that time provided a reasonable basis for confidence that the engines would operate satisfactorily in nuclear service subject to these constraints. The analyses, tests, and inspections performed by the Owners' Group and by individual power plant owners since that time have provided the basis for the substantially less restrictive PNL recommendations summarized in Section 2 and discussed more fully in Section 4.

Between July 1984 and July 1985, PNL prepared technical evaluation reports on TDI engines in seven nuclear power plants: Grand Gulf (July 1984), Catawba (August 1984), Comanche Peak (September 1984), San Onofre (November 1984), Shoreham (December 1984), Perry (February 1985), and River Bend (July 1985). 
The favorable results of engine tests conducted at several of these power plants after implementation of Owners' Group recommendations, and the engine inspections witnessed by PNL staff and consultants, were primary considerations underlying PNL's recommendations to the NRC staff concerning the readiness of the engines for nuclear service.

Included in PNL's evaluations of TDI engines at the seven power plants were reviews of the 16 components with known problems identified by the Owners' Group. As new power plants became candidates for operating licenses and additional information became available from engine tests and inspections, PNL's recommendations on certain components were revised to reflect the increased confidence gained from this broader database. For example, the engine tests confirmed that type AE piston skirts operate without evidence of distress at power levels for which engine BMEP is greater than $185 \mathrm{psig.} \mathrm{PNL's} \mathrm{recommen-}$ dations for maintenance and surveillance of certain components also became less restrictive on the basis of the additional information.

Thus, the scope of PNL's review of the 16 components with known problems went well beyond the information provided by the Owners' Group in the reports submitted during the first phase of the Owners' Group Progran. Instead, the scope evolved as new information became available through tests and inspections of TDI diesel generators at seven nuclear power plants. In the opinion of PNL project staff and consultants, the change in scope was necessary to arrive at meaningful conclusions concerning the components. 



\subsection{COMPONENT REVIEWS}

This section documents PNL's reviews of the actions taken by the Owners' Group to resolve known problems in each of the components addressed during Phase I of the Owners' Group Prograri. Because of engine-specific differences, certain components (e.g., the connecting rods) are discussed under separate headings by engine type (inline and $V$ ) or by engine size (8-, 16-, and 20-cylinder engines). The components are as follows:(a)

Section Component

4.1 Air Start Valve Capscrews

4.2 Auxiliary Module Wiring and Terminations

4.3 Connecting Rods: 8-Cylinder, DSR-4 Series Engines

4.4 Connecting Rods: DSRV-4 Series Engines

4.5 Connecting Rod Bearing Shells

4.6 Crankshaft: 8-Cylinder, DSR-4 Series Engines

4.7 Crankshaft: 16-Cylinder, DSRV-4 Series Engines

4.8 Crankshaft: 20-Cylinder, DSRV-4 Series Engines

4.9 Cylinder Block

4.10 Cylinder Heads

4.11 Cylinder Head Studs

4.12 Engine Base and Bearing Caps: 8-Cylinder, DSR-4 Series Engines

4.13 Engine Base and Bearing Caps: DSRV-4 Series Engines

4.14 Fuel 0il Injection Tubing

4.15 Jacket Water Pump

4.16 Piston Skirts

(a) One of the 16 components, the cylinder liner, that the Owners' Group identified for evaluation during Phase I of the Owners' Group Progran is mentioned in the report prepared by Failure Analysis Associates on the cylinder block, and is the subject of recommended surveillance in the design review/quality revalidation reports prepared by the Owners' Group. The recommended surveillance is summarized in Section 4.9 together with PNL's review of the cylinder block. 
Section

Component

4.17 Push Rods

4.18 Rocker Arm Capscrews

4.19 Turbochargers

4.2 


\subsection{AIR START VALVE CAPSCREWS}




\subsection{AIR START VALVE CAPSCREWS}

This section summarizes PNL's review of action taken by the Owners' Group to evaluate the air start value capscrews for the TDI engines in nuclear service. A more detailed account of PNL's review is presented in PNL-5200-21 (Pacific Northwest Laboratory March 1985).

\subsubsection{Component Description}

Two air start valve capscrews hold each air start valve assembly in place in a cylinder head. A capscrew failure, or an inappropriately long capscrew, will prevent the air start valve housing from sealing properly in the head. Lack of a secure seal will allow combustion gases to leak past the air start valve housing to the engine room.

\subsubsection{Failure History}

No failures of the capscrews themselves have been reported. However, Transamerica Delaval Inc. (TDI) reported in Service Information Memorandum No. 360 of May 13, 1982, that the 3/4-10 x 3-inch capscrews may "bottom out" in the holes in the cylinder heads, resulting in insufficient clamping of the air start valve assembly. TDI recomended that 2-3/4-inch capscrews be installed, torqued to $150 \mathrm{ft}-1 \mathrm{~b}$ during installation, and retorqued periodically.

Air start valve capscrews were reported to have loosened in the TOI engines at the Shoreham and Grand Gulf nuclear stations because they had bottomed out during installation. This problem was corrected at both installations by replacing the original 3-inch-long capscrews with 2-3/4-inch-long capscrews as recommended by TDI.

\subsubsection{Owners' Group Evaluation}

Stone \& Webster Engineering Corporation (SWEC), a consultant to the Owners' Group, evaluated the functional attributes of the $2-3 / 4-i n c h-10 n g$ capscrews. SWEC's conclusions and recommendations are documented in two reports: 1) Emergency Diesel Generator Air Start Valve Capscrew Dimensional and Stress Analysis (March 1984) and 2) a supplement dated April 1984. The details of SWEC's analysis are documented in SWEC calculation number $11600.60-245.1-M 3$. 


\subsubsection{Scope}

As part of this evaluation, SWEC

- performed a dimensional check to determine whether or not the capscrews could bottom out under the most adverse dimensional tolerances of the bolted assembly

- determined if the specified torque value ensures adequate capscrew preload

- determined the total resultant bolt stress

- evaluated TDI's recommended retorquing requirements.

\subsubsection{Results and Conclusions}

The results of SWEC's evaluation are summarized below. On the basis of these results, SWEC concluded that the 2-3/4-inch-long air start valve capscrews are adequate for service in TDI engines installed at nuclear power plants.

- The dimensional check indicates that a 0.2 -inch minimum clearance exists within the cylinder head tapped hole. Thus, the air start valve capscrew will not bottom out upon torquing.

- The preload stress in the capscrews due to the TDI-recommended torque is acceptable, and the capscrew design is adequate to resist fatigue failure.

- During engine startup, a stress is imposed on the capscrews due to starting air pressure within the air start valve assembly. This stress is insignificant compared to the greater alternating stress induced by cylinder firing pressures.

- During engine operation, the copper gasket that seals the air start valve housing in the cylinder head is subjected to elevated temperatures. Gasket creep may occur, decreasing the total capscrew preload. Existing maintenance procedures require retorquing at specified intervals to compensate for gasket creep. When no change 
in torque is detected, the gasket is fully compressed. Capscrew preload will then be maintained through the full range of engine operation.

\subsubsection{Recommendations}

SWEC's recommendations included the following:

- Capscrew length should be measured on a sampling basis as part of the design review/quality revalidation (DR/QR) effort for each nuclear plant.

- Following initial installation of the capscrews with $150 \mathrm{ft}-$ lb torque, the capscrews should be retorqued every 8 hours until no further change in torque is noted.

\subsubsection{PNL's Review}

The PNL evaluation encompassed reviews of the reports referenced in Section 4.1.3.

\subsubsection{Reviewers}

The PNL consultants who participated in this review were

- S. H. Bush, Review and Synthesis Associates

- A. J. Henriksen, A. J. Henriksen, Inc.

- 8. J. Kirkwood, Covenant Engineering

- P. J. Louzecky, Engineered Applications Corporation.

\subsubsection{Conclusions and Recommendations}

PNL concurs with SWEC and the Owners' Group that the air start valve capscrews of the length (2-3/4 inches) evaluated by SWEC are adequate for service in TDI engines installed at nuclear power plants, provided that 1) proper capscrew length is verified as part of the OR/QR process for each engine installation and 2) the capscrews are torqued during initial installation and retorqued periodically in accordance with TDI and SWEC recommendations. PNL recommends that the periodic checks include retorquing following the first period of engine operation after replacement of the copper gasket, to ensure that no additional gasket creep occurs as a result of the additional therina? and mechanical stresses. 


\subsubsection{References}

Pacific Northwest Laboratory. March 1985. Review of Emergency Diesel Generator Air Start Valve Capscrews. PNL-5200-21, Richland, Washington.

Stone \& Webster Engineering Corporation. March 1984. Emergency Diesel Generator Air Start Valve Capscrew Dimension and Stress Analysis. Boston, Massachusetts:

Stone \& Webster Engineering Corporation. April 1984. "Air Start Valve Capscrew Dimension and Stress Analysis." Calculation 11600.60-245.1-M3, Boston, Massachusetts.

Stone \& Webster Engineering Corporation. April 1984. Supplement to the Emergency 0iesel Generator Air Start Valve Capscrew Dimension and Stress Analysis. Boston, Massachusetts.

Transamerica Delaval Inc. May 13, 1982. "Service Information Memo №. 360." 0akland, California. 


\subsection{AUXILIARY MDULE MIRING}

AND TERMINATIONS 


\subsection{AUXILIARY MODULE WIRING AND TERMINATIONS}

This section sumarizes PNL's review of action taken by the Owners' Group to evaluate the auxiliary module wiring and teminations supplied with the TDI emergency diesel generators at the Catawba, Comanche Peak, Grand Gulf, Midland, Perry, Rancho Seco, River Bend, San Onofre, Shearon Harris, and Shoreharf nuclear power stations. A more detailed account of this review is documented in PNL-5200-3 (Pacific Northwest Laboratory May 1985).

\subsubsection{Component Description}

All cable/wire associated with the TDI diesel generators is generally routed in either electrical metallic tubing, rigid galvanized steel conduit, or flexible conduit. A variety of wire and insulation types is used, depending on the characteristics of the circuit. These include types SIS, MTW, XLPE, and $X H H W$. The conduits supported away from the engine are potentially subject to the maximum engine room temperature $\left(120^{\circ} \mathrm{F}\right.$ to $\left.140^{\circ} \mathrm{F}\right)$. The junction boxes, conduits, and cables attached to the engine block are potentially subject to at least the engine cooling jacket/lubricating oil temperature $\left(180^{\circ} \mathrm{F}\right)$. Wire/ cable materials unable to withstand the service environinent could jeopardize the electrical integrity of the diesel generator and pose a possible hazard to personnel.

\subsubsection{Failure History}

TDI's Service Information Memorandum (SIM) 361, Rev. 1, notified the engine owners of potentially defective engine-mounted cables associated with the Woodward governor/actuator and the Air-Pax magnetic pickup. This memo led the Owners* Group to question the suitability of all class IE auxiliary module wiring and terminations currently installed on the diesel engines. Of special interest was the suitability of this wiring with respect to flame-retardancy of the insulation, qualification to industry standards, routing of conduit, compatibility with circuit requirements, and the need for special requirements such as shielding. 


\subsubsection{Owners' Group Evaluation}

The Owners' Group authorized Stone \& Webster Engineering Corporation (SWEC) to evaluate the functional attributes of the class IE auxiliary module wiring and terminations supplied with the engines. The evaluations were documented in five SWEC reports:

- Emergency Diesel Generator Engine and Auxiliary Module Wiring and Termination Qualification to IEEE-383-1974, Aprit 1984

- Supplement to the Emergency Diesel Generator Auxiliary Module Control Wiring and Termination Qual ification Review, DR4-210-013, May 4, 1984

- Supplement to the Emergency Diesel Generator Auxiliary Module Control Wiring and Termination Qualification Review, B2-1160060-2, June 1984

- Supplement to the Emergency Diesel Generator Auxiliary Module Control Wiring and Termination Qualification Review, B2-1160060-4, June 1984

- Emergency Diesel Generator Auxiliary Module Control Wiring and Termination Qualification Review, TD10287, Juity 1984.

\subsubsection{Scope}

In field surveys of the engine installations, SWEC investigated the compatibility of the wiring and terminations with the electrical and environmental service characteristics at 10 nuclear plants: Catawba, Comanche Peak, Grand Gulf, Midland, Perry, Rancho Seco, River Bend, San Onofre, Shearon Harris, and Shoreham. ANSI/IEEE Standard 383-1974 was used as the basis for SWEC's reviews.

The scope of SWEC's investigation encompassed the following activities:

- Identify all wiring and terminations supplied with the diesel engines from TDI manuals (or, in the case of Shoreham, from the SWEC design documents).

- Review the wiring insulation for compatibility with circuit requi rements. 
- Determine if the insulating material is known to have generic fireretardant characteristics and is qualified to selected industry standards.

- Review the wiring installation routing to determine the physical environment for each cable.

- Evaluate circuit requirements to determine if special cable is required.

- Compare the termination types, materials, sizes, and insulation ratings as given in the manufacturer's specifications with the characteristics required for the particular circuit and environment.

\subsubsection{Conclusions and Recommendations}

SWEC concluded that the existing wiring and terminations are acceptable for service in seven installations:

- Comanche Peak

- Grand Gulf

- Perry

- Rancho Seco

- River Bend

- San Onofre Engine No. 2

- Shearon Harris.

For the remaining installations, SWEC recomended certain plant-specific actions:

- Catawba - TDI SIM 361 should be implemented, the period of manufacture of the States-type sliding link terminal blocks should be verified, and certain Kyner-insulated wire should be replaced.

- Midland - TOI SIM 361 should be implemented, and the period of manufacture of the States-type sliding link terminal blocks should be verified. (Construction of this power plant was subsequently suspended.)

- San Onofre Engine No. 1 - TDI SIM 361 should be implemented. 
- Shorehan - Wiring with type MTW insulation should be replaced in the circuits for the crankcase vacuum fans and the starting air supply solenoid valves.

\subsubsection{PNL's Review}

PNL's evaluation focused on the five SWEC reports cited in Section 4.2.3. Some use was made of additional written and oral information requested from and provided by the Owners' Group.

\subsubsection{Reviewers}

The following PNL consultants participated in the reviews of the docunentation on engine and auxiliary module wiring and terminations:

- E. Loftus, electrical engineer, Kaiser Engineers Hanford Co.

- P. J. Louzecky, Engineered Applications Corporation

- W. R. McSpadden, Ph.0., engineering consultant

- J. E. Horner, Seaworthy Systems, Inc.

- N. N. Rivera, Designers and Planners, Inc. (Tracor Hydronautics, Inc.). 4.2.4.2 Scope

The PNL reviewers addressed four primary questions:

- Were the methods of analysis and approaches taken in the studies satisfactory?

- Are the information and data collected in the field surveys adequate for proper evaluation?

- Are the conclusions and recommendations supportable?

- Have the objectives of the study been met?

\subsubsection{Conclusions and Recommendations}

PNL concurs with the approach used to evaluate the class IE auxiliary module wiring and terminations currently installed on TDI diesel generators at 10 nuclear power plants owned by members of the TDI Diesel Generator Owners' Group. PNL also concurs with the conclusions and recommendations presented in 
the five SWEC reports on the field surveys of the wiring and terminations. PNL's views are discussed more fully below.

4.2.4.3.1. Installations for Which No Further Action Is Necessary. SWEC concluded that the existing class IE auxiliary module wirting and terminations are acceptable for service on Tol diesel engines at seven installations. On the basis of the field surveys reported by SWEC, PNL concurs that no further action is necessary to upgrade the engine-mounted wiring and terminations at these installations:

- Comanche Peak Steam Electric Station Unit 1

- Grand Gulf Nuclear Station Unit 1

- Perry Nuclear Power Plant Unit 1

- Rancho Seco Nuclear Power Station Unit 1

- River Bend Station Unit 1

- San Onofre Nuclear Generating Station Unit 1, Engine No. 2

- Shearon Harris Nuclear Power Plant Unic 1.

4.2.4.3.2 Installations for which Further Action was Recomended. SWEC concluded that the wiring and terminations on TDI diesel engines are acceptable for service at three other installations, subject to implementation of certain recomendations. These recomnendations, and the status of action on each at the time PNL-5200-3 was written, are as follows:

- San Onofre Nuclear Generating Station Unit 1, Engine No. 1

- SWEC Recormendation: TDI SIM 361 should be implemented.

- Status: In a letter to NRC (C. H. Berlinger) dated April 3, 1985, the Owners' Group (A. M. Segrest) confirmed that SIM 361 has been implemented on this engine. (TDI SIM 361 had previously been implemented on Engine No. 2.)

- Shoreharn Nuclear Power Station

- SWEC Recommendation: Wiring with type MTW insulation should be replaced in three circuits for the crankcase vacuum fans and the starting air supply solenoid valves. The selected replacement cable, Okonite 1/C\#12-19x Black Okozel (Tefzel insulation), is acceptable for the expected operating temperature. 
- Status: In a letter to NRC (C. H. Berlinger) dated May 7, 1985, Duke Power Company (A. M. Segrest) confirmed on behalf of the Owners' Group that this recormendation has been implemented.

- Catawba Nuclear Station Unit 1

- SWEC Recommendations:

a. TD1 SIM 361 should be implemented.

b. The period of manufacture of States-type NT sliding link terminal blocks should be verified in accordance with NRC IE Information Notice No. 80-08 of March 7, 1980.

c. Certain Kyner-insulated, 14 AWG wire should be replaced with wire qualified to IEEE-383-1974.

- Status: In a letter to NRC (C. H. Berlinger) dated April 3, 1985, Duke Power Company (A. M. Segrest) confirmed on behalf of the Owners' Group that SiM 361 has been implemented (recoinmendation a., above), but that the verification of the sliding link terminal blocks has not been performed to date (recommendation b.). Duke Power (A. M. Segrest) stated in a letter to NRC (C. H. Berlinger) dated May 7, 1985 that the Kyner-insulated wire has not yet been replaced (recommendation c.).

- PNL Recommendation: SWEC recommendations b. and c., above, should be implemented by Duke Power Company in a timely manner and no later than the first outage for power plant refueling.

- Midland Nuclear Power Plant

- SWEC Recomnendations: TDI SIM 361 should be implemented, and the period of manufacture of States-type link terininal blocks should be verified.

- Status: Construction of the Midland plant was suspended, and the owner, Consumers Power Company, withdrew from the TDI Diesel Generator Owners' Group. 
- PNL Recommendation: The SWEC recomendations should be implemented if construction of the Midland plant is resumed.

4.2.4.3.3 Reviews Deferred to Phase II of Owners' Group Program. PNL reviewers noted SWEC's observation that wiring and terminations on engines not reviewed during Phase I of the Owners' Group Program will be reviewed as part of Phase II, the Design Review/Quality Revalidation Program. PNL recommends that these later reviews be conducted using the same approach and with the same thoroughness as was used in the reviews already completed.

\subsubsection{References}

ANSI/IEEE STO 383-1974. IEEE Standard for Type Test of Class IE Electric Cables, Field Splices, and Connections for Nuclear Power Generating Stations. The Institute of Electrical and Electronics Engineers, Inc., New York, New York.

Pacific Northwest Laboratory. May 1985. Review of Emergency Diesel Generator Engine and Auxiliary Module Wiring and Terminations. PNL-5200-3, Richland, Washington.

Segrest, A. M. April 3, 1985. Letter to NRC (C. H. Berlinger) re Response of TOI Owners' Group to Questions on Engine Wiring and Terminations.

Segrest, A. M. May 7, 1985. Letter to NRC (C. H. Berlinger) re Response of TOI Owners' Group to Questions on Engine Wiring and terminations.

Stone \& Webster Engineering Corporation. April 1984. Emergency Diesel Generator Engine and Auxiliary Module Wiring and Termination Qualification to IEEE-383-1974. Boston, Massachusetts.

Stone Webster Engineering Corporation. May 1984. Supplement to the Emergency Diesel Generator Auxiliary Module Control Wiring and Termination Qualification Review. DR4-210-013, Boston, Massachusetts.

Stone \& Webster Engineering Corporation. June 1984. Supplement to the Emergency Diesel Generator Auxiliary Module Control Wiring and Termination Qualification Review. B2-1160060-2, Boston, Massachusetts.

Stone \& Webster Engineering Corporation. June 1984. Supplement to the Emergency Oiesel Generator Auxiliary Module Control Wiring and Termination Qualification Review. B2-1160060-4, Boston, Massachusetts.

Stone \& Webster Engineering Corporation. July 1984. Emergency Diesel Generator Auxiljary Module Control Wiring and Termination Qualification Review. TO10287, Boston, Massachusetts. 


\subsection{CONNECTING RODS: 8-CYLINDER, DSR-4 SERIES ENGINES}




\subsection{CONNECTING RODS: 8-CYLINDER, DSR-4 SERIES ENGINES}

This section describes PNL's review of action taken by the Owners' Group to evaluate the connecting rods installed in TDI 8-cylinder, DSR-4 series engines. Nuclear power plants with intine DSR-48 engines include Shoreham, River Bend, and Rancho Seco.

\subsubsection{Component Description}

The connecting rod assembly for the TDI inline model DSR-48 diesel engine is shown in Figure 4.3.1. This assembly includes the connecting rod, connecting rod cap, connecting rod bolts and nuts, connecting rod bearing shells, and rod-eye bushing. The passageway shown in Figure 4.3 .1 at the center of the connecting rod conducts oil pumped via the crankpin journal to the wrist pin. This oil serves to both lubricate the components and cool the piston secured by the wrist pin to the upper end of the connecting rod.

The primary function of the connecting rod is to transmit engine firing forces from the pistons to the crankshaft. The connecting rod must have sufficient column strength and fatigue resistance to withstand the cylinder firing forces and inertial laads. Further, the flexure of the rod must not exceed limits that would produce excessive axial bearing misalignment. The other components included in the connecting rod assembly must also be sufficiently rugged to withstand the firing forces and inertial forces to which they are exposed.

\subsubsection{Failure History}

Only one in-service failure of connecting rods in TDI DSR-4 series engines has been reported. This failure consisted of a longitudinal split through the oil hole in a DSR-46 engine at Glennallen, Alaska. According to Failure Analysis Associates (June 1984), the failure report supplied by TDI did not identify the origin of the crack; however, no material abnormalities were reported. The engine reportedly had been operated for over 8000 hours, and had been run extensively at a much higher peak firing pressure (1975 psi) than that measured for the Shoreham engines (1680 psi). 


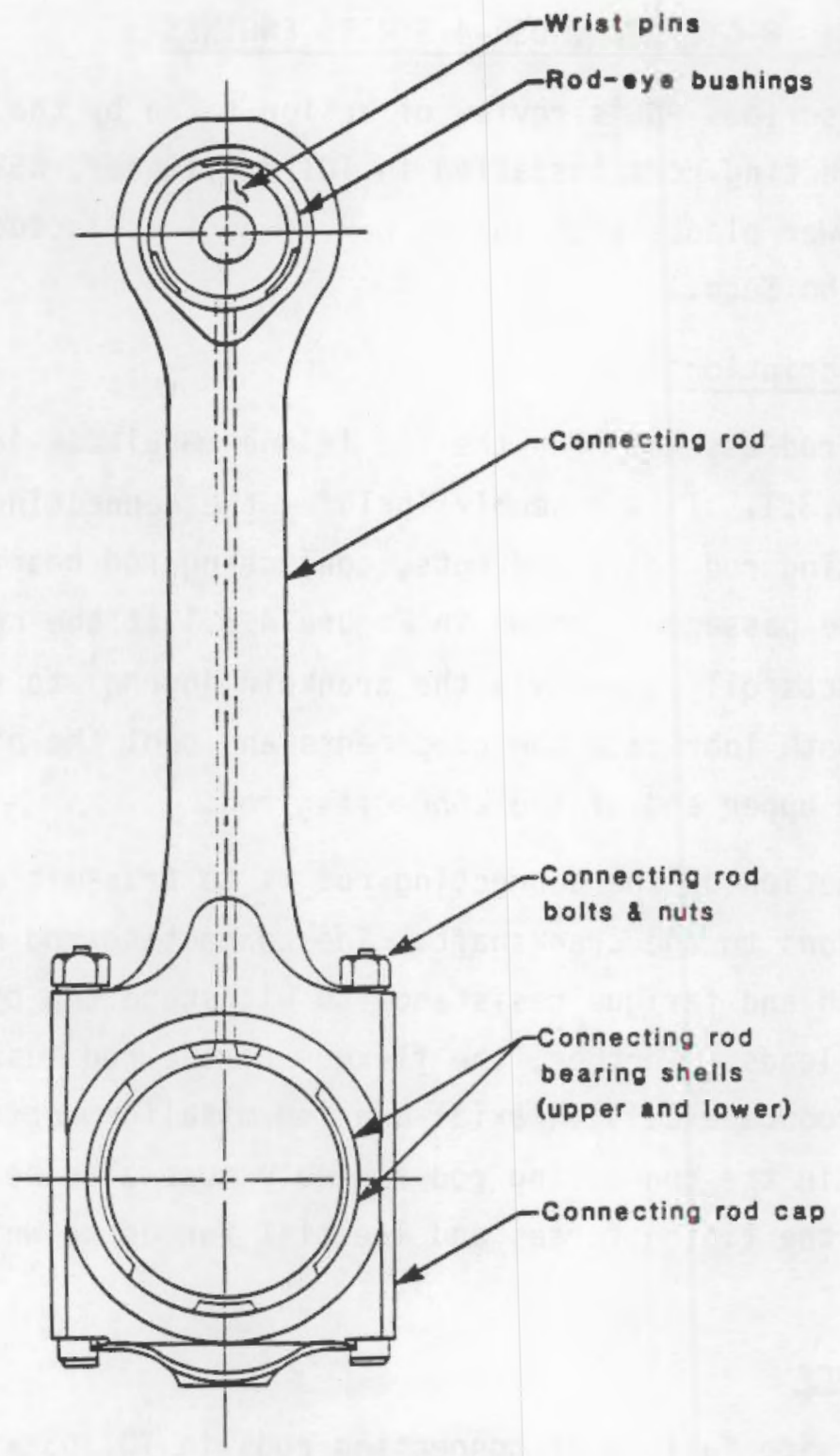

FIGURE 4.3.1. Connecting Rod, Model R-4 Inline Engine Source: Failure Analysis Associates (June 1984, p. 1-4) 


\subsubsection{Owners' Group Evaluation}

Failure Analysis Associates (FaAA), a consultant to the Owners' Group, assessed the structural integrity of the connecting rods of TDI DSR-4B engines. Their evaluation is documented in FaAA-34-3-13 (June 1984).

\subsubsection{Scope}

The FaAA design review considered four major parts of the connecting rod assembly:

- the rod-eye bushing

- the rod eye

- the connecting rod bearing housing and cap

- the connecting rod itself.

Liquid penetrant, metallographic, and fractographic examinations were performed on certain rod-eye bushings from engines at Shoreham. A journal orbit analysis of these bushings and stress and fracture mechanics analyses were also performed. The rod-eye end of the connecting rod and the connecting rod bearing housing and cap were also evaluated by stress and fatigue analyses. The rod itself was analyzed for buckling stability.

\subsubsection{Analysis and Results}

4.3.3.2.1 Rod-Eye Bushing. Rod-eye bushings in the replacement connecting rods for all three Shoreham diesel generators were inspected following startup testing, which included 168 hours at $75 \%$ rated load and 100 hours at rated load for each engine. Liquid penetrant examination revealed linear indications on both the inside and outside diameters of all rod-eye bushings. Similar indications were also found in new, unused bushings.

The linear indications were determined to be casting defects resulting from interdendritic shrinkage or porosity. No service-induced fatigue extension of the casting defects was observed.

A journal orbit analysis of the rod-eye bushing was performed to determine peak oil film pressures for the two extreme loading conditions: 1) the exhaust 
stroke inertial loading and 2) the firing pressure loading. The calculated oil pressures were used in stress and fatigue analyses of the bushing for these loading conditions.

The results of the fatigue analysis indicate that defects on the outside diameter of the bushing will not propagate. Bushing defects on the inside diameter may propagate if they originate within the most heavily loaded region between \pm 15 degrees of bottom dead center, but only if the crack faces are exposed to the full range of oil film pressure. This is unlikely because of the compressive hoop stress in the bushing.

4.3.3.2.2 Rod Eye. The rod eye itself was analyzed for the same loading conditions just described for the rod-eye bushing. The predicted stress range was found to be below the fatigue initiation stress range for the rod material.

Because of the possibility of pre-existing defects raised by the failure at Glennallen, Alaska, a fracture mechanics analysis was performed to determine the threshold crack size for fatigue failure of the rod eye. Using conservative values for the threshold range of the stress intensity factor, FaAA found that the critical crack depth for the worst-case condition is 0.043 inch. The critical area for this defect is the intersection of the oil nole with the bore of the rod eye. FaAA commented that a flaw of this size would be readily detected by visual inspection.

4.3.3.2.3 Connecting Rod Bearing Housing and Cap. The crankpin bearing cap is attached to the connecting rod with four bolts that extend entirely through the foot of the connecting rod. Prestressing of these bolts creates compressive stresses in the lower connecting rod assembly and tensile stresses in the bolts. Two extreme loading conditions, firing stroke and exhaust stroke, were considered in the stress and fatigue analyses of the bolts. The critical depth for crack propagation was found to be 0.133 inch at the thread root of the bolt. Because the lower connecting rod assembly is predominately in a state of compression, FaAA concluded that fatigue is not a consideration in this portion of the rod. 
4.3.3.2.4 Connecting Rod. The lateral buckling stability of the connecting rod was analyzed under the maximum cylinder firing pressure. Safety factors of 6.28 for connecting rod yielding and of 5.72 for connecting rod lateral buckling were determined.

\subsubsection{Conclusions and Recommendations}

4.3.3.3.1 FaAA Evaluation. FaAA reached the following conclusions:

- The connecting rod shows adequate margins of safety for fatigue of the bolted joint between the crankpin bearing cap and bearing housing, and for buckling of the rod.

- Fracture mechanics calculations show that interdendritic cracks in rod eye bushings within \pm 15 degrees of the bottom dead center position can propagate, aithough no such crack growth has yet been observed. Even though cracking of a bushing appears to have no adverse effects on engine operation, it is recommended that bushings be replaced if linear indications are observed within \pm 15 deyrees of bottom dead center.

- There is no risk of fatigue failure in the critical region of the oil holes of rod eyes manufactured in accordance with TDI procedures.

4.3.3.3.2 Owners' Group DR/QR. Citing the FaAA reviews, the Owners' Group concluded in their DR/QR reports for Shoreham (December 1984) and River Bend (February 1985) that the DSR-48 connecting rod, rod-eye bushing, rod eye, and crankpin bearing housing, cap, and bolting are acceptable for their intended design functions. The Owners' Group recommended no inodifications to the connecting rod assembly.

No specific recomendations for connecting rod maintenance are included in the DR/QR report for Shoreham. The only maintenance specified in Appendix II of the DR/QR report for River Bend is to perform the TDI-recomanded inspection and measurements identified in the TDI Instruction Manual Volume 1, Section 6. This is to be accomplished at 5-year intervals. 


\subsubsection{PNL's Review}

The PNL evaluation encompassed a review of the faAA report and supporting information, as well as a review of the recommendations presented in the $D R / Q R$ reports for Shoreham (December 1984) and River Bend (February 1985).

\subsubsection{Reviewers}

The following PNL consultants participated in this review:

- S. H. Bush, Review and Synthesis Associates

- A. J. Henriksen, A. J. Henriksen, Inc.

- B. J. Kirkwood, Covenant Engineering

- P. J. Louzecky, Engineered Applications Corporation

- the late A. Sarsten, Norwegian Institute of Technology.

\subsubsection{Results}

In reviewing the FaAA report (June 1984) and additional information provided by the Owners' Group (Ray June 20, 1984), PNL concluded that FaAA had examined the appropriate significant failure modes. These included crack propagation in the rod eye bushing, fatigue and crack propagation in the rod eye itself, fatigue and possible pretension loss in the connecting rod bolts, and buckling of the connecting rod. The bounding load cases of exhaust stroke inertial loads and firing pressure loads were appropriate for the analyses.

\subsubsection{Conclusions and Recommendations}

Based upon review of the documentation cited previously, PNL concurs with the Dwners' Group that the DSR-48 connecting rods are adequate for their intended service in emergency diesel generators for nuclear power plants. PNL also concurs with the faAA recommendation that linear indications in the rodeye bushing are not acceptable within \pm 15 degrees of the bottom dead center position. Further, PNL concurs with FaAA that cracks deeper than 0.04 inch in the rod eye are not acceptable, nor are cracks acceptable at the root of the connecting rod bolt threads.

The following PNL recomendations apply for periodic surveillance of all connecting rods for TDI inline engines in nuclear service: 
- The connecting rods for all inline engines should be inspected during each major (5-year) engine disassembly in accordance with the recomendations in Appendix II of the $D R / Q R$ report for River Bend.

- All connecting rod bolts, nuts, and washers should be visually inspected during each major (5-year) engine disassembly, and damaged parts should be replaced. The bolts should be magnetic-particle (MT) inspected to verify the continued absence of cracking. For future bolt inspections, PNL recommends the wet-fluorescent MT technique, which will provide the enhanced sensitivity normally specified for bolt examinations. No detectable cracks should be allowed at the root of the threads.

- During any disassembly that exposes the inside diameter of a rod-eye bushing, the surface of the bushing should be examined with liquid penetrant to verify the continued absence of linear indications in the heavily-loaded zone within \pm 15 degrees of the bottom dead center position.

- Any rod eye not previously examined in accordance with the acceptance criteria recommended by FaAA should be examined using an appropriate nondestructive technique at the first major (5-year) engine disassembly. No indications deeper than 0.04 inch should be allowed.

\subsubsection{References}

Failure Analysis Associates (FaAA). June 1984. Design Review of Connecting Rods of Transamerica Delaval Inl ine DSR-48 Einergency Diesel Generators. FaAA-84-3-13, Palo Alto, California.

Ray, C. L., Jr. June 20, 1984. Letter 0GTP-85 to Mr. C. Berlinger, "TDI Diesel Generator Owners' Group Answers to PNL Letter Oated June 4, 1984."

TDI Diesel Generator Owners' Group. February 1985. TDi Diesel Generator Design Review and Quality Revalidation Report - River Bend Station. Revision 1.

TDI Diesel Generator Owners' Group. December 1984. TOI Diesel Generator Design Review and Quality Revalidation Report - Shoreham Nuclear Power Station. Revision 1. 


\subsection{CONNECTING RODS: DSRV-4 SERIES ENGINES}




\subsection{CONNECTING RODS: DSRV-4 SERIES ENGINES}

Summarized in this section is PNL's review of action taken by the Owners' Group to evaluate the connecting rods for the TOI V-type, DSRV-4 series engines installed at several nuclear power plants.

\subsubsection{Component Description}

The connecting rods used in the DSRV-4 engines are of an articulated design that operates two pistons off each crank throw. This design is illustrated in Figure 4.4.1. The main components of the connecting rod assembly are the master rod, link rod, link rod box, link rod pin, link rod bolts, upper and lower connecting rod bolts, connecting rod bearing shells, and rod-eye bushings.

The $V$-engine connecting rods were manufactured with either 1-7/8-inch- or 1-1/2-inch-diameter connecting rod bolts. Connecting rods with the 1-7/8-inch bolts are installed in the DSRV-16-4 engines at the Grand Gulf Nuclear Station. Al1 other TOI DSRV-4 engines in nuclear service are fitted with connecting rods having 1-1/2-inch bolts. In connecting rods with bolts of either size, oil is pumped through the crankpin journal and conducted through a series of drilled holes to the rod eye bushings in both the master and link rods. This oil serves to both lubricate the components and cool the piston crowns.

The primary function of the connecting rods is to transmit engine firing forces from the pistons to the crankshaft. The connecting rods must have sufficient column strength and fatigue resistance to withstand the cylinder firing forces and inertial loads. The design of the joint between the link rod box and the master rod of the $V$-engine connecting rods incorporates mating serrations that are lapped to achieve close contact, thereby reducing local stress concentrations and fretting.

\subsubsection{Failure History}

In report No. FaAA-84-3-14 (August 1984), FaAA documented the results of a telephone survey to determine the extent of connecting rod component failures experienced in DSRV-4 engines in non-nuclear service. This survey included the service experience of 12 owners with a total of 146 connecting rod assemblies. of these 146 assemblies, two connecting rods with 1-1/2-inch-diameter bolts and 


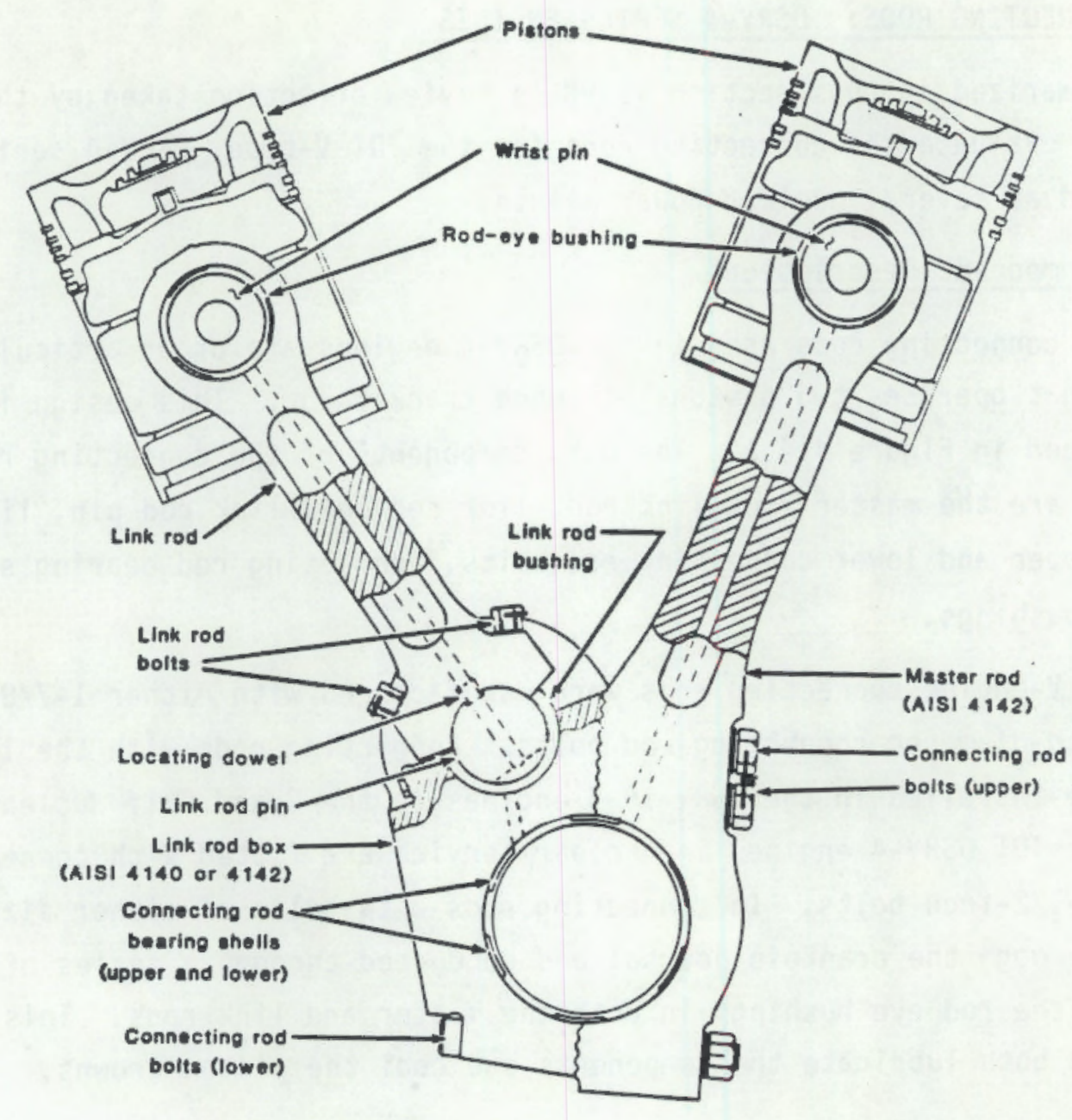

FIGURE 4.4.1. Connecting Rod, Model RV-4 V-Engine

Source: Failure Analysis Associates (August 1984, p. 1-8)

four connecting rods with the 1-7/8-inch-diameter bolts had cracked, according to the owners. In addition, two of the owners reported that several (number not specified) 1-7/8-inch bolts had cracked.

Most of the owners included in FaAA's survey reported that the connecting rods in their engines had operated for many hours with no rod problems. The following examples of favorable experience and an example of rod failure are taken from the FaAA report: 
- Kodiak, Alaska

RV12 - 42,323 operating hours at $80 \%$ maximum load, no rod problems, $1-7 / 8-i n c h$ bolts

RV12 - 41,975 operating hours at $80 \%$ maximum load, no rod problems, $1-7 / 8-i n c h$ bolts

RV16 - 16,300 operating hours, no rod problems, 1-1/2-inch bolts

- Nebraska City, Nebraska

RV16 - 32,600 operating hours, runs at $80 \%$ to $85 \%$ maximum load, no rod problems, 1-7/8-inch bolts

RV16 - 8,300 operating hours, runs at $80 \%$ to $85 \%$ load, no rod problems, 1-1/2-inch bolts

- United States Steel, Motor Vessel Edwin H. Gott

RV16 - 20,000 operating hours, runs at 90\% load, no rod problems, $1-1 / 2-i n c h$ bolts, torqued to $1700 \mathrm{ft}-1 \mathrm{~b}$

RV16 - 20,000 operating hours, runs at $90 \%$ load, no rod problems, $1-1 / 2-$ inch bolts, torqued to $1700 \mathrm{ft}-1 \mathrm{~b}$

- Falcon Shipping

RV16 - 11,000 operating hours, 2 broken connecting rods (1-1/2-inch boits).

In addition to the incidents cited by FaAA, connecting rod problems on the MV Columbia have been reported by the State of Alaska. The MV Columbia operates two TDI DSRV-16 engines for marine propulsion. Reported problems include cracks in the connecting rods, failure of the 1-7/8-inch connecting rod bolts, and fretting in the serrated joint.

TOI identified two failure mechanisms in these non-nuclear applications (TDE SIM No. 349, September 198D). The first mechanism was fatigue of the link rod bolts resulting from loss of bolt preload. According to TDI SIM No. 349, engines manufactured between 1972 and February 1980 may have been shipped with an insufficient locating dowel counterbore depth in the link rod or link pin, resulting in clearance between the link rod and link pin. Under firing load, 
this dowel will yield, resulting in reduced tension in the link rod bolts. The second mechanism was fatigue cracking of the connecting rod bolts and/or the link rod box in the mating threads. TDI indicated knowledge of numerous instances of bolt or rod fatigue of this nature where low assembly torque values were specified. TOI attributed these rod cracks to "thread fretting" resulting from distortion of the rod and bolt under operating loads in the area of the mating threads. TDI described a static load strain gage test of an assembled connecting rod with 1-7/8-inch bolts in which the alternating stresses near the 1 ink rod bushing were reduced $25 \%$ by increasing the assembly torque from $2200 \mathrm{ft}-1 \mathrm{~b}$ to $3200 \mathrm{ft}-1 \mathrm{~b}$. According to TDI, the effect of this preload is to stiffen the threaded joint by distributing load over more threads, thus reducing the concentrated stress in both the bolt and the bolt hole. The current torque specification for the 1-7/8-inch-diameter bolts is $2600 \mathrm{ft}-1 \mathrm{~b}$.

More recently manufactured OSRV-16-4 engines have connecting rods with 1-1/2-inch bolts. Currently, only the engines installed at Grand Gulf Nuclear Station are reported to have the 1-7/8-inch bolt design. TOI indicated that the design change to smaller-diameter bolts was intended to provide greater section thickness in the link rod box around the bolt threads. The specified torque for the $1-1 / 2-i n c h$ bolts is $1700 \mathrm{ft}-1 \mathrm{~b}$.

According to TOI, there have been no reports of cracked connecting rods with either bolt size when the specified torque is applied during assembly. However, FaAA noted that two cracked rods have been found in a marine engine assembled and operated during the time period when the higher specified torque was supposedly in effect.

Inspections of all of the connecting rods and bolts and bolt holes for cracking in the Catawba Nuclear Power Station 1 A engine, after more than 800 hours of operation, disclosed no relevant indications.

\subsubsection{Owners' Group Evaluation}

Failure Analysis Associates evaluated the structural integrity of the articulated connecting rods for the Owners' Group. The FaAA assessinent included 1) a rod bow analysis, 2) a finite element analysis of the lower 
connecting rod assembly, 3) a fracture mechanics analysis of the bolt holes, and 4) rod eye stress and fatigue analysis. The results of the FaAA study were reported in FaAA-84-3-14 (August 1984).

FaAA's evaluation is summarized in the following sections.

\subsubsection{Connecting Rod Bow Analysis}

Forging practices may result in the manufacture of connecting rods with slightly curved centerlines. Further, a connecting rod can flex under load, producing an axial misalignment of the connecting rod bearing. The objective of the FaAA analysis was to identify the degree of centerline bow that can be tolerated without exceeding the requirements of related components.

The FaAA analysis took into account allowable axial bearing misalignment and the corresponding offset in the position of the connecting rod reaction forces. This offset may be assumed to consist of two components: 1) the offset that results directly from misalignment or tilting of the connecting rod and 2) the further offset that develops as the result of loading a curved colum in compression. Solving for both components yielded the maximum allowable centerline bow of 0.47 inch in a forged, H-section connecting rod.

\subsubsection{Lower Connecting Rod Assembly Stress Analysis}

A two-dimensional finite element stress analysis of a V-engine connecting rod was performed to assess the range of cyclic stresses caused by the cylinder gas pressure plus dynamic loads exerted on the connecting rod. Emphasis was on the region of the four upper bolts. The model was developed with the interactive mesh generation code PATRAN. The analysis was performed using the MARC general purpose finite element code. The computer code CONROD was used to determine the magnitude of the total force that acts on the connecting rod as a result of gas pressure and inertia. In addition, stresses caused by bolt preloads were considered. The results of the finite element analysis inciuded:

- Maximum tensile stresses occur in the link rod box near top dead center of the link rod when peak firing pressure occurs.

- Maximum stresses occur at the crankpin hole near a 1 ine connecting the crankpin center to the link pin center. 
- Tensile stresses in the connecting rod result from the noncolinear loads exerted at the link pin hole and the reaction on the crankpin hole. This of fset in loads produces a bending moment that causes tensile stresses in the link rod above the crankpin and adjacent to the lower of the upper four bolts.

- Nominal stresses near the upper bolts are slightly lower than at the crankpin hole; however, because of the presence of the threads, higher stresses may occur near the bolts due to the stress concentration effect of the threads.

- For the 1-7/8-inch bolt design, the maximum range and direction of the cyclic principal stresses at the bolt hole is $9.88 \mathrm{ksi}$ at 49.4 degrees to the axis of the bolt hole.

- For the 1-1/2-inch bolt design, the maximum range and direction of cyclic stresses at the bolt hole is $9.01 \mathrm{ksi}$ and 57.8 degrees.

- The maximum cyclic stress range occurs at the 1 ink pin bearing hole at the minimum ligament between the crankpin hole and the link pin hole. The maximum stress range here is $28.86 \mathrm{ksi}$. There are no significant stress concentration effects at this location; therefore, this stress range is less critical than that at the bolt hole.

\subsubsection{Fracture Mechanics Analys is of Bolt Holes}

Through an analysis involving the use of a modified Goodman diagram, FaAA assessed the possibility of fatigue crack initiation in the bolt holes. FaAA's results included the following:

- Connecting rods with 1-1/2-inch bolts: Peak stresses are slightly below the fatigue initiation curve, and the margin of safety in crack initiation is relatively low. Accordingly, crack propagation was considered by comparing the cyclic stress intensity factor to the fatigue threshold. Based on a crack model where the bolt hole threads are assumed to behave as sharp cracks, crack propagation is unlikely in the absence of preexisting flaws (i.e., flaws introduced during manufacturing). 
Strain-gage testing of a connecting rod with 1-1/2-inch bolts showed that cyclic and mean stresses are lower than those predicted in the finite-element analysis, and that the cyclic stresses are insensitive to the level of bolt preload over the range tested, $i . e ., 800 \mathrm{ft}-1 \mathrm{~b}$ to $2100 \mathrm{ft}-1 \mathrm{~b}$.

- Connecting rods with 1-7/8-inch bolts: Peak stresses are slightly above the fatigue initiation curve, indicating that fatigue initiation is possible. Based on an analysis using the same approach as that used for the connecting rods with $1-1 / 2-i n c h$ bolts, crack propagation is unlikely in the absence of preexisting flaws. However, in the extrene case where yield-level stresses are assumed near the threads, the cyclic stress intensity factor could exceed the threshold of fatigue.

\subsubsection{Rod-Eye Analys is}

FaAA concluded that the rod eye and rod-eye bushing are subject to the same loads and acceptance/rejection criteria as for the connecting rods used in the inline engines. The rod-eye analysis for the latter connecting rods is reviewed in Section 4.3.3.2.2 of this report.

\subsubsection{Conclusions and Recommendations}

The conclusions and recommendations of the Owners' Group are incorporated in the $D R / Q R$ reports for each of the nuclear stations having DSRV engines. They are generally developed from FaAA's conclusions and recomendations.

\subsection{FaAA's Conclusions and Recommendations. FaAA concluded that} the connecting rods for the DSRV-4 series engines are adequate for their intended service, provided that the following inspections and surveillance operations are performed:

- The clearance between the link pin and the link rod should be inspected to ensure that the condition addressed in TDI SIM 349 (see Section 4.4.2) does not exist. TOI recommends that this clearance be checked with a 0.0015 inch feeler gage; FaAA, however, recommended that this dimension be zero when the bolt torque is $1050 \mathrm{ft}-1 \mathrm{~b}$. 
- The centerline bowing of the connecting rod should be verified to be less than 0.47 inch.

- The first pair of bolts and bolt holes above the crankpin should be inspected with eddy current to detect any pre-existing flaws. The proper bolt torque, as specified by the manufacturer, inust be ensured, and specified contact of the serrated surfaces should exist. The breakaway torque should be measured, and complete dimensional checking of both surfaces of the serrated joint should be performed if the breakaway torque is less than $1600 \mathrm{ft}-1 \mathrm{~b}$.

- The first pair of 1-7/8-inch diameter bolts above the crankpin should be removed and magnetic-particle inspected and the threads of the holes examined for cracking by eddy current or other methods. The permissible tine at $50 \%$ of full load between inspections is 200 hours, based upon the reliability of the eddy-current inspection (currently limited to detecting cracks $1 / 8$-inch in length or greater) and pending strain-gage tests. This time was later changed to 270 hours (NRC/06 Meeting, February 11, 1985). Proper bolt torque, as specified by the manufacturer, must be ensured, and adequate contact should exist at the serrated joint. Breakaway torque should be measured, and complete dimensional checks of both surfaces of the serrated joints should be made if the breakaway torque is less then $2400 \mathrm{ft}-1 \mathrm{~b}$.

- The rod eye and the rod-eye bushing are similar to those in the OSR-48 connecting rods, and the same maintenance is recommended.

4.4.3.5.2 Design Review/Quality Revalidation Reports. In the $D R / Q R$ report for the TDI engines at the Grand Gulf Nuclear Station, the Owners' Group recomends the following inspections for the connecting rods (which are equipped with 1-7/8-inch bolts):

- Until each engine has accumulated 800 hours at loads between $60 \%$ and $100 \%$ of rated load, the first pair of bolts above the crankpin and the threaded holes in which they are installed should be inspected at intervals that depend on the sensitivity of the inspection technique 
for detecting cracks in the threaded holes. The two bolts should be removed and magnetic-particle inspected. The threads of the two holes should be examined by appropriate methods. During these inspections, breakaway bolt torque should be measured. The recomended intervals are as follows:

- If the inspection method is shown to be capable of detecting any crack that is no larger than 0.125 inch deep and 0.25 inch long at the root of the bolt hole threads, this inspection should be performed at each refueling outage or after 270 hours of operation at 60 to $110 \%$ load, whichever comes first.

- If the inspection method is shown to be capable of detecting any crack that is no larger than 0.050 inch deep and 0.100 inch long, the inspection should be performed after 800 hours at loads between 60 and $110 \%$ load.

- Regardless of the sensitivity of the inspection method used for initial verification that the holes are free of defects, the two bolts and bolt holes above the crankpin should be inspected for fatigue cracks after each engine has accumulated 800 hours of operation at 60 to $110 \%$ load. The bolt torque should also be checked. If the torque is less than $2400 \mathrm{ft}-1 \mathrm{~b}$, a more detailed examination of bolts, bolt holes, and contact surface areas should be performed. Such an inspection should also be performed any time the rods are disassembled for any reason.

Additional recommendations in the $D R / Q R$ report for the engines at Grand Gulf included the following:

- Bolt torque and fit between the mating surfaces of the rack joints should meet manufacturer's specifications.

- The clearance between the link pin and the link rod should be examined. This dimension must be zero when the specified torque is applied to the link rod bolts. 
The surveillance recommended by the Owners' Group for other DSRV engines differs from the recommendations for the engines at Grand Gulf because the connecting rods in all of the other $V$-engines are equipped with $1-1 / 2-i n c h$ rather than 1-7/8-inch bolts. The Owners' Group recommends the following (e.g., DR/QR report for the engines at Comanche Peak):

- An initial inspection of the bolts and bolt holes above the crankpin should be performed to verify the absence of pre-existing flaws. In addition, the mating surfaces should be examined to verify that the percentage of contact meets manufacturer's recommendations. The bolt torque must also meet manufacturer's recommendations.

- The clearance between the link pin and the link rod should be examined initially and at 5-year intervals. This dimension must be zero when the specified bolt torque is applied.

- At the first 5-year overhaul the surfaces of the rack teeth should be inspected for signs of fretting. The mating surfaces should also be examined to ensure that the percentage of contact meets

manufacturer's recomnendations.

\subsubsection{PNL's Review}

The following PNL consultants participated in various aspects of PNL'S review of the connecting rods for TDI OSRV-4 engines:

- S. H. Bush, Review and Synthesis Associates

- A. J. Henriksen, A. J. Henriksen, Inc.

- B. J. Kirkwood, Covenant Engineering

- P. J. Louzecky, Engineered Applications Corporation

- the late A. Sarsten, Norwegian Institute of Technology.

In addition, J. C. Spanner of PNL's Nondestructive Testing Section reviewed nondestructive testing procedures used by members of the Owners' Group to examine the bolt holes.

PNL's review encompassed the following activities:

- a review of FaAA-84-3-14 (August 1984) and reviews of two representative Owners' Group DR/QR reports (for Grand Gulf and Comanche Peak) 
- reviews performed in the preparation of PNL technical evaluation reports for the TDI DSRV-4 diesel generators at five nuclear power plants that became candidates for operating licenses: Catawba, Comanche Peak, Grand Gulf, Perry, and San Onofre - Engine components reviewed included the $V$-connecting rods. As part of this effort, PNL representatives reviewed post-test disassemblies and inspections of diesel engines at Catawba, Comanche Peak, and Grand Gulf.

- information reviewed by PNL representatives in connection with the preparation of testimony for an Atomic Safety and Licensing Board hearing on the Perry Nuclear Power Plant.

4.4.4.1 Rod Bowing Evaluation

PNL concurs that the approach taken by FaAA in the analysis of an allowable limit on connecting rod bowing is appropriate.

\subsubsection{Rod-Eye Bushing Analys is}

The rod eye and bushing of the inline and $V$-engine connecting rods are similar and experience virtually the same loadings. PNL's comments on the analysis of the rod eye and bushing for the inline connecting rod are sumnarized in Section 4.3 .4 .

\subsubsection{Connecting Rod Bolts and Link Rod Box}

In the opinion of PNL's reviewers, FaAA's two-dimensional finite element analysis and FaAA's fracture mechanics analysis do not, by themselves, provide a conclusive basis for determining the adequacy of the connecting rods for their intended use in standby diesel generators for nuclear power plants. As discussed in FaAA-84-3-14, the predicted peak stresses are slightly below the fatigue initiation curve for connecting rods with $1-1 / 2-i n c h$ bolts and slightiy above the fatigue initiation curve for connecting rods with 1-7/8-inch bolts. Also according to the FaAA report, strain-gage testing of a connecting rod with 1-1/2-inch bolts shows that cyclic and mean stresses are lower than those predicted by analysis. However, the differences are not quantified in the report. Considering the approximate nature of the calculated stresses and the unknown level of conservatism of the analyses, PNL's reviewers cannot draw unequivocal conclusions from the results. 
Operating experience discussed in FaAA-84-3-14 for TDI DSRV-4 connecting rods in non-nuclear installations also falls short of providing a conclusive basis for determining the adequacy of the rods. Df the owners surveyed by FaAA, one (Falcon Shipping) reported two broken connecting rods (equipped with 1-1/2-inch bolts) following 11,000 operating hours at an unspecified load. Most of the owners reported no rod problems, even in engines run several tens of thousands of hours at relatively high loads. For example, an RV 16 engine in Nebraska City, Nebraska, was reported to have operated 32,600 hours at $80 \%$ to $85 \%$ load with no rod problems. The bolt size reported for the connecting rods in that engine is $1-7 / 8$ inch. These examples 111 ustrate that the results of service experience are mixed.

PNL notes that in a test program completed in March 1984, diesel generator $1 \mathrm{~A}$ at Catawba had been operated for more than 800 hours. Over half of those hours were at loads equal to or greater than $5800 \mathrm{~kW}$ ( $83 \%$ of rated load). Diesel generator $1 B$ had been operated for more than 750 hours in a test program completed in July 1984. Over 600 of those hours were at loads equal to or greater than $5800 \mathrm{~kW}$. Post-test inspections of the connecting rods (which use 1-1/2-inch bolts) revealed no evidence of cracking. Similar experience exists for the engines at Grand Gulf (with 1-7/8-inch bolts in the connecting rods).

The mixed results of service experience are consistent with what might be expected from variations in assembly practices and, possibly, from variations in manufacturing practices rather than from design deficiencies. The information available at this time does not provide an adequate basis for PNL's reviewers to reach an unequivocal conclusion in this regard. Nevertheless, a substantial portion of the service experience demonstrates that the DSRV-4 connecting rods can be operated for extended periods with no problems.

\subsubsection{Conclusions and Recommendations}

Subject to the recommendations discussed later in this section, PNL concurs with the Owners' Group that the DSRV-4 connecting rods are adequate for their intended service in emergency diesel generators for nuclear power plants. PNL's recommendations concern additional surveillance of the connecting rods to facilitate the timely identification of any problems that may develop in service. In PNL's opinion, the additional surveillance is necessary in light of 
the mixed results of known service experience, the unknown level of conservatism of FaAA's stress analysis, and the difficulties inherent in inspecting threaded bolt holes for small flaws. PNL notes that the number of engine operating hours that may be anticipated between the recommended inspections is small compared to the extended periods that DSRV-4 connecting rods have been operated with no problems.

A key consideration in the inspection of the threaded holes is the adequacy of the procedure for detecting flaws above a specified size. The surface condition of the threads and the difficulty of thoroughly cleaning a threaded hole may complicate the problem of reliably detecting flaws. Furthermore, the sensitivity of an inspection method may depend on crack orientation, which is an uncertain factor.

PNL notes that FaAA has developed an eddy-current inspection procedure for threaded carbon steel holes (NDE 11.9, Rev. 1). The acceptance standards in this procedure are based on electric-discharge-inachining notches in a calibration block. PNL is also aware that a boroscopic method of inspection has been used by at least one member of the Owners' Group. FaAA's recommended inspection interval for connecting rods with 1-7/8-inch bolts (Section 2.2.4 of FaAA-84-3-14) assumes that cracks greater than 1/8-inch depth are detectable. However, none of the documents available for $\mathrm{PNL}$ 's review addresses the minimum flaw size in bolt holes that existing methods have been demonstrated to detect.

PNL's recommendations are as follows:

4.4.4.4.1 Preservice Inspections. PNL concurs with the recomnendations of FaAA and the Owners' Group for preservice inspections of the connecting rods with certain comments noted below. The rod eyes and rod-eye bushings should be subject to the same inspections recommended for the inline connecting rods (Section 4.3). Rod bow shou?d be within the FaAA-recommended limit. Inspections of the lower connecting rod assemblies of all rods should include the following:

- bolt holes in link rod box - As recommended in the $D R / Q R$ reports for the TOI engines at Comanche Peak and Grand Gulf, all of the threaded holes for the connecting rod bolts should be inspected using an 
appropriate nondestructive technique. The purpose of this inspection is to verify the absence of preexisting flaws. As discussed above, the demonstrated sensitivity of existing inspection methods has not been addressed in the documents available for PNL's review. However, PNL infers from FaAA-84-3-14 that any indication over $1 / 8$ inch in depth in the pair of bolt holes imnediately above the crankpin is rejectable. All indications should be recorded for engineering evaluation.

- connecting rod bolts - Also as recommended in the $D R / Q R$ reports for Comanche Peak and Grand Gulf, all connecting rod bolts should be examined. The $D R / Q R$ reports call for a magnetic particle test (MT), but do not specify the technique. In future examinations, PNL recommends that these bolts be examined using the wet fluorescent MT technique (in conjunction with a yoke) rather than the dry particle technique (and direct-current prods). The wet fluorescent technique would provide the enhanced sensitivity normally specified for bolt examinations. The washers used with the bolts should be examined visually for signs of galling, as specified in the Comanche Peak and Grand Gu?f $Q R / Q R$ reports.

- connecting rod bolt torque - All connecting rod bolts should be lubricated in accordance with the engine manufacturer's instructions and torqued to the specifications of the manufacturer. As discussed in FaAA-84-3-14, the current torque specifications for the 1-1/2-inch bolts and the 1-7/8-inch bolts are, respectively, $1700 \mathrm{ft}-1 \mathrm{~b}$ and $2600 \mathrm{ft}-\mathrm{lb}$.

PNL suggests that the lengths of the two pairs of connecting rod bolts above the crankpin be measured ultrasonically pre- and posttensioning. These measurements would provide an accurate check on whether or not the desired bolt stretch has been achieved through application of the specified torque. In addition, these measurements would provide a useful reference for later ultrasonic checks of bolt preload. FaAA-84-3-14 and the OR/QR report for Grand Gulf recommend that breakaway torque be measured at any time the link rod box is 
disassembled, and that the bolts, bolt holes, and contact surface areas be carefully examined if the breakaway torque is less than $1600 \mathrm{ft}-1 \mathrm{~b}$ for 1-1/2-inch bolts or less than $2400 \mathrm{ft}-1 \mathrm{~b}$ for 1-7/8-inch bolts. PNL notes that breakaway torque may not be an accurate measure of bolt preload, particularly after a connecting rod has been in service. Inaccuracies may be introduced by such factors as thread galling. Ultrasonic measurements of bolt length would provide a more reliable check because they would not be affected by the condition of the threads.

- contact at serrated joint - The contact between mating surfaces of the link rod box should be no less than the minimum specified by the engine manufacturer. The percentage of contact should be verified for each joint using an appropriate method (e.g., "blueing").

- link rod clearance - Clearance between the link pin and the link rod should be examined. PNL concurs with FaAA's recominendation that this dimension must be zero when the link rod bolts are torqued to $1050 \mathrm{ft}-1 \mathrm{~b}$ as specified by the manufacturer.

4.4.4.4.2 Periodic Inspections. As discussed in Section 4.4.3.5.2 of this report, the $D R / Q R$ report for Grand Gulf recominends that the first pair of bolts (1-7/8-inch-diameter) and bolt holes immediately above the crankpin be inspected at intervals that depend on the sensitivity of the method used for the initial inspection. These inspections may be discontinued, according to the $D R / Q R$ report, after each engine has accumulated 800 hours at loads at or above $60 \%$ of rated load. No such inspections are recommended by FaAA or by the Owners' Group for connecting rods with $1-1 / 2-i n c h$ bolts.

In PNL's opinion, additional periodic inspections are warranted for reasons discussed earlier in this section. PNL recommends that, during each major (5-year) engine disassembly, certain inspections be performed in addition to those already specified in the $D R / Q R$ reports. These recommendations apply to all connecting rods installed in DSRV-4 engines at nuclear power plants, regardless of connecting-rod bolt size. 
- If connecting-rod bolt stretch was measured ultrasonically during reassembly following the preservice inspection as suggested by PNL, the lengths of the two pairs of bolts above the connecting rod should be remeasured ultrasonically before the link rod box is disassembled. Alternatively, the breakaway torque should be measured. If bolt tension determined by either method is less than $93 \%$ of the value at installation (as recomnended by FaAA), the cause should be determined, appropriate corrective action should be taken, and the interval between checks of bolt torque should be reevaluated.

- All connecting rod bolts should be visually inspected for thread danage (e.g., galling), and the two pairs of connecting rod bolts above the crankpin should be MT inspected to verify the continued absence of cracking. PNL recommends the wet-fiuorescent MT technique as discussed above for the preservice inspections of the bolts. All washers used with the bolts should be examined visually for signs of galling or cracking, and replaced if damaged.

- A visual inspection should be performed of all external surfaces of the link rod box to verify the absence of any signs of serviceinduced distress.

- All of the bolt holes in the link rod box should be inspected for thread damage (e.g., galling) or other signs of abnormalities. In addition, the bolt holes subject to the highest stresses (i.e., the pair imediately above the crankpin) should be examined with an appropriate nondestructive method to verify the continued absence of cracking. Any indications should be recorded for engineering evaluation and appropriate corrective action.

- The rack teeth in the serrated joint of the link rod box should be visually inspected for signs of fretting. (In the $D R / Q R$ report for Grand Gulf, this inspection is called for at the first 5-year overhaul only. The $D R / Q R$ report for Comanche Peak calls for this inspection every 5 years.) If fretting has occurred, it should be subject to engineering evaluation for appropriate corrective action. 
- The surface contact at the serrated joint and the zero clearance condition between the link pin and the link rod should be checked for compliance with the recommendations discussed above for the initial inspections.

- Al1 connecting rod bolts should be lubricated in accordance with the engine manufacturer's instructions and torqued to the specifications of the manufacturer. As discussed in Section 4.4.4.4.1, the current torque specifications for the 1-1/2-inch bolts and the 1-7/8-inch bolts are, respectively, $1700 \mathrm{ft}-1 \mathrm{~b}$ and $2600 \mathrm{ft}-1 \mathrm{~b}$. PNL suggests that the lengths of the two pairs of bolts above the crankpin be measured ultrasonically pre- and post-tensioning, for reasons also discussed in Section 4.4.4.4.1.

4.4.4.4.3 Other Disassemblies. If the connecting rods are disassembled at times other than the major (5-year) engine overhauls, they should receive the inspections summarized in Section 4.4.4.4.2.

\subsubsection{References}

Failure Analysis Associates (FaAA). August 1984. Design Review of Connecting Rods for Transamerica Delaval DSRV-4 Series Diesel Generators. FaAA-84-3-14, Palo Alto, California.

Failure Analysis Associates (FaAA). July 1984. Eddy Current Inspection Procedure for Threaded Carbon Steel Holes. NDE 11.9 (Rev. 1), Palo Alto, California.

TDI Diesel Generator Owners' Group. January 1985. TDI Diesel Generator Design Review and Quality Revalidation Report - Comanche Peak Steam Electric Station (Rev. 1).

TDI Diesel Generator Owners' Group. February 1985. IDI Diesel Generator Design Review and Quality Revalidation Report - Grand Gulf Nuclear Station Unit 1 (Rev. 1).

Transamerica Delaval, Inc. September 18, 1980. "Service Information Memo No. 349." Dakland, California.

U.S. Nuclear Regulatory Commission (NRC). February 11, 1985. Transcribed proceedings, "Nuclear Regulatory Comission Staff Meeting with TDI Owners' Group, Bethesda, Maryland." Washington, D.C. 


\subsection{CONHECTING ROD BEARING SHELLS}




\subsection{CONNECTING ROD BEARING SHELLS}

This section documents PNL's evaluation of action taken by the Owners' Group to resolve potential problems identified with the 12 -inch- and 13-inch-diameter connecting rod bearing shells used in the TDI DSR-4 and DSRV-4 series engines.

\subsubsection{Component Description}

The connecting rod bearing shells interface the connecting rods with the crankshaft. The connecting rod bearings in the TDI DSR-4 and DSRV-4 series engines are installed in the connecting rod in the form of half-shells made from cast aluminum-6\% tin (Alcoa alloy B850). The half-shells are electroplated on the inner surface with a lead-base babbitt to form the bearing surface on the connecting rod journal. The bearings are lubricated under pressure, and a substantial flow of oil proceeds through machined channels in the shells from the drilled crankshaft oil holes to the passageways within the connecting rods and on to the pistons. The upper bearing half is subject to the piston firing loads and therefore is more highly loaded than the lower half.

The in-line, 8-cylinder engines at Shorehan were originally supplied with crankshafts with 1l-inch-dianeter connecting rod bearings. However, these were replaced with new crankshafts with 12 -inch bearings incorporating design modifications that address problems identified following the crankshaft failure in August 1983. Other TDI in-line engines at nuclear power plants also are equipped with 12-inch connecting-rod bearings. The TDI V-block engines use 13-inch bearings.

\subsubsection{Failure History}

When the original crankshafts in the Shoreham emergency diesel generators were replaced with new crankshafts with 12-inch-diameter bearings, four of the original forty-eight 11 -inch-diameter connecting rod bearing shells were found damaged. The damage consisted principally of cracking in the upper half-shell, which experienced heavier loadings because of combustion forces. One halfshell was fractured into two pieces; the others were cracked in the same relative position, but the cracks had not completely passed through the half- 
shells. This cracking was discovered after 600 to 800 hours of operation, including approximately 250 hours at or above $100 \%$ load.

Subsequent to the change to 12 -inch bearings, a cracked bearing was dis. covered at Shoreham after about 100 hours operation at full load (Owners' Group meeting March 22, 1984, p. 162). Normally, the connecting rod bearings in engines of this size are expected to last thousands of hours. There have apparently been no other reports of similar failures in TDI engines in nuclear service. However, some bearing shells have been replaced because they were found to be in nonconformance with acceptance criteria recommended by failure Analysis Associates for voids in the base material.

Connecting rod bearing failures in non-nuclear service have included severe wear, possibly due to unsatisfactory alloy makeup; cracked and broken shells; and excessive fretting in the connecting rod bore, due to improper clamping force. Specific failures are itemized in the $0 R / Q R$ report for Comanche Peak (TOI OG January 1985).

\subsubsection{Owners Group Evaluation}

Failure Analysis Associates conducted a design review for the Owners' Group. FaAA's investigation is presented in report FaAA-84-3-1 (March 1984). The objectives of the FaAA effort were 1) to determine the cause of the cracking in the original 11-inch bearing shells in the Shoreham engines and 2) to review the design adequacy of the connecting rod bearings in the DSR-4 and DSRV-4 series TDI engines with 12-inch and 13-inch bearings.

\subsubsection{Scope}

The scope of the FaAA investigation performed for the Owners' Group included

- detailed examinations of the failed 11-inch Shoreham connecting rod bearing shells as well as visual examination of the replacement 12-inch Shoreham bearings and the 13-inch Grand Gulf bearings - These detailed examinations included I) scanning electron microscopy, 2) tensile testing, 3) radiography, and 4) chemical analysis. 
- journal orbit analysis to determine the pressure distribution in the hydrodynamic oil film acting on the connecting rod bearing shells

- finite element stress analysis to compare the tensile stresses in the three bearing shell designs and to furnish information for the subsequent fracture mechanics analysis

- fracture mechanics analysis to determine the fatigue life of the bearing shells.

\subsubsection{FaAA's Conclusions and Recommendations}

FaAA's conclusions and recommendations documented in FaAA-84-3-1 include the following:

- High axial stresses led to fatigue cracking of the original 11-inchdiameter connecting rod bearing shells installed at Shoreham. Contributing factors were 1) unsupported bearing ends resulting from a 1/4-inch chamber in the connecting rod bore, 2) edge loading patterns, and 3) excessive peak oil film pressure (Swanger 1983). A journal orbit analysis performed for FaAA by Imperial Clevite, Inc., predicted a peak oil film pressure of 29,700 psi, which exceeds an industry guideline of 26,000 psi. FaAA's finite element analysis of. the 11-inch shells predicted a maximum tensile stress of 17,700 psi, near the site of crack initiation. On the basis of FaAA's fatigue analysis, this stress could result in crack initiation after approximately 250 hours of operation at full load.

- Laboratory analyses show that the failed 11-inch bearing shells were of the proper composition and ultimate tensile strength.

- The 12-inch-diameter connecting rods now installed in the engines at Shoreham provide complete support to the bearing shell ends. The stress range that led to fatigue cracking of the 11-inch bearing shells is reduced by a factor of two in the 12-inch bearing shells, thereby raising the predicted fatigue life to about 38,000 hours at full load. Because the 13-inch connecting rod bearing shells used in TDI $V$-engines have a stress distribution that very nearly matches the 
stress distribution in the 12-inch shells, the predicted fatigue iife of the 13-inch she1ls is also about 38,000 hours at full load.

- On the basis of an analysis performed with the BIGIF fracture mechanics computer code, discontinuities up to 0.050 inch may be allowed in the "critical zone" of the upper connecting rod bearing shells. This critical zone is bounded as follows. Along the axis of the bearing shel1, it encompasses a band that begins 0.4 inch from each end of the shell and extends inward 1.4 inches toward the oil groove. It also extends circumferentially 2.5 inches to either side of the oil hole for 12-inch diameter shells and 5.0 inches for 13-inch shells. (a) Outside this critical zone and in the lower shells, the acceptable void size is 0.250 inch. FaAA recommended the use of radiography to ensure compliance with these acceptance criteria, and developed a procedure (FaAA NDE 9.2) for conducting the inspections.

- The crack found in a 12-inch-diameter bearing shell at Shorehan was apparently caused by a $3 / 15$-inch discontinuity in the bearing material (Owners' Group meeting on March 22, 1984, p. 162). This was a factor in the development of the acceptance criteria recommended by FaAA as described above.

\subsubsection{Owners' Group Recommendations in $D R / Q R$ Reports}

Recommendations of the Owners' Group for inspections of the connecting rod shells include the following (as documented, e.g., in the $O R / Q R$ reports for Conanche Peak, River Bend, and San Onofre):

- Inspect and measure the connecting rod bearing shells to verify lube oil maintenance, which affects wear rate. The visual and dimensional inspection of the bearing shells should be conducted at the fuel outage that precedes 500 nours of operation by at least the sum of hours of operation in a LOOP/LOCA event plus the expected hours of operation between outages.

(a) This circumferential boundary for the critical zone of the 13-inch shells is documented in the $D R / Q R$ report for River Bend (TOI OG February 1985). 
- As part of the $O R / Q R$ of each engine, examine the bearing shells radiographically to the acceptance criteria developed by FaAA and adopted by the Owners' Group (Section 4.5.3.2, above). Also examine all replacement bearing shells in this manner.

For the 20-cylinder engines at San Onofre Unit 1, the Owners' Group recommends that the above-mentioned inspections be performed at the first major enyine overhaul to confirm continued satisfactory performance of the bearing shells. This recommendation stems from the substantial crankshaft torsional vibrations experienced in the San Onofre engines during startup and shutdown transients. These vibratory conditions, which are discussed in Section 4.8 of this report, are unique to San Onofre because no other nuclear power plant in the United States is equipped with $20-c y l$ inder TDI engines.

\subsubsection{PNL's Review}

PNL's review of the connecting rod bearing shells encompassed the FaAA report and the Owners' Group OR/QR reports referenced in Section 4.5.3, and also encompassed information obtained by PNL representatives in connection with plant visits, some at times of engine disassemblies.

\subsubsection{Reviewers}

The FaAA design review of the TDI connecting rod bearing shells used in the USR-48 and OSRV series engines was evaluated by the following PNL consultants:

- S. H. Bush, Review and Synthesis Associates

- A. J. Henriksen, A. J. Henriksen, Inc.

- B. J. Kirkwood, Covenant Engineering

- P. J. Louzecky, Engineered Applications Corporation.

\subsubsection{Conclusions and Recommendations}

PNL concurs that FaAA's stress and fatigue andyses of the 12-inchdiameter connecting rod bearing shells for TOI in-line engines, and 13-inch bearing shells for TDI V-engines, substantiate the adequacy of these bearings for nuclear standby service. However, PNL notes that the known service experience with these bearing shells is too limited to substantiate FaAA's predicted bearing fatigue life of about 38,000 hours. Nevertheless, PNL concurs that 
these bearing shells have adequate life for nuclear standby service based on 1) the current base of service experience and 2) the anticipated operating hours for the engines between major engine disassemblies planned by members of the Owners' Group.

During periods between successive major (5-year) engine inspections, it is anticipated that the total number of hours of operation will be on the order of what has already been successfully demonstrated. For example, several EDGs have already operated in excess of 500 hours without degradation of the integrity of the connecting rod bearing shells. The $1 \mathrm{~A}$ EDG at Catawba has operated for over 800 hours, over half of which were at loads above $5800 \mathrm{~kW}$ (the load under LOOP/LOCA conditions). The 18 EDG has operated for 750 hours at loads above $5800 \mathrm{~kW}$. At Shoreham, the EDG 103 operated for more than 740 hours at $3300 \mathrm{~kW}$ (the "qualified" load that encompasses all emergency service needs). Following the operation of the Shoreham engine, the connecting rod bearing shells were viewed by several of PNL's consultants and found to be in excellent condition (Henriksen et a1. 0ecember 1984). The known service experience provides a strong basis for confidence that the connecting rod bearing shells will operate satisfactorily between major engine inspections, if initially inspected as recommended by the owners' Group.

With regard to connecting rod bearing inspections, PNL suggests that the critical zone of radiography for new, 12-inch bearings intended for use in 8-cylinder engines be extended axially to the bearing ends (rather than beginning 0.4 inch from each end, as recomended by FaAA). This suggestion is made in recognition of end loadings that have been noted in certain TDI 8-cylinder engines (TOI Owners' Group, March 22, 1984, p. 166). PNL recognizes that the FaAA analysis accounts for this effect, that bearings in service will be inspected for cracks at each engine disassembly, and that bearings with cracks will be replaced. Nevertheless, in PNL's view it wouid be prudent to include the end zones in radiographic inspections of 12 -inch replacement bearings.

On the basis of the wear patterns exhibited by certain connecting rod bearings viewed by PNL's consultants, PNL offers a suggestion concerning oi] pressure to the bearings. PNL consultants have viewed connecting rod bearings removed from the engines at Catawba and Grand Gu?f. The Catawba bearings 
displayed a wear pattern thought to be a result of some cavitation, possibly arising from a "column effect" (Henriksen 1960), whereas the Grand Gulf bearings had no visible pattern of this type. The oil pressure in the Catawba engines reportedly was about $10 \%$ below that in the Grand Gulf engines. Thus, PNL's consultants suggest that consideration be given to increasing the oil pressure to the $v$-connecting rod bearings to the level used in the engines at Grand Gulf but within the limits of TOI specifications. This suggestion is offered only as a possible means to prolong bearing life; it is recognized that periodic bearing inspections planned by members of the Owners' Group provide for timely detection of bearing wear before it could affect the operability of the engines.

PNL concurs with the connecting rod bearing shell inspections recommended by the Owners' Group in the DR/QR reports referenced in Section 4.5.3.3. However, PNL recomends that an oil contamination analysis be performed on a regularly scheduled basis as recommended by the oil supplier. Such a periodic analysis not only could provide an early warning of the deterioration of the bearing shells, but could warn of other developing engine or lubrication problems.

\subsubsection{References}

Failure Analysis Associates (FaAA). March 12, 1984. Design Review of Connecting Rod Bearing Shells for Transamerica Delaval Enterprise Engines. FaAA-84-3-1, Palo Alto, California.

Henriksen, A. J. 1960. "Turbocharging of a Large Two Cycle Diesel Engine." ASME, Winter Meeting, 1960.

Henriksen, A. J., B. J. Kirkwood, W. W. Laity, P. J. Louzecky, J. F. Nesbitt, and L. G. Van Fleet. December 3, 1984. Post-Test Examination of Transamerica Delaval, Inc. Emergency Diesel Generator 103 at Shoreham Nuclear Power Station for U.S. Muclear Regulatory Commission Staff. Before the Atomic Safety and Licensing Board, Docket No. 50-322-0L

Swanger, L. October 13, 1983. "Summary of Findings: Energency Diesel Engine Connecting Rod Bearings." Failure Analysis Associates memorandum to M. Hilligan.

TDI Diesel Generator Owners' Group (TOI OG). January 1985. TOI Diesel Generator Design Review and Qual ity Revalidation Report - Comanche Peak Steam Electric Station. Revision 1 . 
TOI Diesel Generator Owners' Group (TDI OG). February 1985. TDI Diesel Generator Design Review and Quality Revalidation Report - River Bend Station. Revision 1.

TDI Diesel Generator Owners' Group (TDI OG). January 1985. TDI Diesel Generator Design Review and Quality Revalidation Report - San Onofre Nuclear Generating Station. Forwarded to NRC (H. R. Denton) as Enclosure 1 of Southern California Edison Company (M. 0. Medford) letter dated September 3, 1985.

TDI Diese1 Generator Owners' Group Meeting. March 22, 1984. Wading River, New York. Reported by Tayloe Associates, Court Reporters, Washington, D.C. 
4.6 CRANKSHAFT: 8-CYLINDER, DSR-4 SERIES ENGINES 


\subsection{CRANKSHAFT: 8-CYLINDER, DSR-4 SERIES ENGINES}

PNL reviewed the action taken by the Owners' Group to evaluate the crankshafts for the TDI 8-cylinder, DSR-4 series engines at the River Bend and Shoreham nuclear power stations. The conclusions drawn from PNL's review are applicable to these installations only. However, these conclusions may be extended to crankshafts of the same design in TDI 8-cylinder engines at other nuclear power stations, provided that the crankshaft mechanical properties and the crankshaft torsional stresses are shown to be similar to those in the Shoreham and River Bend installations.

\subsubsection{Component Description}

The crankshaft for TDI 8-cylinder, DSR-4 series engines is a steel forging through which power is transmitted from eight piston and connecting rod assemblies installed in an inline engine block. The diameters of the crankpin journals and the main bearing journals are 12 inches and 13 inches, respectively, and the overall crankshaft length is approximately 19 feet 7 inches.

The 8-cylinder, DSR-4 diesel generators purchased for nuclear service are rated by TDI for continuous operation at $3500 \mathrm{~kW}$ when loaded to a brake mean effective pressure (BMEP) of $225 \mathrm{psig}$ at the design speed of $450 \mathrm{rpm}$. These engines are also rated by TDI to operate for 2 hours out of every 24 operating hours at $10 \%$ overload $(3850 \mathrm{~kW})$.

\subsubsection{Design Guidelines}

In a publication titled Standard Practices for Low and Medium Speed Stationary Diesel and Gas Engines (1972), the Diesel Engine Manufacturers Association (DEMA) provided recomendations for allowable torsional vibratory stresses in crankshafts. The OEMA publication is referenced in the Institute of Electrical and Electronics Engineers (IEEE) Standard 387-1977, IEEE Standard Criteria for Diesel-Generator Units Applied as Standby Power Supplies for Nuclear Power Generating Stations. According to NRC Regulatory Guide 1.9, Revision 2 (1979), which addresses the design of standby diesel generators, conformance with IEEE Std. 387-1977 is acceptable for meeting NRC staff 
requirements. Thus, the DEMA recommendations were used as a basis for the crankshaft evaluations performed by the TDI Diesel Generator Owners' Group and the reviews performed by PNL.

Included in the DEMA Standard Practices (1972, p. 55) are specific recommendations on crankshaft torsional stresses. Crankshaft stresses determined through analyses and tests of 8-cylinder TDI engines at nuclear power plants are compared later in this report with these DEMA recommendations:

In the case of constant speed units, such as generator sets, the objective is to insure that no harmful torsional vibratory stresses occur within five percent above and below rated speed.

For crankshafts, connecting shafts, flange or coupling components, etc., made of conventional materials, torsional vibratory conditions shall generally be considered safe when they induce a superimposed stress of less than 5000 psi, created by a single order of vibration, or a superimposed stress of less than 7000 psi, created by the summation of the major orders of vibration which might come into phase periodically.

\subsubsection{Failure History}

In August 1983, the crankshaft in the EDG 102 engine at the Shoreham Nuclear Power Station (SNPS) fractured during plant preoperational tests. The fracture occurred at the crankpin journal of cylinder No. 7, and involved the web connecting the crankpin to an adjacent main bearing journal. Following this failure, severe cracks were discovered in the crankshafts of the other two TDI diesels at SNPS. All three crankshafts were replaced with crankshafts of a more recent design. The principal difference between the original crankshafts and the crankshafts currentiy installed is an increase in crankpin dianeter from 11 inches to 12 inches. The crankpin fillet radius also was increased.

Failure Analysis Associates investigated the failed crankshaft for Long Island Lighting Company (LILCO), the owner of SNPS. The results of that investigation are presented in report No. FaAA-83-10-2.1 (October 1983). Franklin Research Center (R. C. Herrick) performed an independent technical review of the failure for NRC, and documented the results in a report dated April 6, 1984. Both investigations attributed the crankshaft failure to highcycle torsional fatigue. 


\subsubsection{Owners' Group Evaluation: Shoreham Engines}

The adequacy of the replacement crankshafts for the TDI engines at SNPS was evaluated by Failure Analysis Associates, a consultant to the Owners' Group. FaAA's investigation is presented in report No. FaAA-84-3-16 (May 1984). Included in the FaAA report are comparisons of predicted crankshaft stresses with stresses determined experimentally from a torsiograph test and from strain-gage tests that Stone \& Webster Engineering Corporation conducted on EOG 103. Additional evaluations were performed for LILCO by consultants identified in Section 4.6.4.2, below.

LILCO performed a 74D-hour test on EDG 103 to confirm the fatigue resistance of the crankshaft at $3300 \mathrm{~kW}$, the load that bounds the maximum predicted emergency service load on any of the three SNPS engines under design-basis accident conditions. Crankshaft inspections performed by LILCO following the test revealed no evidence of damage.

These analytical and experimental investigations are discussed in more detail in the following sections.

\subsubsection{FaAA's Evaluation}

FaAA's evaluation encompassed the following activities, which are discussed in report No. FaAA-84-3-16 (May 1984):

4.6.4.1.1 Review of TDI's Evaluation. By modeling the crankshaft torsional system as lumped mass moments of inertia connected by torsional springs, and using the Holzer method to solve the resulting eigenvalue problem, TDI determined that the first three natural frequencies of the replacement crankshaft are $38.7,92.9$, and $116.7 \mathrm{~Hz}$. The first natural frequency produces a 4th-order resonance at $581 \mathrm{rpm}$.

TDI also calculated the dynamic torsional response of the crankshaft for whole- and half-orders of vibration from 0.5 to 12.0 , each considered separately. The largest single-order shear stress amplitude computed by TDI for engine operation at rated load (3500 $\mathrm{kW})$ and rated speed $(450 \mathrm{rpm})$ is 2980 psi, corresponding to the 4 th order. This is well below the DEMArecommended limit of 5000 psi for a single order. 


\subsection{Review of SWEC's Torsiograph Test. SWEC performed a}

torsiograph test on EDG 103 to measure the amplitude of free-end crankshaft vibration under various operating conditions. The first natural frequency was found to be $38.6 \mathrm{~Hz}$, which is in excellent agreement with TDI's calculated value of $38.7 \mathrm{~Hz}$. Nominal shear stresses corresponding to crankshaft responses measured by SWEC are as follows for engine operation at rated speed:

\begin{tabular}{|c|c|c|c|}
\hline & $\begin{array}{c}\text { Ful1 load } \\
3500 \mathrm{kw} \\
\end{array}$ & $\begin{array}{l}\text { Overload } \\
3800 \mathrm{~kW} \\
\end{array}$ & $\begin{array}{c}\text { DEMA } \\
\text { allowable } \\
\end{array}$ \\
\hline Max. single order $(4.0)$ & 3108 psi & 3242 psi & 5000 psi \\
\hline Combined response & 6626 psi & 6875 psi & 7000 psi \\
\hline
\end{tabular}

4.6.4.1.3 Oynamic Torsional Analysis. FaAA performed a modal superposition analysis with harmonic loading to determine the combined response of the crankshaft to the first 24 orders of vibration. Gas pressure, reciprocating inertia, and frictional loads were considered by FaAA in calculating the harmonic loading on the crankshaft. The gas pressure loading was obtained from pressure versus crank angle data measured in one cylinder of a SNPS engine by SWEC. The reciprocating inertia included the mass of the connecting rod and piston assembly in each cylinder. All 11 modes of the lumped inertia and torsional spring model of the crankshaft were considered in the analysis.

The amplitude of free-end crankshaft vibration calculated by FaAA is 0.662 degrees at full load and rated speed. The corresponding value from SWEC's torsiograph test is 0.693 degrees. FaAA's analysis also predicts that the maximum nominal shear stress at full rated load for a single order (the 4th order) is 3792 psi, between cylinder No. 8 and the flywheel. FaAA's predicted nominal shear stress amplitude for the combined response of 24 orders at full rated load ( $3500 \mathrm{~kW}$ ) and rated speed (450 rpin) is 7006 psi, between cylinders No. 5 and 6 . The maximum nominal stresses for full load at 428 rpm ( $-5 \%$ rated speed) and also at $473 \mathrm{rpm}$ ( $+5 \%$ rated speed) equal the DEMA limit of 7000 psi within $\pm 3 \%$, according to FaAA's calculations. FaAA commented that the variation reflects the uncertainty in the torsional loadings at these speeds.

4.6.4.1.4 Finite Element Analysis. FaAA performed a three-dimensional finite element analysis of a quarter section of a crank throw to predict 
maximum stresses as influenced by crankshaft geometry and stress concentrations. Included in the quarter section were portions of a crankpin, a main journal, and the web between them. FaAA found good agreement in a comparison of predicted results with the results of data recorded by SWEC from strain gages mounted in the fillets of crank throws No. 5 and 7 of the replacenent crankshaft in EDG 103. The maximum principal stress range measured by SWEC was $44.9 \mathrm{ksi}$, in crankpin No. 5. This measured value is bounded by FaAA's predictions using two separate sets of boundary conditions.

4.6.4.1.5 Factor of Safety Against Fatigue Failure. FaAA determined the endurance limit for the failed crankshafts from strain-gage data. This endurance limit was then scaled to account for the higher ultimate tensile strength of the replacement crankshafts, and compared on a Goodman diagram with the maximum equivalent alternating stress determined from strain gages mounted in the fillets of a replacenent crankshaft. From this comparison, FaAA estimated that the factor of safety against fatigue failure of the replacement crankshafts at full rated engine load is 1.48 when the effect of shotpeening is not considered. Shotpeening would be expected to produce an increase in the fatigue limit, but the effect was not quantified for the replacenent crankshafts.

4.6.4.1.6 FaAA's Conclusions. FaAA reached the following conclusions:

- The TDI calculations of stresses for single orders are appropriate and show that the stresses in the replacement crankshafts are below the DEMA-recommended 1 init for single orders.

- The SWEC torsiograph tests show that the stresses in the replacenent crankshafts are below DEMA-recommended limits for both single and combined orders of torsional vibration at $3500 \mathrm{~kW}(100 \%$ load) and at $3800 \mathrm{~kW}$. A linear extrapolation to $3900 \mathrm{~kW}$ also shows compliance.

- The factor of safety against fatigue failure of the replacement crankshafts is 1.48 for operation at $3500 \mathrm{~kW}$. This factor of safety does not account for the beneficial effects of shotpeening.

- The replacement crankshafts are suitable for unlimited operation in the emergency diesel generators at SNPS. 


\subsubsection{Other Evaluations}

Other evaluations of the adequacy of the replacement crankshafts were performed for LILCO by Dr. Franz Pischinger, president of FEV (Research Society for Energy, Technology and Internal Combustion Engines) and a professor at the University of Aachen in West Germany; and by Dr. Simon Chen, owner and president of Power and Energy International, Inc., a private consulting firm in Beioit, Wisconsin. Dr. Pischinger independently reviewed the work performed by FaAA on the crankshafts, and compared the design of the crankshafts against the Kritzer-Stahl design criteria. He concluded that the crankshafts should have unlimited life for operation at $3500 \mathrm{~kW}$, and that the crankshafts should be able to operate at $3900 \mathrm{~kW}$ for a minimum of 600 hours.

Using 12 orders of vibration in his TORVAP computer program and harmonic coefficients based on data from Lloyd's Registry of Shipping, Or. Chen concluded that the replacement crankshafts comply with DEMA standard practices at $3500 \mathrm{~kW}$ and $3900 \mathrm{~kW}$.

\subsubsection{Inspections and Confirmatory Test}

The replacement crankshafts installed by LILCO were manufactured by the West German firm of Krupp Stah1, A.G., using a forged slab, hot-twist fabrication process. Nondestructive examinations performed by Krupp inciuded uitrasonic inspection (to detect subsurface flaws) and magnetic particle inspection (to detect surface and near-surface flaws). Krupp's inspections revealed no relevant indications.

The fillet areas of two of the three replacement crankshafts were shotpeened by TDI before these crankshafts were shipped to LILCO. They were repeened for LILCO by Metal Improvements Company, InC., when receipt inspection revealed that the original shotpeening did not meet LILCO requirenents. Before the repeening was performed, the crankshafts were subjected to magnetic particle and liquid penetrant inspections of the fillets. These inspections showed that no relevant indications were introduced in the first shotpeening. The third crankshaft was shipped directly from Krupp to LILCO, and shotpeened by Metal Improvements Company. 
As part of the Owners' Group DR/QR of the Shoreham engines (TDI OG December 1984), the three crankshafts were reinspected in the areas of highest torsional stress after each crankshaft had been operated for approximately 300 hours, including approximately 100 hours at $3500 \mathrm{~kW}$ and above. The reinspection of each crankshaft involved eddy-current testing and liquid penetrant testing of the crankpin journal fillets of cylinders No. 5, 6, 7, and 8. No rejectable indications were found.

On October 22, 1984, LILCO submitted a Final Safety Analysis Report (FSAR) amendment to the NRC staff to support $3300 \mathrm{~kW}$ as the load that bounds the maximum predicted emergency service load on any of the three SNPS engines under design-basis accident conditions. In a letter to the NRC staff dated October 18, 1984, LILCO described the protocol for a 740-hour test of the EDG 103 engine to confirm $3300 \mathrm{~kW}$ as the "qualified" load for the SNPS engines. The test was completed early in November 1984.

Inspections performed by LILCO following the test referred to above included 1) liquid penetrant inspection of all crankshaft fillet areas and external radii of $0 i 1$ holes except for fillets and oil holes at main bearings No. $1,2,10$, and $11 ; 2)$ eddy-current inspection for evaluation of all recordable indications; and 3) eddy-current inspection of oil holes to a depth of 3 inches from the journal surface except oil holes in main bearing journals No. 1, 2, 10, and 11. (The latter journals, which are not the most highly loaded, were not accessible for inspection because the cylinder block remained installed on the engine base.) No relevant indications were found.

\subsubsection{PNL's Review: Shoreham Engines}

The following PNL consultants participated in various aspects of PNL's review of the crankshafts for the TDI 8-cylinder, OSR-4 series engines installed at SNPS:

- S. H. Bush, Review and 5ynthesis Associates

- A. J. Henriksen, A. J. Henriksen, Inc.

- P. 3. Louzecky, Engineered Applications Corporation

- Ricardo Consulting Engineers Ltd., Sussex, England

- the late A. Sarsten, Norwegian Institute of Technology. 
Through arrangements made by Prof. Sarsten, PNL also obtained advice from Det Norske Veritas, a maritime classification society in 0s10, Norway. In addition, J. C. Spanner and L. G. Vanfleet of PNL's Nondestructive Testing Section visited SNPS to observe certain nondestructive examinations of the crankshafts and to review the procedures used.

Three of PNL's consultants--Dr. Bush, Mr. Henrixsen, and Prof. Sarsten-testified on matters pertaining to the replacement crankshafts in an Atomic Safety and Licensing Board hearing on contentions concerning the TDI emergency diesel generators at SNPS. The reviews on which their testimony was based included those summarized in this section.

\subsubsection{Post-Test Review of EDG 103}

PNL reviewed the post-test inspection of EDG 103 following the endurance test described above. The purpose of the review was to determine, through an independent audit of the condition of key engine components, whether or not they exhibited any evidence of abnormal behavior under the conditions imposed during the test. This audit was performed by consultants under contract to PNL who have extensive experience in diesel engine technology, and by a PNL. Specialist in nondestructive testing. PNL's findings on the crankshaft are documented in a report dated December 3, 1984, for the Atomic Safety and Licensing Board. In summary, PNL's consultants found nothing in their visual inspections of the crankshaft journals and the corresponding bearing shells that would be indicative of crankshaft deficiencies. Furthermore, no rejectable indications were found in the nondestructive examinations witnessed by PNL's NDT specialist.

\subsubsection{Reviews of Crankshaft Stresses}

PNL's consultants also performed independent reviews of the adequacy of the replacement crankshafts relative to DEMA standard practices and to the rules established by several classification societies for marine engines. Although TDI was not obligated to follow rules of marine classification societies in the design of the Shoreham engines, application of such rules provides a basis for an independent evaluation. The results of PNL's reviews are summarized in the subsections below. 
4.6.5.2.1 DEMA. The late Prof. Sarsten used his program COMHOL2 (COMplex HOLzer version 2) to calculate torsional stresses for single orders and for the sum of 24 orders of vibration. His analysis employed the same harmonic data used by FaAA. His results predict that the crankshaft stresses are within the DEMA-recommended limit of $5000 \mathrm{ps} i$ for single orders, but exceed the DEMArecommended limit of 7000 psi for the sum of orders at $3500 \mathrm{~kW}$. At $3300 \mathrm{~kW}$, his results predict that the crankshaft torsional stresses are below the DEMA limit for the sum of orders over the speed range of $5 \%$ below rated speed through 5\% above rated speed, except for that portion of the speed range above $466 \mathrm{rpm}$. (Rated engine speed is $450 \mathrm{rpm}$.) Both Prof. Sarsten's analysis and FaAA's analysis agree on the location of the maximurn torsional stresses, i.e., shaft No. 6 between crankpins No. 5 and 6 .

The following table summarizes Prof. Sarsten's results. Certain predicted and measured results from FaAA's torsional analys is and SWEC's torsiograph tests are included for comparison.

Torsiograph, EDG 103

Maximum Nominal Torsional Stresses, Sum of 24 Orders, and Amplitude of Free-End Vibration Nominal Torsional Stresses Free-End Amp a $3500 \mathrm{~kW} \& 450 \mathrm{rpm}$ $\frac{428 \mathrm{rpm}}{\ldots} \frac{450 \mathrm{rpm}}{\ldots} \frac{473 \mathrm{rpm}}{\ldots} \frac{\mathrm{Calc}}{\ldots} \frac{\text { Meas. }}{0.693^{\circ}}$

Prof. Sarsten, $3500 \mathrm{~kW}$ 7051 psi $7096 \mathrm{psi}$

7851 psi

$0.690^{\circ}$

FaAA, $3500 \mathrm{~kW}$ -.- 7006 psi $\cdots \quad 0.662^{\circ}$

Prof. Sarsten, $3300 \mathrm{~kW}$ 6300 psi 6456 psi 7300 psi (approx) --- (approx)

4.6.5.2.2 American Bureau of Shipping. PNL consultants confirmed that crankshaft web dimensions satisfy ABS rules. However, torsional stresses predicted by PNL consultant A. Sarsten for single and combined orders at $3500 \mathrm{KW}$ (3608 psi and $7096 \mathrm{psi}$, respectively) exceed stress limits calculated by TDI based on paragraph 34.47 of the 1984 ABS Rules. As documented on page 21 of 
TOI's Report on Crankshaft Torsional Stresses by R. Yang (April 4, 1984), the 1 imits calculated by TOI are 3357 psi for a single order and 5035 psi for total allowable stress.

4.6.5.2.3 International Association of Classification Societies. Ricardo Consulting Engineers of England calculated the factor of safery of the Shoreham replacement crankshafts for PNL according to the proposed rules of the IACS. For $3200 \mathrm{kw}, 450 \mathrm{rpm}$, and a brake mean effective cylinder pressure of 206 psi, the calculated factor of safety is 0.93 in comparison to the IACS-proposed minimum of 1.1 .

4.6.5.2.4 Det Norske Veritas. Allowing for the stationary application of the Shoreham engines and for an estimated influence of shotpeening, this classification society in 0s 10 , Norway, concluded that the crankshaft safety margin would not be adequate for loads exceeding $3200 \mathrm{~kW}$.

PNL has the following comments on the various analyses of the replacement crankshafts and on LILCO's 740-hour confirmatory test of EOG 103:

- In light of the conflieting results of the analyses performed for LILCO and the analyses performed independentiy for PNL, the analytical evidence alone does not provide a sufficient basis for concluding unequivocally that the crankshafts are adequate for LILCO's "qualified" load of $3300 \mathrm{~kW}$ (discussed in Section 4.6.4.3).

- The crankshafts for the Shoreham engines are not required to satisfy any or all of the requirements of the various marine classification societies. Even if a crankshaft does not meet such rules, it may still perform adequately. The rules of the classification societies reflect the rigors and uncertainties of marine service. Furthermore, the rules are often subject to interpretation and discussion with the classification society, and approval does not necessarily depend on strict compliance with the rules.

- The results of the EDG 103 test completed in November 1984 provide important and, in PNL's view, definitive information regarding the fatigue resistance of the Shoreham crankshafts for service at $3300 \mathrm{~kW}$. The test duration of 746 hours at the rated engine speed of 
450 rpm corresponds to just above $10^{7}$ crankshaft stress cycles at or above the qualified load in a 4-cycle engine. This number of cycles is generaliy accepted as sufficient to demonstrate high-cycle fatigue resistance in ferritic steels, provided that no cracks develop under the conditions imposed during the test. The post-test examinations of the EDG 103 crankshaft demonstrated that it had completed the test with no indications of cracking.

- Loads at which EDG 103 was operated as part of the confirmatory test, and the post-test examination that revealed no evidence of damage to the crankshaft, provide a basis for an inference about the fatigue limit of the crankshaft. Based on LILCO's test data, EOG 103 sustained over 220 hours (approximately $3 \times 10^{6}$ cycles) at instrumentindicated loads of $3500 \mathrm{~kW}$ or above. With a conservative application of instrument error from calibrations performed by LILCO preceding and following the time the higher-load testing was performed, PNL estimates that the actual load during this period was at least $3430 \mathrm{~kW}$. If cracks had initiated during this testing, it is likely that they would have propagated during subsequent operation at approximately $3300 \mathrm{~kW}$ for the time necessary to bring the total cycles to $1 \times 10^{7}$. But no cracks were found in the crankshaft. This strongly suggests that the endurance limit is at or above $3430 \mathrm{~kW}$, allowing for instrument error.

\subsubsection{Conclusions and Recommendations}

PNL's conclusions and recommendations regarding the replacement crankshafts for EDG 101, EDG 102, and EDG 103 at SNPS were presented at an Atoinic Safety and Licensing Board (ASLB) hearing by the PNL consultants who testified on behalf of the NRC staff. In its Partial Initial Decision of June 14, 1985, the ASLB incorporated the principal conclusions and recomendations of PNL's consultants into its findings on the crankshafts. The ASL 3 findings apply for engine operation and component inspections through the first reactor fuel cycle, according to the Decision. They include: 
- There is reasonable assurance that the TDI emergency diesel generators can perfom their required safety function, if necessary, at a qualified load level up to $3300 \mathrm{~kW}$.

- Routine required surveillance testing can be conducted at $3300 \mathrm{~kW}$ $\$ 100 \mathrm{~kW}$ without leading to failure of the crankshaft.

- In addition to the required surveillance testing, cumulative operation of each engine for up to 2 hours at loads between $3300 \mathrm{~kW}$ and $3400 \mathrm{~kW}$ is permissible. If either the cumulative time limit or the load limit is exceeded, crankshaft inspections required during the first refueling outage must be performed as soon as the affected diesel may safely be removed from service.

- As a requirement of the operating license, there must be a control room alarm to alert operators in the event an EOG exceeds $3300 \mathrm{~kW}$ during times other than the surveillance test runs.

- Crankshaft inspections at the first refueling outage must include items 1 and 2 of LILCO's commitments as set forth in the attachment provided by LILCO and reproduced on page 87 of the Partial Initial Decision. According to the first comnitment, LilCO will measure and record hot and cold crankshaft web deflection readings on each of the diesels at each refueling outage. The second commitment calls for examinations of crankpin journals №. 5, 6, and 7 in EDG 101 and EOG 102 using liquid penetrant (PT) and eddy current (ET) as appropriate. The ASLB added two conditions: crankpin journals No. 5, 6, and 7 in EOG 103 must be examined in the manner planned for EDGs 101 and 102, and the main bearing journals between these three crankpins must also be examined on all three engines.

In PNL's opinion, operation of the TDI engines at SNPS beyond the first reactor fuel cycle would be justified if the inspections required at the first outage provide confirmatory evidence of normal operation of the engine components. PNL recommends that the load restrictions ordered by the ASLB be continued beyond the first fuel cycle. PNL also recomends that certain highstress areas of all three crankshafts be exanined periodically as discussed 
below to confirm that no cracks develop in service. If these examinations reveal nothing of significance, the scope and/or frequency of the examinations coutd be reconsidered.

- During the second and subsequent refueling outages, the fillets and oil holes in two of the three crankpin journals subject to the highest stresses (No. 5, 6, and 7) should be examined using ET and fluorescent PT as appropriate. These inspections should be performed on a11 three engines. This recommendation is consistent with the third of LILCO's commitments reproduced on page 87 of the Partial Initial Decision.

- In accordance with an agreement between the NRC staff and LILCO, the fillets and oil holes of the two main bearing journals between crankpin journals No. 5, 6, and 7 should be examined every third refueling outage (from the most recent previous inspection) using ET and fluorescent PT as appropriate. This is consistent with the fourth of LILCO's commitments referenced above. Alternatively, this inspection could be performed during each major (5-year) engine overhaul. As noted earlier, the ASLB requires that these main bearing journals be inspected in all three engines at the first refueling outage.

PNL concurs with LILCO's commitment to measure crankshaft deflection under both "hot" and "cold" conditions at each refueling outage. PNL's recommendations on the conduct of the deflection checks are documented in a previous evaluation of the Shoreham engines (PNL-5342, December 1984).

\subsubsection{Owners' Group Evaluation: River Bend Engines}

Two 8-cylinder TOI diesel generators, designated standby diesel $1 \mathrm{~A}$ (SO 1A) and standby diesel 1B (SD 1B), are installed at River Bend Station (RBS) Unit 1. The crankshafts in these engines have the same dimensions as the replacement crankshafts for the TDI engines at SNPS, i.e., 12-inch-diameter crankpins with 3/4-inch-radius fillets. However, the generators and flywheels differ between the two installations, resulting in differences in crankshaft torsional stresses. Furthermore, the fillets of the crankshaft journals in the SNPS engines are shotpeened while those in the RBS engines are not. These 
differences were addressed by consultants to the Owners' Group in their evaluations of the RBS crankshafts.

El lwood City Forge Corporation manufactured the crankshafts for the RBS engines, using a forged slab, hot-twist fabrication process. Nondestructive examinations performed by Ellwood City Forge included ultrasonic testing of the rough machined crankshafts (to detect subsurface flaws) and magnetic particle inspection of the finished crankshafts (to detect surface and near-surface flaws). These inspections revealed no reportable indications.

\subsubsection{Design Review/Quality Revalidation}

Guif States Utilities Company (GSU), the owner of RBS, found no relevant indications in preservice inspections of the crankshafts. Additional crankshaft examinations performed by the Owners' Group as part of the design review/ quality revalidation (DR/QR) of the RBS engines also revealed no relevant indications. As discussed in the DR/QR report (February 1985), these inspections included eddy-current and liquid penetrant examinations of the oil holes and fillets in crankpins No. 5 through 8 of SO $1 \mathrm{~A}$, and of the ofl holes in the same crankpins of SO 18.

Aiso included in the RBS DR/QR report are the Owners' Group comments on stress analyses of the RBS crankshafts. The Owners" Group noted the following:

- Using the pressure loading obtained from an engine test at the Shoreham Nuclear Power Station, a modal superposition analysis was performed to determine the nominal shear stresses in the crankpins and main journals of the RBS crankshaft. The maximurn torsional stress corresponding to a load of $3500 \mathrm{~kW}$ was found to be 7357 psi between cylinders No. 5 and 6 . The predicted nominal stresses at this load do not satisfy DEMA-recomnended limits of 5000 psi for a single order and 7000 psi for combined orders.

- The natural frequencies and free-end amplitudes from the torsiograph test performed on SD $1 A$ were found to be in agreement with the modal superposition analysis. It was determined that the nominal stresses 
during steady-state conditions at $3130 \mathrm{~kW}$ (the maximum emergency load under design-basis accident conditions) would satisfy DEMA

recomendations.

- Nominal crankshaft torsional stresses in the SNPS engines at $3300 \mathrm{~kW}$ are equivalent to nominal crankshaft torsional stresses in the RBS engines at $3130 \mathrm{~kW}$ (accounting for differences in the torsional systems of the engines at the two plants).

- Holzer calculations performed by TDI were found to be accurate and in agreement with the modal superposition analysis.

- The material certification reports for the SD $1 A$ and $1 B$ crankshafts are within the original design specifications. Based on a minimum ultimate tensile strength of $94 \mathrm{ksi}$ for the SO $1 \mathrm{~A}$ crankshaft, the factors of safety against fatigue failure in the main journal oil holes and the crankpin fillets are 1.36 and 1.29 , respectively, at $3500 \mathrm{~kW}$.

Based on the $D R / Q R$ review, the Owners' Group concluded that the crankshafts in the SO $1 A$ and $1 B$ engines are acceptable for their intended function at RBS, provided that the engines are operated at loads no greater than $3130 \mathrm{~kW}$.

\subsubsection{FaAA Evaluation}

Additional information on analyses and tests of the crankshafts for the engines at River Bend is presented by Failure Analysis Associates in report No. FaAA-85-5-10 (May 1985). Some of this information clarifies information presented earlier in the $O R / Q R$ report for River Bend. FaAA addressed the torsional calculations prepared by TOI, the results of two torsiograph tests of the SD 1A engine, the fatigue analys is performed by FaAA to determine the safety margin of the crankshafts at $3130 \mathrm{~kW}$, the endurance test of a SNPS engine and the applicability of the test to the RBS crankshafts, and the results of the crankshaft fillet and oil hole inspections performed by $F a A A$ in July 1984. FaAA's cominents and conclusions include those summarized under the three subheadings that follow. 
4.6.6.2.1 Torsiograph Tests. SWEC performed two torsiograph tests on the SD 1 A engine at RBS. The first, in September 1984, measured torsiograph responses during steady-state operation. The second, in May 1985, measured responses during transient operation, and repeated the variable load portion of the first test to determine responses after the engine had been run in. Between the first and second tests, the SD 1A engine accumulated 87 hours of operation at $3500 \mathrm{~kW}$ or greater loads. The torsiograph responses during the second test were lower than those during the first, which is typical for an engine after run-in. FaAA views the results of the second test as more indicative of the future response of the engine.

FaAA's conclusions from these tests include the following:

- The torsiograph test results show that the combined order stresses at $3500 \mathrm{~kW}$ and the rated speed of $450 \mathrm{rpm}$ comply with DEMA recomnendations.

- Based on RBS test data taken over a range of loads, there is a $7 \%$ change in torsional response for a $10 \%$ change in load. This linear relationship also holds for the SNPS torsiograph test data.

- Even though the 5th-order harmonic is in resonance at an engine speed of $455 \mathrm{rpm}$, the response is quite small and there are six other orders with greater magnitude. Accordingly, the 5th-order response is not large enough to be of concern.

4.6.6.2.2 Fatigue Analysis. FaAA computed a factor of safety against fatigue failure for the crankshafts in the RBS engines through a process that took into account fatigue data and strain-gage data obtained in crankshaft tests at SNPS. The principal factors considered in the analysis are as follows:

- Through a dynamic torsional analysis of the crankshaft, FaAA determined the range of torque at each crank throw and the nominal torsional stresses at $3500 \mathrm{~kW}$ over the speed range of $450 \mathrm{rpm} \pm 5 \%$. The gas pressure loading used in this analysis was obtained from pressure versus crank angle data measured at SNPS by SWEC. The results of this analysis agree well with the RBS torsiograph test results 
obtained by SWEC in May 1985. For example, the FaAA analys is predicts a front-end amplitude of 0.700 degrees at $3500 \mathrm{~kW}$ and $450 \mathrm{rpm}$, while the value measured by SWEC is 0.733 degrees. Over the speed range of $450 \mathrm{rpm} \pm 5 \%$, there is also good agreement for both the RBS and SNPS installations between FaAA's stress predictions and stress predictions from COMHOL2, the computer program developed by the late Prof. Sarsten of the Norwegian Institute of Technology.

- Torsional stresses at loads below $3500 \mathrm{~kW}$ were calculated from the values at $3500 \mathrm{~kW}$, using the linear stress-load relationship determined from the torsiograph tests. FaAA found that the stresses in the RBS crankshafts at $3130 \mathrm{~kW}$ are comparable to the stresses in the SNPS crankshafts at $3300 \mathrm{~kW}$, the nominal load at which a SNPS engine was tested to $10^{7}$ cycles.

- The maximum stresses in the RBS crankshaft fillets were determined from dynamic strain-gage data taken at SNPS. The experimental values were adjusted for the differences in torsional crankshaft stresses corresponding to the differences in the mass-elastic systems of the two installations. To determine stresses in the oil holes, a stress concentration factor was applied to the computed values of the nominal torsional stresses.

- The fatigue endurance limit of the RBS crankshafts was determined from an analysis of the crankshafts that failed at SNPS. The predicted value was confirmed by other fatigue data published in the 1iterature.

From the stress and fatigue data described above, FaAA determined that the factor of safety against fatigue cracking of the RBS crankshafts is 1.39 at $3130 \mathrm{~kW}$ and $450 \mathrm{rpm}$. FaAA concluded that this factor of safety provides sufficient margin for safe operation at loads up to $3130 \mathrm{~kW}$.

4.6.6.2.3 Endurance Testing. Although the 8-cylinder engines at RBS are similar to the 8-cylinder engines that have undergone extensive testing at SNPS, the generators and flywheels differ between the two installations, resulting in differences in crankshaft torsional stresses. Furthermore, the 
fillets of the SNPS crankshafts are shotpeened while those of the RBS crankshafts are not. FaAA addressed the effects of these differences on the applicability to the RBS crankshafts of the $10^{7}$-cycle endurance test performed on a SNPS engine at a nominal load of $3300 \mathrm{~kW}$. Even with the differences, FaAA found that the endurance test at SNPS provides additional assurance of the adequacy of the RBS crankshafts at $3130 \mathrm{~kW}$.

FaAA noted that the replacement crankshafts installed in the engines at SNPS are of the same design and were made to the same material specifications as the crankshafts in the engines at RBS. The crankshafts at both installations meet the minimum requirements of ABS Grade 4 steel and have ultimate tensile strength (UTS) values within the expected range for this material. However, the lowest UTS measurement for the RBS crankshafts is about $7 \%$ less than the lowest measurement for the SNPS crankshafts.

FaAA commented as follows on the effects of the differences:

- Based on a $7 \%$ change in stress for a $10 \%$ change in load (the linear relationship FaAA detemined from torsiograph data as discussed above in Section 4.6.6.2.1), a load of $3071 \mathrm{kH}$ at RBS produces the same crankshaft stress as a load of $3300 \mathrm{~kW}$ at SNPS.

- The crankshaft fatigue limit is approximately proportional to the UTS of the material. Thus, the factor of safety in the SNPS crankshafts at $3300 \mathrm{~kW}$ is approximately $7 \%$ higher than in the RBS crankshafts at $3071 \mathrm{~kW}$. However, this effect is small in comparison to the factor of safety in the RBS crankshafts.

- FaAA's calculations show that the highest stress in a main journal oil hole is about $7 \%$ less than the highest stress in a crankpin fillet. Thus, if shotpeening has more than a $7 \%$ effect on the crankpin fillets, the oil holes will govern crankshaft life. This effect is also small when compared to the safety margin.

- The margin between RBS crankshaft stress at $3071 \mathrm{~kW}$ and the highcycle fatigue (S-N) curve for the RBS crankshaft corresponding to the lowest UTS measurement is adequate to ensure reliable operation of the RQS crankshafts for their intended service at $3130 \mathrm{~kW}$. 
4.6.6.2.4 Crankshaft Inspections. FaAA reached the following conclusions from nondestructive tests of the crankshafts in the two TDI engines at RBS in July 1984:

- The eddy-current inspection of the fillets revealed no reportable indications.

- No crack-1ike indications were observed in the liquid penetrant inspections of the main journal and crankpin journal oil hole radii.

- All readings from the eddy-current inspection of the main journal oil holes were within the acceptance criteria.

\subsubsection{FEV Evaluation}

The crankshafts in the TDI engines at RBS were also evaluated for Gulf States Utilities Company by Dr. Franz Pischinger, president of FEV (Research Society for Energy, Technology and Internal Combustion Engines) in West Germany. His evaluation is documented in a FEV report on this subject dated June 1, 1985.

FEV used the Kritzer-Stahl method to determine the equivalent stress amplitude at the highest-stressed location of the crankshaft. FEV also determined an endurance limit that incorporates the experience with crankpin fillet fatigue damage identified in the three crankshafts originally installed in the TDI DSR-48 engines at SNPS. From the equivalent stress amplitude and the endurance limit, FEV calculated a safety factor of 1.205 for the RBS crankshafts operated at $3130 \mathrm{~kW}$ and $450 \mathrm{rpm}$. This safety factor, according to FEV, is within the range normally considered adequate by German engine manufacturers. The known fatigue data on which this safety factor is based also enabled FEV to conclude that the safety factor is sufficient to assure the adequacy of the crankshaft for the operating conditions just mentioned.

The FEV report noted that the stress values computed by FaAA and FEV are in excellent agreement. Differences in the values of the endurance limit and the safety factor calculated by the two organizations were attributed by FEV to the use of different $S-N$ curves. FEV used an $S-N$ curve that is based on experimental investigations of actual crankshafts and that contains known 
conservative features. FaAA, according to FEV, used an $\mathrm{S}-\mathrm{N}$ curve based on laboratory data for the given material.

4.6.6.4 Additional Information from Gulf States Utilities Company

In a letter dated June 12, 1985, to NRC (H. R. Denton), GSU (J. E. Booker) provided additional information concerning the RBS crankshafts. Items addressed in attachments to the letter include the following:

4.6.6.4.1 Precautions to Avoid Operation of the Engine at the Resonant Speed of the 5th-0rder Harmonic. FaAA has concluded that the response to the 5 th-order harmonic (which is in resonance at $455 \mathrm{rpm}$ ) is quite small, and that there are six other orders with greater magnitude (as discussed in Section 4.6.6.2.1 of this report). Furthermore, the 5th order is excited only by variations in combustion pressure from cylinder to cylinder. GSU will adopt the following operating and maintenance practices to prevent sustained operations under conditions of cylinder imbalance and overspeed:

- A caution statement will be added to the operation and surveillance procedures for the two engines to avoid continuous operation between 453 and $457 \mathrm{rpm}$.

- During engine operation, exhaust gas temperatures will be monitored to verify that they remain within the range of $\pm 50^{\circ} \mathrm{F}$ of the average for all cylinders. The temperature measurenents will be recorded monthly, and cylinder firing pressures will be recorded quarterly. Trend analyses will be performed to detect changes that might indicate a need for maintenance of fuel injection equipment.

- Station 0perating Procedure SOP-0053 includes the requirement to monitor and maintain generator frequency within $60 \mathrm{~Hz} \pm 0.2 \mathrm{~Hz}$.

4.6.6.4.2 Nondestructive Tests of Crankpin Fillets. Nondestructive examinations of crankpins No. 5, 6, and 7 of SO 1 A were conducted from June 4 to June 8,1985 . The crankpin fillets and oil hole entrance regions were inspected using liquid penetrant. The crankpin oil holes were eddy-current tested. These inspections revealed no evidence of fatigue crack initiation after 330 hours of operation. 


\subsubsection{PNL's Review: River Bend Engines}

The following PNL consultants participated in various aspects of PNL's review of the crankshafts for the TDI B-cylinder, DSR-4 series engines installed at RBS:

- S. H. Bush, Review and Synthesis Assocjates

- H. Engja, Norwegian Marine Technology Research Institute

- H. M. Mardy, consulting engineer

- A. J. Henriksen, A. J. Henriksen, Inc.

- P. J. Louzecky, Engineered Applications Corporation

- the late A. Sarsten, Norwegian Institute of Technology

- T. W. Spaetgens, consulting vibration engineer.

In addition, S. J. Foreman of PNL's Nondestructive Testing Section visited RBS to observe certain nondestructive examinations of the crankshafts and to review the procedures used.

\subsubsection{Review Scope}

PNL's review focused on the differences between the crankshaft torsional systerns of the RBS engines and the SNPS engines, and the effects of these differences on RBS crankshaft stresses. PNL also reviewed records of inspections performed during manufacture of the RBS crankshafts. In addition, PNL staff and consultants attended meetings on April 26 and May 20, 1985, to discuss RBS crankshaft stresses with NRC staff and with GSU staff and consultants. Specific aspects of PNL's review included:

- torsional stresses - As in PNL's review of the crankshafts for the SNPS engines, torsional stresses in the RBS engines were analyzed using the COMHOL2 computer program. The agreenent with FaAA's results may be illustrated by comparing the predicted stresses for both the SNPS crankshafts and the RBS crankshafts operated at $3500 \mathrm{~kW}$ and $450 \mathrm{rpm}$. For each installation, the results of the two approaches agree within $2 \%$. This agreenent contributes to the assurance that FaAA's torsional analysis of the RBS crankshaft is reasonable. Furthermore, PNL concurs with FaAA that the experimental 
data cited in FaAA-85-5-10 (May 1985) support the linear stress-load relationship used by FaA to calculate torsional stresses at loads below $3500 \mathrm{kH}$.

- crankshaft endurance limit - As discussed in Section 4.6.6.2.2 of this report, FaAA determined the fatigue endurance limit of the RBS crankshafts from an analysis of the crankshafts that failed at SNPS, and confimed the prediction by other fatigue data published in the 1 iterature. PNL consultant S. Bush performed an independent review of fatigue data considered pertinent to the RBS crankshafts. In particular, he reviewed a paper by Nishihara and Fukui (1976) regarding fatigue testing of large-diameter, slab-forged and hottwisted crankshafts. He concluded that the data reported in this paper confirm the endurance limit determined by FaAA.

- factor of safety - Dr. Bush also reviewed the dynamic straín-gage data reported by FaAA for a SNPS crankshaft, and checked FaAA's equivalent stress calculations used in determining a factor of safety for the RBS crankshafts. He concluded that the factor of safety reported by FaAA is consistent with the data.

- crankshaft inspection - S. Foreman of PNL witnessed the crankshaft inspection performed at RBS on June 4 through june 8,1985 . The three most highly loaded crankpins of the crankshaft in the SD IA engine were examined by fluorescent liquid penetrant and eddy current, as discussed in Section 4.6.6.4.2, above. No evidence of fatigue crack initiation was found.

\subsubsection{Conclusions and Recomendations}

PNL concurs that the crankshafts for the SD $1 A$ and $S D 1 B$ engines at RBS are acceptable for their intended service at loads up to $3130 \mathrm{kH}$, subject to implementation of the operating and maintenance procedures formulated by GSU as discussed in Section 4.6 .6 .4 .1 of this report, and to the additional PNL recomendations discussed in this section. The stress and fatigue analyses documented in the FaAA report of May 1985 and in the FEV report of June 1985 substantiate the adequacy of the crankshafts for operation to $3130 \mathrm{~kW}$. 
Furthermore, the results of these analyses are supported by the extensive testing of the SNPS engines and by the absence of any evidence of fatigue crack initiation in the RBS crankshafts.

PNL's recommendations for load tolerances during engine surveillance tests and for a load alarm are discussed first, followed by PNL's recommendations for periodic nondestructive examinations of the more highly stressed crankshaft surfaces.

In its Partial Initial Decision of June 14, 1985, on the TDI engines at SNPS, the ASLB noted that a tolerance band on permissible engine load is required as a practical matter for engine surveillance tests. LILCO witnesses had testified that it is difficult to maintain a constant engine load during tests when the engine is connected to the grid, and that the wattmeter exhibits an independent pulsation effect in response to the load fluctuations. They had also testified that the actual load may differ from the indicated load by a relatively small amount $( \pm 70 \mathrm{~kW}$ for EDG 103) due to instrument error. The ASLB found that a tolerance band of $\pm 100 \mathrm{~kW}$ for surveillance tests of the SNPS engines is appropriate, and that the additional load meter instrument error described by LILCO witnesses will have no adverse impact on the SNPS engines.

In PNL's opinion, the load tolerance band described above is appropriate also for surveillance tests of the RBS engines. Further, it is PNL's opinion that instrument error equivalent to that discussed above for the SNPS engines would not be detrimental to RBS engine reliability. The operators of the RBS engines should control the load close to $3130 \mathrm{~kW}$ during surveillance tests. To the extent that this load may be exceeded within the allowable tolerance band and/or because of instrument error, the total operating time at the higher load ( $\sim 1$ hour per month for the surveillance tests) would be relatively short between the inspections that PNL recommends for the crankshafts at each refue ing outage. It is PNL's opinion that the recomended inspections will provide adequate survejllance to detect any evidence of crankshaft distress before engine reliability would be jeopardized.

PNL recommends that an alarm be installed in the control room to alert operators in the event an RBS engine exceeds $3130 \mathrm{~kW}$ during times other than the surveillance tests. This is consistent with a requirement of the ASLB for 
the SNPS engines. Furthermore, it will reinforce the need to avoid operation of the RBS engines at loads above $3130 \mathrm{~kW}$ under circumstances other than those described above. The need to avoid such operation stems from the lower factor of safety of the RBS crankshafts compared to the SNPS crankshafts. It also stems from FaAA's conclusion in report No. FaAA-85-5-10 (May 1985) that the factor of safety of 1.39 for the RBS crankshafts "...provides sufficient inargin for safe operation at loads up to $3130 \mathrm{~kW} . "$

If the load limit of $3130 \mathrm{~kW}$ is exceeded under circumstances other than those described for the surveillance tests, the need for an immediate crankshaft inspection should be evaluated by the utility on a case-by-case basis, taking into account the load reached and the time operated at that load. The results of the evaluation should be subject to NRC review before the engine is returned to nuclear service.

PNL recomnends that the continued absence of cracking in the RBS crankshafts be verified through the nondestructive examinations listed below. If these examinations reveal nothing of significance after several refueling outages, GSU may wish to propose a change in the frequency of the examinations to NRC.

- During the first refueling outage, the fillets and oil holes of the three crankpin journais (Nos. 5, 6, and 7) subject to the highest stresses should be examined with fluorescent liquid penetrant (PT) and, as appropriate, with eddy current (ET) in the crankshaft of the So $1 B$ engine. These examinations are not considered necessary for the SD $1 A$ crankshaft at the first refueling outage because of the examinations just performed on that crankshaft in June 1985 .

- During the second and subsequent refueling outages, the fillets and oil holes in two of the three crankpin journals (No. 5, 6, and 7) subject to the highest stresses should be examined using ET and fluorescent PT as appropriate. These inspections should be performed on both the SD $1 A$ and the SD $1 B$ engines.

- During each major (5-year) engine overhaul, the fillets and oil noles of the two main bearing journals between crankpin journals No. 5,6 , 
and 7 should be examined using ET and fluorescent PT as appropriate. Alternatively, this inspection could be performed every third refueling outage to be consistent with an agreement between the NRC staff and LILCO for inspection of the main bearing journals in the TOI engines at SNPS.

To verify that crankshaft alignment remains within manufacturer's recommendations, crankshaft deflection should be measured under both "hot" and "cold" conditions at each refueling outage (as planned at RBS). PNL's recommendations on the conduct of the deflection checks are documented in a previous evaluation of these engines (PNL-5485, July 1985).

\subsubsection{Extension of Conclusions to Other 8-Cylinder TOI Engines}

To establish whether or not the conclusions reached in this section may be extended to crankshafts of the same design in TDI 8-cylinder engines at other nuclear power plants, the following action is recormended by PNL for each installation. This action is in addition to any tests performed by the manufacturer to confirm proper engine assembly, balance, and timing:

- The utility should establish the plant-specific engine load that bounds the maximum predicted emergency service load under design. basis accident conditions. If each engine of a multiple-engine installation is shown to be capable of carrying this load as was done at RBS and SNPS, then this becomes the "qualified" load for the engines.

- A torsiograph test should be performed on at least one engine of a multiple-engine installation. One test will be sufficient if the torsional systems of the engines are of the same design. Each engine should be tested if the torsional systems differ (e.g., if the generators are of different designs). The test should include variable-speed operation over the entire speed range from shutdown to $+5 \%$ of rated speed, to determine the location of any potentially serious resonances. In addition, the test should include variableload operation to determine crankshaft responses up to at least the qualified load discussed above. The test results and torsional 
stresses calculated from these results should be compared with similar data for the TDI engines at SNPS and RBS. Depending on the outcome of these comparisons, further testing and analysis may be necessary to establish crankshaft adequacy.

- The materials certification reports on the crankshafts should be reviewed to verify that the crankshaft mechanical properties (e.g., ultimate tensile strength) are within design specifications. Actua) crankshaft properties should be considered in the evaluation of crankshaft adequacy to carry the qualified load, as was done for the RBS and SNPS engines.

- Preservice crankshaft inspections should include fluorescent liquid penetrant and, as appropriate, eddy-current examinations of the oil holes and fillets of the three crankpin journals (No. 5, 6, and 7) subject to the highest torsional stresses. The two main bearing journals between these crankpins also should be inspected in this manner.

\subsubsection{References}

Atomic Safety and Licensing Board. June 14, 1985. Partial Initial Decision on Emergency Diesel Generators. In the Matter of Long Island Lighting Company, Shoreham Nuclear Power Station, Unit 1, Docket No, 50-322-0L, LBP-85-18.

Diesel Engine Manufacturers Association (DEMA). 1972. Standard Practices for Low and Medium Speed Stationary Diesel and Gas Engines. 6th ed. New York, New York.

Failure Analysis Associates (FaAA). October 31, 1983. Emergency 0iesel Generator Crankshaft Failure Investigation, Shoreham Nuclear Power Station. FaAA-83-10-2.1, Palo Alto, California.

Failure Arialysis Associates (FaAA). May 22, 1984. Evaluation of Emergency Diesel Generator Crankshafts at Shoreham and Grand Gulf Nuclear Power Stations. FaAA-84-3-16, Palo A7to, California.

Failure Analysis Associates (FaAA). May 18, 1985. Evaluation of DSR-48 Emergency Diesel Generator Crankshafts at River Bend Station. FaAA-85-5-10, Palo Alto, California. 
Forschungsgesellschaft fur Energietechnik und Verbrennungsmotoren MBH (FEV). June 1, 1985. Operational Safety of TDI DSR-48 Emergency Diesel Generator Crankshafts at River Bend Station, Gulf States Utilities. Aachen, West Germany.

Gulf States Utilities Company (J. E. Booker) letter dated June 12, 1985, to the NRC Office of Nuclear Reactor Regulation (H. R. Denton), transmitting responses to NRC requests for additional information on RBS crankshafts.

Henriksen, A. J., B. J. Kirkwood, W. W. Laity, P. J. Louzecky, J. F. Nesbitt, and L. G. Vanfleet. December 3, 1984. Post-Test Examination of Transamerica Delaval, Inc. Emergency Diesel Generator 103 at Shoreham Nuclear Power Station for U.S. Nuclear Regulatory Commission Staff. Before the Atomic Safety and Licensing Board, Docket No. 50-322-0L.

Herrick, R. C. April 6, 1984. Evaluation of Diesel Generator Failure at Shoreham Unit 1. Final Report, Failure Cause Evaluation. Franklin Research Center, Philadelphia, Pennsyivania.

Long Island Lighting Company (J. D. Leonard, Jr.) letter dated October 18 , 1984, to the NRC Office of Nuclear Reactor Regulation (H. R. Denton). Subject: Confirmatory Testing of TDI biesel Generators at Shoreham Nuclear Power Station Unit 1, Docket No. 50-322.

Long Island Lighting Company (J. D. Leonard, Jr.) letter dated October 22, 1984, to the NRC Office of Nuclear Reactor Regulation (H. R. Denton). Subject: Submittal of FSAR Revision Qualified Load - TDI Diesel Generators at Shoreham Nuclear Power Station Unit 1, Docket No. 50-322.

Nishihara, M., and Y. Fukui. January 1976. "Fatigue Properties of Full Scale Forged and Cast Steel Crankshafts." Transactions of the Institute of Marine Engineering. Series B on Component Design for Highly Pressure-Charged Diesel Engines, London, England.

Pacific Northwest Laboratory. July 1985. Review and Evaluation of Transamerica Delaval, Inc., Diesel Engine Reliability and Operability - River Bend Station Unit 1. PNL-5485, Richtand, Washington.

Pacific Northwest Laboratory. December 1984. Review and Evaluation of Transamerica Oelaval, Inc., Diesel Engine Reliability and Operability Shoreham Nuclear Power Station Unit 1. PNL-5342, Richland, Washington.

TDI Diesel Generator Owners' Group. February 1985. TDI Diesel Generator Design Review and Quality Revalidation Report - River Bend Station. Revision 1. 
TDI Diesel Generator Owners' Group. December 1984. TDI Diesel Generator Design Review and Quality Revalidation Report - Shoreham Nuclear Power Station. Revision 1.

Yang, R. April 4, 1984. Report on Crankshaft Torsional Stresses, Transamerica Delaval Model DSR-48, Serial No. 74010/12, for Long Island Lighting

Company. Transamerica Delaval Inc., Oakland, California. 
4.7 CRANKSHAFT: 16-CYLINDER, DSRY-4 SERIES ENGIMES 


\subsection{CRANKSHAFT: 16-CYLINDER, DSRV-4 SERIES ENGINES}

PNL reviewed the action taken by the Owners' Group to evaluate the crankshafts for the TDI 16-cylinder, V-type, DSRV-4 series engines at the Catawba, Comanche Peak, Grand Gulf, and Perry nuclear power stations. The conclusions drawn from PNL's review are applicable only to these installations. However, these conclusions may be extended to crankshafts of the same design in TDI 16-cylinder engines at other nuclear installations, provided that the crankshaft mechanical properties and the torsional crankshaft stresses are shown to be similar to those in the installations just mentioned.

PNL's evaluation is presented following a discussion of the crankshaft reviews, analyses, and tests performed for the above-named installations by consultants to the Owners' Group and to individual licensees.

\subsubsection{Component Description}

The crankshaft for TOI 16-cylinder, OSRV-4 series engines is a steel forging with eight crank throws driven by 16 articulated connecting rods, through which reciprocating power is transmitted from pistons arranged in two 8-cylinder banks in a V-type engine block. Each crankshaft in the abovementioned installations is equipped with four counterweights. The crankpin journals and the main bearing journals are 13 inches in diameter, and the overall crankshaft length is approximately 20 feet 7 inches.

The 16-cylinder, DSRV-4 diesel generators purchased for nuclear service are rated by TDI for continuous operation at $7000 \mathrm{~kW}$ when loaded to an engine brake mean effective pressure (BMEP) of 225 psig at the design speed of $450 \mathrm{rpm}$. These engines are also rated by TDI to operate for 2 hours of every 24 operating hours at $7700 \mathrm{~kW}$.

\subsubsection{Design Guidelines}

As discussed in Section 4.6.2 of this report, the recommendations in Standard Practices (1972) of the Diesel Engine Manufacturers Association (DEMA) were used as a basis for the crankshaft evaluations performed by the TDI Diesel Generator Owners' Group and the reviews performed by PNL. The DEMA recommendations for torsional crankshaft stresses are summarized in that section. 
Torsional crankshaft stresses determined through analyses and tests of 16-cylinder engines at nuclear power plants are compared in this report with the DEMA recommendations.

\subsubsection{Failure History}

On the basis of information provided by TDI, FaAA reported (FaAA-84-3-16, May 1984) that three crankshafts for 16-cylinder, DSRV-4 engines have failed since 1976. All three failures occurred in engines in non-nuclear service. One failure occurred at Mora, Minnesota, in February 1976, in main journal No. 8. Two failures (one in June 1976, the other in March 1979) occurred at the Anamax mine near Tucson, Arizona. One was located in main journal No. 8; the other was in main journal No. 6. TDI attributed all three failures to torsional fatigue cracks initiating in the oil holes of these main journals.

These engines were found to have a 4 th-order critical speed at $446 \mathrm{rpm}$, which is close to the operating speed of $450 \mathrm{rpm}$. Each engine was subsequentiy fitted with four counterwejghts, which lowered the 4th-order critical speed to about $430 \mathrm{rpm}$. In addition, TDI changed the angular location of the oil holes and increased the radius where the ends of each hole intersect with the journal surface.

FaAA noted in the report referenced above that torsional stress is independent of angular location, and that the oil holes are areas of stress concentration. Accordingly, FaAA views the oil holes as critical sites for possible fatigue crack initiation, even with the modifications just described.

\subsubsection{Owners' Group Evaluation: Grand Gulf Engines}

The adequacy of the crankshafts for the 16-cylinder TDI engines at the Grand Gulf Nuclear Station (GGNS) was evaluated by Failure Analysis Associates for the Owners' Group, and by Bechtel Power Corporation for Mississippi Power \& Light Company, the owner of GGNS. Although the 16-cylinder engines in the other three nuclear power plants discussed in this section are similar to those at Grand Gulf, differences in generators and flywheels at the four installations result in differences in crankshaft torsional stresses. Accordingly, the crankshafts in each installation were evaluated on a plant-5pecific basis. 


\subsubsection{FaAA's Evaluation}

FaAA's evaluation of the crankshafts for the GGNS engines is presented in two reports: FaAA-84-3-16 (May 1984) and FaAA-84-7-10 (July 1984). In the first report, FaAA reviewed the torsional critical speed analysis performed by TOI in October 1975 and compared the calculated responses with the results of a torsiograph test that TDI performed on a GGNS engine before it was shipped from TDI's Oakland plant. In addition, the results of FaAA's dynamic torsional analysis are presented. The torsiograph test that FaAA performed on an engine at GGNS is addressed in the second report.

4.7.4.1.1 FaAA's Review of TDI's Evaluation. As discussed in FaAA-84-3-16, diesel generator torques due to dynamic response are usually calculated in two steps. The first step is to determine the natural frequencies of vibration of the crankshaft torsional system, the corresponding engine speeds, and the orders of vibration that resonate at these speeds. The second step is to determine the dynamic torsional response of the crankshaft due to gas pressure and reciprocating inertia loading. TDI calculated the response at the rated engine load of $7000 \mathrm{~kW}$.

By modeling the crankshaft torsional system as lumped mass monents of inertia connected by torsional springs and using the Holzer method to solve the resulting eigenvalue problem, TDI determined that the first three natural frequencies of the crankshaft are $28.8,83.0$, and $113.0 \mathrm{~Hz}$. The first natural frequency produces a 4 th-order resonance at $432 \mathrm{rpm}$.

FaAA commented that the response of the 4th-order resonance is important because of the proximity of this resonance to the engine operating speed of $450 \mathrm{rpm}$. As noted by FaAA, the 4th-order loading from one bank of a $\mathrm{V}-16$ engine with articulated connecting rods almost cancels that from the other bank, reducing the excitation. However, FaAA also noted that this excitation is sensitive to the power balance between the two banks.

TDI determined the dynamic torsional response of the crankshaft for wholeand half-orders of vibration from 0.5 to 12.0, each considered separately. (The lst order is a harmonic that repeats once per revolution of the crankshaft. Harmonics of order $0.5,1.0,1.5,2.0,2.5 \ldots$ exist for a four-stroke 
engine.) The largest nominal shear stress amplitude computed by TDI for a single order of vibration is $1956 \mathrm{ps} i$, corresponding to the 3.5 order. This is well below the DEMA-recommended limit of 5000 psi for a single order.

TDI also performed a torsiograph test on one of the GGNS engines. A torsiograph test measures the angular displacement of the free end of the crankshaft under various operating conditions, and is commonly used to confirm torsional vibration calculations. A typical test consists of first operating the engine without load at various speeds to locate critica? speeds, and then operating the engine at its rated speed with variable load to determine the forced vibrational response.

FaAA compared the TDI-calculated responses to the results of TDI's torsiograph test. The variable speed test showed that the first natural frequency is $28.7 \mathrm{~Hz}$, which agrees well with TDI's calculated value of $28.8 \mathrm{~Hz}$. The nominal shear stress amplitude for the maximum measured single-order response at the rated load of $7000 \mathrm{~kW}$ is $2028 \mathrm{psi}$, corresponding to the 3.5 order. This compares well with the stress of $1956 \mathrm{ps} j$ for TDI's calculated response to the 3.5 order, and is well below the DEMA-recommended limit of 5000 psi. From torsiograph data taken by TDI at $7700 \mathrm{~kW}$ (110\% rated load), the nominal shear stress amplitude for the largest single-order response (the 3.5 order) is 2366 psi.

FaAA also commented on crankshaft stresses for off-speed conditions. The stresses are within DEMA-recomended limits over a speed range of 440 rpm to $450 \mathrm{rpm}+5 \%$, according to $F a A A$, provided that adequate engine balance is maintained. FaAA recommends that the engines not be allowed to operate below $440 \mathrm{rpm}$ except during startup and shutdown, because of the presence of the 4 th-order resonance at $432 \mathrm{rpm}$.

4.7.4.1.2 FaAA's Dynamic Torsional Analysis. FaAA noted that TDI did not calculate the phase angle associated with the response of each order, and therefore the combined response of the orders cannot be determined from TDI's results. FaAA also noted that the measurements necessary to determine stresses for the combined orders were not taken during TDI's torsiograph test. Thus, neither TDI's calculations nor TDI's measurements can be used to compare the stresses for combined orders with the DEMA-recomnended 1 imit of 7000 psi. 
To supplement TDI's calculations, FaAA analyzed the combined response of the crankshaft using modal superposition for the first 24 orders of vibration. This analysis was similar to FaAA's torsional analysis of the crankshafts for the TDI engines at the Shoreham Nuclear Power Station (SNPS). All 11 modes of the Tumped inertia and torsional spring model of the crankshaft were considered in the analysis.

In calculating the harmonic loading on the crankshaft, FaAA considered gas pressure, reciprocating inertia, and estimated frictional loads. The gas pressure loading was obtained from pressure versus crank angle data measured in an 8-cylinder engine at SNPS. FaAA considered these measurements to be applicable to the 16-cylinder engines at GGNS, because the cylinders of TDI R4-series engines are designed to operate under the same conditions regardless of the number of cylinders.

To simulate the effects of cylinder bank imbalance on crankshaft response to the 4th order of vibration, FaAA's analysis assumed a 1-degree difference in timing between the two banks. Damping equal to $2.5 \%$ of critical damping was assumed for the analysis, but FaAA found that the assumed value had little effect on the calculated response because the orders of vibration are not in resonance at the engine operating speed of $450 \mathrm{rpm}$.

FaAA's calculated amplitudes of free-end displacement for the significant orders of vibration agree well with values measured in TDI's torsiograph test of the engine. The largest response occurs for the 3.5 order. FaAA's calculated amplitude for this order at full load is 0.269 degrees. The corresponding value from TDI's torsiograph test is 0.24 degrees.

FaAA's results also include the range of torque at each crank throw, and the corresponding nominal shear stress amplitude. The calculated stress levels are highest between cylinders No. 3 and 4,5 and 6 , and 7 and 8 . FaAA found that the highest nominal shear stress amplitude for the vector summation of 24 orders at full rated engine load is 5367 psi, occurring between cylinders No. 5 and 6 . This value is below the DEMA-recomnended limit of 7000 psi for combined orders. FaAA commented that the nominal shear stress amplitudes for $110 \%$ load may be determined by extrapolation, and are also below the DEMA-recomended 1 imit. However, FaAA did not report the values for $110 \%$ load. 
4.7.4.1.3 FaAA's Torsiograph Test. As reported in FaAA-84-7-10, FaAA performed a torsiograph test of a TDI diesel generator at GGNS at eight speeds between 410 and $470 \mathrm{rpm}$ under no-load conditions, and at loads of $25 \%, 50 \%$, $75 \%, 100 \%$, and $110 \%$ of rated load while the engine was operated at rated speed. The variable speed test was performed to determine the frequency of the first mode of the crankshaft torsional system. The variable load test was performed to determine the amplitude of free-end crankshaft vibration and to estimate the nominal shear stress as a function of load.

FaAA's findings and conclusions from the torsiograph test include the following:

- The 4th-order critical speed is reached at about $430 \mathrm{rpm}$. Thus, the first natural frequency is approximately $28.7 \mathrm{~Hz}$. This is in good agreement with TDI's calculated value of $28.8 \mathrm{~Hz}$.

- With the assumption that the shaft is vibrating in its first node, the following values of the amplitude of nominal shear stress were estimated from the measured amplitudes of free-end vibration:

\begin{tabular}{|c|c|c|c|}
\hline & $\begin{array}{c}\text { Ful1 Load } \\
7000 \mathrm{~kW} \\
\end{array}$ & $\begin{array}{l}\text { Overload } \\
7700 \mathrm{kH} \\
\end{array}$ & $\begin{array}{c}\text { DEMA } \\
\text { allowable } \\
\end{array}$ \\
\hline Single order (3.5) & 2062 psi & 2172 psi & 5000 psi \\
\hline Combined response & 4775 psi & 5113 psi & 7000 psi \\
\hline
\end{tabular}

- The results of the variable load tests show that the largest responses occur for the $1.5,2.5$, and 3.5 orders, and increase with increasing load. However, the 4 th-order response increases slightly over a portion of the load range and then decreases, with the result that it is approximately the same at full load as at no load.

4.7.4.1.4 FaAA's Conclusions and Recommendations. FaAA's conclusions and recommendations from the analyses and tests of the crankshafts for the GGNS engines include the following, as discussed in FaAA-84-3-16:

- The single-order calculations performed by TDI for a GGNS engine are appropriate and show that the crankshaft stresses are below the DEMArecommended limit for a single order. 
- The results of TUI's torsiograph test of a GGNS engine also show that the crankshaft stresses are below the DEMA-recomnended limit for a single order, for both $7000 \mathrm{~kW}$ (rated load) and $7700 \mathrm{~kW}$ (110\% rated load).

- The crankshafts are adequate for their intended service, subject to the following recommendations:

- The oil holes in main journals No. 4, 6, and 8 represent a more critical stress concentration in torsion than do the crankpin fillets and should be inspected for fatigue cracks and machining discontinuities.

- The engines should not be allowed to operate below $440 \mathrm{rpm}$ except during startup and shutdown.

- The adequacy of the TDI specification for balancing of cylinders, in combination with the speed tolerances allowed by the governor, should be determined by torsiograph testing. These tests would provide a database for the expected variations of speed and balance. With the additional data, it may be possible to eliminate inspection of oil holes.

- If an engine is operated in a severely unbalanced condition, it may be necessary to reinspect the oil holes for fatigue cracks.

\subsubsection{Bechtel's Evaluation}

In a report submitted to NRC ( $H$. Denton) as an enclosure to a Mississippi Power \& Light Company (J. McGaughy) letter dated February 20, 1984, MP\&L described the action taken at that time on the TDI engines at GGNS. Included in the report are the results of a crankshaft evaluation performed for MP\&L by the Bechtel Power Corporation. In an independent dynamic analysis of the crankshaft, Bechtel used five sets of harmonic coefficients and applied modal superposition to sum the effects of the responses. Cylinder pressures measured at Shoreham were used in determining the harmonic loading.

Bechtel's torsional analysis yielded a "single order stress" of 2389 psi and a "total average stress" of 5084 psi for the GGNS crankshafts at rated 
load. These values are consistent with the results obtained by TDI and by FaAA for single and combined orders, and are within the DEMA-recommended 1 imits. Bechtel also determined that the peak stress over a stress cycle is 6034 psi. This, too, meets DEMA criteria.

\subsubsection{Owners' Group Evaluation: Perry Engines}

FaAA performed torsiograph tests and related analyses of the crankshafts for the Unit 1 Division 1 (U1DI) and the Unit 1 Division 2 (U102) diesel generators at the Perry Nuclear Power Plant (PNPP). Both unjts are TDI 16-cylinder, DSRV-4 series engines.

For each engine, FaAA obtained data at 10 speeds between 400 and 470 rpin under no-load conditions, and at loads of $25 \%, 50 \%, 75 \%$, and $100 \%$ of rated load while the engine was operated at rated speed. FaAA also obtained transient data during fast starts of each engine from four different initial crankshaft positions, and during four coastdowns from rated speed. The initial positions for the four startup tests were at 180-degree intervals of crankshaft rotation to cover the full 720-degree firing cycle. Finally, FaAA measured the crankshaft response of each engine to operation under conditions of cylinder imbalance. The imbalance was introduced by cutting off the fuel to one cylinder (cylinder No. 5, left bank), chosen on the basis of an analysis that showed it would produce the largest increase in stress.

The steady-state and transient tests are discussed in FaAA-85-4-1 (May 1985). FaAA's conclusions are as follows:

- The 4th-order critical speed is reached at about 436 rpm for each crankshaft. Thus, the first natural frequency of the torsional system is approximately $29.1 \mathrm{~Hz}$. This value is in good agreenent with TOI's calculated value of $29.2 \mathrm{~Hz}$ for the PNPP engines.

- With the assumption that the shaft is vibrating in its first mode, the following values of the amplitude of nominal shear stress were estimated from the measured amplitudes of free-end vibration: 


Diesel Generator
Unit 1 - Division 1
Unit 1 - Division 2
DEMA-recomnended limit

Amplitude of Nominal Shear

Stress at Full Load $(7000 \mathrm{~kW})$

single Order Combined Order

1891 psi

4659 psi

2020 psi

4642 psi

5000 psi

7000 psi

- The coastdown transient response is repeatable and has a inaximurn peak-to-peak amplitude of approximately 0.96 degrees, which produces a maximum amplitude of nominal stress of 3970 psi.

- A typical transient response to a 6-second fast start has a maximum peak-to-peak amplitude of 1.86 degrees. The effect of initial crankshaft position on the transient response is small. This was confirmed by a transient analysis for each of the four conditions tested. The analysis, which used pressure-time data recorded during a fast start on a OSRV-4 series engine at another plant, indicates that a typical fast start produces a maximum amplitude of nominal stress of 7650 psi, occurring between cylinders No. 7 and 8 . This stress amplitude exists for only a few cycles on each startup.

- The results of the torsiograph test indicate that the crankshafts are adequate for their intended service at PNPP.

The cylinder imbalance tests are discussed in FaAA-PA-R-85-06-11 (June 1985), an addendum to FaAA-85-4-1. FaAA noted that the effect of imbalance is typically greatest in the 0.5 -order response. However, the response of the 4th order to cylinder imbalance was of particular interest for the PNPP engines, because the critical speed (436 rpm) for that order is close to the normal operating speed of $450 \mathrm{rpm}$.

FaAA measured the effects of imbalance at no load and at $50 \%$ of rated load. Using the modal superposition model discussed in Section 4.7.4.1.2 of this report, FaAA extrapolated the effects of imbalance to full load $(7000 \mathrm{~kW})$. FaAA's conclusions include:

- The U1D2 engine is better balanced (i.e., the pressure versus time curve is closer to the same for each cylinder) than the UID1 engine, 
as indicated by the 10wer 0.5-order response of U1D2 during both normal and imbalanced operation. However, the 0.5 -order response for both engines was within the normal range.

- The total response during the cylinder imbalance tests with no load is essentially the same as the response during normal balanced operation with no load.

- An analytical extrapolation of the measurenents at $50 \%$ of rated load indicates that, at rated load $(7000 \mathrm{~kW})$, the maximum amplitude of nominal stress would increase from 5330 psi to 6910 psi due to the imbalanced condition. This increase is not large enough to affect the adequacy of the crankshaft in either engine.

- The 4th-order response showed a small increase in the U1Dl engine and a large increase in the U1D2 engine during the imbalance tests. The difference in the responses is due to the different balance between the left and right banks in the two engines. However, neither response is large enough to affect crankshaft adequacy.

\subsubsection{Owners' Group Evaluation: Catawba Engines}

Duke Power Company, the owner of Catawba, performed extensive tests on two 16-cylinder TDI diesel generators, designated $1 A$ and $1 B$, that are installed at Catawba Nuclear Station Unit 1. In addition, FaAA performed a torsiograph test of the $1 A$ engine. The operational tests and the torsiograph test are discussed under the following two subheadings.

\subsubsection{Operational Tests}

The engine tests performed by Duke Power Company provide substantial evidence concerning the fatigue resistance of the crankshafts under the conditions imposed during the tests. These tests are the subject of numerous letters and reports reviewed by PNL in the preparation of a technical evaluation report on the Catawba engines (PNL-5211, August 1984).

In summary, diesel generator $1 A$ was operated for more than 800 hours in a test program completed in March 1984. Over half of those hours were at loads equal or to greater than $5800 \mathrm{~kW}$ ( $83 \%$ of rated $10 a d)$. Diesel generator 18 was 
operated for more than 750 hours in a test program completed in July 1984. Over 600 of those hours were at loads equal to or greater than $5800 \mathrm{kw}$. Posttest inspections of the crankshafts, including fluorescent dye penetrant tests of the lube oil holes subject to the highest torsional stresses (i.e., in main journals No. 4,6 , and 8 ), revealed no evidence of fatigue crack initiation.

\subsubsection{Torsiograph Test}

As reported in FaAA-84-5-23 (May 1984), the torsiograph test was performed at nine speeds between 410 and 470 rpm under no-load conditions, and at loads of $50 \%, 75 \%, 100 \%$, and $110 \%$ of rated load while the engine was operated at rated speed.

FaAA reached the following conclusions: (a)

- The 4th-order critical speed is reached at about $429 \mathrm{rpm}$, indicating that the first natural frequency is $28.6 \mathrm{~Hz}$. This agrees well with TDI's calculated value of $28.8 \mathrm{~Hz}$ for the Catawba engines.

- With the assumption that the shaft is vibrating in its first mode, the following values of the amplitude of nominal shear stress were estimated from the measured amplitudes of free-end vibration:

\begin{tabular}{|c|c|c|c|}
\hline & $\begin{array}{c}\text { Full Load } \\
7000 \mathrm{kw} \\
\end{array}$ & $\begin{array}{l}\text { Overload } \\
7700 \mathrm{KW} \\
\end{array}$ & $\begin{array}{c}\text { OEMA } \\
\text { allowable } \\
\end{array}$ \\
\hline Single order (3.5) & 2079 psi & 2172 psi & 5000 psi \\
\hline Combined response & 4987 psi & 5071 psi & 7000 psi \\
\hline
\end{tabular}

\subsubsection{Owners' Group Evaluation: Comanche Peak Engines}

FaAA also performed a torsioyraph test of the 16-cylinder TDI diesel generator designated Unit 1, OG2 at the Comanche Peak Steam Electric Station (CPSES). As reported in FaAA-85-1-8 (February 1985), the test was conducted at seven speeds between 410 and 450 rpm under no-load conditions, and at loads of

(a) PNL notes that engine $1 A$ was equipped with type AN piston skirts at the time FaAA conducted the torsiograph test at Catawba. The AN piston skirts were later replaced with type AE piston skirts. In the opinion of PNL's reviewers, this change in piston skirts has no significant effect on the torsional system. Accordingly, the change does not affect the conclusions reached by FaAA. 
$25 \%, 50 \%, 75 \%, 100 \%$, and $110 \%$ of rated load while the engine was operated at rated speed. FaAA also obtained transient data during two fast starts and two coastdowns.

FaAA's conclusions include:

- The 4th-order critical speed is reached at about $432 \mathrm{rpm}$. Thus, the first natural frequency of the torsional system is approximately $28.8 \mathrm{~Hz}$. This is in good agreement with TDI's calculated value of 28.9 $\mathrm{Hz}$ for the CPSES engines.

- With the assumption that the shaft is vibrating in its first mode, the following values of the amplitude of nominal shear stress were estimated from the measured amplitudes of free-end vibration:

$\begin{array}{lllll} & \begin{array}{c}\text { Full Load } \\ 7000 \mathrm{~kW}\end{array} & & \begin{array}{l}\text { Overload } \\ 7700 \mathrm{~kW}\end{array} & \begin{array}{c}\text { DEMA } \\ \text { allowable }\end{array} \\ \text { Single order (3.5) } & \frac{1971 \mathrm{psi}}{2064 \mathrm{psi}} & & 5000 \mathrm{psi} \\ \text { Combined response } & 4544 \mathrm{psi} & 5011 \mathrm{psi} & 7000 \mathrm{psi}\end{array}$

- The maximum peak-to-peak free-end response for the two fast starts was found to be 1.64 degrees; for the two coastdowns it was 0.77 degrees. The corresponding amplitudes of nominal shear stress, calculated with the assumption that the shaft is vibrating in its first mode, are $6956 \mathrm{psi}$ and 3270 psi, respectively.

\subsubsection{PNL's Review}

The following PNL consultants participated in various aspects of PNL's reviews of the crankshafts for the TOI 16-cylinder, DSRV-4 series engines:

- S. H. Bush, Review and Synthesis Associates

- H. Engja, Norwegian Marine Technology Research Institute

- H. M. Hardy, consulting engineer

- A. J. Henriksen, A. J. Henriksen, Inc.

- B. J. Kirkwood, Covenant Engineering

- P. J. Louzecky, Engineered Applications Corporation

- the late A. Sarsten, Norwegian Institute of Technology 
- T. W. Spaetgens, consulting vibration engineer

- H. Valland, Norwegian Marine Technology Research Institute.

In addition, J. Spanner of PNL's Nondestructive Testing section reviewed nondestructive testing procedures used by members of the Owners' Group to exalnine the crankshafts.

PNL's review of the crankshafts for the TOI 16-cylinder, DSRV-4 engines encompassed the following activities:

- reviews of the reports referenced in Sections 4.7 .4 through 4.7 .7 regarding the analyses and torsiograph tests of the crankshafts at four nuclear power plants

- independent analyses performed by PNL's consultants to provide a basis for comparison with the torsional stresses computed for the Owners' Group by Failure Analysis Associates

- reviews performed in the preparation of PNL technical evaluation reports for the 16-cylinder TDI diesel generators at four nuclear power plants that became candidates for operating licenses: Catawba, Comanche Peak, Grand Gulf, and Perry - The crankshaft was one of the components reviewed. PNL representatives visited Catawba following completion of each of the two engine tests discussed in Section 4.7.6.1 of this report, and reviewed the post-test disassemblies and inspections of the $1 A$ and $1 B$ diesel generators. PNL representatives also reviewed disassemblies and inspections of the unit 1, DG2 engine at Comanche Peak and the unit 1 , DG1 engine at Grand Gulf.

The results of several analyses performed by PNL's consultants are summarized in Section 4.7.8.1, and compared with corresponding results of investigations by the Owners' Group. PNL's comments on the torsiograph tests performed on 16-cylinder engines at four nuclear power plants are discussed in Section 4.7.8.2. Finally, PNL's conclusions and recommendations on the bas is of all of the information reviewed are presented in Section 4.7.8.3. 


\subsubsection{Analyses Performed by PNL's Consultants}

4.7.8.1.1 Torsional Stresses Below Rated Speed. Using his program COMHOL2 (COMplex HOLzer version 2), Prof. Sarsten analyzed the torsional vibration characteristics of the crankshaft for the TOI engines at Grand Gulf, over the range of 100 to $470 \mathrm{rpm}$. His results are for forced, damped vibrations during steady-state operation at certain speeds and, as such, do not represent true transient conditions during startup and coastdown. Nevertheless, his analysis predicts the resonant stress amplitudes of the principal orders of vibration and the rpm range over which each order is significant. The harmonic coefficients used in his calculations correspond to the full-load engine brake mean effective pressure (8MEP) of 225 psig. The actual BMEP may be less during startup, and would be considerably less during coastdown.

The results of Prof. Sarsten's analysis are summarized in Figures 4.7.1 through 4.7.3. Figure 4.7.1 shows the amplitude of free-end vibration of the crankshaft as a function of engine rpm. Figure 4.7.2 shows nominal torsional vibratory stresses for single orders of vibration, plotted as a function of engine rpm. Figure 4.7.3 shows nominal torsional vibratory stresses for the sum of 24 orders of vibration, also as a function of engine rpm. The dynamic magnifier cited in the three graphs is a function of the assumed damping, the masses, and the associated natural frequency of the torsional system for firstmode vibration.

Prof. Sarsten made the following observations on the results summarized in Figures 4.7.1 through 4.7.3:

- The resonant peaks at speeds corresponding to orders 4.5, 5.5, 6.5, and 8 are not closely spaced, and therefore would not be expected to augment each other during engine startup. The vibratory conditions associated with these resonances are acceptable for engine acceleration through this speed range. No significant resonances of higher modes were detected in the speed range investigated. 


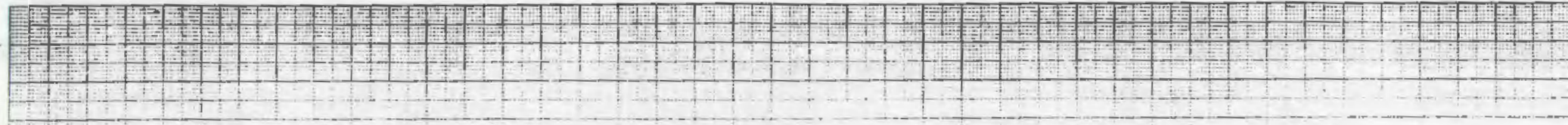

\section{MPUTUDE}

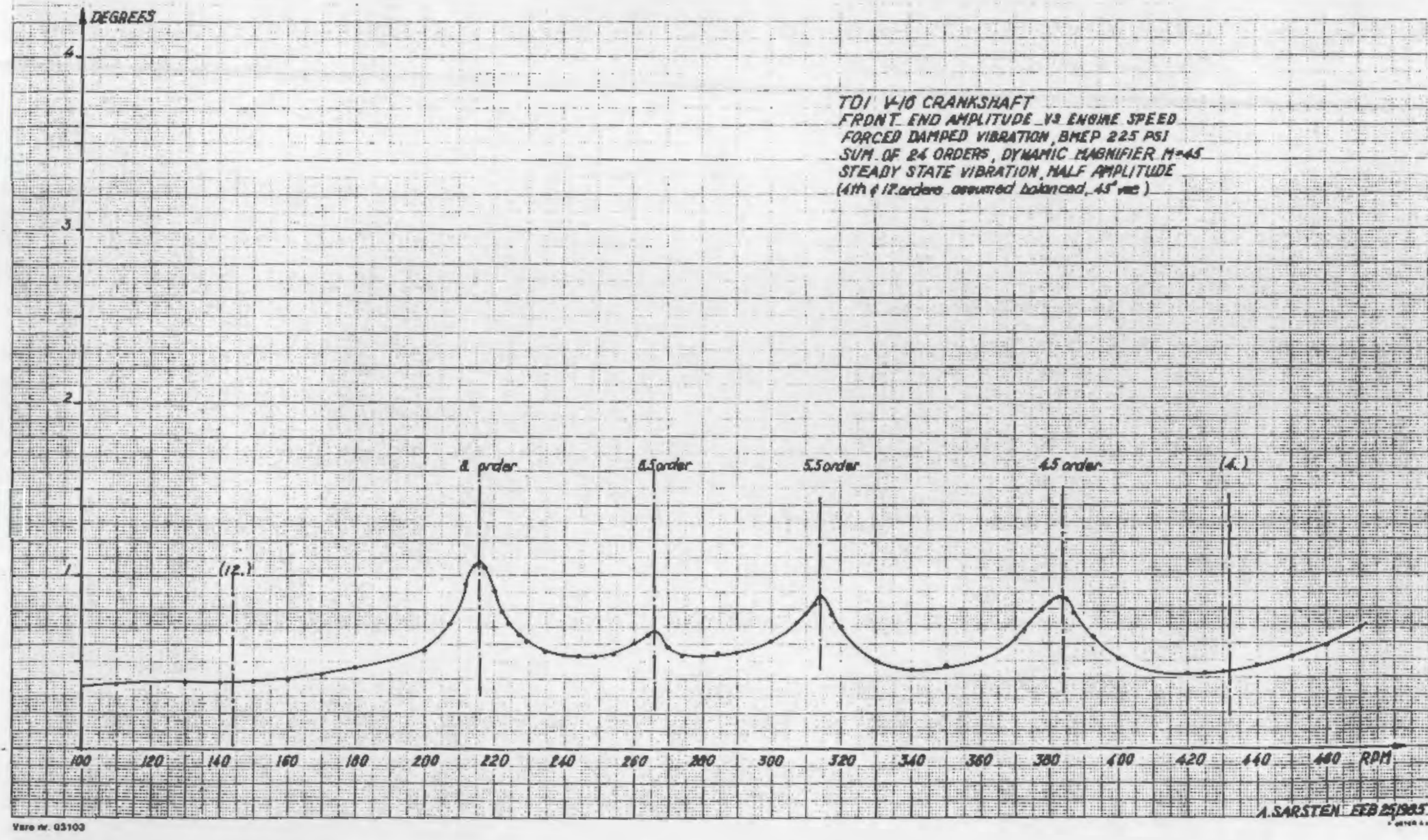

FIGURE 4.7.1. Variation of Free-End Crankshaft Vibration with Engine RPM for Sum of 24 Orders in TDI DSRV-16-4 Crankshaft 


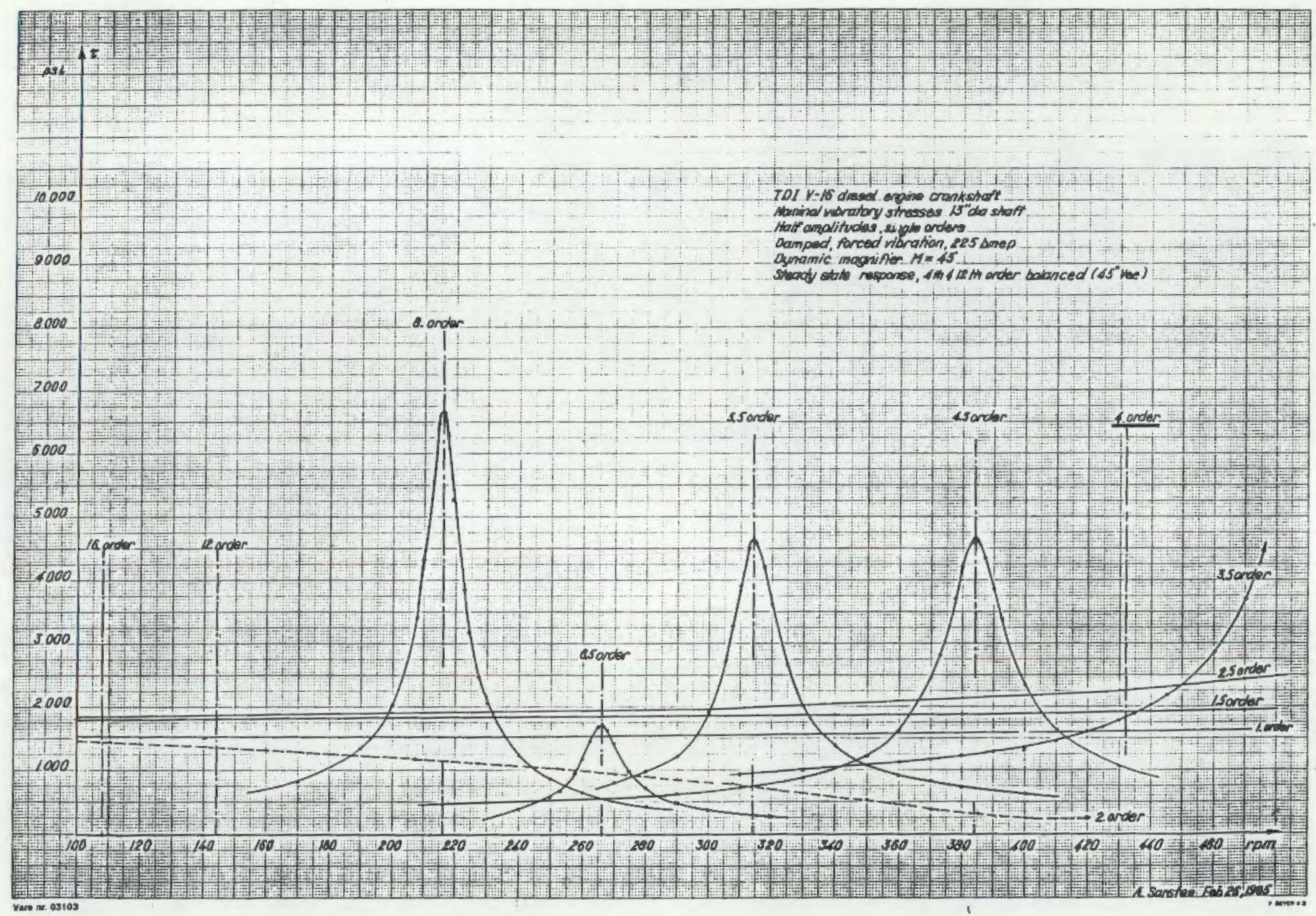

FIGURE 4.7.2. Torsional Vibratory Stresses for Single Orders in TOI DSRV-16-4 Crankshaft 


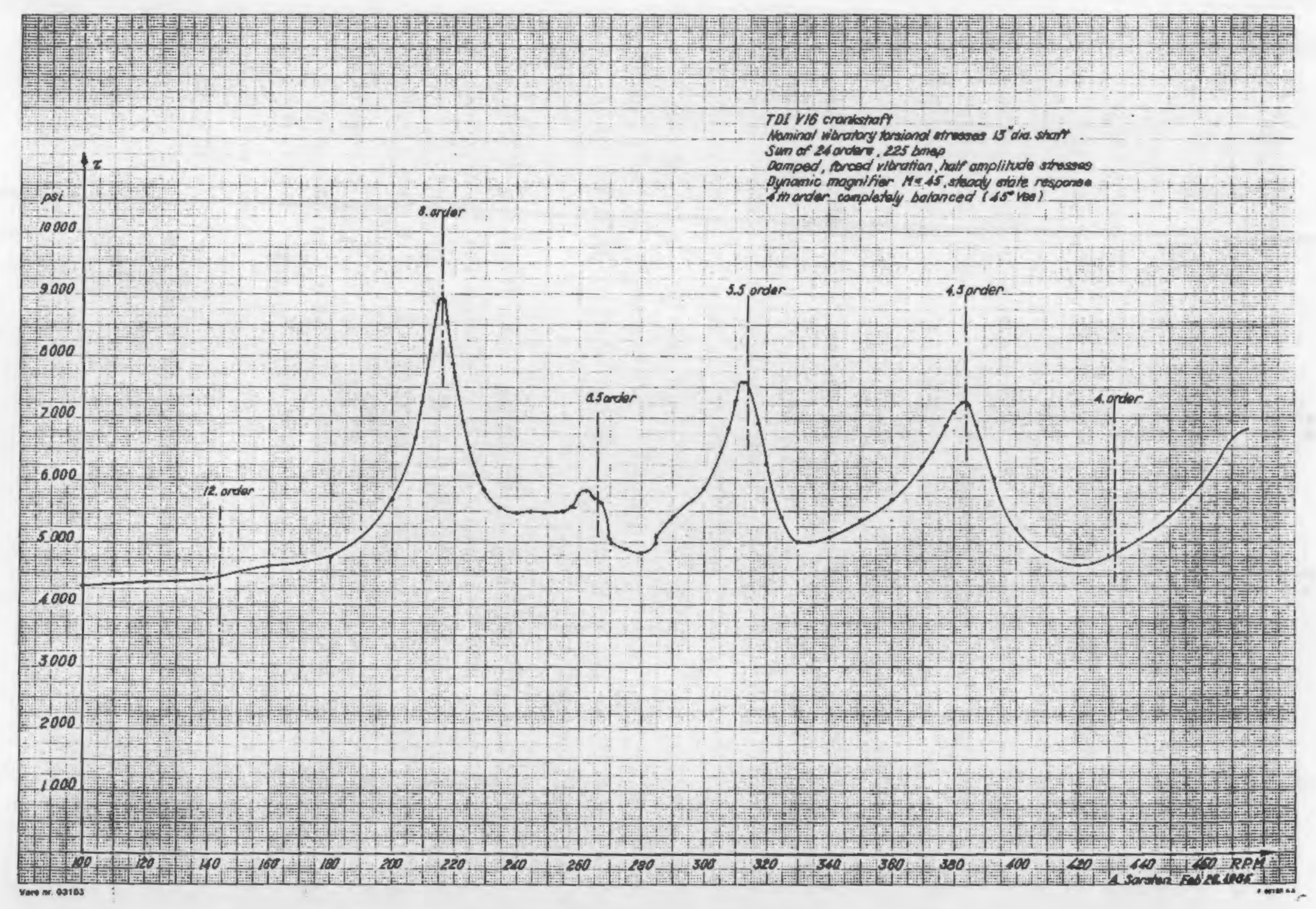

FIGURE 4.7.3. Torsional Vibratory Stresses for the Sum of 24 orders in TDI DSRV-16-4 Crankshaft 
- No responses are shown for the 4th and 12th orders, because these orders vanish under the assumptions used in the analysis. The excitations of these orders from one bank of the $\mathrm{V}$-engine cancel the excitations from the other bank, assuming the cylinders are evenly balanced and disregarding the effect of the articulated connecting rods on piston motion and timing. However, the 4th order in the actual engine is important because it occurs within $-5 \%$ of the rated engine speed. Any lack of uniformity in the pressure diagrams of individual cylinders will excite this order, as will the slightly different piston motions and timing associated with the articulated connecting rods.

PNL notes from FaAA's torsiograph tests of the engines at Perry and Comanche Peak (Sections 4.7 .5 and 4.7 .7 ) that the maximum transient responses measured during startups and coastdowns produce nominal stress amplitudes well below the maximum resonant stress predicted in Prof. Sarsten's analysis (i.e., the $8 \mathrm{th}$-order response of $8900 \mathrm{psi}$ at $217 \mathrm{rpm}$, plotted in Figure 6.4.3). Thus, the torsiograph test results confirm that peak stresses under normal transient conditions are lower than the peak resonant stress predicted from Prof. Sarsten's steady-state analysis.

4.7.8.1.2 Torsional Stresses at Rated Speed. Following the untimely death of Prof. Sarsten, Professors Engja and Valland used the computer program COMHOL2 to analyze the torsional system of the TDI engines at Comanche Peak. They computed crankshaft torsional stresses for operation at full power (225 BMEP) and rated speed, with and without misfiring, for single orders and for the sum of the first 24 orders of vibration. Misfiring was assumed to occur at cylinder No. 5 left bank (cylinder $5 \mathrm{~L}$ ), for consistency with FaAA's investigation of misfiring (Section 4.7 .5 of this report). To explore the effect of damping, the stresses were computed for two different values of the damping magnification factor, $M$. The results are as follows: 


\begin{tabular}{|c|c|c|c|c|}
\hline & \multirow{2}{*}{\multicolumn{2}{|c|}{$\begin{array}{r}\begin{array}{r}\text { Maximum Nominal } \\
\text { in psi, at } 225 \text { BMEP }\end{array} \\
\text { Normal Misfiring } \\
\text { Firing Cyl. } 5 L\end{array}$}} & \multicolumn{2}{|c|}{$\begin{array}{l}\text { Stresses, } \\
\text { and } 450 \mathrm{rpm}\end{array}$} \\
\hline & & & $\begin{array}{l}\text { Normas } \\
\text { Firing }\end{array}$ & $\begin{array}{l}=50 \\
\text { Misfiring } \\
\text { Cyl. } 5 \mathrm{~L} \\
\end{array}$ \\
\hline Single order (3.5) & 2265 & 2910 & 2281 & 2982 \\
\hline $\begin{array}{l}\text { Combined response } \\
\text { ( } 24 \text { orders) }\end{array}$ & 5347 & 7188 & 5377 & 7364 \\
\hline $\begin{array}{l}\text { Free-end amplitude, } \\
\text { degrees }\end{array}$ & 0.503 & 0.888 & 0.507 & 0.880 \\
\hline
\end{tabular}

The above resuits for the combined response under normal firing conditions bracket the maximum nominal shear stress amplitude of 5367 psi from FaAA's dynamic torsional analysis of the crankshaft for the Grand Gulf engines (Section 4.7.4.1.2 of this report). FaAA's analysis accounted for the same number of orders, and was performed for a similar torsional system operating at the same power and speed. The independent analyses using COMHOL2 and FaAA's program also agree on the location of the maximum nominal stress, which is predicted to occur between cylinders No. 5 and 6 . These comparisons further reinforce the observation in PNL's review of the crankshafts for 8-cylinder TDI engines (Section 4.6) that the two computer programs yield consistent results.

The stresses predicted with COMHOL2 for normal firing are higher by about 800 psi than the stresses estimated by FaAA from the results of the torsiograph test of a Comanche Peak engine (Section 4.7.7). For the Grand Gulf engines there is a similar difference between the results of FaAA's torsional analysis (Section 4.7.4.1.2) and the stresses estimated by FaAA from torsiograph data (Section $4.7 .4 \cdot 1.3$ ). These comparisons suggest that the results produced by the two computer programs are conservative for the torsional systems modeled.

For misfiring of cylinder $5 \mathrm{~L}$, the stresses predicted with COMHOL2 for the Comanche Peak engines are also 280 to 450 psi higher than the stresses estimated by FaAA from torsiograph data taken during imbalance tests of the Perry engines (Section 4.7.5). The difference varies with the damping assumed in the analysis. 


\subsubsection{Review of Torsiograph Test Results}

The torsiograph tests performed by FaAA on five engines at four nuciear power plants provide actual crankshaft responses for a wide variety of steadystate and transient operating conditions, including ioads through $110 \%$ rated load, startup and coastdown transients, off-speed operation, and operation with imbalance in cylinder firing. From a review of these tests, PNL's observations are as follows:

- The instrumentation used in the tests, and the procedures followed in performing the tests, are consistent with established measurement practice. Confidence in the test data is enhanced by the close correspondence between pre-test and post-test calibration measurements.

- The nominal shear stresses estimated from the torsiograph data confirm that crankshaft torsional stresses at rated speed and at engine loads up to $110 \%$ of rated load are well below DEMA-recommended limits for both single orders and combined orders of vibration.

- Maximum nominal stresses estimated from the torsiograph data taken during startup and coastdown tests of engines at Perry and Comanche Peak are lower than the peak resonant stress predicted in Prof. Sarsten's steady-state analysis of resonant stress amplitudes below rated speed. In addition, the maximum transient responses during coastdown tests were found to be approximately one-half the maximum transient responses during fast starts, indicating that the lower BMEP during coastdown resulted in a significant reduction in excitation. Startup transients measured on the Perry engines were found to have very little sensitivity to initial crankshaft position. These results confirm Prof. Sarsten's observation that the resonant peaks identified in his analysis (Figure 6.4.3) are acceptable for engine acceleration to rated speed. Further, these results show that the transient responses are acceptable for either the slow starts (with lower BMEP) or the fast starts of the type conducted during the tests. 
- Measured values of the 4th-order critical speed are within $-5 \%$ of rated engine speed for all five engines tested, and range from 429 rpm at Catawba to 436 rpm at Perry. This range reflects the differences in the crankshaft torsional systems of the engines. The test results also show the contribution of the 4th-order response under various operating conditions. For example, the 4th order contributed 0.240 degrees to the 0.340 -degree total amplitude of free-end crankshaft vibration measured at Perry during no-load operation of the 4101 engine at $434 \mathrm{rpm}$. FaAA found that the increases in the 4th-order response during imbalance tests of two engines at Perry were not large enough to affect crankshaft adequacy.

- The test results confirm the computed values of the first-mode natural frequencies of the torsional systems of all five engines.

\subsubsection{Conclusions and Recommendations}

Subject to implementation of the recommendations discussed later in this section, PNL concurs with the Owners' Group that the crankshafts for the TDI 16-cylinder, OSRV-4 series engines at the Catawba, Comanche Peak, Grand Gulf, and Perry nuclear power stations are adequate for their intended service at loads to full rated 1 oad of $7000 \mathrm{~kW}$, and to $110 \%$ rated load $(7700 \mathrm{~kW})$ for the percentage of operating time at overload that is allowed by the manufacturer. The torsional analyses and the torsiograph tests discussed in Sections 4.7 .4 through 4.7 .8 of this report substantiate the adequacy of the crankshafts of these engines for nuclear service. Furthermore, the results of these evaluations are supported by satisfactory performance of the crankshafts in several extended operational tests (e.g., at Catawba) and by the absence of any evidence of fatigue crack initiation in the crankshafts during post-test inspections.

These conclusions may be extended to crankshafts of the same design in TDI engines at other nuclear installations, provided that the crankshaft mechanical properties and the torsional crankshaft stresses are shown to be similar to those in the installations just mentioned. Recommendations for establishing this similarity are included in Section 4.7 .9 . 
PNL's recommendations are as follows:

- To avoid the effects of the 4th-order resonance, steady operation at speeds more than a few rpm below the rated speed of $450 \mathrm{rpm}$ should be avoided, particularly for the engines at Perry. At $436 \mathrm{rpm}$, the measured value of the 4 th-order critical speed of the Perry engines is the closest of the engines tested to the rated operating speed. The effect of the 4th order on crankshaft stresses varjes with the extent of imbalance between individual cylinders, and extends to either side of the critical speed as shown in FaAA's torsiograph test data for each engine tested.

- Because torsional analyses and torsiograph tests confirm that cylinder imbalance may have a significant effect on crankshaft stresses, appropriate precautions should be taken to prevent sustained engine operation with this condition. Exhaust gas temperatures should be monitored during engine operation to verify that differences between individual cylinder temperatures and the average temperature for all cylinders remain within the range recommended by TDt. In addition, cylinder firing pressures should be measured no less frequently than the interval recommended by TDI. It would also be prudent to analyze the trends of cylinder pressure and temperature measurements to detect changes that might indicate a need for maintenance of fuel injection equipment. Any abnormalities should be corrected expeditiously.

- PNL concurs with FaAA's comment (Section 4.7.4.1.4) that if an engine is operated in a severely unbalanced condition, it may be necessary to reinspect the oil holes for fatigue cracks. The need for an immediate inspection should be evaluated by the utility, taking into consideration the particular circumstances of the abnormal operation. The results of this evaluation should be subject to NRC review before the engine is returned to service.

- During each major (5-year) engine disassembly and inspection, the oil holes and fillets of the three main bearing journals (No5. 4, 6, and 8) subject to the highest torsional stresses should be examined with 
fluorescent liquid penetrant and, as appropriate, with eddy current. The oil holes and fillets in at least three of the crankpin journals No. 3 through 8 also should be examined in this manner. These inspections are recommended to verify the continued absence of fatigue cracks. PNL notes the comment of FaAA ( $P$. Johnston) in a meeting with the TDI Diesel generator Owners' Group (transcript dated October 22, 1984) that the fillet is the location of highest stress in a crankpin of these $V$-engine crankshafts. Further, PNL notes FaAA's observation in report FaAA-84-3-16 (May 1984) that the oil holes in the main journals represent a more critical stress concentration in torsion than the crankpin fillets. Thus, the oil holes in the main journals are the areas of highest stress. Nevertheless, PNL views the fillets of the most highly-stressed main journals and the fillets and oil holes of the crankpins as critical surfaces tht also warrant surveillance. If cumulative results for several engines show that these examinations reveal nothing of significance, the scope and/or frequency of the examinations could be reconsidered.

- To verify that crankshaft alignment remains within manufacturer's recomnendations, crankshaft deflection should be measured under both "hot" and "cold" conditions at each refueling outage (as planned at the four nuclear power plants with 16-cylinder engines addressed in this review). PNL's recommendations on the conduct of these examinations have been documented previously in the plant-specific technical evaluation report for the Catawba Nuclear Station (PNL-5211, August 1984). It may become appropriate to reconsider the frequency of these deflection measurements if substantial evidence develops that no significant changes are found from outage to outage. Any new interval between checks should, of course, be no less than the frequency recommended by the manufacturer.

\subsubsection{Extension of Conclusions to Other 16-Cylinder TDl Engines}

To establish whether or not the conclusions reached in PNL's review may be extended to crankshafts of the same design in TDI 16-cylinder engines at other nuclear power plants, the following action should be taken for each 
installation. This section is in addition to any tests performed by the manufacturer to confirm proper engine assembly, balance, and timing.

- A torsiograph test should be performed on at least one engine of a multiple-engine installation. One test will be sufficient if the torsional systems of the engines are of the same design. Each engine should be tested if the torsional systems differ (e.g., if the generators are of different designs). The test should include variablespeed operation over the entire speed range from shutdown to $+5 \%$ of rated speed, to determine the location of any potentially serious resonances (e.g., the 4th order). In addition, the test should include variable-load operation to determine crankshaft responses up to at least full rated load. The test results and torsional stresses calculated from these results should be compared with similar data for other 16-cylinder engines at nuclear power plants. Depending on the outcome of these comparisons, further testing and analysis may be necessary to establish crankshaft adequacy.

- The materials certification reports on the crankshafts should be reviewed to verify that the crankshaft mechanical properties (e.g., ultimate tensile strength) are within design specifications.

- Preservice crankshaft inspections should include fluorescent liquid penetrant and, as appropriate, eddy-current examinations of the oil holes and fillets of the three main bearing journals (Nos. 4, 6, and 8) subject to the highest torsional stresses. These inspections are recommended to verify the absence of rejectable machining irregularities and crack-like indications.

\subsubsection{References}

Diesel Engine Manufacturers Association (OEMA). 1972. Standard Practices for Low and Medium Speed Stationary Diesel and Gas Engines. 6th ed. New York, New York.

Failure Analysis Associates (FaAA). May 22, 1984. Evaluation of Emergency Diesel Generator Crankshafts at Shoreham and Grand Gulf Nuclear Power Stations. FaĀ-84-3-16, Palo Alto, California. 
Failure Analysis Associates (FaAA). May 29, 1984. Torsiograph Test of Emergency Diesel Generator $1 A$ at Catawba Nuclear Power Station.

FaAA-84-5-23, Palo Alto, California.

Failure Analysis Associates (FaAA). July 24, 1984. Torsiogragh Test of Emergency Diesel Generator Div. 1 at Grand Gulf Nuclear Generating Station. FaAA-84-7-10, Palo Alto, California.

Failure Analysis Associates (FaAA). February 1985. Torsiograph Test of Emergency Diesel Generator 1DG2 at Comanche Peak Steam Electric Station. FaAA-85-1-8, Palo Alto, California.

Failure Analysis Associates (FaAA). May 1985. Torsiograph Tests of Emergency Diesel Generators, Divisions 1 and 2, at Perry Nuclear Power Plant--Unit 1. FaAA-85-4-1, Palo Alto, California.

Failure Analysis Associates (FaAA). June 1985. Addendum to Torsiograph Tests of Emergency Diesel Generators, Divisions 1 and 2, at Perry Nuclear Power Plant--Unit 1 on Cylinder Imbalance. FaAA-PA-R-85-06-11, Palo Alto, California.

Grand Gulf Nuclear Station. February 1984. Comprehensive Report on Standby Diesel Generators - Significant Activities to Enhance and Verify Reliability. Forwarded to NRC (H. R. Denton) as Enclosure 2 of Mississippi Power Light Company (J. P. McGaughy) letter dated February 20, 1984.

Pacific Northwest Laboratory. August 1984. Review and Evaluation of Iransamerica Delaval, Inc., Diesel Engine Reliabitity and UperabiTity = Catawba Nuclear Station Unit 1. PNL-5211, Richland, Washington. 
4.8 CRANKSHAFT: 20-CYLINDER, DSRY-4 SERIES ENGINES 


\subsection{CRANKSHAFT: 20-CYLINDER, DSRV-4 SERIES ENGINES}

PNL reviewed the action taken by the Owners' Group to evaluate the crankshafts for the two TOI 20-cylinder, DSRV-4 series engines at the San Onofre Nuclear Generating Station Unit 1. The San Onofre station, operated by the Southern California Edison Company (SCE), is the only nuclear power plant in the United States equipped with TDI 20-cylinder engines.

\subsubsection{Component Description}

The crankshaft for TDI 20-cylinder, OSRV-4 series engines is a stee 1 forging with 10 crank throws driven by 20 articulated connecting rods, through which reciprocating power is transmitted from pistons arranged in two 10-cylinder banks in a $V$-type engine block. The crankpin journals and the main bearing journals are 13 inches in diameter, and the overall crankshaft length is approximately 24 feet 7 inches.

The DSR4 series inline and V-block engines are rated by TOI for continuous operation at a BMEP of $225 \mathrm{psig}$, when run at the design speed of $450 \mathrm{rpm}$. These engines are also rated by TDI to operate for 2 hours out of every 24 hours at $10 \%$ overload. The corresponding power levels for a 20 -cylinder diesel generator are $8750 \mathrm{~kW}$ and $9625 \mathrm{kH}$, respectively.

However, each of the two 20-cylinder diesel generators at San Onofre is rated for continuous operation at $6000 \mathrm{kw}$, the rating of the generator driven by each engine. Engine loading for periodic surveillance tests is limited by SCE to $4500 \mathrm{~kW} \pm 5 \%$, the load that bounds the maximum emergency service lodd for each engine [see, e.g., SCE's (K. F. Baskin) letter dated February 14, 1985, to NRC (H. R. Denton)]. This load corresponds to an engine BMEP of 116 psig (ibid.)

\subsubsection{Design Guidelines}

The recomendations in the Diesel engine Manufacturers Association (DEMA) Standard Practices (1972) were used as a basis for the crankshaft evaluations performed by the Owners' Group and the reviews performed by PNL. The OEMA recomendations for torsional crankshaft stresses are sumarized in Section 4.6 .2 of this report, and are compared with the results of analyses and tests of the 20-cylinder engines at San Onofre in several sections that follow. 


\subsubsection{Operating History}

\subsubsection{San Onofre}

The operating history of the two 20-cylinder diesel generators at San Onofre, designated DG1 and DG2, is summarized by Failure Analysis Associates (FaAA) in report FaAA-84-12-13 (April 1985). Prior to nondestructive examinations of the crankshafts during July through October 1984, the two engines had experienced the number of starts and accumulated the operating hours summarized below.

\begin{tabular}{|c|c|c|}
\hline \multirow[b]{2}{*}{ Operation } & \multicolumn{2}{|c|}{ Engine } \\
\hline & $\overline{D G 1}$ & $D \overline{G 2}$ \\
\hline Number of starts & 740 & 450 \\
\hline Total hours & 725 & 550 \\
\hline
\end{tabular}

The difference in the number of starts for the two units is due to the appraximately 300 fast starts that TDI performed as part of "lead engine" tests on DGI while that unit was at TDI's Oakland plant.

Certain main journal ail holes in the crankshafts of the two units were found by eddy-current inspection to have fatigue cracks generally oriented along 45-degree planes. The cracks in the DG1 crankshaft were much more severe than those in the DG2 crankshaft.

\subsubsection{Non-Nuclear Installations}

In its investigation of non-nuclear operating experience with TDI 20-cylinder diesel generators, the Owners' Group found (transcript of meeting with NRC and PNL on October 22, 1984) only two installations other than San Onofre where these units are used in the United States. A municipal utility in Homestead, Florida, operates one, and a municipal utility in Princeton, Illinois, operates another. The units at both installations are rated at $8750 \mathrm{~kW}$.

According to information obtained by the Owners' Group, the diesel generators at Homestead and Princeton have been operated well over 17,000 hours and 15,000 hours, respectively. Each engine has accumulated several thousand 
starts (for Homestead, the estimate is about 4000 starts). Both engines are typically brought up to operating speed in 20 seconds (versus 6 seconds at San Onofre during a fast start). No problems have been experienced with the crankshafts in these engines.

Following the discovery of cracks in the oil holes of certain main bearing journals at San Onofre, the Owners' Group made arrangenents to perform a limited examination of the crankshafts at both Homestead and Princeton. A fluorescent liquid penetrant examination of the oil hole through each engine's No. 9 main bearing journal (the journal subject to the highest torsional stresses) revealed no evidence of cracking.

Although the engines used at San Onofre, Homestead, and Princeton are of the same type, the generators used at the latter two installations are larger than the generators used at San Onofre $(8750 \mathrm{~kW}$ versus $6000 \mathrm{~kW})$. Thus, the torsional mass-elastic systems differ. The mechanical properties of the crankshafts also differ, but the quantitative differences have not been reported.

\subsubsection{Owners' Group Evaluation}

Fatlure Analysis Associates, a consultant to the Owners' Group, evaluated the adequacy of the crankshafts for the engines at San Onofre. One aspect of this effort involved nondestructive examinations that revealed cracks in several main journal oil holes. Other aspects inciuded torsional analyses of crankshaft stresses for steady-state operation and for startup and coastdown transients, torsiograph tests of the OGI unit under steady-state and transient conditions, and a fracture mechanics analysis to evaluate crack initiation and propagation.

\subsubsection{Nondestructive Examinations}

Following the hours of operation and the number of starts summarized in Section 4.8.3.1 above, the crankshaft of the DGl engine was found to contain numerous cracks in certain main journal oil holes. Similar but less severe cracks were also found in the crankshaft of the UG2 engine. Included in report FaAA-84-12-14 (April 1985) is a discussion of these cracks and the action taken 
to remove them. Additional information on crankshaft examinations and corrective action taken is included in the transcript of the meeting between the Owners' Group and NRC on October 22, 1984, and in the design review/quality revalidation report on the San Onofre engines that was prepared by the Owners' Group and submitted to NRC ( $\mathrm{J}$. Zwolinski) as an enclosure to an SCE (M. Medford) letter of September 3, 1985.

As discussed in FaAA-84-12-14 (April 1985), the oil-hole cracks in the main journals of both crankshafts were generally oriented along 45-degree planes (i.e., 45, 135, 225, and 315 degrees) to the axis of rotation. This orientation is evidence that the cracks were induced by torsional stresses rather than by bending stresses. The presence of cracks in adjoining quadrants (e.g., 45 and 135 degrees) is evidence of sign reversals in the torsional stresses, and indicates that the cracks were induced by vibration rather than by overload.

Metallographic replicas taken in cracked regions of the DGI crankshaft show closely-spaced parallel cracks in a number of locations. There is no evidence of large plastic deformation that might be associated with fatigue resulting from very few cycles. The cracks shown on the replicas are primarily transgranular, without any preferred orientation relative to the metallurgical microstructure.

The main journal oil holes found to be cracked in the DGI and DG2 crankshafts and the actions taken to remove the cracks are summarized by crankshaft as follows:

- DGl crankshaft - FaAA performed eddy-current examinations of the oil holes in main journals No. 3, 4, 8, 9, and 10, and found cracks in the latter three holes. SCE examined the oil hole of main journal No. 11 using liquid penetrant, and found that it also was cracked. Cracks existed at both ends of the oil holes in main journals No. 9 and 10. The oil hole in main journal No. 9 contained the longest cracks, several of which were over 3 inches long by up to $1 / 8$ inch deep. It also contained the deepest crack, which was between $1 / 4$ and $9 / 32$ inch in depth. 
The cracks in the $0 i 1$ holes of journals No. 9 and 10 were removed by increasing the hole diameter in 1/8-inch increments until no recordable eddy-current indications remained. Each hole was drilled in a series of passes with coring drill bits of increasing diameter. After each pass, the hole was reinspected to map changes in crack size. The holes in main journals No. 9 and 10 were enlarged in this manner from an initial diameter of $15 / 16$ inch to final diameters of 1-1/2 inches and 1-5/16 inches, respectively. Subsequent to the drilling, the oil holes were re-radiused at the intersection with each journal surface, polished, and reinspected with fluorescent dye penetrant to confirm the reinoval of the cracks. The cracks found in the oil holes of journals No. 8 and 11 were sufficiently short and shallow to permit removal by grinding and polishing. The reworked areas were examined using fluorescent dye penetrant to confirm the removal of the cracks.

- 0G2 crankshaft - FaAA performed eddy-current inspections of the 011 holes in main bearing journals No. 8, 9, and, 10 and found shallow indications on one end only of the oil hole in journal No. 9. These indications were polished out, and the hole was reinspected in the manner noted above.

FaAA investigated the effect on torsional stress of enlarging the oil holes in main journals No. 9 and 10 of the DGl crankshaft, and concluded that the effect is insignificant. The change in the stress concentration factor for the gross section of the shaft is influenced by the combined effect of two factors: 1) the reduction in the polar moment of inertia of the section and 2) the change in the stress concentration factor for the net section of the shaft. The stress concentration factor for the gross section stays essentially the same as the oil hole is increased from $15 / 16$ inch to $1-1 / 2$ inches in diameter; therefore, the change in torsional stress is negligible.

4.8.4.2 Nominal Torsional Stresses for Steady-State Operation

FaAA's evaluation of crankshaft torsional stresses for full-load engine operation at rated speed and at $\pm 5 \%$ of rated speed is presented in FaAA-84-6-54 
(June 1984). FaAA first reviewed a torsional critical speed analysis performed by TDI for single orders of vibration, and then performed a dynamic torsional analysis using modal superposition to determine the combined response of the crankshaft for the first 24 orders of vibration. All 13 modes of the lumped inertia and torsional spring model of the crankshaft were considered in FaAA's analysis. In calculating the harmonic loading on the crankshaft, FaAA used gas pressure loading for engine operation at $8750 \mathrm{~kW}$ rather than for operation at the actual rated load of $6000 \mathrm{~kW}$. This contributed to a conservative estimate of crankshaft stresses.

FaAA's conclusions from these analyses are as follows:

- TDI's calculations show that the maximum single-order nominal shear stress is $408 \mathrm{psi}$, which is well within the DEMA-recommended limit of 5000 psi for a single order.

- The highest nominal shear stress amplitudes for FaAA's summation of 24 orders at an engine load of $3750 \mathrm{kh}$ are as follows for rated speed and $\pm 5 \%$ of rated speed:

\begin{tabular}{|c|c|c|c|c|}
\hline & \multicolumn{3}{|c|}{ Engine Speed } & \multirow{2}{*}{$\begin{array}{c}\text { DEMA } \\
\text { allowable }\end{array}$} \\
\hline & $427.5 \mathrm{rpm}$ & $450 \mathrm{rpm}$ & $472.5 \mathrm{rpm}$ & \\
\hline $\begin{array}{l}\text { ax. combined response } \\
\text { between cyls. } 8 \text { and } 9 \text { ) }\end{array}$ & $3991 \mathrm{psi}$ & 4018 psj & 4436 psi & 7000 psi \\
\hline
\end{tabular}

FaAA's torsiograph test of the $D G 1$ unit to determine crankshaft responses under steady-state conditions is discussed in report FaAA 84-10-9 dated October 12, 1984. FaAA found that the first and second naturai frequencies of the torsional system agree within $1 \%$ of TOI's predicted values. Further, the nominal shear stress amplitudes estimated by FaAA from the measured amplitudes of free-end vibration at $6000 \mathrm{~kW}$ are within the values predicted from FaAA's dynamic torsional analysis.

\subsubsection{Torsjograph Testing Under Transient Conditions}

As reported in FaAA-84-12-14 (April 1985), FaAA measured the angular vibration of the front end of the crankshaft under conditions of fast start, slow start, and coastdown. In addition to the torsiograph, the instrumentation 
for these tests included two accelerometers used to obtain an independent measure of crankshaft vibration. These accelerometers were mounted on a slip ring assembly attached to the torsiograph. Thus, crankshaft torsional responses could be measured even if the limits of the torsiograph were exceeded during the transient tests.

Pressure transducers were mounted on the bleed ports of cylinder No. 8 left bank and cylinder No. 8 right bank, to monitor firing pressures throughout the tests.

Key results of these tests include the following:

- coastdown - For the coastdowns monitored (four examples are cited in FaAA-84-12-14), the crankshaft response was repeatable in both shape and magnitude. The response is governed by the $4.5,5$, and 5.5 orders of vibration, which occur at 264, 240, and $217 \mathrm{rpm}$, respectively. The maximum peak-to-peak amplitude was 3.2 degrees, measured at the 4.5-order critical speed of 264 rpm. A similar response was found at the 5th-order critical speed. The length of time for a typical coastdown is approximately 70 seconds.

- slow start - With a maximum peak-to-peak amplitude of 3.4 degrees, which occurred at the 5th-order critical speed of $240 \mathrm{rpm}$, the crankshaft response during a 24-second slow start was found to be similar to the response during a coastdown.

- fast start - Crankshaft responses measured during three 6-second fast starts varied substantially with the initial position of the crankshaft. When the piston in cylinder No. 8 right bank was inttially at bottom dead center of its compression stroke (designated fast start "F" in FaAA-84-12-14), the maximum measured peak-to-peak amplitude during startup was 2.0 degrees. However, the maximum peak-to-peak amplitude was 5.0 degrees when this same piston was initially at bottom dead center of its exhaust stroke (fast start "D"). The latter response was obtained from accelerometer data, because the torsiograph signal for this response went well beyond the range of 
the instrument. These responses differ by a factor of 2.5 for starting positions that differ by 360 degrees of crankshaft rotation.

4.8.4.4 Torsional Analysis of Crankshaft for Startup and Coastdown Iransients

FaAA developed an analytical model for predicting crankshaft responses and corresponding torsional crankshaft stresses under transient conditions, and used the model in an analysis that encompassed the test conditions summarized above and several transient conditions other than those tested. The model and the analysis are discussed in FaAA-84-12-14 (April 1985).

To determine the time-dependent response of the crankshaft, FaAA used modal superposition with step-by-step response calculations. Pressure loads used in the analysis were calculated from cylinder pressures measured during the transient tests.

4.8.4.4.1 Coastdown Analys is. The coastdown was modeled as a 70-5econd transient during which the engine speed decreases lineariy from 450 rpm to $0 \mathrm{rpm}$, with a peak cylinder pressure of $450 \mathrm{psi}$ (the peak measured in the coastdown tests). The time-step algorithm was executed using a step size of 3 degrees of crankshaft rotation.

With a damping of 0.6 percent of critical modal damping in each mode, the calculated crankshaft response agrees well with the measured crankshaft response as a function of engine speed during the coastdown. The calculated value of the maximum peax-to-peak amplitude is 3.25 degrees, which is essentially the same as the measured value of 3.2 degrees.

The maximum amplitude of nominal torsional stress predicted in the analysis is $11.86 \mathrm{ksi}$, in main journal No. 10. The torsional stresses in main journals No. 8 through 12 are predicted to be nearly as high.

4.8.4.4.2 Startup Analysis. The startup analysis addressed the effects on crankshaft response of initial crankshaft position and the time taken to bring the engine to operating speed. Cylinder pressures assumed for the analysis correspond to the pressure-time trace recorded in cylinder No. 8 left 
bank during the startup that resulted in the largest measured crankshaft response (fast start "D"). A uniform time step of 0.00074 second was used in the time-step algorithm.

The starting conditions analyzed and the results obtained for these conditions included the following:

- fast start "F" - Crankshaft responses and corresponding stresses were analyzed for the conditions used in fast start "F" of the torsiograph tests. The predicted and measured peak-to-peak responses are similar as a function of startup time. In particular, the calculated value of the maximum response is 2.0 degrees peak-to-peak, which is the same as the peak-to-peak value obtained from the test data.

- fast start "D" - For the conditions used in fast start " 0 " of the torsiograph tests, the predicted crankshaft responses also agree closely with the measured responses as a function of startup time. The calculated value of the maximum peak-to-peak vibration is 5.1 degrees, which is in excellent agreement with the value of 5.0 degrees obtained from accelerometer data.

- effect of initial crankshaft position on response - To further explore the effect of initial crankshaft position on crankshaft torsional vibration during a fast start, the response as a function of time was analyzed for eight initial positions in addition to the two just discussed. With a uniform spacing of 72 degrees of crankshaft rotation, the 10 positions cover two revolutions (720 degrees) of the crankshaft. The engine was assumed to be brought to rated speed in 6 seconds from each of the initial positions. Key results of this analysis include the following:

- The minimum response occurs when the crankshaft orientation is as described above for fast start " $F$." The maximum amplitude of nominal torsional stress predicted for this start is $11.91 \mathrm{ksi}$, in main journal No. 10 (Table 4-4 of FaAA-84-12-14). The torsional stresses in main journals No. $8,9,11$, and 12 are nearly as high. 
- The highest level of vibration (5.6 degrees peak-to-peak) occurs when the piston in cylinder No. 10 right bank is initially at bottom dead center of its exhaust stroke. The maximum predicted amplitude of nominal torsional stress is $23.82 \mathrm{ksi}$, in main journals No. 11 and 12 (Table 4-5 of FaAA-84-12-14). The torsional stresses in journals No. 8,9 , and 10 are nearly as high.

- effect of duration of fast start on response - To explore the effect on crankshaft response of varying the duration of the fast start, the analysis described above for a 6-second start was repeated for start durations of 5 and 7 seconds. All 10 initial erankshaft positions were considered for each of the three startup times, giving a total of 30 cases. Because cylinder pressure measurements for 5- and 7-second starts were not available, a single full-load pressure curve was used and timed to achieve a linear increase in speed from 0 to $450 \mathrm{rpm}$ for the cases analyzed. The full-load pressure curve used in the analysis may differ significantly from actual pressures during startup; hence, absolute values of predicted peak-to-peak vibrations are not meaningful. However, FaAA noted that a comparison of relative peak-to-peak vibrations for the various cases provides useful insight into the effect of startup duration on crankshaft response. As shown in Figure 4-6 of FaAA 84-12-14, the highest peak-to-peak vibration is independent of startup duration for the range of startup durations considered in the analysis. However, crankshaft response is strongly influenced by the interrelated effects of startup duration and initial crankshaft position as illustrated by the following observations:

- The initial crankshaft position that produces the highest vibration is highly dependent on the startup duration. For example, the response is a minimum for a 6-second start but a maximum for a 5- or 7-second start when the piston in cylinder No. 3 right bank is initially at bottom dead center of its exhaust stroke. 
- To control fast-start response when an initial starting position is chosen, the duration of the start must be kept within \pm 0.5 second.

\subsubsection{Fracture Mechanics Analysis}

FaAA analyzed crack initiation and growth in the oil holes of the main journals, taking into consideration the nominal stresses calculated in the crankshaft torsional analysis and the stress concentration around the oil holes. The results of this analysis provide a basis for predicting the effects of alternative strategies to control startup stresses. The models used in the analysis, the results obtained, and FaAA's recommendations for crankshaft surveillance are discussed in FaAA-84-12-14.

4.8.4.5.1 Stress Concentration at 0il Holes. To determine the stress distribution in the vicinity of the oil holes in main bearing journals No. 2 through 11 and the holes of the same diameter but different depth and blend radius in journal No. 12, FaAA used a finite element model of the geometry with axial syminetry about the hole centerline. This analysis predicts that the maximum principal stress is approximately 4 times the nominal shear stress on the oil hole surface in the blend radius of journais No. 2 through 11 . The maximum predicted stress concentration in the blend radius of the holes in journal No. 12 is approximately the same. Thus, FaAA's analysis of crack initiation and propagation did not distinguish between the geometries of these noles.

4.8.4.5.2 Crack Initiation. The stress cycles for the most severe fast start (piston in cylinder No. 10 right bank initially at bottoin dead center of its exhaust stroke) and for coastdown were compared on a Goodman diagram with the $10^{7}$-cycle endurance limit for the crankshaft material. Many of the stress cycles during each start-stop are well beyond the endurance limit, thus indicating that crack initiation will occur.

Using a linear cumulative damage approach and low-cycle fatigue data for materials similar to the crankshaft material, FaAA estimated that 95 startstops on main journal No. 10 will produce a cumulative damage of 0.8 . FaAA noted that, although cracks are likely to initiate in the more highly stressed 
journals, the number of start-stops at which crack initiation will occur cannot be estimated with a high degree of certainty because of the considerable scatter in low-cycle fatigue data.

4.8.4.5.3 Crack Propagation. FaAA used the BIGIF fracture mechanics code in conjunction with two geometric models to predict crack propagation rates. One model includes the journal surface, the oil hole surface, and the blend radius, and allows a three-degree-of-freedom elliptical-shaped crack to be analyzed at any point on the surface. A bivariate stress field can be used with this model to describe the stresses in the journal near the oil hole.

The second model includes just the oil hole surface, and allows a onedegree-of-freedom edge crack to be analyzed in a univariate stress field. This model is more conservative than the first model because it will predict higher propagation rates. It was used because the appearance of long cracks in certain oil holes of the DGI crankshaft suggests that a univariate stress field would represent a realistic model.

Four different starting conditions were considered as part of a loading sequence that included 2 hours of steady-state operation at full load (6000 kW) followed by a coastdown. The four conditions encompassed the fast start from the initial crankshaft position that produces the least vibration, the fast start from the initial crankshaft position that produces the most vibration, a fast start representing the average response of all ten initial crankshaft positions analyzed (Section 4.8.4.4.2 above), and a slow start assumed to consist of the same stress cycles as a coastdown.

FaAA's observations and conclusions from this analys is include:

- Once a crack is large enough for steady-state stresses to contribute to its growth, the crack propagates at a rapid rate. For the threedegree-of-freedom crack model, steady-state stresses contribute to crack growth when the crack reaches a depth of 50 mils. The corresponding depth for the one-degree-of-freedon crack model is $18 \mathrm{mits}$.

- Crack size versus load history predicted with the onedegree-of-freedon model correlates well with field experience at San Onofre. 
- The "best case" fast start (from the initial crankshaft position that produces the least vibration) is less damaging than a slow start.

- The "worst case" fast start promotes the fastest crack growth.

- The fastest crack growth is predicted to occur in main journals No. $9,10,11$, and 12. As discussed in Section 4.8 .4 .1 of this report, main journals No. $g$ and 10 were found to have the largest cracks at San Onofre. FaAA noted that main journal No. 11 on DG2 and main journal No. 12 on DGI and DG2 were not included in the inspection that revealed these cracks.

4.8.4.5.4. Effect of Residual Stresses and Martensite on Growth. FaAA commented on metallurgical considerations that could result in residual stresses on the outer crankshaft surfaces, even though the forgings for TDI crankshafts are normalized and annealed. FaAA estimates that tensile residual stresses of up to $20 \mathrm{ksi}$ could exist in an oil hole, and that polishing the hole could produce higher residual stresses over a very thin layer near the surface of the hole. Results of an analysis performed by FaAA (Figures 5.11 and 5.12 of FaAA-84-12-14) indicate that residual stresses would result in significantly faster crack growth.

FaAA also noted that if an oil hole were ground at elevated temperatures, a thin layer (perhaps 5 mils deep) of martensite could possibly form. This material, according to FaAA, has poorer crack growth properties than the ferrite and pearlite that would otherwise be present. As shown in figures 5.11 and 5.12 of the FaAA report, the presence of inartensite, with or without residual stresses, would also result in significantly faster crack growth.

4.8.4.5.5 Conclusions and Recommendations. FaAA's conclusions and recommendations from the fracture mechanics analysis include:

- Stress cycles during startup (both fast and slow) and coastdown are above the endurance limit of the crankshafts.

- Based on the more conservative of the two crack models considered in the analysis, cracks less than $18 \mathrm{mils}$ deep will not propagate during steady-state operation. 
- If the nondestructive examination technique used to inspect oil hole regions is sensitive enough to detect 10 -mil-deep cracks, then the number of start-stops to propagate a crack from $10 \mathrm{mils}$ to a depth of $18 \mathrm{mils}$ represents the effective life of the crankshaft. (The $1 \mathrm{ife}$ may be extended by crack removal.)

- Based on FaAA's analysis of crack propagation, the crankshafts should be inspected at each refueling outage so that the inspection interval is approximately 50 start-stops.

- When cracks are detected they should be removed.

- Initially, main journals No. 4 through 12 should be inspected. A smaller number of journals could be included in future inspections so long as no cracks are found.

\subsubsection{PNL's Review}

The following PNL consultants participated in various aspects of PNL's review of the crankshafts for the TDI 20-cylinder, DSRV-4 series engines installed at San Onofre:

- 5. H. Bush, Review and Synthesis Associates

- H. Engja, Norwegian Marine Technology Research Institute

- H. M. Hardy, consulting engineer

- P. J. Louzecky, Engineered Applications Corporation

- the late A. Sarsten, Norwegian Institute of Technology

- T. W. Spaetgens, consulting vibration engineer

- H. Valland, Norwegian Marine Technology Research Institute.

In addition, J. C. Spanner and R. H. Ferris of PNL's Nondestructive Testing Section visited San Onofre to observe certain nondestructive examinations of the crankshafts and to review the procedures used.

PNL's review of the crankshafts for the $20-c y 1$ inder engines encompassed

- reviews of the reports referenced in Section 4.8 .4 regarding actions taken by the Owners' Group to evaluate the adequacy of the crankshafts 
- independent analyses performed by PNL's consultants to provide a basis for comparison with torsional stresses computed for the Owners' Group by FaAA

- reviews performed in the preparation of PNL technical evaluation report PNL-5304 (November 1984), which evaluated the status of the two TDI diesel generators in support of NRC's review of SCE's returnto-service plan for San Onofre Unit 1 - The crankshaft was one of the components reviewed. PNL representatives visited San Onofre in August 1984 and in October 1984 to observe ongoing nondestructive examinations of crankshaft journals in the DG1 engine and DG2 engine, respectively, and to review the procedures used in the examinations.

The results of several analyses performed by PNL's consultants are summarized in Section 4.8.5.1 and compared with corresponding results of investigations by the Owners' Group. Other aspects of the Owners' Group investigation reviewed in this report include torsiograph test results (Section 4.8.5.2), predicted stresses during startup and coastdown (Section 4.8.5.3), and predicted crack propagation rates (Section 4.8.5.4). Alternative approaches to reduce crankshaft torsional stresses during startup and coastdown are discussed in Section 4.8.5.5. Finally, PNL's conclusions and recommendations on the basis of all of the information reviewed are presented in Section 4.8.5.6.

\subsubsection{Analyses Performed by PNL's Consultants}

4.8.5.1.1 Nominal Torsional Stresses for Full-Load Operation. Prof. Sarsten used his program COMHOL2 (COMplex HOLzer version 2) to compute crankshaft torsional stresses for full-load engine operation at rated speed and over the range of $\pm 5 \%$ of rated speed, for single orders and for the sum of the first 24 orders of vibration. As in FaAA's torsional analysis for full-load operation (discussed in Section 4.8.4.2 of this report), Prof. Sarsten used gas pressure loading for engine operation at $8750 \mathrm{~kW}$ (225 BMEP) rather than for operation at the actual rated load of $6000 \mathrm{~kW}$. This contributes to a conservative estimate of crankshaft stresses.

The results of Prof. Sarsten's analysis are summarized in Figure 4.8.1 for single orders of vibration, and in Figure 4.8 .2 for the sum of 24 orders of 


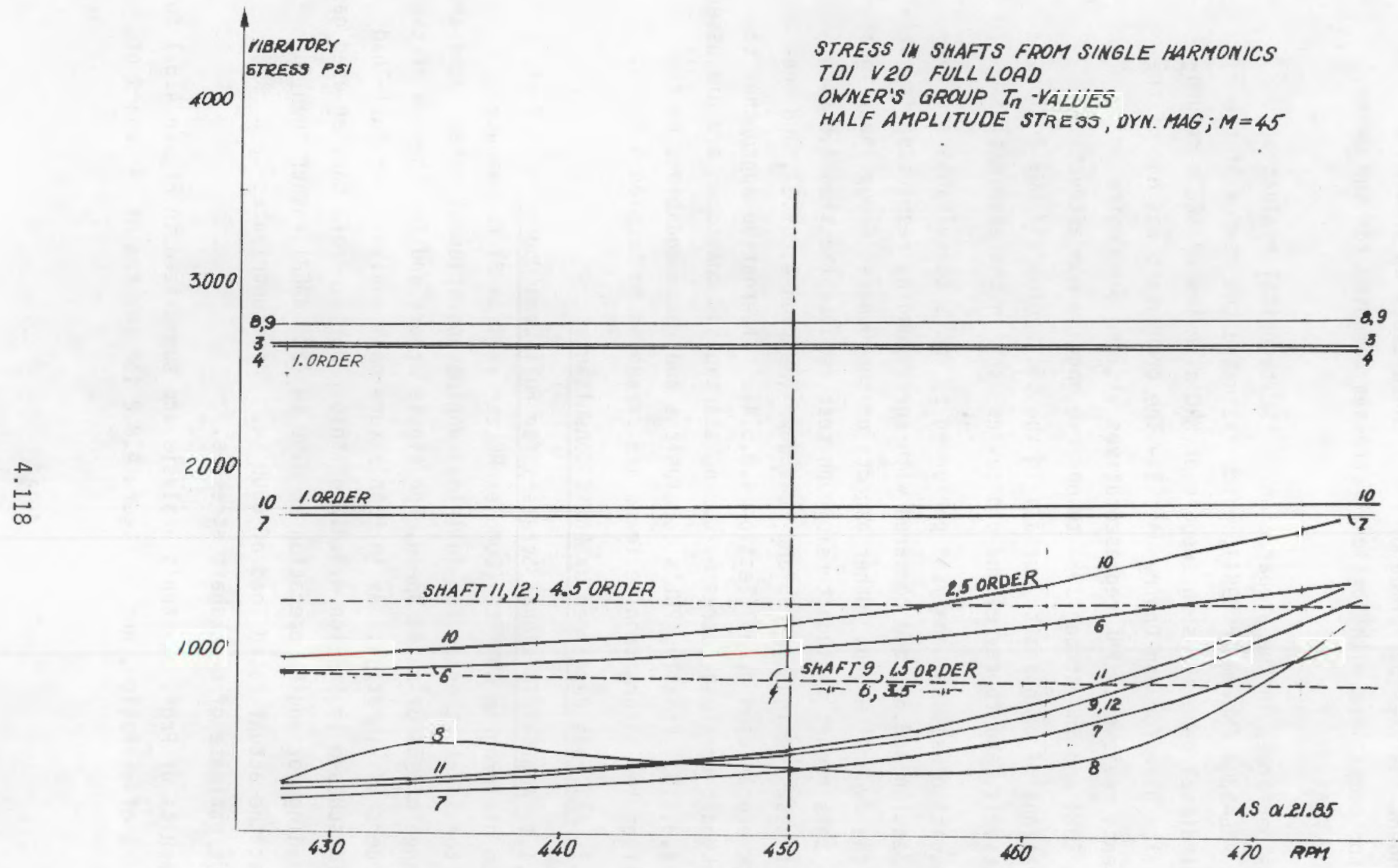

FIGURE 4.8.1. Torsional Vibratory Stresses for Single Orders in TDI DSRV-20-4 Crankshaft at Full Load 


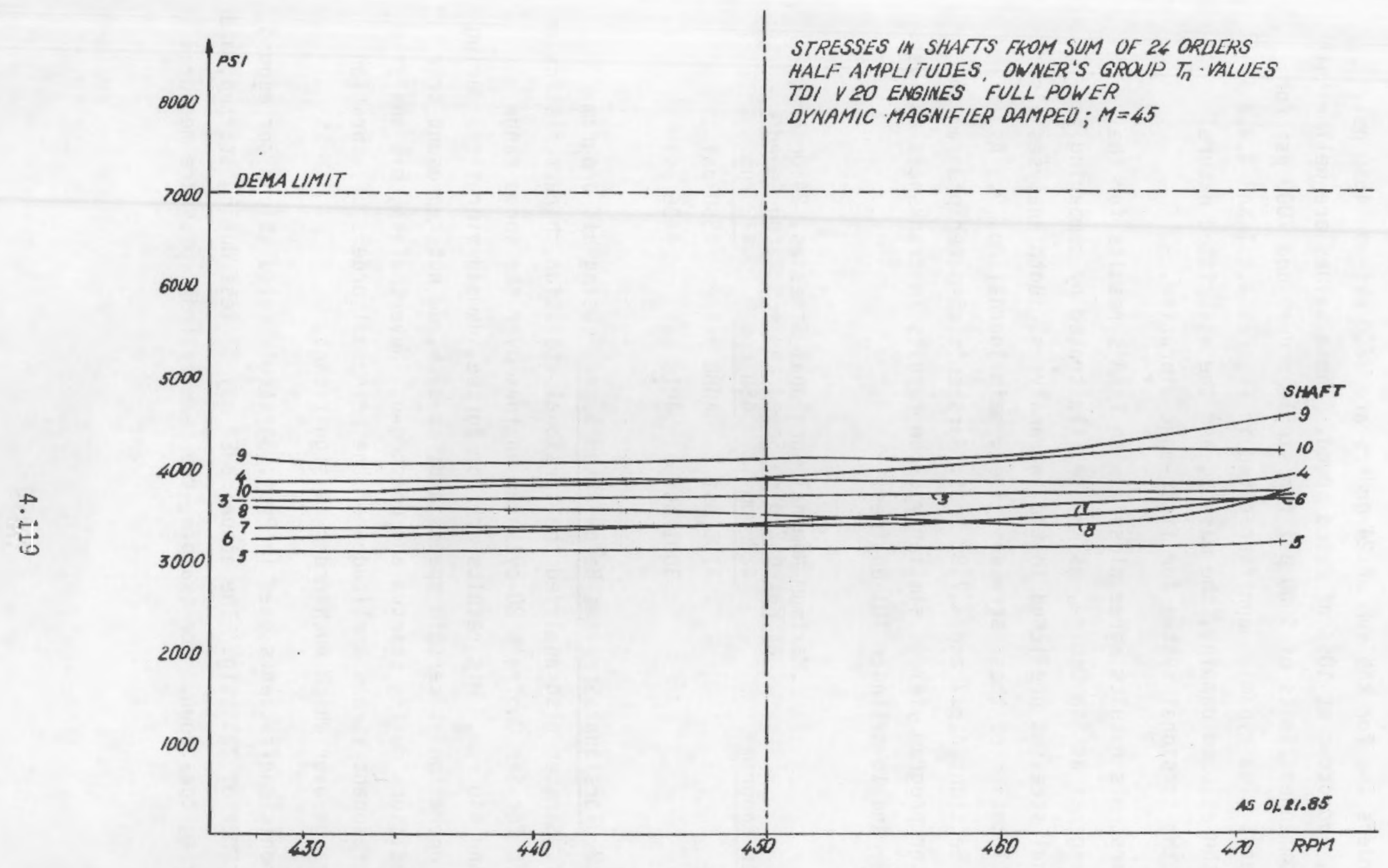

FIGURE 4.8.2. Torsional Vibratory Stresses for Sum of 24 0rders in TDI DSRV-20-4 Crankshaft at Full Load 
vibration. As shown in these figures, the maximum nominal torsional stresses for single orders and for the sum of 24 orders are 2800 psi and 4550 psi, respectively, and occur at $105 \%$ of rated speed. These values are well within the DEMA-recommended limits of 5000 psi for single orders and 7000 psi for combined orders. The dynamic magnifier cited in Figures 4.8 .1 and 4.8 .2 is a function of the assumed damping, the masses, and the associated natural frequency of the torsional system for first-mode vibration.

Prof. Sarsten's results agree closely with FaAA's results for the 20-cylinder engines at San Onofre, as may be illustrated by comparing the maximum nominal stresses predicted in the two analyses. Both analyses also agree on the location of these stresses, i.e., main journal No.9. As discussed in Sections 4.6.7 and 4.7.8, Prof. Sarsten's computer program and FaAA's computer program yielded similarly close results in crankshaft analyses for certain 8- and 16-cylinder TDI engines.

\begin{tabular}{llll} 
& \multicolumn{3}{c}{$\begin{array}{l}\text { Maximum Nominal Torsional Stresses, } 24 \text { Orders, } \\
\text { at Rated Engine Speed and } \pm 5 \% \text { Rated Speed }\end{array}$} \\
\cline { 2 - 3 } Computer Program & $\frac{428 \text { rpm }}{4100 \text { psi }}$ & $\frac{450 \text { rpm }}{4080 \text { psi }}$ & $\frac{472 \text { rpm }}{4550 \text { psi }}$ \\
\hline COMHOL2 & 3001 psi & 4018 psi & 4436 psi
\end{tabular}

4.8.5.1.2 Torsional Stresses Below Rated Speed. Using his program COMHOL2, Prof. Sarsten also analyzed the torsional vibration characteristics of the crankshaft for San Onofre's 20-cylinder engines over the speed range between 100 and $440 \mathrm{rpm}$. His results are for forced, damped vibrations during steady-state operation at certain speeds and, as such, do not represent true transient conditions during startup and coastdown. Nevertheless, his analysis predicts the resonant stress amplitudes of the principal orders of vibration and the rpm range over which each order is significant.

The harmonic coefficients used in Prof. Sarsten's calculations correspond to an engine BMEP of 225 psig. The actual BMEP may be less during startup, and much less during coastdown. For example, the peak cylinder pressure measured 
during FaAA's torsiograph tests was 1340 psi, for the fast start that produced the highest crankshaft torsional response (start "F" discussed in Section 4.8.4.3, above). The corresponding BMEP is under 210 psig.

The results of Prof. Sarsten's analysis are summarized in Figures 4.8 .3 through 4.8.5. Figure 4.8 .3 shows the amplitude of free-end vibration of the crankshaft as a function of engine rpm. Figure 4.8 .4 shows nominal torsional vibratory stresses for single orders of vibration, plotted as a function of engine rpm. Figure 4.8 .5 shows nominal torsional vibratory stresses for the sum of 24 orders of vibration, also as a function of engine rpin. As noted earlier, the dynamic magnifier cited in these three graphs is a function of the assumed damping, the masses, and the associated natural frequency of the torsional system for first-mode vibration.

Prof. Sarsten made the following observations on the results summarized in Figures 4.8 .3 through 4.8 .5 :

- The vibratory conditions corresponding to the resonant peaks for the $4.5,5$, and 5.5 orders of vibration form a band of high stresses that extends over a significant portion of the speed range through which the engine passes during startup and coastdown. Because of the close spacing of these peaks, the large vibrations initiated by the first will still be "ringing" when the crankshaft enters the speed range of the second, and the stresses will once again be augmented as the crankshaft passes from the second to the third.

- No responses are shown for the 4th and 12th orders. The excitations of these orders from one bank of the $V$ engine cancel the excitations from the other bank, assuming the cylinders are evenly balanced and disregarding the effect of the articulated connecting rods on piston motion and engine timing.

- Main bearing journals No. 9 and 10 are exposed to the highest torsional stresses. Journals No. 8,11 , and 12 are also highly loaded. 


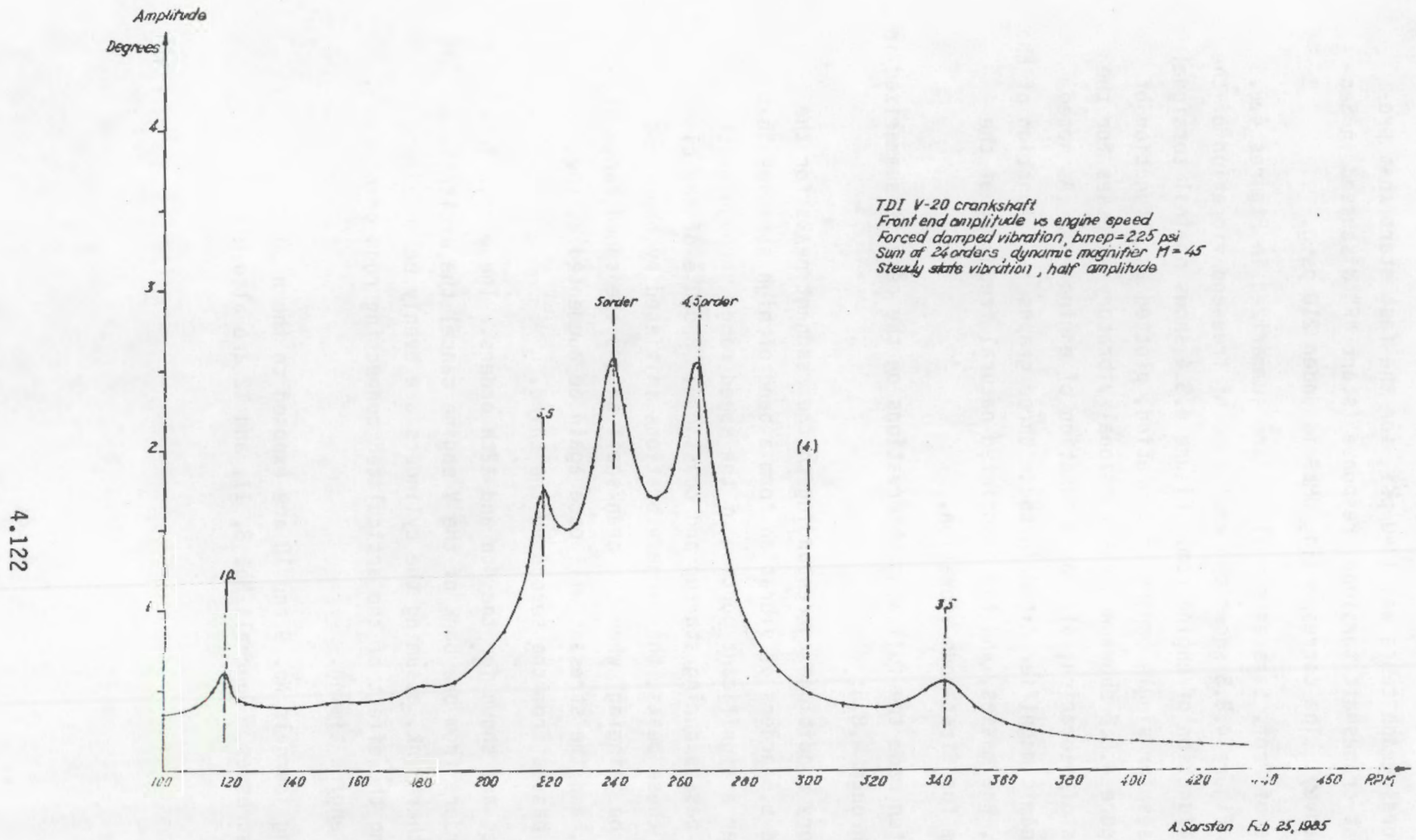

FIGURE 4.8.3. Variation of Free-End Crankshaft Vibration with Engine RPM for Sum of 24 orders in TDI DSRV-20-4 Crankshaft 


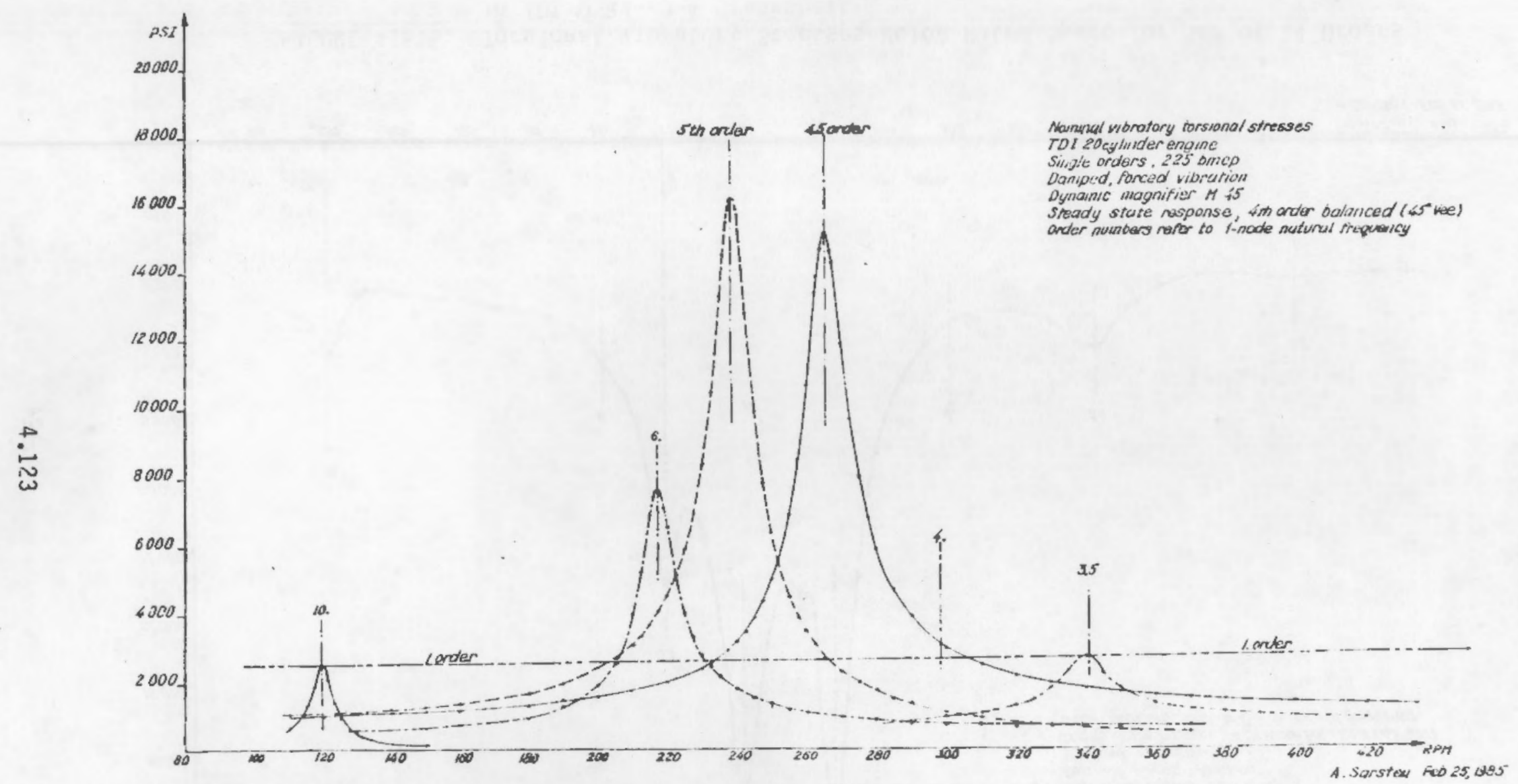

FIGURE 4.8.4. Torsional Vibratory Stresses Below Rated Speed for Single Orders in TDI DSRV-20-4 Crankshaft 


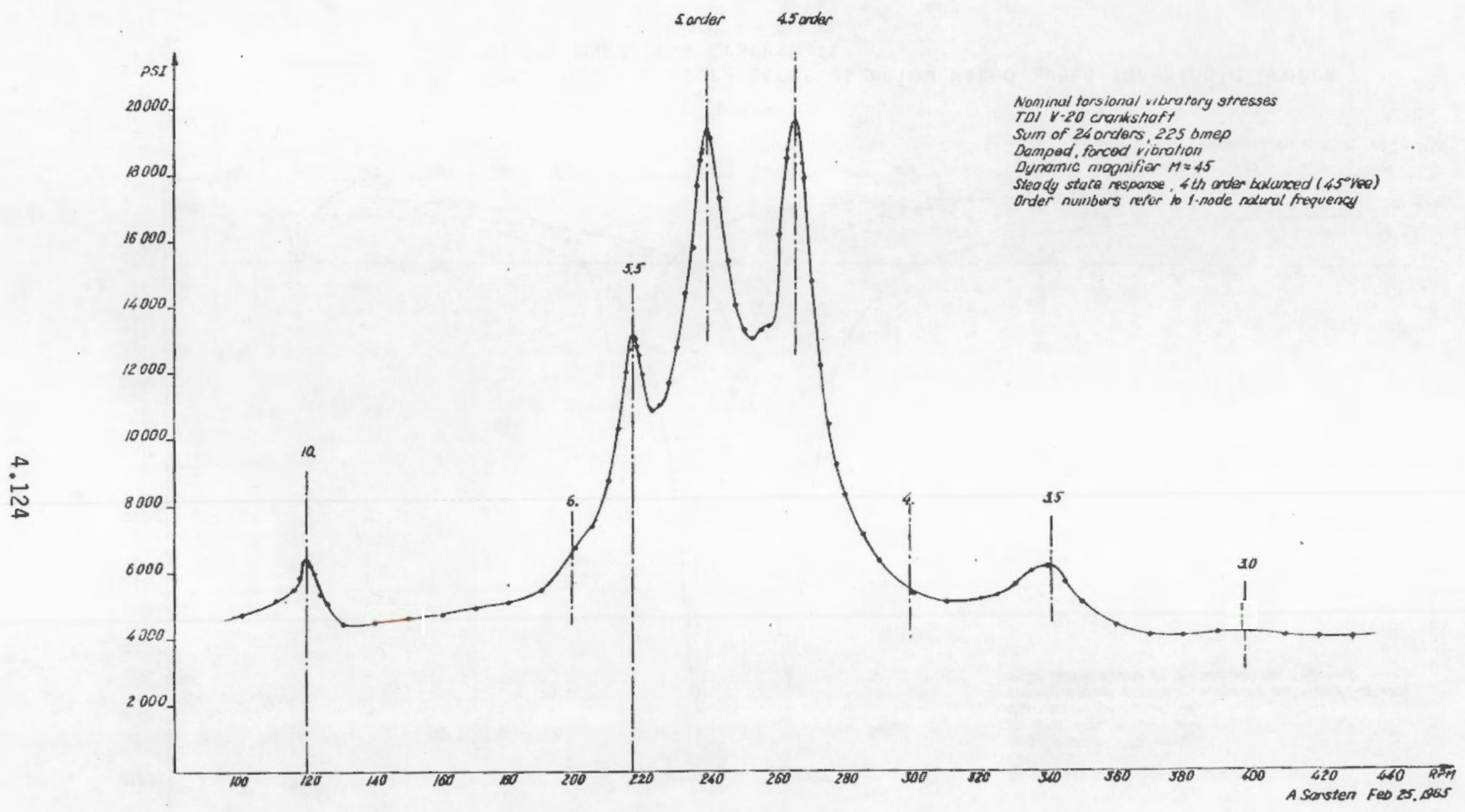

FIGURE 4.8.5. Torsional Vibratory Stresses Below Rated Speed for Sum of 24 Orders in TDI DSRV-20-4 Crankshaft 
- A slow start would appear to be preferable to a fast start for accelerating through the criticals, for two reasons. First, the peak stresses would be shifted downward because the gas pressure loading would be lower. The advantage of lower stresses should outweigh the disadvantage of the increased number of cycles in the critical speed range. Second, the vibration initiated by one critical would be less likely to augment the vibration initiated by a neighboring critical.

- A transient torsional analysis or an experimental study would be required to quantify the possible benefits of slow starts. A transient analysis might also yield information on a starting position and possibly a speed sequence that would reduce crankshaft stresses when accelerating through the critical speed range.

PNL notes that Prof. Sarsten's predictions of the most significant orders of vibration and the resonant speeds of those orders agree with the results of FaAA's transient torsional analysis and transient torsiograph tests. Furthermore, FaAA and Prof. Sarsten concluded independently that main journals No. 9 and 10 are exposed to the highest torsional stresses during startup and coastdown, and that journals No. 8,11 , and 12 are also highly loaded.

The stresses computed by Prof. Sarsten for steady-state operation at various speeds below rated speed agree qualitatively with the results of FaAA's transient analysis. Close quantitative agreement would not be expected because Prof. Sarsten's analysis does not represent actual transient conditions during startup and coastdown. Another factor contributing to the differences is Prof. Sarsten's assumed cylinder pressure loading, which is substantially higher than the actual loading measured by FaAA.

It is also pertinent to note the circumstances under which Prof. Sarsten performed his analysis. He had been informed that cracks were found in the oil holes of certain main journals in the engines at San Onofre, but he did not have the inspection results showing the specific journals in which the cracks were located. Further, the results of FaAA's transient analysis and transient torsiograph tests had not yet been reported. Thus, Prof. Sarsten and FaAA arrived at confirmatory conclusions not only by independent methods, but without knowledge of the other's work. 
Prof. Sarsten transmitted the results of his crankshaft analysis for the engines at San Onofre one day before his untimely death. His crankshaft analysis for the 16-cylinder engines was completed at about the same time. The curves summarizing his results for these engines have not been typeset but are reproduced in this report exactly as he drew then, in memory of his contributions.

4.8.5.1.3 Stresses with Misfiring of Une Cylinder. Prof. Sarsten had observed that the 2.5-order response to misfiring could result in a substantial increase in torsional vibratory stresses, especially at overspeed. The critical speed for the 2.5 order is approximately 477 rpm. Following Prof. Sarsten's death, Prof. Engja used the computer program COMHOL2 to analyze crankshaft torsional stresses with misfiring in one of the cylinders on crank throw No. 1. The engine was assumed to be operating at full power (225 BMEP) and rated speed $(450 \mathrm{rpm})$. This analysis was performed as a check on misfiring conditions, and did not address the effects of misfiring of other cylinders or the change in stresses with operation at off-speed conditions.

Prof. Engja's results for the combined response of 24 orders of vibration predict that the highest nominal torsional stress under the conditions assumed for misfiring is approximately 7500 psi, in main journal No. 9. The 2.5-order response for this case is approximately $4000 \mathrm{psi}$. These results confirm that cylinder imbalance is a significant factor in crankshaft stresses at rated speed. The effect of the 2.5 order would be expected to increase substantially at speeds above rated speed.

FaAA has also analyzed misfiring for the conditions described above, as discussed in a telephone conversation between PNL (W. Laity) and FaAA (P. Johnston) in June 1985. FaAA's results and Prof. Engja's results are in close agreement.

\subsubsection{Comments on Transient Tests}

The torsiograph tests performed by FaAA on the DGl engine at San Onofre provide actual crankshaft torsional responses for the conditions of primary concern in the 20-cylinder engines, i.e., fast start, slow start, and coastdown. PNL's reviewers noted that the instrumentation and techniques used in 
the tests were appropriate, and that confidence in the test data is enhanced by agreement between torsional responses measured independently with the torsiograph and with accelerometers. Together with FaAA's transient analysis, the torsiograph tests contribute substantially toward an understanding of the effects of key critical resonances on crankshaft stresses.

\subsubsection{Comments on Torsional Analysis for Transient Conditions}

The close agreement between the test results for certain startup and coastdown transients and the results of FaAA's analysis of the same transients provides a strong basis for confidence in the validity of FaAA's analytical approach. Calculated and measured values of peak crankshaft responses for the conditions tested are essentially the same, as discussed in Section 4.8.4.4 of this report. Traces of predicted and measured free-end crankshaft responses show excellent agreement for a coastdown and for several startups over the entire duration of each transient, as may be seen by referring to Figures 4.2 through 4.4 of FaAA-84-12-14 (Apri1 1985).

With FaAA's analytical approach validated by close agreement between representative calculated and experimental results, a reasonable basis has been established for using FaAA's approach to make inferences concerning the effects of transients for which test results are not available.

\subsubsection{Combents on Fracture Mechanics Analysis}

4.8.5.4.1 Stress Concentration at 0il Holes. FaAA used a finite element model to determine the stress distribution in the vicinity of the oil holes of the main journals. PNL compared FaAA's results with a solution using Equation 61 in Article 35 of Timoshenko and Goodier (1970), and found close agreement in the stress concentration at the journal surface.

PNL concurs with FaAA that the stress concentration factor for the gross section of a main journal remains essentially the same for oil hole diameters between 15/16 inch and 1-1/2 inches (the range in the DGl crankshaft following removal of cracks). However, PNL notes that the stress concentration factor decays more slowly with distance away from the hole for the larger holes. This may adversely influence the rate of crack growth in the larger holes following crack initiation. 
4.8.5.4.2 Crack Initiation. FaAA's fatigue analysis shows that many crankshaft stress cycles are well beyond the endurance limit of the material during startup and coastdown. Accordingly, these stress cycles are likely to lead to initiation of fatigue cracks. PNL concurs with FaAA that the number of start-stops at which crack initiation will occur cannot be estimated with certainty. Given the scatter typically found in low-cycle fatigue data and the lack of any basis for validating FaAA's linear cumulative damage estimate of start-stop cycles for crack initiation, the actual cycles required to initiate a crack may differ significantly from FaAA's estimate. However, the uncertainties inherent in estimating crack initiation essentially preclude arriving at an estimate that is subject to only small error.

\subsection{Crack Propagation. PNL notes from FaAA's results (e.g.,} Figures $5.7,5.9$, and 5.12 of FaAA-84-12-14) that the rate of crack propagation predicted with the one-degree-of-freedom crack model increases rapidiy after the crack has grown from an initial assumed depth of 5 mils to the 10-mil depth assumed to be detectable in nondestructive examinations. The number of startstop cycles over which the crack depth is predicted to grow from 10 mils to $18 \mathrm{mils}$ is on the order of 100 . At $18 \mathrm{mils}$, according to this model, the crack becomes large enough to propagate under steady-state stresses. The presence of residual stresses or martensite would promote more rapid growth to the 18-mil threshold, as shown in FaAA's Figure 5.12.

PNL has no basis for estimating the degree of conservatism in FaAA's predictions of crack propagation rates. The nigh rates predicted with the onedegree-of-freedom model reinforce the potentially serious consequences of the stresses encountered in startup and coastdown transients.

\subsubsection{Options For Reducing Crankshaft Stresses}

The results of FaAA's torsiograph test for three fast starts (Section 4.8.4.3 of this report) show that crankshaft response is dependent upon the initial position of the crankshaft. It would appear from these results that high crankshaft stresses during startup could be alleviated by positioning the crankshaft in a preferred position before each start. However, FaAA's analysis of startup transients (Section 4.8 .4 .4 .2 ) shows that crankshaft response is strongly influenced by the interrelated effects of startup duration 
and initial crankshaft position. FaAA found that the duration of the start must be kept within \pm 0.5 second to control fast-start response when an initial starting position is chosen, or the selected position may produce very high crankshaft responses rather than the intended responses. Because of inevitable differences in startup time, there is no assurance that starting from a preferred initial crankshaft position would alleviate high crankshaft stresses.

FaAA's torsiograph test results also show that crankshaft response during a slow start (24 seconds) is similar to that during a coastdown (70 seconds). Further, the measured responses to these transients are significantly less than the responses to the most severe fast-start transients. Nevertheless, the slow-start and coastdown transients include stress cycles that exceed the endurance limit of the crankshaft material, as shown in FaAA's fracture mechanics analysis. Accordingly, cracks may reinitiate in the crankshafts even if slow starts rather than fast starts are used during periodic engine tests.

Thus, operating restrictions alone (i.e., slow starts for surveillance tests) are not sufficient to ensure that cracks will not reinitiate in the crankshafts of the San Onofre engines. However, crankshaft vibratory stresses may be mitigated in other ways. Several examples are listed below. These examples are by no means inclusive; other alternatives in addition to these may be found in the literature on diesel engine technology. Additional analysis would be required to determine the potential effectiveness of any particular alternative for reducing the transient responses of the crankshafts at San Onofre. Furthermore, engine testing would be necessary to confirm the actual effects of any option chosen.

Potential alternatives include:

- viscous damper - A potentially large reduction in crankshaft responses may be achieved by installing a viscous damper on the front end of the crankshaft. This well-known device, which serves to absorb a portion of the energy associated with crankshaft vibration, is commercially available in various sizes. The engines at San Onofre are not designed to accommodate a viscous damper, and therefore the installation of such a device would require significant engine modifications. 
- pendulum damper - A pendulum damper is a mass designed to vibrate in opposition to the crankshaft vibration produced by a particular torsional resonance, thereby reducing the crankshaft response to the resonance. The damper may be attached to the front end of the crankshaft or to a crankweb. Multiple dampers are required to reduce crankshaft responses to multiple resonances. The modifications required to accommodate pendulum dampers in the San Onofre engines might be significant, depending on pendulum size versus available space.

- changes in rotating masses - The three critical speeds of particular importance during startup and coastdown of the San Onofre engines could be shifted by changes in the inertia of the rotating masses (e.g., crankshaft counterweights). But the additional masses would not, by themselves, alter the sequence of the three closely-spaced criticals, and therefore they might not contribute to any significant change in the adverse torsional responses.

- change in firing order - A change in the firing order and/or a change in the timing of firing between corresponding cylinders in the left and right cylinder banks would influence the effects of individual orders of vibration. Whether this would result in a net reduction of crankshaft vibratory stresses during startup and coastdown transients could be determined only by additional analysis. The consequences of such a change for operation under load at rated speed would also have to be evaluated.

\subsubsection{Conclusions and Recommendations}

PNL concurs with the Owners' Group that the crankshafts for the TDI 20-cylinder, DSRV-4 series engines at San Onofre are adequate for continued service, subject to the periodic inspections and to the load and startup limitations recommended later in this section. However, PNL recommends that prompt action be taken to modify the engines as necessary to alleviate the crankshaft torsional stresses that have led to cracking under startup and coastdown transients. PNL's recomendations are discussed under the following four subheadings. 
4.8.5.6.1 Engine Modifications. Of primary concern are the effects of three closely-spaced resonant peaks within the speed range through which the engine passes during startup and coastdown. As shown by FaAA, the vibratory conditions associated with these resonances result in stress cycies that are well beyond the endurance limit of the crankshaft. The fatigue cracks found in the oil holes of certain main bearing journals illustrate that cracks have initiated and propagated under these operating conditions. Cracks may be expected to initiate again, even if "slow" starts rather than "fast" starts are used during engine tests. PNL concurs with FaAA that the number of start-stops at which crack initiation will occur cannot be estimated with certainty.

The likelihood of crack reinitiation leads PNL to conclude that the root cause of the cracking should be corrected to ensure long-term reliability of the engines. Appropriate design changes should be developed, and they should be subject to NRC review. The parts necessary to modify the engines should be obtained and installed in a timely manner.

4.8.5.6.2 Component Inspections. PNL concurs with FaAA that certain critical crankshaft surfaces should be examined at each refueling outage so that the inspection interval is approximately every 50 start-stop cycles. Further, PNL concurs that these examinations will provide adequate surveillance to detect new cracks before they would jeopardize engine reliability.

If cracks reinitiate in the oil holes where they were previously discovered and removed, or if cracks initiate in other crankshaft surfaces, they should be removed and the adequacy of the repaired crankshaft(s) should be reanalyzed as a prerequisite to additional service. This analys is should address whether or not the new cracks and the operating history under which they developed are consistent with the predictions of the analys is documented in FaAA-84-12-14 (April 1985). The analysis and the conclusions drawn from it should be subject to NRC review.

PNL's recommendations for crankshaft inspections pending engine modifications to reduce crankshaft transient responses are as follows: 
- The holes $(a)$ and the fillets in main journal No. 12 of the DG1 engine should be examined at the earliest reasonable time using the same nondestructive techniques employed in previous examinations of 011 holes and fillets in certain other main journals. Main journal No. 12 is one of the most highly loaded journals, but it was not included in the earlier inspections reported by FaAA and the Owners' Group. If cracks are found in this journal, main journal No. 12 of the DG2 engine should also be inspected. Any cracks found in either journal should be evaluated in the context of the analysis documented in FaAA-84-12-14, and should be removed before the engines are returned to service.

- The oil holes in main journals No. 4 through 11 , and the 1.5-inch-deep dowel holes in main journal No. 12, should be inspected in both engines at the first refueling outage using eddy current and fluorescent liquid penetrant as appropriate. If no cracks are found, PNL considers it sufficient at each subsequent refueling outage to limit the nondestructive examinations to the holes in the five most highly loaded journals, i.e., journals No. 8 through 12 . Any cracks found during inspections should be removed, and the adequacy of the crankshaft as repaired should be reevaluated as a prerequisite to additional service.

- During each major (5-year) engine disassembly and inspection, the fillets of the most highly loaded main journals (No. 4 through 12) should be inspected together with the oil holes, using nondestructive techniques of the type just mentioned. In addition, PNL suggests that it would be prudent to inspect the oil holes and fillets in at least three of the crankpin journals at 5-year intervals. The oil holes in the main journals are the areas of highest stress, but these other critical crankshaft surfaces also warrant periodic surveillance.

(a) Crankshaft drawings show two 1.5-inch-deep dowel holes in the rearmost journal of the crankshaft. Both should be inspected. 
Additional inspections recommended by PNL are listed below. If the inspections reveal any evidence of abnormal component wear, the parts should be repaired or replaced as appropriate.

- The bolts and the mating faces of the coupling between the flywheel and the generator of each engine should be inspected at the next major (5-year) engine disassembly to verify that they remain in satisfactory condition. This inspection is recommended because the coupling may be exposed to high vibratory torques associated with the resonances encountered during startup and coastdown.

- All accessible gears in the gear train should be inspected at the next refueling outage to verify their continued satisfactory condition. The remaining gears should be inspected during the next major engine disassembly, unless an earlier inspection is indicated by the condition of the gears inspected during the next refueling outage. These inspections are recommended because the vibratory amplitudes in the gear train may lead to gear tooth separation and accompanying gear impact, particularly during the startup and coastdown transients.

4.8.5.6.3 Operating Restrictions During Engine Surveillance Tests. PNL recommends that operating restrictions listed below be followed during engine surveillance tests, pending implementation of the engine modifications discussed earlier:

- Because the depth at which a crack will propagate under steady-state stresses is inversely proportional to engine power level, the engine loading for periodic surveillance tests should continue to be limited to $4500 \mathrm{~kW}+5 \%$ rather than to the $6000-\mathrm{kW}$ rating of the generator on each engine. SCE initiated the 4500-kW limit, which bounds the maximuri emergency service load for each engine. (PNL also recommends this limit on power level for the modified type Af piston skirts installed in the San Onofre engines, as discussed in Section 4.16.4.3. Thus, modifications to reduce crankshaft transient responses will not affect this recommendation unless other steps discussed in Section 4.16.4.3 are also taken.) 
- "Slow" starts should be used for the monthiy surveillance tests, to reduce the cumulative fatigue damage to the crankshafts. As shown in FaAA's transient torsiograph tests, crankshaft response during a slow start is similar to the response during a coastdown and is generally less severe than the response during a fast start. The oniy planned engine test for which PNL recommends a fast start is the one performed at 18-month intervals to demonstrate operation under simulated design-basis emergency power requirements. [This change has already been addressed in correspondence between NRC and SCE. See, e.g., SCE's (K. F. Baskin) letter dated February 14, 1985, to NRC (H. R. Denton).]

- Because a torsional analysis (Section 4.8.5.1.3) indicates that cylinder imbalance may have a significant effect on crankshaft stresses, appropriate precautions should be taken to prevent sustained engine operation with this condition. Exhaust gas temperatures should be monitored during engine operation to verify that differences between individual cylinder temperatures and the average temperature for all cylinders remain within the range recommended by TOI. In addition, cylinder firing pressures should be measured no less frequently than the interval recommended by TDI. PNL recommends that SCE analyze the trends of cylinder pressure and temperature measurements to detect changes that inight indicate a need for maintenance of fuel injection equipment. Any abnormalities should be corrected expeditiously.

- To avoid the effects of the 2.5-order critical, continuous operation of the engine at speeds more than a few rpm above the rated speed of $450 \mathrm{rpm}$ should be avoided. This is particularly important during engine startup, when imbalance in cylinder firing is more likely to occur. The 2.5-order response becomes significant under conditions of engine imbalance, as discussed in Section 4.8.5.1.3 of this report. PNL recommends that SCE take appropriate action to make operators aware of this situation. 
4.8.5.6.4 Other Recomnended Inspections. PNL recommends that the following periodic inspections and measurements also be included in the maintenance and surveillance program for the crankshafts:

- During each major (5-year) engine disassembly and inspection after the engine modifications discussed in Section 4.8.5.6.4 have been performed, the oil holes and fillets of the three main bearing journals subject to the highest torsional stresses should be examined with fluorescent liquid penetrant and, as appropriate, with eddy current. The oil holes and fillets in at least three of the crankpin journals should also be examined in this manner. These inspections are recommended to verify the continued absence of fatigue cracks.

- To verify that crankshaft alignment remains within manufacturer's recommendations, crankshaft deflection should be measured under both "hot" and "cold" conditions at each refueling outage (as planned by SCE at San Onofre). PNL's recomnendations on the conduct of these examinations have been documented in a previous evaluation of these engines (i.e., PNL-5304, November 1984).

\subsubsection{References}

Diesel Engine Manufacturers Association (DEMA). 1972. Standard Practices for Low and Medium Speed Stationary Diesel and Gas Engines. 6th ed. New York, New York.

Failure Analysis Associates (FaAA). June 1984. Evaluation of Emergency 0iesel Generator Crankshafts at Midland and San Onofre Nuclear Generating Stations. FaAA-84-6-54, Palo Alto, California.

Failure Analysis Associates (FaAA). October 12, 1984. Torsiogragh Test of Emergency Diesel Generator \#1 at San Onofre Nuclear Generating Station. FaAA-84-10-9, Palo Alto, California.

Fatlure Analysis Associates (FaAA). April !985. Evaluation of Transient Conditions on Emergency Diesel Generator Crankshafts at San Onofre Nuclear Generating Station Unit 1. FaAA-84-12-14, Rev. 1.0, Palo Alto, California.

Pacific Northwest Laboratory. November 1984. Review and Evaluation of Transamerica Oelaval, Inc., 0iesel Engine Reliability and Operability - San Onofre Nuclear Generating Station Unit 1. PNL-5304, Rich and, Washington. 
Southern California Edison Company (K. P. Baskin) letter dated February 14, 1985, to the NRC Office of Nuclear Reactor Regulation (H. R. Denton). Subject: Docket No. 50-206, Amendment Application No. 126, San Onofre Nuclear Generating Station Unit 1.

TDI Diesel Generator Owners' Group. January 1985. TDI Diesel Generator Design Review and Quality Revalidation Report - San Onofre Nuclear Generat ing Station. Forwarded to NRC (H. R. Denton) as Enclosure 1 of Southern California Edison Company (M. 0. Medford) letter dated September 3, 1985.

Timoshenko, S. P., and J. N. Goodier. 1970. Theory of Elasticity. 3rd ed. McGraw-Hill, New York, New York.

Transcript of Meeting on October 22, 1984, between NRC and the TDI Owners' Group. Free State Reporting Inc., Washington, D.C. 


\subsection{CYLINDER BLOCK}




\subsection{CYLINDER BLOCK}

This section addresses PNL's review of action taken by the Owners' Group to evaluate the cylinder blocks for the TDI inline and $V$-type $R-4$ series engines installed at several nuclear power plants.

\subsubsection{Component Description}

The cylinder block is a grey-iron casting that forins the franework for the upper-engine assembly. It provides support for the upper-engine components (e.9., cylinder liners, pistons, and cylinder heads), and contains passageways for the engine cooling water. The block is subjected to both mechanical and thermal stresses resulting from the combustion processes.

Although the cylinders in the $V$-type engines are arranged in two banks while those in the inline engines are in a single bank, there is no difference between the two configurations in block top thickness, cylinder head spacing, upper support of the cylinder liner, and the stud boss region that anchors the cylinder head studs. Minor design changes have been incorporated in recent years to reduce the protrusion of the cylinder liner collar above the block top (called "liner proudness") and to increase the cold radial clearance between the cylinder liner and the block, thereby reducing stresses in the block top.

\subsubsection{Service History}

Cracks have been reported in cylinder blocks of both DSR-4 (inline) and DSRV-4 ( $V$ ) engines in nuclear and non-nuclear applications. Several types of cracks have occurred in cylinder block tops. Cracks have also occurred in the camshaft galleries of inline engines, in the vertical wall just above the camshaft bearing supports. The following is a summary of the types of cracks and the engines in which they have been found as reported by FaAA (FaAA-84-9-11.1, December 1984).

1. Ligament cracks - A i igament crack is oriented vertically and extends between the counterbore for the cylinder liner landing and a cylinder head stud hole. Numerous cracks of this type have been identified in the top surfaces of the EDG 101, EDG 102, and original EDG 103 engine blocks at the Shoreham Nuclear Power Station (SNPS). Ligament cracks 
have also been reported in the marine and stationary installations listed below. These engines were reported to have operated with such cracks from 6,000 to 28,000 hours.

\begin{tabular}{ll} 
Engine Series & \multicolumn{1}{c}{ Installation } \\
& Copper Valley Electric Corporation \\
DSR-4 & MV Trader \\
DSR-4 & MV Traveler \\
DSRV-20-4 & Homestead, Florida \\
DSRV-16-4 & MV Gott \\
DSRV-16-4 & MV Columbia
\end{tabular}

2. Stud-to-stud cracks - A stud-to-stud crack is also oriented vertically, and extends between two cylinder block stud holes of adjacent cylinders. A related type of crack can occur at the ends of blocks where the crack extends from a stud hole to the vertical surface at the end of the block. This type of crack has been observed oniy in blocks having ligament cracks in the stud hole regions. In nuclear applications, stud-to-stud cracks have been identified only in the original block for the SNPS EDG 103 engine. Following replacement of the crankshaft in that engine and an engine test of 100 hours at or above the nameplate rating of $3500 \mathrm{~kW}$, a crack was discovered that extended between two adjacent stud holes on the exhaust side of cylinders No. 4 and 5. Later, after EDG 103 had experienced an abnormal load excursion while being operated at full load, and had then been operated for a brief period (less than 2 hours) at $3900 \mathrm{~kW}$, reexamination of the engine block revealed additional cracks between stud holes. Furthermore, the original stud-to-stud crack between cylinders No. 4 and 5 had grown. The block was replaced. Destructive examinations revealed that the original EDG 103 block contained extensive amounts of degenerate Widmanstaetten graphite, which severely reduced the strength and fatigue resistance of the block. 
3. Circumferential cracks - Cracks of this type are found in the corner formed by the cylinder liner landing and the cylinder liner counterbore. They may extend circumferentially around the landing and downward into the block. Such cracks were discovered in the original SNPS EDG 103 block through destructive metallurgical examinations, which revealed a maximum crack depth of approximateiy $3 / 8$ inch.

4. Camshaft gallery cracks - This type of crack appears as a horizontal indication in the upper radius of a canshaft bearing saddle support, and extends in essentially a horizontal plane toward the engine jacket cooling water system. Cracks of this type have been discovered in the camshaft galleries of Shoreham's EDG 101, EDG 102, original EDG 103, and replacement EDG 103 cylinder blocks. Weld repairs that are essentially cosmetic in nature had been performed on the camshaft gallery cracks in the first three blocks before the engines were delivered to Shoreham. These repairs did not involve complete removal of the crack; furthermore, additional cracking occurred between the weld "nuggets" and the base material in the three original blocks.

Several indications were discovered in the DSRV-16-4 engines at Comanche Peak that differed from the types of cracks described above. These indications are oriented vertically and extend radially into the block from the cylinder liner landing and cylinder liner counterbore. Through metallurgical examinations, FaAA identified these cracks as interdendritic shrinkage or porosity resulting from the casting process. They have not been found in any other TDI engines in nuclear service.

\subsubsection{Owners' Group Evaluation}

The structural adequacy of the TDI R-4 series diesel engine blocks was addressed in a study performed by Failure Analysis Associates for the Owners' Group (FaAA, December 1984). This study was directed principally at determining the significance of various cracks in the engine blocks at SNPS because these blocks represented the worst case of cracking experienced in TDI engines in nuclear service. 
The FaAA evaluation consisted of 1) materials evaluation of the SNPS blocks including chemical and microstructure analyses, tensile tests, and fatigue tests; 2) an analysis of the loads on the block that influence fatigue and fracture; 3) a stress analysis to estimate the level of stresses caused by these loads; and 4) a fracture and fatigue life analysis.

The load analysis considered the combined effects of 1) the preload on the cylinder head studs, 2) the load distribution between the cylinder heads and the block, 3) the load between each cylinder head and the corresponding cylinder liner, and 4) the thermal and pressure loads between the cylinder liners and the block. These loads were used as inputs to the stress analysis to provide estimates of the stress levels in the block. The stress analyses consisted of 1) strain-gage tests performed on the original SNPS EDG 103 bTock and 2) both two- and three-dimensional finite element analyses to determine conservative scale factors for use in extrapolation of the strain-gage measurements to other locations in the block and to both cracked and uncracked ligaments.

The results of the stress analysis were compared with conservative material properties on a Goodman diagram to determine the likelihood of crack initiation. FaAA determined that 1) block top cracking may initiate at $100 \%$ of the nameplate load from high-cycle fatigue or after 100 starts to full power due to low-cycle fatigue, 2) the possibility of ligament cracks is much greater than the possibility of either stud-to-stud or stud-to-end cracks, and 3) once ligament cracks develop, the possibility of stud-to-stud and stud-to-end cracks increases. The possibility of fatigue crack initiation below the block top was also examined; FaAA concluded that such cracks would not initiate at either the stud hole counterbore or the stud hole threads.

FaAA performed a cumulative damage analys is to predict the propagation of stud-to-stud and stud-to-end cracks under anticipated service conditions. The analysis takes into account 1) the demonstrated performane of engine blocks with cracks present, 2) engine load and duration of operation required for a LOOP/LOCA event, 3) known crack depth, and 4) fatigue resistance of the block material. From this analysis, FaAA developed a procedure based on a cumulative fatigue damage index that can be applied on an engine-specific basis to define 
requirements for block-top inspections, permissible operation to the next inspection, and the suitability of the block for further service.

FaAA also analyzed the circumferential cracks and determined that they would not threaten engine performance. However, FaAA noted that decreasing the protrusion of the liners above the block top will reduce the probability of circumferential cracking.

FaAA's metallographic examination of the cam gallery cracks identified them as shrinkage cracks. Neither these shrinkage cracks nor other cracks associated with weld repairs of these cracks were found to have grown during engine operation. Further, FaAA experimentally determined that the stresses in the region of the cracks are compressive. Therefore, FaAA concluded that these cracks will not propagate.

\subsubsection{Owners' Group Conclusions and Recommendations}

4.9.3.1.1 FaAA's Conclusions and Recommendations. Included in report FaAA-84-9-11.1 (Decenber 1984) are FaAA's conclusions and recommendations regarding the predicted effects of the cracks described in Section 4.9 .2 of this report, and the cylinder block inspections that should be performed for both DSR-4 and DSRV-4 series engines. Among FaAA's findings are those summarized below. A detailed discussion of these findings and others not included in this summary is presented in Section 9 of the FaAA report.

- All blocks should be metallurgically evaluated to verify that the microstructure is characteristic of typical grey cast iron.

- Periodic inspections are necessary to ensure that each cylinder block is capable of meeting its intended function as a component in a diesel generator in nuclear standby service.

- Cracks may initiate in the ligament between stud hole and liner counterbore after the engine accumulates a certain number of hours at high load and/or engine starts to high load. Operating experience demonstrates that such cracks initiate at the block top surface and propagate downward toward the cylinder liner landing, where they arrest. The observed ligament cracks have no effect on engine operation because they are contained between the liner and the block 
material beyond the stud holes. Degraded material properties contribute to the extent of ligament crack initiation.

- The presence of liganent cracks at a stud hole increases the stress and the probability of initiating a crack at the adjacent stud-tostud or stud-to-end location. Stud-to-stud or stud-tomend cracks may initiate after the engine accumulates a certain number of hours at high load and/or engine starts to high load as predicted by Goodmian diagram analyses based upon conservative finite element analyses and conservative materials properties. Such cracks are predicted to initiate at the block top surface and propagate downward, as occurred in the original EDG 103 block at SNPS. The deepest stud-to-stud and stud-to-end cracks measured in the EDG 103 block were 3.0 inches and 4.4 inches, respectively. These cracks did not result in degraded engine performance or loosening of the cylinder head studs. Degraded mechanica? properties of the block material will reduce the resistance to initiation and growth of these cracks.

- Based on cumulative dainage analysis of LOOP/LOCA requirements and the demonstrated performance of the original SNPS EDG 103 block that had ligament cracks and degraded mechanical properties, the blocks of TDI engines are predicted to withstand a LOOP/LOCA event with sufficient margin, provided that no stud-to-stud cracks are present between adjacent cylinders and that the microstructure of the block is typical of grey cast iron.

- Cylinder blocks that are inspected and found to be free of ligament, stud-to-stud, and stud-to-end cracks can be operated without additional block top inspections for a combination of load and time deterinined on an engine-specific basis in accordance with FaAA's cumulative damage procedure discussed in Section 5 of the FaAA report.

- The blocks of engines that have been operated without block top inspection or that have been operated for a time in excess of the allowable fatigue damage index described in the FaAA report should conservatively be assumed to have ligament cracks. 
- For blocks with known or assumed ligament cracks, the absence of detectable stud-to-stud cracks or stud-to-end cracks should be established by inspection between adjacent cylinders before the engine is returned to emergency standby service after any operation in excess of $50 \%$ of nameplate load. Any stud-to-stud or stud-to-end crack indications must be subject to detailed inspection to ensure that they extend less than 1.5 inches from the black top before the engine is returned to emergency standby service, and this inspection must be repeated following each subsequent engine operation above 50\% load. In addition, it is necessary to ensure that the microstructure is typical of grey cast iron.

- If circumferential cracks initiate at the intersection of the cylinder liner landing and the cylinder counterbore, they are predicted to propagate into a fully compressive stress field and arrest. They are not predicted to result in degradation of engine performance.

- Cracking in the camshaft galleries of the three emergency diesel generators at Shoreham was found by metaliurgical analysis to have occurred during the casting process. Further, no metallurgical evidence was found that the cracks had propagated during engine operation. Analysis and strain-gage testing of the cam gallery region confirmed that the area where the cracks occurred is under compression, and that the cracks will not propagate during engine operation. The geometry of the camshaft supports where the cracking occurred is unique to inline engines.

4.9.3.1.2 Design Review/Quality Revalidation Reports. Recontuendations of the Owners' Group for maintenance and surveillance of the cylinder blocks are included in Appendix II of each of the design review/quality revalidation (DR/QR) reports prepared for the TDI engines at various nuclear power plants. The recommendations included in the following two DR/QR reports for the cylinder blocks are briefly summarized in this section as examples: 1) Comanche Peak Steam Electric Station (TDI OG January 1985) and 2) the Perry Nuclear Power Plant (TDI OG December 1984). 
Inspections of the block top in accordance with FaAA recommendations are recommended in both $D R / Q R$ reports. In addition, visual inspection of the cylinder liners is recommended at each refueling outage to monitor wear. According to the reports, boroscopic inspection is acceptable if the cylinder heads are not to be removed.

\subsubsection{Atomic Safety and Licensing Board Hearing on Shoreham Engines}

Two of PNL's consultants -- Dr. Bush and Mr. Henriksen $\rightarrow$ testified on matters pertaining to cylinder blocks in an Atomic Safety and Licensing Board (ASLB) hearing concerning the TDI emergency diesel generators at SNPS. Among the issues in controversy were contentions concerning the cylinder blocks of the three engines. The reviews on wich the testimony of PNL's consultants was based included those discussed in Section 4.9 .5 of this report.

The Partial Initial Decision issued by the ASLB on June 14, 1985, approves operation of the TDI engines at SNPS through the first reactor fuel cycle. Included in the Partial Initial Decision (pp. 62-63) is the following summary of the ASLB's conclusions regarding block top inspections:

A. During the first fuel cycle:

1. EDGs 101, 102, and 103

a. During any period of continuous operation following automatic diesel generator initiation, the Long Island Lighting Company (LILCO) will perform daily visual inspections of the area between adjacent cylinder heads and the general block top. Lil.CO will also perform visual inspections of the same areas under intense light during the monthly surveillance testing.

b. LILCO will perform a liquid penetrant and, as appropriate, ultrasonic inspection of the cylinder liner landing at any time a cylinder liner is removed for any other reason.

2. EDGs 101 and 102

LILCO will perform eddy current testing between adjacent cylinder heads after any operation of EDG 101 and 102 at greater than $1800 \mathrm{~kW}$. 
B. Following any LDDP event during the first fuel cycle, and during the first refueling outage, LILCO will inspect the top surface of the block exposed by the removal of two appropriate cylinder heads from each of the three EDG engines. Inspections will be by liquid penetrant, with eddy current for any identified cracks, to determine the presence of new cracks and the depth of any new or old cracks.

C. Following the first fuel cycle, the NRC staff should reevaluate the TDI EDG block top inspection requirements.

The ASLB also orders (ibid., $\rho .49$ ) that any license authorizing operation of the TDI EDGs $1 D 1$ and 102 be conditioned to require additional analysis upon discovery of a stud-to-stud crack, prior to continued operation.

An agreement on monitoring of cracks in the camshaft galleries of EDG 101 and EDG 102 was reached by the parties to the ASLB hearing, accepted by the $A S L B$, and bound into the transcript of the hearing (as an unnumbered page immediately following transcript page No. 28,766). Under the agreement, LILCO will inspect the camshaft gallery cracks at least once every 3 months from the time the diesel generators are initially placed in operation for emergency standby service until the first refueling outage. The inspections will involve liquid penetrant examinations in the vicinity of camshaft bearing saddles №. 2 and 8 to monitor crack length, followed by TSI depth gage measurements to inonitor crack depth.

\subsubsection{PNL's Review}

PNL's review encompassed 1) the FaAA design review of the cylinder blocks, 2) reviews performed in the preparation of PNL technical evaluation reports for TDI diesel generators at seven nuclear power plants (identified in Section 3 of this report), 3) testimonies of the parties to the ASLB hearing on the TDI engines at SNPS, and 4 ) the $D R / Q R$ reports referenced in Section 4.9 .3 .1 .2 .

\subsubsection{Review Participants}

The following PNL consultants participated in various aspects of PNL's review of the cylinder blocks for TOI DSR-4 and DSRV-4 series diesel generators: 
- 5. H. Bush, Review and Synthesis Associates

- H. M. Hardy, consulting engineer

- A. J. Henriksen, A. J. Henriksen, Inc.

- B. J. Kirkwood, Covenant Engineering

- P. J. Louzecky, Engineered Applications Corporation.

In addition, J. C. Spanner of the PNL Nondestructive Testing Section reviewed NOE procedures for the block top inspections.

\subsubsection{Conclusions and Recommendations}

Subject to the recommendations discussed in this section, PNL concurs with the Owners' Group that the engine blocks for TDI R-4 and RV-4 series engines are adequate for their intended service in nuclear standby diese1 generators. PNL's conclusions and recomnendations are consistent with the ASLB findings from the hearing discussed in Section 4.9.4, above.

- Block Microstructure - PNL concurs with FaAA's recomnendation that all blocks of TOI engines at nuclear power plants should be metallurgically examined to ensure that the inicrostructure is characteristic of typical grey cast iron of the grade specified for the block. PNL recommends that any block in which a degraded microstructure is found (e.g., degenerate Widmanstaetten graphite) should not be placed in service in a nuclear standby engine without thorough justification by the engine owner and review by the NRC staff.

- Ligament Cracks - FaAA's analysis of ligament crack initiation and propagation substantiates reported operating experience with TOI engine blocks known to contain ligament cracks. PNL concurs with FaAA that Tigament cracking results in increased stresses in the adjacent stud-to-stud and stud-to-end locations. Further, PNL concurs that if a ligament crack were to propagate to the engine cooling water jacket, the worst-case consequence would be coolant seepage to the block top and out between the heads. FaAA's prediction that such cracks will arrest at the cylinder liner landing is 
consistent with observations of known liganent cracks. Thus, postulated leakage is an extreme condition that has not been experienced in service. Even if leakage occurred, however, it would not affect the operability of the engine.

- Stud-to-Stud Cracks - PNL concurs with FaAA's conclusion that, if the block material is typical grey cast iron and if no stud-to-stud or stud-to-end cracks are present, the block will withstand a LOOP/LOCA event with sufficient margin. PNL also concurs with FaAA's recommendation that blocks with known or assumed ligament cracks should be inspected following each operation in excess of $50 \%$ of nameplate load, to verify the continued absence of stud-to-stud and stud-to-end cracks. PNL recommends that eddy-current testing or a similarly sensitive nondestructive testing technique be used to perform these inspections.

FaAA recommends that, if a stud-to-stud crack or stud-to-end crack is discovered, a detailed inspection be performed to ensure that the crack extends no more than 1.5 inches in depth from the block top. PNL recommends further that the engine not be returned to nuclear service pending further analysis of the crack and its implications for engine reliability. The analysis and the conclusions drawn from it should be subject to NRC review before the engine is returned to service.

- Circumferential Cracks in Liner Bore - The results of FaAA's analysis of circumferential crack propagation are consistent with the findings of FaAA's metallurgical examination of a circumferential crack found in the original block for the EDG 103 engine at Shoreham. FaAA's analysis shows that circumferential cracks will arrest as they propagate from a region of relatively high stress concentration into a fully compressive stress field. The circumferential crack examined in the original EDG 103 engine block had propagated only $1 / 8$ to $3 / 8$ inch into the block, even though the mechanical properties of the block were substandard. PNL concurs with FaAA that circumferential cracks do not represent a hazard to engine reliability. 
However, PNL recommends that, at any time a cylinder liner is removed, the liner landing be inspected for circumferential cracks. If a crack is found, its length and depth should be characterized through appropriate nondestructive tests. The characteristics of the crack should be evaluated relative to FaAA's predictions for circumferential crack behavior. PNL does not recommend removal of cylinder liners for the sole purpose of this inspection.

- Camshaft Gallery Cracks - LILCO's plans for monitoring cracks in the Camshaft galleries of EDG 101 and EDG 102 at SNPS are consistent with recommendations in testimony presented by two of PNL's consultants at the ASL8 hearing discussed in Section 4.9.4, above. If cracks are found in camshaft galleries of TDI inline engines at other nuclear power plants, they should be evaluated on a case-by-case basis relative to the results of the investigations of the camshaft gallery cracks in the SNPS engines.

- Visual Inspections of Block Top - During any period of continuous engine operation, a visual inspection of the block top should be perforined daily under intense light to detect any obvious evidence of cracking. Areas between adjacent cylinder heads should be included in this inspection. In addition, the block top should be inspected visually under intense light during the monthiy surveillance testing.

- Liquid Penetrant Inspections of 8lock Top - 8locks with known or assumed ligament cracks should be inspected at each refueling outage, to determine whether or not cracks have initiated on the top surface exposed by the removal of two or more cylinder heads. This process should be repeated over several refueling outages until the entire block top has been inspected. Liquid-penetrant testing or a similariy sensitive nondestructive testing technique shouid be used to detect cracking, and eddy current should be used as appropriate to determine the depth of any cracks discovered.

PNL notes that the $D R / Q R$ reports referenced in Section 4.9 .3 .1 .2 call for ASTM E125 as the standard for evaluating indications found in nondestructive tests of the block top. This standard is also refer- 
enced in the $D R / Q R$ reports for evaluating indications found in cylinder heads. PNL notes further that ASTM E125 applies only to magnetic particle inspections. For reasons discussed in Section 4.10.4.3, PNL recommends that alternative procedures and acceptance criteria be used in future inspections of these components. A well-established methodology for magnetic-particle examinations may be found in Section V, Article 7 of the ASME Code (1983), and acceptance criteria for such examinations may be found in ASME SA-613, Section 19. Methodology for liquid-penetrant examinations may be found in ASME Section V, Article 6, and acceptance criteria in ASME SA-613, Section 20. The ASME standards just referenced are widely used throughout the nuclear industry.

- Inspections of Cylinder Liners - PNL concurs that the periodic visual inspection recommended by the Owners' Group as discussed in Section 4.9.3.1.2 is prudent for monitoring wear of the cylinder iiners. PNL also concurs that boroscopic inspection is acceptable if the heads are not to be removed.

If cumulative results of these inspections over several power plant fuel cycles show that one or more of the inspections reveal nothing of significance, the scope and/or frequency of the inspections could be reconsidered. PNL recommends that any changes be subject to NRC review before they are implemented.

\subsubsection{References}

Atomic Safety and Licensing Board. March 7, 1985. Transcript of Hearing on Emergency Diesel Generators, pages 28,584 - 28,767. In the Matter of Long Island Lighting Company, Shoreham Nuclear Power Station, Docket No. 50-322-0L.

Atomic Safety and Licensing Board. June 14, 1985. Partial Initial Decision on Emergency Diesel Generators. In the Matter of Long Island Lighting Company, Shoreham Nuclear Power Station, Unit 1, Docket No. 50-322-0L, LBP-85-18.

Failure Analysis Associates (FaAA). December 1984. Design Review of TDI R-4 and RV-4 Series Emergency Diesel Generator Cylinder Blocks. FaAA-84-9-11.1, Palo Alto, California. 
TDI Diesel Generator Owners' Group. December 1984. TDI Diesel Generator Design Review and Quality Revalidation Report - Perry Nuclear Power Plant.

TDI Diesel Generator Dwners 'Group. January 1985. TDI Diesel Generator Design Review and Quality Revalidation Report - Comanche Peak Steam Electric Station, Unit 1. Revision 1. 


\subsection{CYLINDER HEADS}




\subsection{CYLINDER HEADS}

Summarized in this section is PNL's review of action taken by the Owners' Group to evaluate the cylinder heads for the TOI inline and $V$-type $R-4$ series engines installed at several nuclear power plants.

\subsubsection{Component Description}

The cylinder head is a complex steel casting with passages for cooling water, fuel, starting air, combustion air, and exhaust gases. Included in the cylinder head assembly are an air-start valve, a fuel injector, two intake valves, and two exhaust valves and a cylinder test cock. Each cylinder in both the inline and V-type engine blocks of TOI R-4 series engines is equipped with a separate cylinder head assembly, which is bolted to the block by means of eight studs that extend through the head.

The lower surface of the cylinder head (the fire deck) is subjected to combustion pressure within the cylinder, vertical loading from the rim of the cylinder liner, and the clamping force and bending moment resulting from preload of the cylinder head studs. In addition, the fire deck and the exhaust passages are subjected to themal stresses resulting from temperature differences across these boundaries.

The basic cylinder head configuration is comrion to all TDI R-4 engines. However, in recent years TDI made changes in manufacturing procedures and in quality control, as well as minor design changes. Failure Analysis Associates (FaAA), a consultant to the Owners' Group, described these changes in report FaAA-84-5-12 (August 1984). FaAA categorized the heads into one of three groups according to when certain changes were implemented: those cast prior to October 1978 are Group I; those cast between October 1978 and September 1980 are Group II; and those cast after September 1980 are Group III.

According to information compiled by TOI and discussed in the FaAA report, 1040 R-4 cylinder heads have been installed in emergency diesel generators in the United States and overseas. Categorized by the dates when these heads were cast, 420 are Group I, 309 are Group II, and 311 are Group III. 


\subsubsection{Failure History}

As discussed in the FaAA report, cylinder heads cast before September 1980 (both Group I and Group II) were subject to core shift, inadequate control of solidification, and inadequate control of the Stellite valve seat weld deposition process. In addition, heads cast before October 1978 (Group I) were not stress-relieved and are subject to fatigue crack growth in thin sections and/or from fabrication-induced defects. Heads cast after September 1980 (Group III) are much less prone to manufacturing defects. These latter castings have received magnetic particle inspections for several years. Commencing April 1984, magnetic particle inspection was also implemented at the factory for the machined surface of the fire deck.

FaAA's summary of nuclear and non-nuclear experience with R-4 cylinder heads includes a discussion of cylinder head defects found at the Shoreham, Grand Gulf, Comanche Peak, and Catawba nuclear power piants. FaAA noted that the fire deck, the bridge between the exhaust valves, the exhaust valve seats, and the injection port have been the critical locations of cracks in heads at the nuclear power plants.

- At Shoreham, all of the cylinder heads originally installed on the TDI 8-cylinder engines were Group I. Five of these heads developed leaks through which water could enter the cylinders. All but two of the original heads were subsequently replaced with Group 111 heads.

- Eight of the 32 cylinder heads on the two 16-cylinder TDI engines at Grand Gulf were found to have linear indications in the Stellite valve seat weld overiay, and one valve seat showed signs of water leakage. With the exception of the latter defect, all of the indications were apparently confined to the Stellite overlay. All of these heads were Group 1.

- Four of the 16 cylinder heads on the $1 A$ engine at Comanche Peak were inspected after the engine had accumulated approximately 95 hours of operation. Two of the four contained linear indications between the intake valve ports, and three of the four contained indications 
between the exhaust ports. These heads were Group II. All of the heads at Comanche Peak were subsequently replaced with Group III heads.

- Following approximately 830 nours of operation of the 16-cylinder $1 A$ engine at Catawba, the heads were removed and inspected. No relevant indications were found, nor were any other signs of distress apparent. Several of these heads (number not specified) were from Groups I and II. During previous operation, however, two heads were found to have water leaks in the vicinity of the fuel injector port. The leakage was to the exterior of the engine rather than into the cylinders.

An additional instance of cylinder head leakage was reported in a letter dated July 30, 1984, from Mississippi Power \& Light Company (L, F. Dale) to NRC (H. R. Denton). According to MP\&L's letter, water was observed coming from the open cylinder cock on one of the cylinder heads of the Division I TDI engine at Grand Gulf wile the engine was undergoing routine maintenance. MP\& found that a 2-inch through-wall crack had developed in the right exhaust port casting surface between the valve seat area and the exhaust valve guide. The failed head was one of the original heads (Group I) supplied with the engine. It had been operated $\sim 1500$ hours, of which 335 hours were at $100 \%$ load and 31 hours were at $110 \%$ load.

According to information obtained by FaAA from TDI, there have been oniy six instances in Group II cylinder heads of leaks that resulted in water entering the cylinders. These leaks occurred in marine installations. No leaks of water into the cylinders have been reported in Group III heads.

FaAA also sumarized information obtained from TOI concerning 225 cylinder head deficiencies that occurred in non-nuclear service between 1972 and 1976. TOI attributed about half of these deficiencies to thin sections (due to core shift during casting) and/or hot tears in the walls of the exhaust bridge and exhaust ports. Several (around 10 to 20 ) were attributed to fatigue crack growth from hot tears in the fire deck. 


\subsubsection{Owners' Group Evaluation}

On behalf of the Owners' Group, FaAA evaluated the adequacy of the R-4 cylinder heads for engines installed at nuclear power plants. FaAA's investigation is presented in report FaAA-84-5-12 (August 1984). Included in the report are FaAA's observations on metallurgical evaluations of cylinder heads from several nuclear power plants, and FaAA's conclusions from an analys is of therma1 and pressure stresses.

\subsubsection{Metallurgical Evaluations}

Defects in cylinder heads from Comanche Peak, Grand Gulf, and Catawba were examined metallurgically, with the following results:

- FaAA examined a flaw approximately 2 inches long by 0.4 inch deep located between the intake ports of a cylinder head from an engine at Comanche Peak, and attributed the flaw to a large interdendritic shrinkage or porosity casting defect.

- Middle South Services Inc. found that a crack through the fire deck of a cylinder head at Grand Gulf resulted from a pre-existing void associated with a weld repair and a shrinkage crack in the Stellite weld deposit. There was evidence of corrosion from exhaust yas but no fatigue crack growth or lack of fusion.

- A cylinder head flaw through which water leaked to the exterior of an engine at Catawba was found by FaAA to be a cracked fuel injector port. The crack started from the corner of a welded, machined insert, and propagated in high-cycle fatigue.

\subsubsection{Thermal and Pressure Stress Evaluation}

FaAA analyzed the relative levels of themal and pressure stresses, to estimate the influence of these stresses on deformation and fatigue of the cylinder head. Temperature distributions across the fire deck were determined using a one-dimensional model of a flat plate. To calculate pressure stresses, the cylinder head was modeled as two plates, representing the fire deck and the upper deck, which were assumed to be clanped at the edges. From the fire deck temperature distribution and cylinder firing pressure, global stresses 
developed in the fire deck were estimated. FaAA noted that the complexity of the cylinder head passageways prevented detailed calculations of concentrated stresses.

The results, according to FaAA, show that thermal stresses during a fast startup are about the same as steady-state thermal stresses. The thermal and pressure stress calculations show that the fire deck may be subject to stresses outside the elastic range. However, FaAA noted that in the critical region in the vicinity of the pressure seal, the inelastic deformation would be confined to the surface of the fire deck and would not lead to progressive deformation.

4.10.3.3 Conclusions and Recommendations

The following conclusions and recommendations are presented in report FaAA-84-5-12:

- Al1 three groups of heads are adequate for their intended service at nuclear power plants. However, there is a potential for cracks to propagate from pre-existing flaws in the heads, leading to leaks into the cylinders. The potential for pre-existing flaws in Group III heads is significantly less than in Group I and Group II heads.

- The following recommendations apply to all heads:

- liquid penetrant inspection of valve seating surfaces; manetic particle inspection of the fire deck area, excluding valve seats; and ultrasonic measurement of the fire deck thickness at six locations

- engine "barring over" immediately prior to manual startups and at appropriate intervals after shutdown, to check for water leakage into the cylinders - If evidence of leakage is found in a cylinder, the corresponding head should be replaced.

- The injection port of each cylinder head should be visually inspected for water leaks during the monthly surveillance runs. This inspection is recommended because the weld repair technique sometimes used by TDI to repair casting flaws in the fuel injection port can lead to 
water leakage toward the exterior of the engine. If leakage due to cracking is detected, the head should be replaced.

Included in Appendix $A$ of FaAA-84-5-12 are acceptance criteria for the recomnended inspections. These criteria are also included in the $D R / Q R$ report for Comanche Peak (September 1984), together with a sketch showing where the six measurements of fire deck thickness are to be performed. ASTM E125 is cited as the reference standard for determining whether or not linear indications, shrinkage, inclusions, or porosity are reportable. The minimum fire deck thickness allowed under the criteria is 0.400 inch.

\subsubsection{Maintenance and Surveillance}

Recomendations of the Owners' Group for maintenance and surveillance of cylinder heads may be found in the $D R / Q R$ reports for individual installations. The following recommendations are included in the $D R / Q R$ reports for Comanche Peak (January 1985) and River Bend (February 1985), in addition to the recomnendations in FaAA-84-5-12:

- "Blow over" the engine (with the air-start system) after engine shutdown to detect any water that may have leaked into the cylinders. The Comanche Peak DR/QR calls for "barring over" the engine (with the turning gear). In the event water is detected in a cylinder, the corresponding cylinder head should be replaced.

- Visually inspect the fuel injection port on each head for water leaks during the monthly surveillance tests.

- Visually inspect all cylinder heads every 5 years.

- Record cold compression pressures and maximum firing pressures at each refueling outage.

4.10.4 PNL's Review

\subsubsection{Reviewers}

The following PNL consultants participated in various aspects of PNL's review of the cylinder heads for the TDI R-4 series engines installed at nuclear power plants: 
- S. H. Bush, Review and Synthesis Associates

- A. J. Henriksen, A. J. Henriksen, Inc.

- B. J. Kirkwood, Covenant Engineering

- P. J. Louzecky, Engineered Applications Corporation

- the late A. Sarsten, Norwegian Institute of Technology.

In addition, J. C. Spanner of PNL's Nondestructive Testing Section reviewed procedures and standards recommended by the Owners' Group for examining the cylinder heads.

\subsubsection{Scope}

PNL's review of the cylinder heads encompassed the following activities:

- review of FaAA report FaAA-84-5-12 - Information related to the FaAA report was a topic of discussion in several public meetings between the NRC staff and the Owners' Group. PNL representatives participated in these meetings on behalf of the NRC staff.

- reviews performed in the preparation of PNL technical evaluation reports on TOI diesel generators at seven power plants that became candidates for operating licenses: Catawba, Comanche Peak, Grand Gulf, Perry, River Bend, San Onofre, and Shoreham - The cylinder head was one of the components reviewed. PNL representatives visited several of these power plants during post-test engine disassemblies and inspections, and examined the condition of cylinder heads that had been removed for inspection.

- testimony prepared by PNL consultants A. U. Henriksen and Prof. Sarsten for an Atomic Safety and Licensing Board hearing on the TDI emergency diesel generators at Shoreham - Their testimony was prepared on behalf of the NRC staff. The cylinder heads were the subject of a settlement dated September 21, 1984, that was signed by the parties to the hearing and accepted by the ASLB. Suffolk County agreed to withdraw its contention concerning the cylinder heads. In return, Long Island Lighting Company agreed to take certain actions 
described in the settiement. Nothing in PNL's conclusions and recommendations that follow in Section 4.10 .4 .3 is intended to affect the agreenents of the parties in any way.

\subsubsection{Conclusions and Recommendations}

In the opinion of PNL's reviewers, FaAA's approximate analysis of combined thermal and pressure stresses does not provide an adequate basis for confirming the design adequacy of the cylinder heads. The structure of a cylinder head is very complex. As discussed in FaAA-84-5-12, the complexity of the geometry prevented detailed calculations of concentrated stresses. FaAA's analysis does, however, provide insight into the effects of the thermal and pressure loadings.

PNL's reviewers also concluded on the basis of known operating experience with the $R-4$ series heads that problems in service are indicative of manufacturing defects rather than design deficiencies. Of colirse, the design of the heads affects the complexity of manufacture. This, in turn, affects the capability of the foundry to produce castings free of unacceptable defects. However, operating experience does not suggest that the design itseif is inherently deficient.

Subject to the recommendations that follow, PNL concurs with the Owners" Group that the R-4 series cylinder heads are adequate for their intended service at nuclear power plants. The problems encountered with cylinder heads in service have resulted from casting or welding practices used in manufacturing the heads, and these problems are well understood. The nondestructive examinations recomnended by the Owners' Group are appropriate for detecting preexisting, surface-connected flaws in the valve seats or elsewhere in the fire deck, and for verifying that the minimum fire deck thickness requirement is met. If water leaks develop because of subsurface flaws or flaws that are otherwise not detectable through the recominended examinations, the presence of water in the cylinders can be detected by air-rolling the engine with the cylinder cocks open. Corrective action can then be taken before the leakage impairs the rapid-start capability of the engine. 
PNL's recommendations are as follows:

- PNL concurs with FaAA that certain liquid penetrant, magnetic particle, and ultrasonic inspections (Section 4.10.3.3, above) should be performed on all cylinder heads intended for use on engines in nuclear standby service. PNL's comments and recomnendations for future cylinder head inspections are as follows.

- Currently, ASTM E125 is referenced as the standard for determining whether or not linear indications, shrinkage, inclusions, or porosity are reportable. PNL notes that this standard applies only to magnetic particle (MT) inspections. Further, PNL notes that ASTM E125 uses references photographs that were assembled by, and for, the foundry industry, and specifies acceptance standards by defect type rather than by the measured dimensions of MT indications. Thus, field inspection personnel must identify the type of defect represented by the indication to determine whether or not the defect is reportable. In PNL's opinion, it is preferable for field-usable criteria to be based on measured dimensions specified in acceptance standards that are readily available at nuclear power plant sites.

- PNL recommends that alternative procedures and acceptance criteria be used in future cylinder head inspections. A wellestablished methodology for MT examinations may be found in Section $V$, Article 7 of the ASME Code (1983), and acceptance criteria for MT examinations may be found in ASME SA-613, Section 19. Methodology for liquid penetrant examinations may be found in ASME Section $V$, Article 6, and acceptance criteria in ASME SA-613, Section 20. The ASME standards just referenced are widely used throughout the nuclear industry.

- Cylinder heads with any through-wall weld repair of the fire deck should not be placed in nuclear standby service if the repair is performed from one side only (i.e., a "plug weld"). The coolant side of the fire deck is not readily accessible for weld repair. Without 
such access, a repair from the combustion side might leave defects on the coolant side that would compromise the integrity of the head.

- Following each engine operation, the engine should be air-rolled at least 4 hours, but not more than 8 hours, after engine shutdown. The cylinder cocks should be open for detection of water leakage into the cylinders. A second air-roll should be performed in the same manner approxinately 24 hours after engine shutdown. In addition, the engine should be air-rolled shortly before any planned start. If water or stean is ejected from any of the open cylinder cocks, the corresponding head should be removed and inspected. The cause of the leakage should be corrected before the engine is returned to service.

PNL notes that the air-start system rolls the engine much more rapidly than the barring-over device, and is therefore more effective for detection of water leakage into the cylinders. Individual engine owners may choose to bar-over an engine before the engine is airrolled, to reduce the possibility of engine damage in the event water is present in a cylinder. However, barring-over an engine should not be a substitute for air-rolling it.

\subsubsection{References}

Fajlure Analysis Associates (FaAA). August 1984. Evaluation of Cylinder Heads of Transamerica Delaval Inc. Series R-4 Diesel Engines. FaAA-84-5-12, Palo ATto, California.

Mississippi Power \& Light Company (L. F. Dale) letter dated July 30, 1984, to the NRC Office of Nuclear Reactor Regulation (H. R. Denton). Subject: Grand Gulf Nuclear Station Units 1 and 2. Supplemental Information on the Division 1, TDI Diesel Generator Inspection. File: 026D/L-860.0/M-018.0.

Resolution of Suffolk County Diesel Generator Contention Regarding Cylinder Heads. September 21, 1984. Before the Atomic Safety and Licensing Board, Docket No. 50-322-0L, in the Matter of Long Island Lighting Company (Shoreham Nuclear Power Station, Unit 1). Bound into transcript of hearing following page 25204.

TDI Diesel Generator Owners' Group. January 1985. TDI Diesel Generator Design Review and Quality Revalidation Report - Comanche Peak Steam Electric Station. Revision 1.

TOI Diesel Generator Owners' Group. February 1985. TDI Diesel Generator Design Review and Quality Revalidation Report - River Bend Station. Revision 1. 


\subsection{CYLIMDER HEAD STUDS}




\subsection{CYLINDER HEAD STUDS}

The cylinder head studs for TOI engines in nuclear service were evaluated by the Owners' Group. PNL's review of action taken by the Owners' Group is described in this section.

\subsubsection{Component Description}

Eight studs per cylinder are used to bolt the heads to the cylinder block. Together they transmit the firing load from the head to the block and provide a required preload on the cylinder head gasket.

Transamerica Delaval has employed studs of two designs in their engines. Studs of the original design have a shank of uniform diameter. Studs of the more recent design have a necked-down shank.

In a letter dated September 24, 1984, the Owners' Group (C. Ray) notified the TDI engine owners of a recommended modification to cylinder head studs with necked-down shanks, and provided a revised installation procedure for all cylinder head studs. The recommended modification applies to all studs with necked-down shanks except those purchased as TOI part No. 03-315-01-0A Revision $G$, which are manufactured in accordance with the design change. The modification involves removing the bottom two threads of the stud, so that the remaining threaded portion that enters the block will be located lower in the stud hole. This placement is intended to reduce the stresses in the top surface of the block.

\subsubsection{Failure History}

To date, no failure of cylinder head studs has occurred in nuciear standby diesel engines. However, isolated cylinder head stud failures have occurred in non-nuclear installations. TOI has determined that these failures were most likely due to insufficient preload.

\subsubsection{Owners' Group Evaluation}

Stone $\&$ Webster Engineering Corporation addressed the adequacy of the cylinder head studs for the Owners' Group. The objective of SWEC's effort was to evaluate the functional attributes of both TOI cylinder head stud designs. 
The actions taken by SWEC were documented in two SWEC reports (March 1984 , Apri1 1984) and in SWEC Calculation No. 245.1-M2 (March 1984).

\section{$4.11 .3 .1 \quad \underline{\text { Scope }}$}

SWEC's evaluation encompassed the following tasks:

- Review the differences between the two head stud designs.

- Determining the firing load applied to the studs via the cylinder heads.

- Evaluate the adequacy of the prescribed torque on the head stud nuts and the associated stud preioad.

- Evaluate the stresses in the studs and the resistance of the studs to fatigue failure.

- Evaluate the resistance of the stud threads to distortion.

\subsubsection{Results}

SWEC determined that the total applied mean stress and the alternating stress in the studs with straight shanks are $45.6 \mathrm{ksi}$ and $\pm 3.8 \mathrm{ksi}$, respectively, under full-load operating conditions and with the prescribed torque. The corresponding stresses in the studs with necked-down shanks were found to be $44.8 \mathrm{ksi}$ and $\pm 2.9 \mathrm{ksi}$, respectively. Using a Goodman diagram, SWEC compared these stresses with the ultimate tensile strength and endurance limit of the stud material and found that fatigue failure is unlikely so long as the studs are preloaded as specified.

SWEC investigated the possibility of thread distortion by calculating the maximum normal stress at the thread root diameter and comparing this stress to the yield strength of the stud material. SWEC found that the yield strength is not exceeded for either stud design for the given service conditions and installation procedures. Accordingly, SWEC concluded that thread distortion will not occur.

SWEC also investigated thermal stresses in the studs under worst-case hypothesized temperature differences, and found that the thermally-induced 
stresses would not exceed $5.4 \mathrm{ksi}$. This stress does not significantly alter the total applied stresses, according to SWEC.

\subsection{1 .3 .3 SWEC Conclusions}

SWEC's conclusions are as follows:

- The stud preload is sufficient to resist the total applied force by a comfortable margin. In addition, the stress levels in the shanks of both stud designs and at the thread root are acceptable, and thread distortion is not expected under the given loading conditions.

- Cyclic stresses carried by both stud designs are acceptable. However, the necked-shank design has a greater margin against fatigue failure due to its greater flexibility.

\subsubsection{PNL's Review}

PNL's review encompassed the two SWEC reports and the SWEC calculation cited in Section 4.11.3, and additional information requested from and provided by the Owners' Group (Ray June 20, 1984).

\subsubsection{Reviewers}

The following PNL consultants participated in this review:

- S. H. Bush, Review and Synthesis Associates

- A. J. Henriksen, A. J. Henriksen, Inc.

- B. J. Kirkwood, Covenant Engineering

- P. J. Louzecky, Engineered Applications Corporation

- the late A. Sarsten, Norwegian Institute of Technology.

\subsubsection{Scope}

PNL reviewed SWEC's analysis of the cylinder head studs, including:

- the analysis of steady and fluctuating loads

- fatigue analysis

- thread distortion anajysis

- thermal load analysis. 


\subsubsection{Conclusions}

Based on this review, and noting the absence of any failures of cylinder head studs in nuclear service, PNL concurs with SWEC that studs of both the straight-shank design and the tapered-shank design are suitable for service in diesel engines at nuclear power plants. This conclusion is predicated on installation of the studs in accordance with the procedures recommended by TDI (see Ray September 24, 1984).

PNL notes that the isolated cylinder head stud failures in non-nuclear installations have been attributed to insufficient torque on the nuts that secure the cylinder heads to the studs. This reinforces the importance of preloading the studs in accordance with TDI specifications discussed in the letter referenced above. Other than following DI's procedures during installation of the studs and heads, no maintenance or surveillance of the studs should be necessary.

\subsubsection{References}

Ray, C. L., Jr. June 20, 1984. Letter OGTP-85 (Duke Power Company) to C. BerTinger (NRC) transmitting answers to PNL's previous questions.

Ray, C. L., Jr. September 24, 1984. Letter OGTP-301-0-161 to J. Deddens (Gulf States Utilities) transmitting an owners' Group recommendation for rework of cylinder head studs.

Stone \& Webster Engineering Corporation. March 1984. Emergency Diesel Generator Cylinder Head Stud Evaluation. Calculation Number 245.1-M2, Boston, Massachusetts.

Stone \& Webster Engineering Corporation. March 1984. Emergency Diesel Generator Cylinder Head Stud Stress Analysis. Boston, Massachusetts.

Stone \& Webster Engineering Corporation. April 1984. Supplement to Emergency Diesel Generator Cylinder Head Stud Stress Analysis. Boston, Massachusetts. 


\subsection{ENGINE BASE AND BEARING CAPS: 8-CYLIMDER, DSR-4 SERIES ENGINES}




\subsection{ENGINE BASE AND BEARING CAPS: 8-CYLINDER, DSR-4 SERIES ENGINES}

Summarized in this section is PNL's review of the action taken by the Dwners' Group to evaluate the engine base and bearing caps for the TDI 8-cylinder, DSR-4 series engines installed at several nuclear power plants. A more detailed discussion of the scope of the work performed by the Owners' Group is presented in PNL-5200-11 Rev. 1 (Pacific Northwest Laboratory July 1985).

\subsubsection{Component Description}

The base assembly supports the crankshaft on bearing saddles and is fastened to both the upper engine assembly at the top and the engine foundation at the bottom. Functionally, the base assembly must support the upper engine, react loads from the crankshaft, and react firing loads transmitted via through-boits from the upper engine to the base. The bearing caps secure the crankshaft to the engine base at the main bearing saddles.

\subsubsection{Fatlure History}

Relatively few problems have been reported in TDI engine bases and bearing caps for either inline or V-block engines.

A number of cracks were found in the main bearing saddles of emergency diesel generators (EOGs) 102 and 103 at the Shoreham Nuclear Power Station (SNPS) during engine disassembly in 1983. These cracks emanated radially from the bearing cap stud holes toward the bearing saddle and, at the narrowest point, extended across the full width. Such cracks were found in 13 bearing cap bolt holes and were attributed to stud removal and replacement procedures that introduced excessive side loads in the stud holes.

In addition, damage was discovered in the SNPS EDG 102 engine base following the crankshaft failure in August 1983. The Dearing bore was displaced in an outward radial direction at three of the four bearing bolt holes of the No. 8 main bearing. This damage was attributed to the fatigue failure of the crankshaft and not to normal operating conditions. Repair consisted of milling the top of the base, reboring the main bearings, and fitting oversized bearings. No subsequent problems with the EDG 102 base have been reported. 
Cracks were also reported in the bearing saddles of DSR-46 engines in the U.S. Coast Guard icebreakers West Wind and North wind. The bearing cap stud preload was increased in these engines; no base assembly problems have been subsequentiy reported.

A through-bolt nut pocket failed in the engine base of one of the nine DSRV-16 engines at the Anamax mine near Tucson, Arizona. TOI concluded that this failure was due to reduced strength caused by nonferrous impurities in the engine base casting.

Two through-bolt failures were reported on a DSR-46 engine operated by Copper Valley Electric in Valdez, Alaska, and were attributed to insufficient bolt preloading. The preload was increased, and no subsequent problems have been reported.

\subsubsection{Owners' Group Evaluation}

Failure Analysis Associates (FaAA), a consultant to the Owners' Group, evaluated the structural adequacy of the engine base and bearing cap assemblies to carry the loads imposed by the crankshaft and by the engine block-to-base through-bolts and nuts. FaAA's conclusions and recommendations for the 8-cylinder OSR-4 series engines are presented in Design Review of Engine Base and Bearing Caps for Transamerica Delaval Diesel Engines (FaAA-84-4-1 Rev. 1, July 1984). Operating experience with TDI engine base assembities in both nuclear and non-nuclear applications is discussed in FaAA-84-4-1 and in FaAA-84-6-53, Design Review of Engine Base and Bearing Caps for Transamerica Delaval DSRV-16 Diesel Engines (August 1984).

\subsubsection{Scope}

FaAA performed stress and fatigue analyses of the following components of the engine base assembly:

- main bearing saddles

- engine block-to-base through-bolts and nuts

- nut pockets

- main bearing caps, studs, and nuts. 
FaAA's evaluation yielded the following results:

- main bearing saddles - The factor of safety against fatigue failure in the most highly stressed region of the bearing saddles is 1.75 . Further, the stress intensity factors for the cracks already present in the bearing saddle areas of the Shoreham EOG 103 engine are all below the threshold value for crack growth in fatigue at full engine load $(3500 \mathrm{~kW})$, with a factor of safety of 1.1 or larger for these cracks. Cracks as large as 0.040 inch by 0.259 inch at the area of maximum stress should not grow, according to the FaA analysis. However, FaAA recomnends periodic inspections to verify that crack growth does not occur.

- main bearing caps - The factor of safety against fatigue failure is 2.42 or greater throughout the bearing cap, and the factor of safety against local yielding in the area of maximum compressive stress is 1.18. FaAA noted that if local yielding were to occur, it would be confined to a small area at bearing No. 6 only, and would not cause a bearing failure.

With the conservative assumption that the contacting surfaces are lubricated, the friction force to resist lateral movement of the bearing cap is 62,800 pounds. The maximum lateral load found from the Clevite journal orbit computer program is 58,500 pounds, acting on the bearing cap at the No. 6 bearing. Thus, the friction force is sufficient to react the maximum lateral load with a factor of safaty of 1.07 .

- bolting and nuts - The through-bolting, bearing studs, and associated nuts have sufficient strength for unlinited operation at full load, with a factor of safety of 1.67 for the through-bolting and higher factors of safety for the studs and nuts.

- nut pockets - Provided that the base casting material has strength equivalent to that of Class 40 grey cast iron, the factors of safety for the through-bolt and the bearing stud nut pockets are 3.51 and 1.87 , respectively. 


\subsubsection{Conclusions and Recommendations}

4.12.3.2.1 FaAA Investigation. FaAA presented the following conclusions regarding the base assembly for the 8-cylinder DSR-4 series engines:

- All components of the base assembly have sufficient strength to operate indefinitely at full load, provided that the base casting and bolting components meet their nominal material and dimensiona] specifications, that the components have not been damaged, and that bolt torque specifications are maintained.

- Problems encountered with TOI engine bases in non-nuclear service are not generic in the engines supplied for nuclear standby service. TDI found that these problems resulted from inadequate bolt preloads and, in the case of one engine base at the Anamax mine in Arizona, from marginal strength due to inferior quality of a casting.

- To ensure that the friction force at the bearing cap/saddle interface is adequate for resisting movement of the bearing cap under lateral crankshaft loads, the mating surfaces should be thoroughly cleaned with solvent prior to first assembly and any reassembly.

- Cracks found in 13 bearing cap stud holes of the EDG 103 engine base at the Shoreham Nuclear Power Station were most likely caused by an inappropriate method of stud removal that introduced excessive side loads in the stud holes. These cracks were monitored for approximately 300 hours of engine operation, including 100 hours at full load $(3500 \mathrm{~kW})$. Furthermore, stress intensity factors computed by FaAA for these cracks are all below the threshold value of crack growth in fatigue at fult engine load. These observations and calculations indicate that the cracks will not propagate. However, FaAA recommends periodic inspections to verify that crack growth does not occur.

- Damage found at the No. 8 main bearing position of the EOG 102 engine base at the Shoreham Nuclear Power Station was caused by failure of the original crankshaft in that engine. The bearing bore was 
displaced radially, and cracks were found in several of the bearing cap stud holes. Snall cracks remained in the stud holes after machining operations to repair the base.

4.12.3.2.2 Design Review/Quality Revalidation Reports. Included in the DR/OR report prepared by the Owners' Group for the Shoreham Nuclear Power Station (December 1984) is a recommendation that the EDG 102 and EDG 103 bearing saddles with known cracks be inspected periodically in accordance with the maintenance procedures outlined in Engineering \& Design Coordination Report (E\&OCR) F-46505. The latter report calls for fluorescent dye, liquid penetrant examinations of these saddles at alternate shutdowns for power plant refueling. Any crack growth is unacceptable, according to the $O R / Q R$ report.

TOI 8-cylinder OSR-4 series diesel generators are installed also at the River Bend Station. The Owners' Group recominends in the DR/QR report for River Bend (February 1985) that, at each power plant refueling outage, a visual inspection be performed of the area adjacent to the main bearing stud nut pockets of each bearing saddle. Similar inspections are recommended by the Owners' Group in the OR/OR reports for TDI I6-cylinder DSRV-4 diesel generators at Comanche Peak (January 1985) and Perry (December 1984). The purpose of this visual inspection, as stated in the $O R / Q R$ report for Comanche Peak, is to verify the continued absence of cracking of the type that was observed in the base of one engine at the Anamax mine.

\subsubsection{PNL's Review}

PNL's review encompassed the FaAA and Owners' Group reports referenced in Section 4.12 .3 .

\subsubsection{Reviewers}

The following PNL consultants participated in this review:

- S. H. Bush, Review and Synthesis Associates

- A. J. Henriksen, A. J. Henriksen, Inc.

- 8. J. Kirkwood, Covenant Engineering

- P. J. Louzecky, Engineered Applications Corporation

- the late A. Sarsten, Norwegian Institute of Technology. 
In addition, J. C. Spanner of PNL's Nondestructive Testing Section reviewed nondestructive testing procedures for the engine base assembly.

\subsubsection{Conclusions and Recommendations}

PNL concurs with the Owners' Group conclusion that the engine base and bearing cap assembly for TDI 8-cylinder DSR-4 series diesel generators is adequate for its intended service at nuclear power p1ants, subject to implementation of the maintenance and surveillance recommendations of FaAA and the Owners' Group and to the additional PNL recomendations discussed later in this section. The stress, fatigue, and fracture analyses documented in FaAA-84-4-1 substantiate the adequacy of the components of this assembly, and the results of these analyses are supported by the operating history sumarized in FaAA84-4-1 and in FaAA-84-6-53. Relatively few problems with engine base assemb1ies have been reported; the reasons for the problems are well understood, and corrective action (principally maintaining bolt preloads at specified values) has been effective.

One of the recomendations of the Owners' Group is to inspect certain bearing saddles of the EDG 102 and EDG 103 engines at the Shoreham Nuclear Power Station at alternate power plant refueling outages, to verify that existing cracks do not grow. The $O R / Q R$ report for Shoreham (December 1984) recommends a magnetic particle inspection, and references E\&DCR F-46505 for details of the procedure. However, the latter report calls for a fluorescent dye, Tiquid penetrant inspection. PNL considers either type of inspection to be satisfactory for monitoring the known surface-connected cracks.

In PNL's opinion, the visual inspection of the engine base recommended by the Owners' Group in several DR/QR reports is a conservative precaution to verify the continued absence of cracking in the vicinity of the stud nut pockets of the bearing saddles. PNL notes that camshaft gallery cracks in the original block for the EOG 103 engine at the Shoreham Nuclear Power Station could be seen by the naked eye as cracks in the white coating applied by TDI to the surface. This suggests that a crack in the engine base will also cause a crack in the white coating applied by TOI to the base, as assumed by the Owners' Group. Therefore, PNL concurs that it is not necessary to remove the coating to perform the inspection. 
PNL recommends that the following provisions be included in maintenance and surveillance plans for the engine base and bearing caps, in addition to those recommended by the Owners' Group:

- The engine base visual inspection recommended by the Owners' Group in the DR/QR report for River Bend should be performed on all TDI DSR-4 series engines at nuclear power plants. Because only one engine base (at the Anamax mine) has been reported to have the type of cracking that this inspection is intended to detect, the inspection will serve to verify the continued absence of an atypical problem rather than a problem representative of a design deficiency. Each engine that may be subject to this problem needs to be inspected to ensure that the problen does not exist. According to the Owners' Group, the inspection should be performed at each refueling outage of the power plant in which the engine is installed. The frequency of the inspection could be reconsidered if warranted by the inspection results over several refueling cycles.

- The mating surfaces at the bearing cap/saddle interface should be inspected whenever they are disassembled, to ensure the absence of surface imperfections that might prevent tight bolt-up. Imperfections should be removed by stoning, machining, or replacement of parts, as needed.

\subsubsection{References}

Failure Analysis Associates (FaAA). July 1984. Design Review of Engine Base and Bearing Caps for Transamerica Delaval Diesel Engines. FaaA-84-4-1 Rev. 1, Palo A7to, California.

Failure Analysis Associates (FaAA). August 1984. Design Review of Engine Base and Bearing Caps for Transamerica Delaval DSRV-16 Diesel Engines. FaaA-84-6-53, Palo ATto, California.

Pacific Northwest Laboratory. July 1985. Review of Engine Base and Bearing Caps for Transamerica Delaval DSR-48 Diesel Engines. PNL-5200-11 Rev. 1, Richland, Washington.

Stone \& Webster Engineering Corporation. Undated. Engineering \& Design Coordination Report No. F-46505 for the Shoreham Nuclear Power Station. Boston, Massachusetts. 
TDI Diesel Generator Owners' Group. January 1985. TDI Diesel Generator Design Review and Quality Revalidation Report - Comanche Peak Steam Electric Station. Revision 1.

TDI Diesel Generator Owners' Group. December 1984. TDI Diesel Generator Design Review and Quality Revalidation Report - Perry Nuclear Power Plant.

TDI Diesel Generator Owners' Group. February 1985. TDI Diesel Generator Design Review and Quality Revalidation Report - River Bend Station. Revision 1.

TDI Diesel Generator Owners' Group. December 1984. TDI Diesel Generator Design Review and Quality Revalidation Report - Shoreham Nuclear Power Station. Revision 1. 


\subsection{ENGINE BASE AND BEARING CAPS: DSRV-4 SERIES EN6INES}




\subsection{ENGINE BASE AND BEARING CAPS: DSRV-4 SERIES ENGINES}

The Owners" Group evaluated the engine base and bearing caps for the TDI DSRV-4 series engines with 12, 16, and 20 cylinders. This section describes PNL's review of action taken by the Owners' Group. The scope of work performed by the Owners' Group is discussed in more detail in PNL-5200-12 Rev. 1 issued previously (Pacific Northwest Laboratory June 1985).

\subsubsection{Component Description}

The engine base assembly and bearing caps for the DSRV-4 series engines are functionally identical to those for the DSR-4 series engines as described in Section 4.12 .1 of this report.

\subsubsection{Failure History}

The failure history of this component is documented in Section 4.12.2 of this report.

\subsubsection{Owners' Group Evaluation}

Failure Analysis Associates (FaAA), a consultant to the Owners' Group, evaluated the structural adequacy of the engine base and bearing cap assemblies to carry the loads imposed by the crankshaft and by the crankcase-to-base through-bolts. FaAA's conclusions and recommendations for the DSRV-4 series engines are presented in Design Review of Engine 8ase and Bearing Caps for Transamerica Delaval DSRV-16 Diesel Engines (FaAA-84-6-53, August 1984).

\subsubsection{Scope}

FaAA performed stress and fatigue analyses of the following components of the engine base assembly for the 16-cylinder DSRV-4 engine:

- main bearing saddles

- crankcase-to-base through-bolts and nuts

- nut pockets

- main bearing caps, studs, and nuts.

\subsubsection{Results}

FaAA found adequate safety factors for all components evaluated. The calculated factor of safety in fatigue for each of the components is as follows: 


\begin{tabular}{lc}
\multicolumn{1}{c}{ Component } & Factor of Safety \\
\hline Bearing saddle & 1.31 \\
Bearing cap & 3.35 \\
Bearing cap stud & 1.30 \\
Through-bolt & 1.45 \\
Bearing stud nut pocket & 1.32 \\
Through-bolt nut pocket & 2.50
\end{tabular}

Friction forces preventing lateral movement of both the bearing cap and the crankcase also were evaluated. The coefficient of friction used to compute the lateral forces on the cap was for steel on cast iron in the presence of a lubricant. Calculated factors of safety are as follows:

$\begin{array}{lc}\frac{\text { Component }}{\text { Cap lateral movement }} & \text { Factor of Safety } \\ \text { Crankcase lateral movement } & 1.19 \\ 1.48\end{array}$

\subsubsection{Conclusions and Recommendations}

4.13.3.3.1 FaAA Investigation. FaAA reached the following conclusions:

- All components of the base assembly for the 16-cylinder DSRV-4 series engine have sufficient strength to operate for indefinite periods at full load, provided that the base casting and bolting components meet their nominal material and dimensional specifications, that the components have not been damaged, and that bolt torque specifications are maintained. This conclusion also applies to the 12- and 2D-cylinder DSRV-4 engines, because the base assemblies of all DSRV-4 engines are similar and because the bearing loads in the latter two engines are lower than those in the 16-cylinder engine.

- Problens encountered with engine bases are not generic in the engines supplied for nuclear service. TOI found that these problems resulted from inadequate bolt preloads and, in the case of one engine base at the Anamax mine in Arizona, from marginal strength due to inferior quality of a casting. 
- To ensure that the friction at the bearing cap/saddle interface is adequate to prevent movement of the bearing cap under lateral crankshaft loads, the mating surfaces should be thoroughly cleaned with solvent prior to first assembly and any reassembly.

4.13.3.3.2 Design Review/Quality Revalidation Reports. Among the nuclear power plants that utilize 16-cylinder OSRV-4 series engines are the Comanche Peak Steam Electric Station and the Perry Nuclear Power Plant. To verify the continued absence of cracking of the type that was observed in the base of one 16-cylinder engine at the Anamax mine (see Section 4.12 .2 of this report), the Owners' Group recommends in the design review/quality revalidation (DR/QR) report for Comanche Peak (January 1985) that a visual inspection of the engine base be performed at each power plant refueling outage. This inspection, according to the $D R / Q R$ report, should include the area adjacent to the main bearing stud nut pockets of each bearing saddle, and should be performed under good lighting several minutes after a thorough wipedown of the surfaces.

As discussed in the Comanche Peak $D R / Q R$ report, the Owners' Group assumes that a crack in the base will cause a crack in the white coating covering the interior of the base and will, therefore, be detectable by a visual inspection. The Owners' Group recommends that any crack detected in this manner be investigated further before the engine is returned to service.

The visual inspection described above is also recommended in the $D R / Q R$ report for Perry (December 1984). This inspection is in addition to the maintenance and surveillance recommendations described in FaAA-84-6-53.

\subsubsection{PNL's Review}

PNL's evaluation of the engine base and bearing caps issue encompassed

- review of report FaAA-84-6-53 (August 1984)

- review of the plant-specific recommendations for maintenance and surveillance of the engine base and bearing cap assemblies presented by the Owners' Group in the DR/QR reports for Comanche Peak (January 1985) and Perry (December 1984). 


\subsubsection{Reviewers}

The PNL consultants who participated in this review were

- S. H. Bush, Review and Synthesis Associates

- A. J. Henriksen, A. J. Henriksen, Inc.

- B. J. Kirkwood, Covenant Engineering

- P. J. Louzecky, Engineered Applications Corporation.

In addition, J. C. Spanner of PNL's Nondestructive Testing Section reviewed the nondestructive testing procedures for the engine base assembly.

\subsubsection{Conclusions and Recommendations}

Based on a review of the reports cited in Section 4.13.4, PNL concurs with the Owners' Group conclusion that the engine base and bearing cap assemblies for the TOI 12-, 16-, and 20-cylinder DSRV-4 series engines are adequate for their intended service at nuclear power plants. PNL also concurs with the recormendations of the Owners' Group for maintenance and surveillance of these assemblies.

The FaAA report notes that the conclusions regarding the adequacy of these components for the DSRV-16 engine can be applied as well to the DSRV-12 and DSRV-20 engines. The engine base, crankshaft, connecting rods, and pistons are similar for all models of the DSRV-4 series engines. Furthermore, the bearing loads calculated by FaAA for the DSRV-12 and DSRV-20 engines are lower than those for the DSRV-16. Under these conditions, PNL concurs that FaAA's conclusions regarding the engine base assembly for the latter engine also apply to the former two engines.

With respect to maintenance and surveillance for the engine base and bearing caps, PNL notes that, once the caps are installed according to the Owners' Group recommendations and torqued to TDI specifications, they should require no further attention until they are removed for other reasons. FaAA's analysis of the friction force resisting lateral motion of the bearing caps (which was calculated using the conservative assumption that the contacting surfaces are lubricated) led the Owners' Group to recommend that all lubricant be renoved from the mating surfaces when the bearing caps are installed. PNL concurs that this should be done whenever a cap is reassembled. 
The visual inspection of the engine base recommended by the Owners' Group in several DR/QR reports is viewed by $P N L$ as a conservative precaution to verify the continued absence of cracking in the vicinity of the stud nut pockets of the bearing saddles. PNL notes that camshaft gallery cracks in the original block for the EDG 103 engine at the Shoreham Nuclear Power Station could be seen by the naked eye as cracks in the white coating applied by TOI to the surface. This suggests that a crack in the engine base will also cause a crack in the white coating applied by TOI to the interior of the base, as assumed by the Owners' Group. Therefore, PNL concurs that it is not necessary to remove the coating to perform the inspection.

PNL recommends that the following provisions be included in maintenance and surveillance plans for the engine base assemblies, in addition to those recommended by the Owners' Group:

- The engine base visual inspection recommended by the Owners' Group in the DR/QR reports for both Comanche Peak and Perry should be performed on al1 TDI OSRV-4 engines at nuclear power plants. Because only one engine base (at the Anamax mine) has been reported to have the type of cracking that this inspection is intended to detect, the inspection will serve to verify the continued absence of an atypical problem rather than a problem representative of a design deficiency. Each engine that may be subject to this problem needs to be inspected to ensure that the problem does not exist. According to the Owners" Group, the inspection should be performed at each refueling outage of the power plant in which the engine is installed. The frequency of the inspection could be reconsidered if warranted by the inspection results over several refueling cycles.

- The mating surfaces at the bearing cap/saddle interface should be inspected whenever they are disassembled, to ensure the absence of surface imperfections that might prevent tight bolt-up. Imperfections should be removed by stoning, machining, or replacement of parts, as needed. 


\subsubsection{References}

Failure Analysis Associates (FaAA). August 1984. Design Review of Engine Base and Bearing Caps for Transamerica Delaval DSRV-16 Diesel Engines. FaAA-84-6-53, Pato Alto, California.

Pacific Nortinwest Laboratory. June 1985. Review of Engine Base and Bearing Caps for Transamerica Delaval DSRV-12, DSRV-16, and DSRV-20 Diesel Engines. PNL-5200-12 Rev. 1, Richland, Washington.

TDI Diesel Generator Owners' Group. January 1985. TDI Diesel Generator Design Review and Quality Revalidation Report - Comanche Peak Steam Electric Station. Revision 1.

TOI Diesel Generator Owners' Group. December 1984. TDI Diesel Generator Design Review and Quality Revalidation Report - Perry Nuclear Power Plant. 
4.14 FUEL OIL INJECTION TUBING 


\subsection{FUEL OIL INJECTION TUBING}

This section documents PNL's review of action taken by the Owners' Group to evaluate the fuel oil injection tubing used on TDI emergency diesel generators installed in nuclear power plants.

\subsubsection{Component Description}

The high pressure fuel oil injection lines transfer fuel from the high pressure fuel injection pump to a fuel injector nozzle at a specific time in the engine operation cycle. The injection tubing must be able to withstand the effects of pulsating fuel pressure. These pressure pulses are high (going from $3 \mathrm{ksi}$ to $14.5 \mathrm{ksi}$ ), brief (0.02-second duration), and rapid (one pulse every 0.27 second per cylinder). The principal tubing stresses are generated by the effects of fuel pressure and pressure pulses.

The TDI high pressure fuel oil injection tubing has a nominal wall thickness of 0.1563 inch and a nominal outer diameter of 0.500 inch. TDI requires the tubing material to be efther SAE-1008 or SAE-1010 carbon steel.

The injection tubing is connected to the injector punps and the injector nozzles by compression fittings manufactured in accordance with the tolerances of an SAE type 2 diesel injection tube fitting for 0.5-inch tubing. TDI uses the SAE type 2 fittings with a cylindrical compression collar on all nuclear standby service diesel injection lines.

\subsubsection{Failure History}

A fuel oil injection tube on a TDI emergency diesel generator at the Shoreham Nuclear Power Station failed during preoperational engine testing. TDI filed a 10 CFR 21 notification on July 20, 1983, to alert NRC to a deficiency involving a possible draw seam on the inside diameter of the high pressure tubing on TDI engines supplied for Shoreham, Grand Gulf, and San Onofre Unit 1. At approximately the same time as the notification, a fuel injection tube in the Division 1 EQG at Grand Gulf unit 1 also failed. Subsequent analysis of the failed tubing from Grand Guif revealed that this faiture was caused by a draw seam as described in the TDI notification. 
Draw seams are defects that occur on the inner surface of tubing. They may be formed either by a slag inclusion in the steel billet during the piercing step prior to drawing, or by a defective mandrel during the initial extrusion phases of the forming process. Additional rolling can lap over the flaw, causing the draw seam. One characteristic of a draw seam is that it extends over either the entire length of the draw or, at least, a significant portion of it. The fuel injection line operating pressure, which cycles from approximately 3 to $15 \mathrm{ksi}$, provides the fatigue loading that can produce cracks along the stress riser provided by the presence of the draw sean.

Other instances of high pressure fuel oil leaks have been observed to occur because of improper assembiy of compression fittings.

\subsubsection{Owners' Group Evaluation}

Stone \& Webster Engineering Corporation (SWEC) evaluated the TDI high pressure fuel oil injection tubing for the Owners' Group. The objectives of this evaluation were to determine the adequacy of the tubing as installed on TOI nuclear standby diesel generators, to establish the cause of the known failures, and to establish criteria which, if implemented, would provide adequate assurance that the tubing would perform its intended function. SwEC's review is documented in a report on this subject dated April 1984.

\subsubsection{Scope}

SWEC's investigation

- determined the maximum stresses in the fuel injection lines in accordance with ASME Section III stress and fatigue analysis

- compared the calculated stresses to the strength of the tubing material

- determined the maximum inner diameter flaw size that will not propagate to tube failure

- evaluated the adequacy of test procedures to detect inner diameter flaws

- evaluated the adequacy of the compression-type connectors of the fuel injection lines 
- evaluated the erosion and corrosion resistance of the tubing to the fuel oil used in nuclear standby service applications.

\subsubsection{Results}

The stresses in the fuel oil injection tubing were calculated for several loading conditions. The single largest contributor to the maximum tubing stress is the hoop and radial stress induced by the maximum fuel pressure. This pressure-related stress was calculated to be 11,596 psi. The maximum tubing stress caused by dead weight was 190 psi; by seismic accelerations, 2,287 psi; and by engine vibration accelerations, $170 \mathrm{psi}$. The total of all of the above stresses is 14,243 psi.

The total of all stresses calculated for the fuel oil injection tubing was compared to the allowable stresses from the ASME Code, Section III, for Class 2 components. The allowable stresses are 14,700 psi for SAE-1008 and 15,900 ps $i$ for SAE-1010. Because the maximum calculated total stress was less than the code allowable for both materials, either was deened suitable from a maximum stress standpoint.

The effects of the pulsating fuel pressure with respect to the durability of the tubing design were investigated in a fatigue analysis. Fatigue of the unflawed tubing was found not to be a problem. A linear elastic fracture mechanics analysis was also performed to determine the maximum inner surface flaw that would not propagate to tube failure. The critical flaw depth was determined to be 0.0054 inch. Flaws shallower than these were predicted to not propagate in tubes having no eccentricity. (a) SWEC also calculated the possible effects of eccentricity of tubing wall thickness on the critical flaw depths (SWEC undated; SWEC March 1984). Based on information supplied by Superior Tube $C_{0}$. that eccentricity of the subject tubing does not exceed 0.050 inch, the maximum nonpropagating flaw size was found to be 0.0044 inch under the influence of inaximum eccentricity.

(a) This result supercedes a determination that the critical fiaw size was between 0.0048 and 0.0055 inches reported in SWEC's April 1984 report (C. Malovrh, October 1985). 
Because some failures of fuel injection tubing were caused by leaking fittings, the cause of these failures was investigated. All instances of leaking fittings on fuel oil injection tubing on TDI engines in nuclear applications were attributed to improper tightening of the fittings. The fittings themselves were judged adequate.

The fuel oil injection tubing's resistance to erosion and corrosion was discussed. There was no reported history of corrosion or erosion of fuel oil injection tubing on TDI engines. The design of the fuel injection pumps and the bends in the fuel injection lines are intended to reduce the erosion potential.

\subsubsection{Conclusions and Recomnendations}

SWEC's conclusions and recommendations are provided next. Additional recommendations of the Owners' Group identified from a review of Owners' Group correspondence, transcripts of NRC/Owners' Group meetings, and representative $Q R / Q R$ reports are also presented.

4.14.3.3.1 SWEC Conclusions. SWEC concluded that the TDI fuel injection high pressure tubing meets the stress criteria of an AS:AE Section III Class 2 piping design. However, SWEC recommended that future tubing purchases specify SAE 1010 material since it is slightly stronger than SAE 1008 material. In addition, SWEC recommended that high pressure tubing fabricated by processes designed to induce compression stresses at the inner surface be investigated for diesel engines in nuclear service. SWEC also recomnended the use of shrouded lines to reduce the possibility of engine fires.

SWEC concluded from a fatigue analysis that the tubing can be expected to perform its function without leaking for an unlimited period of time, provided the tubing inner surface contains no flaws larger than 0.0044 inch, including effects of eccentricity. SWEC noted that tubing which has undergone $10 \mathrm{milli}$ ion fuel pressure pulses without leaking provides reasonable assurance that the tubing contains no flaws larger than the critical size. Nevertheless, SWEC recommended that all installed tubes be inspected to detect fiaws greater than 0.004 inch in the inner surface. 
SWEC also concluded that the compression fittings are adequate, provided that they are installed properiy.

4.14.3.3.2 Owners'Group Conclusions. Examples of the implementation of SWEC's recommendations by the Owners' Group may be found in the design review/ quality revalidation (DR/QR) reports for Shoreham and Comanche Peak. FaAA NDE Procedure 11.10 (May 17, 1984) is referenced for eddy-current inspections of the fuel-oil tubing. This procedure provides for examination of "the full extent of the high pressure fuel lines accessible with the rotating probe." The inspection involves inserting the probe several inches into the tube beyond the area of the compression fittings. According to the $D R / Q R$ reports, the procedure has been qualified to reliably detect flaws in the inner surface of the tubing as small as 0.003 inch deep with an accuracy of \pm 0.0005 inch.

The Owners' Group also recommends that compression fittings on each injection line be inspected for fuel leaks, and that this inspection be performed while the engine is running or whenever the fittings have been disturbed. Any evidence of leakage is unacceptable.

\subsubsection{PNL'S Review}

\subsubsection{Participants}

The following PNL consultants participated in PNL's review of the fuel oil injection tubing:

- S. H. Bush, Review and Synthesis Assocjates

- A. J. Henriksen, A. J. Henriksen, Inc.

- B. J. Kirkwood, Covenant Engineering

- P. J. Louzecky, Engineered Applications Corporation.

In addition, J. C. Spanner of PNL's Nondestructive Testing Section reviewed procedures referenced by the Owners' Group for inspecting the injection tubing.

4.14.4.2 Conclusions and Recomnendations

PNL reviewed the stress and fatigue calculations performed by SWEC that are documented in the references cited in Section 4.14 .5 of this report. Noting that a fuel oil injection tube with a 0.006 -inch defect failed at Shoreham, PNL regards SWEC's calculated critical flaw size of 0.0054 inch to be 
realistic. This flaw size does not account for the effect of eccentricity in the tube wall. Accounting for this effect reduces the maximum nonpropagating flaw size calculated by SWEC to 0.0044 inch. In PNL's opinion, the maximum allowable flaw size of 0.004 inch recommended by SWEC (April 1984) is not sufficiently conservative in light of the critical flaw size just mentioned.

According to the $D R / Q R$ report for Comanche Peak, tubing with flaws deeper than 0.003 inch will be rejected. The Owners' Group also recomnends this acceptance criterion for engines at other nuclear power plants (Transcript of NRC/Owners' Group meeting on July 11, 1984). PNL concurs with this criterion, and also concurs with the Owners' Group that the recommended inspection procedure (FaAA NDE Procedure 11.10) is appropriate for this application.

PNL concurs with SWEC's recommendations that 1) replacenent fuel oil injection tubing be fabricated from SAE-1010 steel rather than SAE-1008 steel because the former is stronger, and 2) the injection tubing should be shrouded to prevent engine fires in the event of a tubing leak. Subject to the SWEC recommendations, the Owners' Group criterion of 0.003 inch as the 1 imit on allowable depth of flaws, and to the additional PNL recommendations that follow, PNl concurs with the Owners' Group that the fuel oil injection tubing analyzed by SWEC is suitable for use on TOI engines installed at nuclear power plants. PNL's recommendations are as follows:

- All fuel oil injection tubing on each engine should be inspected before the engine is initially placed in nuclear standby service. Inspection of each tube at both ends within the limitations imposed by tube bends is adequate. FaAA NOT Procedure 11.10 should be used for the inspection. An alternative procedure may be used if the procedure is verified to reliably detect a minimum $f l a w$ size of 0.003 inch on the inside surface of the tube. Tubing with flaws deeper than 0.003 inch should be rejected.

- Fittings for the injection tubing should be installed and inspected in accordance with the manufacturer's recommendations. The information reviewed by PNL includes no specific instructions for the assembly and tightening of the fittings. Any nuclear plants that do 
not already have such instructions should get them from the manufacturer and incorporate them into their maintenance plans.

- Any injection tubing that is not shrouded on TDI engines in nuclear standby service should be shrouded at the first power plant refueliny outage.

- Replacement tubing should be examined over its full length prior to bending, and any tubing with flaws deeper than 0.003 inch should be rejected. This full-length inspection is recommended for replacement tubing because PNL is aware that some intermittent indications have been found in the injection tubing already examined. PNL suggests that an eddy-current probe capable of traversing the entire tube bore be used for this examination (i.e., the examination would be from the inside of the tube rather than the outside along the entire length).

- Newly-installed injection tubing and fittings should be visually inspected for leaks following engine operation. PNL suggests that these inspections be performed only after the engine is shut down, and that the inspector look for wet fittings or other signs of leakage. Inspection of the tubes during engine operation may be hazardous because of the high pressure of the fuel within the tube.

\subsubsection{References}

Failure Analysis Associates. May 17, 1984. "Eddy-Current Inspection Procedure High Pressure Fuel Lines - Carbon Stee1." NDE Procedure 11.10, Palo Alto, Calfornia.

Malovrh, $C$, and V. Zilberstein. October 15, 1985. Stone \& Webster Engineering Corporation letter no. 4388 to D. A. Dingee (PNL), "TDI Diesel Fuel Injection Lines, Long Island Lighting Company, Shoreham Nuclear Power Station Unit 1," providing clarification on critical flaw size analysis.

Stone Webster Engineering Corporation. Undated. Effect of Eccentricity on the Maximum Nonpropagating Longitudinal Flaw Size in Diesel Fuel Injection Tubing. (Supplement to Stone \& Webster, March 1984). Boston, Massachusetts.

Stone \& Webster Engineering Corporation. March 1984. Effect of Preexisting Longitudinal Flaws on Fitness of Diesel Fuel Injection Line Jubing for Service. 11600-MED-1, Rev. 1. Boston, Massachusetts. 
Stone \& Webster Engineering Corporation. April 1984. Emergency Diesel Generator Fuel $0 i 1$ Injection Tubing. Boston, Massachusetts.

TDI Diesel Generator Owners' Group. December 1984. TDI Diesel Generator Design Review and Quality Revalidation Report - Shoreham Nuclear Power Station. Revision 1.

TDI Diesel Generator Owners' Group. January 1985. TDI Diesel Generator Design Review and Quality Revalidation Report - Comanche Peak Steam Electric Station. Revision 1.

U.S. Nuclear Regulatory Commission (NRC). July 11, 1984. Transcript of TDI Diesel Generator Owners' Group meeting, Charlotte, North Carolina. 


\subsection{JACKET HATER PUMP}




\subsection{JACKET WATER PUMP}

This section documents PNL's review of action taken by the Owners' Group to resolve questions about the jacket water pumps installed on the TDI engines in nuclear service.

\subsubsection{Component Description}

Jacket water pump designs differ slightly, depending on the model of the engine in which the pump is installed.

\subsubsection{DSR-48 Engine Jacket Water Pump}

The engine driven jacket water pump used on DSR-48 engines is a singlestage centrifugal type driven by a gear off the crankshaft. At full load engine speed of $450 \mathrm{rpm}$, the pump speed is $1928 \mathrm{rpm}$. The pump is designed to deliver approximately $800 \mathrm{gpm}$ of treated water to the cylinder jackets, turbocharger, intercooler, lube oil cooler, and jacket water heat exchanger at a total dynamic head of $88 \mathrm{ft}$ of water.

The shaft in the current Shoreham pump design is fabricated from Type 303 stainless steel. On one end of the shaft is a \#4 Morse taper on which the impeller is shrunk. In addition, the ductile iron impeller is retained with a washer and a nut, which are applied with a prescribed torque. On the other end of the shaft, the hardened carbon steel water pump year is shrunk on a \#5 Morse taper. The gear is retained with a washer, castellated nut, and cotter pin.

The cast iron impeller on the water pumps at River Bend and Rancho Seco is shrunk on the type 303 stainless steel shaft, using a procedure similar to that at Shoreham. A \#5 Morse taper is used at the impeller end of the shaft with a keyway. The gear end of the shaft is similar to that at Shoreham.

\subsubsection{DSRV-12 and DSRV-16 Engine Jacket Water Pumps}

The DSRV-12 and -16 engine jacket water pumps used at the Catawba, Comanche Peak, Grand Gulf, Midland, Perry, Shearon Harris, and Vogtle plants are a single-stage centrifugal type driven through a spline coupling by the water pump gear. At full load engine speed of $450 \mathrm{rpm}$, the pump speed is $1470 \mathrm{rpm}$. The pump is designed to deliver 1800 to $2300 \mathrm{gpm}$ (depending on engine size and cooling system design) of treated water to the cylinder 
jackets, turbocharger, intercooler, lube oil cooler, and jacket water heat exchanger at a design head of $70 \mathrm{ft}$ of water.

The 303 stainless steel shaft in these pumps is larger than those in the R-48 engines. On one end, the bronze impeller is mounted on a Morse taper and a keyway. The impeller is driven onto the shaft taper by an impeller nut torqued to $80 \mathrm{ft}-1 \mathrm{~b}$. On the other end of the pump shaft, an external spline is mounted on a taper and a keyway. It is held in place by a castellated nut and cotter pin. The pump shaft is driven through an internally splined coupling that engages this external spline.

\subsubsection{OSRV-20 Engine Jacket Water Pump}

The jacket water pumps on the DSRV-20 engines at San Onofre are a singlestage centrifugal type that are driven from the crankshaft gear through an idler gear. The pump is designed to deliver approximately $1800 \mathrm{gpm}$ of treated water to the cylinder jackets, turbocharger, intercooler, labe oil cooler, and jacket water heat exchanger at $110 \mathrm{ft}$ total dynamic hear, when operating at 1640 rpm.

The impeller end of the 303 stainless steel pump shaft is tapered and has a keyway similar to those on the $V-12$ and $y-16$ engine pumps. The bronze impeller is driven onto the taper by torquing of the impeller nut. Torque is transmitted through the key to the impeller. On the other end of the pump shaft, the water pump drive gear is mounted on a straight keyed fit. It is held in place by a castellated nut and cotter pin.

\subsubsection{Failure History}

In the original jacket water pumps installed on the DSR-48 Shoreham engines, both the impeller and gear were keyed to the shaft on a straight slide fit. This design was modified to utilize a Morse taper with keys for both the impeller and gear after failures of the original design were encountered in similar pumps on R-48 engines in Saudi Arabia. After new pumps of this modified design were installed on the Shoreham diesels, two pump shaft failures occurred due to fatigue initiating at the keyway. TDI subsequently redesigned the pump, removing the keyway on the impeller end and changing the impeller material to ductile iron; the impeller is now driven through its interference 
fit on the shaft. The pumps currently installed on the Shoreham diesels are of this second redesigned configuration. Following the crankshaft failure at Shoreham in August 1983, the pump associated with that failed engine was disassembled and the impeller was found to have rotated on the shaft. However, this rotation was attributed to severe torsional loading during the crankshaft failure.

Because of the jacket water pump failures encountered at Shoreham, these pumps were included in the 1 ist of 16 components with significant known problems examined by the Owners' Group. Included in the review were pumps used on TDI DSRV-12, DSRV-16, and DSRV-20 engines installed at other plants, even though these pumps differ somewhat from the DSR-48 design and have had no significant reported problems.

\subsubsection{Owners' Group Evaluation}

The jacket water pumps were reviewed by Stone \& Webster Engineering Corporation (SWEC), a consultant to the Dwners' Group. The objective of the SWEC effort was to review the various designs of the TOI jacket water pumps to determine their suitability for nuclear EDG service.

\subsubsection{Scope}

In addressing the jacket water pump issue, SWEC

- reviewed TDI analyses associated with changes in impeller attachment configuration

- evaluated design and hydrotest pressures for casings and impellers used for the DSR-48 and the DSRV-4 engines

- verified that the pumps have run with no unacceptable leaks in the pressure boundary components

- verified that the pumps provide sufficient flow and pressure to hold cooling water temperatures to acceptable limits

- evaluated the pump performance test

- verified the absence of unacceptable mechanical seal conditions 
- analyzed stresses in the pump shaft due to bending, torque, and nut tension on both the impeller and gear ends

- evaluated the effects of the fluctuating torque input from the engine.

\subsubsection{Results}

The results of SWEC's review were reported in three documents. The first, issued in Apri1 1984, reviewed the design of the pumps installed in the DSR-48 engines at Shoreham, River Bend, and Rancho Seco. The second, a supplementary report issued in June 1984, dealt with the jacket water pumps installed on the DSRV-12 and DSRV-16 engines. The third report, issued in July 1984, documented SWEC's review of the pumps on the DSRV-20 engines at San Onofre.

\subsection{DSR-48 Engine Pumps. Stone \& Webster found that the pumps} installed in the engines at Shoreham, River Bend, and Rancho Seco are of conventional design and fabricated from materials in common use in pump manufacture. The pump casings were hydrotested at either 56 or 80 psig (depending on model), which is adequate for the intended service. The mechanical seals operate at a conservative face speed of $17 \mathrm{fps}$, and no failures have been experienced. The capability of the pumps to provide adequate cooling water was verified by the review of records of engine water temperatures at Shoreham. The stresses in the shaft, impeller, and gear in the Shoreham pumps are low and well below the endurance limit of 35,000 psi for hot-rolled and annealed stainless steel. The shrink fits of both impeller and gear were judged adequate to prevent relative rotation under normal operating conditions.

The hoop tensile stresses in the bore of the River Bend and Rancho Seco cast iron impellers were calculated to be in excess of 35,000 psi in the area of the keyway and, therefore, are susceptible to cracking at the impeller keyway corners. Stone \& Webster recommended that the impeller material be changed to ductile jron and that the keyway be eliminated as was done at Shoreham.

4.15.3.2.2 DSRV-12 and DSRV-16 Engine Pumps. Stone \& Webster found the pumps installed on the $V-12$ and $V-16$ engines to be of a design and materials routinely used in pumps operating at the specified temperatures. The pump 
casing and components have a design pressure rating of 150 psig, which is well above the 46-psig maximum pressure the pumps can achieve. At full pump speed, the mechanical seal operates at a face speed of $19 \mathrm{fps}$, which is considered to be conservative.

Adequate capability of the pumps to provide cooling water was demonstrated during shop tests for all of the engines of the seven plants. Field operation of the engines has verified the adequacy of those jacket water cooling systems.

4.15.3.2.3 DSRV-20 Engine Pumps. The jacket water pumps on the DSRV-2D engines at San Onofre are also of a conventional design and materials in common use in similar applications. Casings and components were hydrostatically tested to 225 psig, which is well above the 57-psig maximum pressure that can be achieved. The mechanical seals at full pump speed have a sealing surface speed of only $17 \mathrm{fps}$. There have been no reported seal failures or excessive leakage from any DSRV-20 engine installation.

During shop testing of engines with these pumps, adequate cooling capacity was demonstrated. The field tests performed on the San Onofre Unit 1 engines have verified that those pumps provide adequate cooling.

\subsubsection{Conclusions and Recommendations}

4.15.3.3.1 OSR-48 Engine Pumps. Stone \& Webster concluded that the jacket water pumps for the Shoreham, River Bend, and Rancho Seco TDI diesel engines are adequately designed in the following areas:

- pressure boundary

- mechanical seals

- materials of construction (except as covered below)

- capacity.

The shaft/impeller/gear design was judged acceptable for the Shoreham engines. However, SWEC concluded that excessive stresses could occur in the current River Bend and Rancho Seco engine jacket pump impellers. SWEC also recommended that the impellers for the River Bend and Rancho Seco pumps be fabricated from the same ductile iron (ASTM A-536 Grade 65-45-12) as used in 
the pumps at Shoreham. SWEC also recommended that the keyway be eliminated in the new impeliers, to reduce the stress concentration.

4.15.3.3.2 DSRV-12 and DSRV-16 Engine Pumps. In the supplemental report on the jacket water pump for the DSRV-12 and -16 engines, SWEC concluded that the pumps in all of the subject engines at the various nuclear power stations are adequate for the intended service. However, SWEC recomended that installation procedures be revised to ensure that the nut holding the external spline on the individual pump shaft would not be over-or under-torqued (i.e., would be torqued from $120 \mathrm{ft}-1 \mathrm{~b}$ minimum to $660 \mathrm{ft}-1 \mathrm{~b}$ maximum).

4.15.3.3.3 OSRV-20 Engine Pumps. In the supplemental report addressing the jacket water pumps on the $V-20$ engines, SWEC concluded that the pumps at San Onofre Unit 1 are adequate for the intended service, provided that some additions are made to the assembly procedure:

- The impeller end of one shaft should be inspected for overtorquing darnage at the first available maintenance outage, and the nut should be torqued to $150 \mathrm{ft}-1 \mathrm{~b}$. The second pump should be similarly inspected at the next refueling outage.

- The gear end of the shafts should also be inspected at the next refueling outage, and the gear nut should be torqued to a value not to exceed $290 \mathrm{ft}-1 \mathrm{~b}$.

- Keys should be properly fitted in both ends of the pump shaft.

- A second hole should be added in the gear end of the pump shaft to facilitate adequate insertion of the locking cotter pin.

4.15.4 PNL's Review

PNL reviewed the three SWEC reports cited in Section 4.15.3, as well as supplementary calculations and other information provided by the Owners' Group (Ray May 2, 1984).

\subsubsection{Reviewers}

The PNL consultants who participated in various aspects of this review were 
- S. H. Bush, Review and Synthesis Associates

- B. J. Kirkwood, Covenant Engineering

- A. J. Henriksen, A. J. Henriksen, Inc.

- P. J. Louzecky, Engineered Applications Corporation

- the late A. Sarsten, Norwegian Institute of Technology.

\subsubsection{Scope}

The PNL reviewers considered the operating environments and service histories of the jacket water pumps installed in the engine installations evaluated by SWEC. Because of the failure history of some components of the pumps in the DSR-48 engines, the reviewers paid particular attention to the pump shaft and impeller stresses calculated hy SWEC. The predicted stresses in jacket water pump components on the DSRV-20 engine also were closely reviewed because of the limited operating experience with pumps on this engine mode?

PNL also reviewed the Owners' Group DR/QR reports for four plants (Shoreham, Comanche Peak, Perry, and River Bend) for recomended maintenance and surveillance of the jacket water pumps.

\subsubsection{Conclusions and Reconmendations}

Based on a review of SWEC's April 1984 report and calculations provided by the Owners' Group (Ray May 2, 1984), PNL concurs with the latest redesign of the jacket water pumps used at Shoreham and the proposed redesign for the jacket water pumps used at Rancho Seco and River Bend. With the design changes, these pumps are considered by PNL to be satisfactory for nuclear EDG service. SWEC's recommendations (Section 4.15.3.2.1) for the jacket water pumps at Rancho Seco and River Bend should be implemented in a timely manner at both installations.

PNL also concurs with SWEC's conclusion that the design of the DSRV-12 and DSRV-16 engine jacket water pumps is adequate for the intended nuclear EOG service. Further, PNL concurs that torque values and limits should be added to the assembly procedures for the DSRV-12 and DSRV-16 engine jacket water pumps, as recomnended by SWEC.

PNL also concurs with the SWEC conclusion that the jacket water pumps in the DSRV-20 engines at San Dnofre Unit 1 are adequate for the intended service, provided that torque values and limits are added to the assembly procedures of 
these pumps. The pumps on the DSRV-20 engines at San Dnofre should be checked at future maintenance outages as recommended by SWEC, and the shaft(s) replaced if damage is discovered.

PNL concurs with the maintenance and surveillance recommendations for the jacket water pumps presented in Appendix II of the Owners' Group DR/QR reports referenced in Section 4.15.4. PNL recommends that these recominendations be implemented at all plants having similar jacket water pumps and drive components. The Owners' Group recomendations include the following:

- Visually inspect the jacket water pump gear for chipped or broken teeth, excessive wear, pitting, or other abnormal conditions.

- On those pumps with a keyway, check the key to keyway interface for a tight fit.

- Check the torque on any castellated nut used with a tapered fit.

\subsection{5 .5 References}

Ray, C. L., Jr. May 2, 1984. Letter OGTP-16-N-2 to H. R. Denton transinitting related calculations.

Stone \& Webster Engineering Corporation. April 1984. Emergency Diese1 Generator Engine Oriven Jacket Water Pump Design Review. Boston, Massachusetts.

Stone \& Webster Engineering Corporation. June 1984. Supplement to the Emergency Diesel Jacket Water Pump Design Review. Boston, Massachusetts.

Stone \& Webster Engineering Corporation. July 1984. Supplement to the Emergency Diesel Jacket Water Pump Design Review. Boston, Massachusetts.

TDI Diesel Generator Owners' Group. January 1985. TDI Diesel Generator Design Review and Quality Revalidation Report - Comanche Peak Steam Electric Station. Revision 1.

TDI Diesel Generator Owners' Group. December 1984. TDI Diesel Generator Design Review and Quality Revalidation Report - Perry Nuclear Power Plant.

TDI Diesel Generator Owners' Group. February 1985. TDI Diesel Generator Design Review and Quality Revalidation Report - River Bend Station. Revision 1.

TDI Diesel Generator Owners' Group. December 1984. TDI Diesel Generator Design Review and Quality Revalidation Report - Shoreham Nuclear Power Station. Revision 1 . 
4.16 PISTON SKIRTS 


\subsection{PISTON SKIRTS}

This section addresses PNL's review of actions taken by the Owners' Group to resolve questions concerning the adequacy of the piston skirts for TDI DSR-4 and DSRV-4 engines installed at several nuclear power plants.

\subsubsection{Component Description}

The pistons used in TDI R-4 series engines are two-piece assemblies, each consisting of a cast-steel crown bolted to a nodular-iron skirt. The two-piece design is intended to allow thermal growth of the crown without causing excessive bending stresses in the skirt. Combustion pressure acts on the crown. The skirt guides the reciprocating motion of the piston within the cylinder and transfers firing forces to the connecting rod, which links the piston to the crankshaft.

Piston skirts of several designs have been supplied for R-4 series engines installed at nuclear power plants in the United States. These designs have been designated by TDI as types $A E$, modified $A F, A H$, and $A N$ (in three versions). The evolution of the design changes is discussed in FaAA-84-10-3 (November 1984). In summary, the various types of skirts differ in one or more of the following respects:

- themal treatinent given to the cast skirt during fabrication

- configuration of certain areas:

- bosses through which studs extend to secure the crown to the skirt

- circumferential rib between the wrist pin bosses

- wrist pin bosses themselves

- oil cavity above the wrist pin

- geometrical details associated with the control of oil consumption.

\subsubsection{Piston Skirt Evaluations}

Failure Analysis Associates (FaAA), a consultant to the Owners' Group, investigated the structural adequacy of the various types of piston skirts for 
the TDI engines at nuclear power plants. The results of the analytical and experimental analyses performed by FaAA are sumarized for each type of piston skirt in subsequent sections of this report. These sections also address the service experience for each type of skirt, and the conclusions and recommendations reached by PNL from a review of the available information.

The following consultants participated in PNL's review of the piston skirts:

- S. H. Bush, Review and Synthesis Associates

- A. J. Henriksen, A. J. Henriksen, Inc.

- B. J. Kirkwood, Covenant Engineering

- P. J. Louzecky, Engineered Applications Corporation

- the late A. Sarsten, Norwegian Institute of Technology.

\subsubsection{Type AE Skirt}

The type $A E$ piston skirt is the most recent of the several designs developed by TDI for R-4 series engines. Nuclear installations of TDI engines equipped with type $A E$ piston skirts include the Unit 1 power plants at the following sites: Catawba, Comanche Peak, Grand Gulf, Perry, River Bend, and Shoreham.

\subsubsection{Operating Experience}

There have been no reported instances of fatigue cracking in type AE piston skirts.

As discussed in FaAA-84-2-14 (May 1984), a 16-cylinder, DSRV-4 engine at the Kodiak Electric Association in Alaska reportedly experienced over 6000 hours of service with type AE piston skirts. The utility reported to FaAA that a substantial portion of this operation was at a peak firing pressure of 1200 psi (which corresponds to a BMEP of approximately 185 psi). FaAA performed an eddy-current examination of one skirt from this engine and found no relevant indications.

Also as discussed in the above-referenced report, FaAA performed eddycurrent inspections of two type AE piston skirts that had been operated in TDI's prototype $R-5$ series engine. No relevant indications were found. TDI reported to FaAA that the pistons had been operated at a peak firing pressure 
of $2000 \mathrm{psi}$ or above for over 600 hours at $514 \mathrm{rpm}$ (versus the rated speed of 450 rom for R-4 series engines). This peak firing pressure is substantialiy higher than the peak firing pressure of 1670 psig measured by FaAA in an R-4 series engine operating at the nanufacturer's full rated load at the Shoreham Nuclear Power Station.

Following a 740-hour test of the 8-cylinder EDG 103 engine at the Shoreham Nuclear Power Station, the crown-to-skirt stud attachnent bosses were inspected with liquid penetrant in all eight of the type $A E$ piston skirts. No relevant indications were found. The engine had been operated during this test at loads at or above $3300 \mathrm{~kW}$.

\subsubsection{FaAA Evaluation}

FaAA's evaluation of the type AE piston skirt included both analytical and experimental investigations. The approaches taken in these investigations, the results obtained, and FaAA's conclusions are presented in two reports:

FaAA-84-2-14 (May 1984) and FaAA-84-5-18 (June 1984). The FaAA investigations included

- tests to measure residual stresses in an $A E$ piston skirt and to determine its metallurgical and mechanical properties

- stress analysis of the piston skirt with attached crown, both of which were assumed to be isothermal - The analysis was performed using three finite-element models: a "global" model of the skirt, a refined local model of the crown-stud boss in the region of highest stress, and a model of the crown. Loads assumed to be acting on the piston included gas pressure, reciprocating inertia, and friction.

- strain-gage tests of a piston skirt and crown assembly under isothermal conditions - The test assembly included a cylinder liner in which the instrumented piston skirt was installed on a short piece of connecting rod restrained by a support plate. Firing pressures were simulated by subjecting the top of the piston crown to hydrostatic pressures up to 2000 psig.

- analysis of the influence of thermal distortion of the piston crown on the structural integrity of the piston skirt, taking into 
consideration a steady-state temperature field in the piston assembiy based on experimental measurements

- fatigue and fracture mechanics analyses to predict whether or not cracks will initiate and propagate under the stress levels measured in the strain-gage tests or calculated by finite-element analysis. FaAA's conclusions from these investigations include the following:

- Calculated stresses and experimentally-measured stresses in the stud attachment boss area are significantly lower in the AE skirts than in the modified AF skirts (discussed in Section 4.16.4).

- All strains measured in an instrumented AE skirt were in the elastic range.

- Based on experimentally measured stresses, fatigue cracks are predicted neither to initiate nor to propagate in the AE skirt. However, fatigue cracks may or may not initiate based on calculated stresses, depending on the initial value of the gap between the outer ring of the skirt and the crown. Cracks that may initiate are predicted to not propagate.

- Based on the results of inspections of engine-operated AE skirts and upon the results of the analytical and experimental investigations, the AE skirts are adequate for unlimited life.

\subsubsection{PNL's Review}

Subject to the recommendation discussed later in this section, PNL concurs with $F a A A$ that type $A E$ piston skirts are adequate for their intended service in emergency diesel generators for nuclear power piants. This includes operation at any power level within limits set by the engine manufacturer.

PNL's conclusion regarding the adequacy of the type AE piston skirts is based on the following considerations:

- PNL notes FaAA's prediction that cracks may or may not initiate based on calculated stresses, but that if cracks initiate, they will not propagate. Because of the complexity of the stress field in the region of the crown-to-skirt stud attachment bosses, PNL has drawn no 
conclusions from FaAA's analysis regarding crack initiation and growth. However, known operating experience with type AE piston skirts supports FaAA's predictions and provides convincing evidence that these piston skirts are adequate for operation at any power level within the manufacturer's limits.

- From a review of the relevant drawings, PNL notes that the type AE piston skirts used in the $R-5$ engine differ in certain minor respects from those supplied for the R-4 series engines at Shoreham. However, PNL's reviewers found no differences in the critical areas around the crown-to-skirt stud bosses. Accordingly, PNL concurs with FaAA that the operating experience of the type AE skirts in the R-5 engine is applicable to the type $A E$ skirts in $R-4$ engines. FaAA's post-test examination of two of the piston skirts confirmed that they had operated without any evidence of fatigue cracking at loads reported to be substantially higher than the manufacturer's rated load for R.4 series engines.

- Several of PNL's consultants audited the condition of key engine components, including the AE piston skirts, during the disassembly of the EDG 103 engine after the 740-hour test at the Shoreham Nuclear Power Station. In sumary, the PNL review team concluded that the visual examinations and the liquid penetrant inspections of all eight piston skirts revealed no abnormalities indicative of deficiencies under the conditions to which the skirts were inposed during the test. PNL's review is discussed more fully in a report (Henriksen et al. December 14, 1984) to the Atomic Safety and Licensing Board. The DR/QR report for River Bend (TDI OG February 1985) recomends liquid penetrant inspections of type AE piston skirts in the stud boss area, in the rib area near the wrist pin boss, and at the intersection of the rib with the wrist pin boss. PNL recommends that these areas be included in the preservice inspections of all AE piston skirts. The inspections should be performed with liquid penetrant and, as appropriate, with eddy current. Any piston skirts of engines in nuclear service that have not been inspected in these areas should be inspected at the first inajor (5-year) engine disassembly. 
The purpose of these inspections is to verify the absence of preexisting, rejectable flaws in the more highly-stressed areas of the piston skirts, which cannot be monitored in service without significant engine disassembly. The acceptance criteria used in piston-skirt inspections already performed at several nuclear power plants (e.g., Shoreham) should also be used for piston skirts not yet examined. These criteria, referenced in OR/QR reports and/or inspection reports, are summarized below for liquid penetrant inspections:

- no cracks or linear indications

- no rounded indications greater than $3 / 16$ inch in diameter

- no more than four or more indications in a line separated by less than $1 / 16$ inch.

An eddy-current procedure that has been used to differentiate between superficial dye-penetrant indications and cracks in piston skirts is described in FaAA Procedure NDE 11.5 .

\subsubsection{Modified Type AF Skirt}

The two 20-cylinder, DSRV-4 engines at the San Onofre Nuclear Generating Station Unit 1 are equipped with modified type AF piston skirts. Piston skirts of this cype had been installed in the TOI engines at the Shoreham Nuclear Power Station and the Grand Gulf Nuclear Station, but were later replaced with type AE skirts. The TDI-recomended changes to type AF skirts (resulting in "modified" AF skirts) consist of spot-facing the crown-to-skirt stud bosses and replacing the originally-supplied spherical washer sets with two stacks of Belville washers.

\subsubsection{Operating Experience}

As discussed in FaAA-84-2-14 (May 1984), the three TDI 8-cylinder engines at the Shoreham Nuclear Power Station were equipped initially with 23 modified type AF piston skirts and 1 type AN piston skirt. Al1 23 of the AF piston skirts were found to exhibit linear indications in one or more of the crownto-skirt stud attachment bosses during an engine disassembly. (No relevant indications were observed in the AN skirt.) On the basis of destructive inspections of three of the piston skirts, FaAA concluded that the indications 
were fatigue cracks rather than material or fabrication defects. None of the cracks had grown to failure. PNL notes that, during the time the AF pistons were installed at Shoreham, the three engines were routinely tested to the manufacturer's full rated load ( $3500 \mathrm{~kW}$; BMEP of $225 \mathrm{psig})$.

As discussed in Attachment 2 of a Mississippi Power \& Light Company (J. P. McGaughy, Jr.) letter dated February 20, 1984, to NRC (H. R. Denton), MP\&L found rejectable indications in three of the four modified type AF piston skirts inspected on a sampling basis in the 16-cylinder, Unit 1 Division 2 engine at the Grand Gulf Nuclear Station. The remaining modified AF skirts were then inspected, and numerous indications were found. According to $M P \& L$, FaAA concluded that the piston skirts could contain fatigue cracks of the same approximate depth as those found in the AF skirts at Shoreham. MP\&L subsequently replaced all piston skirts in the two 16-cylinder Unit 1 TDI engines with type AE skirts.

The operating experience of the modified type AF pistons in the two 20-cylinder TOI engines at the San Onofre Nuclear Generating Station is discussed in the San Onofre DR/QR report (TDI OG January 1985). At the 6000-kw capacity of the generator installed on each of these engines, the engine BMEP is approximately $154 \mathrm{psig.} \mathrm{This} \mathrm{is} \mathrm{substantially} \mathrm{lower} \mathrm{than} \mathrm{the} \mathrm{manufacturer's}$ rated engine BMEP of $225 \mathrm{psig.} \mathrm{Furthermore,} \mathrm{engine} \mathrm{loading} \mathrm{for} \mathrm{periodic}$ surveillance tests is limited to $4500 \mathrm{~kW}$, the load that bounds the maximum emergency service load for each engine [see, e.g., Southern California Edison's (K. F. Baskin) letter dated February 14, 1985, to NRC (H. R. Denton)]. This load corresponds to an engine BMEP of 116 psig. Thus, the two engines run well below the manufacturer's rated load.

Following over 180 hours of operation at loads at or above $4400 \mathrm{~kW}$ on each of the San Onofre engines, $25 \%$ of the piston skirts ( 5 from each engine) were inspected with liquid penetrant. No relevant indications were found.

Also as discussed in the San Onofre DR/QR report, a 20-cylinder TDI engine at Homestead, Florida, has accumulated approximately 1500 hours with modified type AF piston skirts at loads in the range of $4000 \mathrm{~kW}$ to $5000 \mathrm{~kW}$. No piston skirt failures have been reported. 


\subsubsection{FaAA Evaluation}

FaAA's evaluation of the modified type AF piston skirt included the same analytical and experimental investigations as those that FaAA performed in evaluating the type $A E$ piston skirt. The scope of FaAA's evaluation is summarized in Section 4.16.3.2 of this report. FaAA's approach, results, and conclusions are presented in the same two reports referenced in Section 4.16 .3 .2 .

FaAA's conclusions regarding the modified AF piston skirt included the following:

- As noted in Section 4.16.3.2, calculated stresses and experimentallymeasured stresses in the stud attachment boss area are significantly lower in the $A E$ skirts than in the modified AF skirts.

- The largest strains measured in an instrumented AF skirt (loaded hydrostatically in the test assembly mentioned in Section 4.16.3.2) were well into the plastic range.

- The maximum residual stress measured by FaAA in a modified AF skirt removed from an engine at Shoreham was $11.4 \mathrm{ksi}$. This was a tensile stress on the spot-faced region of a stud boss. (The residual stresses that FaAA measured in this region on an AE skirt were much smaller, i.e., about $1 \mathrm{ksi.)}$

- Cracks are predicted to initiate and may propagate in the modified AF skirt based on the larger of experimentally-measured stresses or on finite-element stress results. However, any cracks are predicted to arrest at depths less than 0.5 inch. This prediction is consistent with field observations.

- Provided that a $100 \%$ inspection of stud boss attachments of modified Af skirts reveals no relevant indications, the skirts are satisfactory for continued service (at manufacturer's rated load) with periodic inspections or for extended service at less than full rated load. FaAA noted that final recomnendations for inspection intervals and/or operation at less than full rated load would depend on plant-specific engine operating conditions. 


\subsubsection{PNL's Review}

FaAA's prediction that fatigue cracks may initiate in the region of the crown-to-skirt stud attachment bosses of modified type Af piston skirts is consistent with the fatigue cracks found in modified AF piston skirts at various installations. Available information does not provide an adequate basis for PNL's reviewers to reach a conclusion regarding FaAA's prediction that cracks will arrest at depths less than 0.5 inch. In PNL's view, the uncertainties inherent in this FaAA prediction are not resolved conclusively by known service experience. These uncertainties stem from the complexity of the stress field in the region of the crown-to-skirt bosses, the geometrical variations from stud boss to stud boss noted by FaAA in inspections of modified AF piston skirts, and the variation in residual stresses resulting from manufacturing processes (e.g., the residual tensile stress of $11.4 \mathrm{ksi}$ measured by FaAA in one modified AF skirt).

However, PNL concurs with FaAA and the Owners' Group that the modified type AF piston skirts are adequate for continued service in the two 20-cylinder TDI engines at San Onofre, subject to the PNL recommendations presented later in this section. This PNL conclusion is based on the following considerations:

- As discussed in Section 4.16.4.1, the load on each engine at San Onofre is limited to $4500 \mathrm{~kW}$. This load corresponds to an engine BMEP of $116 \mathrm{psig}$, which is well below the manufacturer's rated engine BMEP of 225 psig.

- Modified Af piston skirts in a 20-cylinder TDI engine at Homestead, Florida, operated successfully for approximately 1500 hours at loads in the range of 4000 to $5000 \mathrm{~kW}$.

- Liquid penetrant inspections of $25 \%$ of the piston skirts in the two engines at San Onofre, performed after each engine had been operated for over 180 hours at or above $4400 \mathrm{~kW}$, revealed no relevant indications. 
PNL's recomandations for modified type AF piston skirts are as follows:

- The power at which the 20-cylinder engines at San Onofre are operated should be limited to $4500 \mathrm{~kW}+5 \%$, consistent with the load limitation currently in effect. This corresponds to an engine BMEP of approximately 116 psig in these engines.

- Should modified type AF piston skirts be considered for service in nuclear standby engines that would be operated at loads greater than an engine BMEP of 116 psig, the skirts should be tested for $10^{7}$ cycles ( 750 hours at $450 \mathrm{rpm}$ ) at the load that bounds the maximum emergency service load of the engines. The crown-to-skirt stud attachment bosses should be inspected with liquid penetrant before the test, to verify the absence of preexisting cracks, and after the test, to determine whether or not cracks have initiated. Any cracks that develop during the test should be further evaluated to determine their depth and length, and the results should be compared with the predictions of FaAA's analysis. The pistons should not be placed in nuclear standby service without NRC approval at load levels where cracking is found to occur.

- The stud boss attachments of all piston skirts in the 20-cylinder engines at San Onofre should be inspected with liquid penetrant and, as appropriate, with eddy current at the next major disassembly of each engine. PNL recommends the acceptance criteria used by the Owners' Group for inspections of type AE piston skirts as discussed in Section 4.16.3.3, above.

- To verify the continued absence of cracking, all pistons skirts in each San Onofre engine should be inspected in the manner just described at each major (5-year) engine disassembly. These periodic nondestructive examinations may be discontinued for individual skirts of the modified AF type after they have operated without evidence of cracking for 750 hours at $4500 \mathrm{~kW}$ (BMEP of $116 \mathrm{psig}$ ). 


\subsubsection{Type AH Skjrt}

As summarized in Table 2-2 of FaAA-84-10-30 (October 1984), type AH piston skirts were installed in TDI engines at nuclear power plants owned by Cleveland Electric (four $V-16$ engines), TVA Bellefonte (four $V-16$ engines), Washington Public Power Supply System (two $V-16$ engines), Texas Utilities (two $V-16$ engines at Comanche Peak Steam Electric Station Unit 2), and Consumers Power (one $V-12$ engine). Cleveland Electric replaced the type AH piston skirts with type AE skirts in the two TDI engines at the Perry Nuclear Power Plant Unit 1, before that plant became a candidate for an operating license. None of the remaining engines with type $A H$ skirts is in power plants that had become candidates for operating licenses as of the time this report was written.

\subsubsection{Operating Experience}

Included in Table 2-2 of the FaAA-84-10-30 is a summary of information that FaAA obtained from TOI concerning operating experience with type AH piston skirts. No engine installed at a nuclear power plant has been operated with type AH skirts. FaAA's sumnary identifies 20 engines with type AH piston skirts in non-nuclear installations outside the United States. Thirteen of these engines each have over 10,000 operating hours, and 7 of the 13 each have over 17,000 hours. TOI informed FaAA that there have been no reported piston failures in these engines. However, the engine operating loads and the results of any piston inspections that may have been performed were not reported.

As discussed in FaAA-84-10-30, the component tracking system maintained by the Owners' Group was also used to identify reported piston problems, and then to determine if the engines involved had AH piston skirts. The only negative experience in engines with AH piston skirts included in the component tracking system was an incident with one engine at St. Cloud, Florida, that experienced a piston seizure. TDI attributed the failure to overheating of the piston crown. FaAA found no evidence of fatigue failure in the skirt material.

4.16.5.2 FaAA Evaluation

FaAA's evaluation of the type AH piston skirt encompassed the following activities, which are described in FaAA-84-10-30: 
- The maximum stresses in the AH skirt were derived from strain-gage tests of a type AN skirt. According to FaAA, the test results are applicable to both types of skirts because their geometries are virtually identical. The AN skirt and crown assembly were tested at pressures up to 2000 psig using the same approach summarized in Section 4.16.3.2 for the strain-gage tests of a type AE piston skirt.

- Fatigue and fracture analyses were performed to predict whether or not cracks will initiate and propagate under the stress levels measured in the strain-gage test.

- Residual stresses were measured in two cracked AN skirts removed from the Catawba engines and in an AH skirt supplied by Texas Utilities, but were not utilized by FaAA in reaching conclusions about the two types of skirts due to inconsistencies in the results.

FaAA reached the following conclusions:

- Under transient thermal conditions, cracks may possibly initiate in type AH piston skirts that have yield strengths toward the lower end of observed values. However, cracks that may initiate are predicted to not propagate, in the absence of significant residual stresses. Residual stresses are expected to be low in light of the heat treatment reported by TOI to be used during the manufacture of $A H$ skirts.

- The reported lack of service-induced cracking, the absence of AH piston-related incidents in the component tracking system established by the Owners' Group, the prediction based on an analytical and experimental investigation that cracks may initiate but will not propagate, and the low residual stresses anticipated from the heat treatment reported by TOI "...provide no reason to expect that the $A H$ piston skirt is not suitable for service in emergency standby diesel generators for nuclear power plants."

\subsubsection{PNL's Review}

Available information does not provide an adequate basis for PNL's reviewers to reach a conclusion regarding FaAA's prediction that cracks will 
initiate but will not propagate in type AH piston skirts. Uncertainties inherent in FaAA's prediction stem from the complexity of the stress field in the region of the crown-to-skirt stud bosses and in the region of the rib ends, the geometrical variations that may occur in as-manufactured piston skirts, and residual stresses that are predicted, but not confirmed by measurenent, to be low.

Operating experience with type AH piston skirts in non-nuclear installations has been favorable, according to the service history obtained by FaAA from TDI and summarized in Table 2-2 of FaAA-84-10-30. However, all of the engines reported to have accumulated extensive operating hours with AH skirts are in service outside the United States (primarily in the Middle East). Neither the engine loads nor the results of piston inspections that may have been performed are reported. PNL recognizes that such information may not be available. Nevertheless, in the absence of this information, PNL views the reported service history as inconclusive.

A] though the component tracking system established by the Owners' Group also shows no engine failures initiated by AH skirts, PNL views this absence of negative information as inconclusive for reasons similar to those just mentioned. The component tracking system lacks detailed information on the operating history and inspections of AH skirts that, by implication, have operated successfully.

PNL recommends that satisfactory performance of type AH piston skirts be demonstrated in an engine test to $10^{7}$ cycles ( 750 hours at 450 rpm) before skirts of this type are placed in service in nuclear standby engines. The test should be performed at a load that bounds the maximum ennergency service load to which the pistons would be exposed. Appropriate pre-test and post-test inspections of the crown-to-skirt stud attachment bosses and the rib ends should be perforined to establish whether or not cracks form during the test. Type AH skirts should not be placed in nuclear standby service without NRC approval at load levels where cracking is found to occur. 


\subsubsection{Type AN Skirt}

As reported by FaAA (FaAA-84-10-30), the type AN piston skirt has been supplied by TOI in three versions:

- Type AN-I, introduced in April 1978, was identical to the type AH skirt, including heat treatment, except for machining modifications

to improve oil control.

- Type AN-II, introduced in December 1978, employed fan cooling to increase material hardness and deleted the tempering treatment because TDI found tempering unnecessary to achieve the desired mechanical properties.

- Type AN-III, adopted in Detober 1981, employed fan cooling, but reintroduced a $1000^{\circ} \mathrm{F}$ tempering cycle.

Type AN skirts were installed in both of the DSRV-16 engines at Duke Power Company's Catawba Nuclear Station and operated at loads exceeding the maximuln emergency service load at Catawba. In addition, one type AN skirt was operated in a TDI engine at the Shoreham Nuclear Power Station. During the time the AN piston was installed, the Shoreham engine was routinely tested to the manufacturer's full rated load of $3500 \mathrm{~kW}$.

Type AN skirts are in non-nuclear service in both stationary and marine applications (FaAA-84-10-30, Table 2-4).

\subsubsection{Operating Experience}

Although many type AN piston skirts have been reported to perform satisfactorily in non-nuclear service, FaAA notes that numerous fatigue cracks have been observed, including instances of actual breakage of the skirt with catastrophic consequences to the engine. Cracks have been found in crownto-skirt stud attachment bosses, in the circumferential rib between the wrist pin bosses, and at the wrist pin wall ligament. According to FaAA, TDI attributes the spotty performance history of the AN skirt to adverse residual stresses established during fan cooling of the version of this skirt that did not receive subsequent stress relief/temper. 
In nuclear service, six of the 32 type AN skirts installed at Catawba were found to have cracks, four from one engine and two from the other. All cracks were at the rib end; one was found to extend through to the outside of the skirt. No cracks were observed in any of the stud boss regions. The single Shoreham AN piston skirt exhibited no cracks.

\subsubsection{FaAA Evaluation}

FaAA's evaluation of the type AN skirt encompassed the same investigations described in Section 4.16.5.2 as for the type AH skirts.

As in the case of the AH skirts, FaAA predicted that cracks may possibly initiate in the stud boss region under transient conditions, but that they will not propagate in the absence of significant residual stresses. Analyses of the rib ends at the wrist pin bushing area--where severe cracking has occasionally occurred--showed that cracks were unlikely to initiate, and only residual stresses substantially above those measured could account for the cracking observed. FaAA cited four possible reasons for the high residual stresses in AN skirts: 1) AN skirts subjected to fan cooling from austenitizing tempera. tures without subsequent stress relief, 2) ineffective or inproper stress relief, 3) cracking due to factors not related to stress relief, or 4) errors in documentation. The inability to reliably distinguish those AN skirts with high residual stresses and the spotty performance history of these skirts led FaAA to conclude that the type AN piston skirt "is not suited for the extreme reliability requirements associated with emergency standby power at nuclear plants."

\subsubsection{PNL's Review}

PNL concurs with FaAA that, because of the inconsistent service history of the type AN piston skirt and the inability to reliably distinguish those skirts with high residual stresses, the type AN piston skirt should not be used in nuclear service.

\subsubsection{References}

Failure Analysis Associates (FaAA). May 23, 1984. Investigation of Types AF and AE Piston Skirts. FaAA-84-2-14, Palo Alto, CaTifornia. 
Failure Analysis Associates (FaAA). June 1984. The Influence of Thermal Distortion on the Fatigue Performance of $A F$ and $A E$ Piston Skirts. FaAA-84-5-18, Palo Alto, California.

Failure Analysis Associates (FaAA). November 1984. Investigation of Types AN and AH Piston Skirts. FaAA-84-10-30, Palo Alto, California.

Henriksen, A. J., B. J. Kirkwood, H. W. Laity, P. J. Louzecky, J. F. Nesbitt, and L. G. Vanfleet. Oecember 14, 1984. Post-Test Examination of Transamerica Delaval, Inc. Emergency DieseT Generator 103 Pistons and Related components at shoreham Nuclear Power Station for U.S. Nuclear Regulatory Commission Staff. Before the Atonic Safety and Licensing Board, Docket No. 50-322-0L.

Mississippi Power \& Light Company (J. P. McGaughy, Jr.) letter dated February 20, 1984, to the NRC Office of Nuclear Reactor Regulation (H. R. Denton). Subject: Comprehensive Reliability Report and Status of GGNS Standby Diesel Generators.

Pacific Northwest Laboratory. August 1984. Review and Evaluation of Transamerica Delaval, Inc., Diesel Engine Reliability and Operability Catawba Nuclear Station Unit 1. PNL-5200, Richland, washington.

Southern California Edison Company (K. P. Baskin) letter dated February 14, 1985, to the NRC Office of Nuclear Reactor Regulation (H. R. Denton). Subject: Amendment Application No. 126, San Onofre Nuclear Generating Station Unit 1.

TOI Diesel Generator Owners'Group. February 1985. TOI Uiesel Generator Design Review and Quality Revalidation Report - River Bend Station. Revision 1 .

TDI Diesel Generator Owners' Group. January 1985. TDI Diesel Generator Design Review and Quality Revalidation Report - San Onofre Nuclear Generating Station. Forwarded to NRC ( $H$. R. Denton) as Enclosure 1 of Southern California Edison Company (M. 0. Medford) letter dated September 3, 1985. 
4.17 PUSH RODS 


\subsection{PUSH RODS}

This section describes PNL's review of Owners' Group efforts to evaluate the push rods installed in TDI diesel engines in nuclear service.

\subsubsection{Component Description}

The push rods transmit camshaft follower notion to the cylinder intake and exhaust valves, thereby controlling valve opening and closing. There are two types of push rods: main and intermediate. The motion of the intake cam follower is transmitted through the main intake push rod to a rocker arm and then to the intake valves. The motion of the exhaust cam follower is transmitted by the majn push rod to an intermediate rocker arm, then through the intermediate push rod to another rocker arm, and finally to the exhaust valves.

All push rods used on TDI nuclear standby diesel engines have tubular bodies. However, three different rod end configurations have been used: 1) forged-head design, plug-welded to the tubular body; 2) a bal1, filletwelded to the tubular body; and 3) a solid cylindrical rod end, friction-welded to the tubular body.

The forged-head design consists of a tubular steel shaft fitted with hardened steel end pieces. These end pieces slip into the tube ends and are retained with four plug welds.

The ball-end push rod has a tubular steel shaft fillet-welded to carbon steel balls at both ends. This ball material is very difficult to weld and is susceptible to underbead cracking in the heat-affected zone.

The friction-welded design uses a tubular steel shaft friction-welded to solid steel plugs at both ends. The friction-welding is performed by rotating one piece at a relatively high speed and holding it with controlled pressure against the other piece, which is held stationary. When the interface is at fusion temperature from the effects of friction, rotation is stopped and the parts are allowed to cool. Following welding, the ends are machined and induction-hardened. 


\subsubsection{Operating History}

The development history of gush rods was provided to FaAA by TDI and documented in the Failure Analysis Associates report FaAA-84-3-17 (April 1984). The FaAA report also provides a case history of the push rods at Grand Gulf Nuclear Station, to indicate general trends in operation.

Originally, intake and exhaust push rods were of the forged-head design. The ball-end design was developed to reduce fabrication costs. The frictionwelded design was introduced when cracking was discovered in intermediate oush rods of the ball-end design.

The diesel engines at Grand Gulf Unit 1 were originally equipped with both main and intermediate push rods of the ball-end design. However, the main push rods were replaced with push rods of the forged-end design. Subsequently, reports of forged-end cracking at other installations prompted the plant's owner to convert to the friction-welded design for all main push rods. Later, the intermediate push rods of the ball-end design were inspected; 27 of the 32 rods were found to be cracked in the fillet weld area or to have the balls totally separated from the tubes. All ball-end push rods were subsequently taken out of service at the Grand Gulf Nuclear Station and replaced with friction-welded push rods. Following about 6 months of operation, all these friction-welded push rods were inspected by liquid penetrant, and no relevant indications were found.

\subsubsection{Owners' Group Evaluation}

Failure Analysis Associates, on behalf of the Owners' Group, examined the structural integrity of main and intermediate push rods of all three designs described in Section 4.17.1. The review is documented in FaAA's April 1984 report, Design Review of Push Rods for Transamerica Delaval Oiesel Generators.

\subsubsection{Scope}

FaAA's investigation included:

- review of the metallurgical analysis of the fillet-welded ball-end design 
- determination of the fatigue behavior of the forged-head and friction-welded designs

- examination of the buckling stability and wear resistance of all three designs.

\subsubsection{Results}

FaAA reviewed the metallurgical analysis of the ball and tube material for the ball-end design and found the results typical of the specified materials. Metallurgical analysis of the weld joints showed underbead cracking. Some cracking was determined to be caused by lack of penetration and slag inclusions. FaAA noted that the ball material, AISI 52100 high carbon chromium steel, is generally classified as an "unweldable" steel, and welds free of critically-sized cracks cannot be guaranteed with this material.

FaAA's review of the forged-head design included buckling analysis, fatigue analysis, and metallurgical evaluations. The results of the chemical analyses of all components were typical for the materials specified. The microstructure and hardness of the forged-head fitting were within specifications.

From the buckling analysis of the forged-head rods, it was determined that the critical buckling loads would be 49.5 kips and 32.1 kips using the Euler equation and the short column equation, respectively. In comparison, the maximum total loads were estimated at 2.5, 6.9, and 11.4 kips for the intake, main exhaust, and intermediate exhaust push rods, respectively, so that buck ling of these push rods is not predicted.

Two fatigue analyses were performed for rods with forged heads. The first addressed the possibility of propagation of a hypothetical worst-case throughthickness fabrication crack extending 0.25 inch from the weld. The results of this analysis show that such a crack will not propagate around the tube and separate the end from the shaft. The second fatigue analysis investigated the fatigue shear capacity of the plug welds, assuming 1) a gap exists between the end of the cubular shaft and the shoulder of the forged head and 2) the weld contains a crack of the maximum size observed in the fieid. The results of this analysis indicate that an existing crack could cause fracture of the weld. 
An experimental fatigue evaluation was performed on three forged-head push rods that had already been used for a total of 800 hours. This evaluation subjected the rods to an additional $10^{7}$ cycles at a load $25 \%$ in excess of the maximum theoretical service load. Radiographic and fiuorescent magnetic particle examinations were performed before and after testing. No cracks or indications were observed to result from the test.

FaAA used analyses similar to those for the forged-head rods to evaluate the friction-welded push rods. The results of the metallurgical evaluations showed no major discrepancies in the chemical composition, hardness, or microstructures of any components. The buckling analysis showed that the critical buckling loads far exceeded the maximum expected inservice loads, indicating that no rod buckling can be expected. A fatigue crack growth analysis showed that, under cyclic loading, no potential fabrication cracks are expected to propagate in either the main or intermediate push rods using the friction-welded design. A fatigue test that included $10^{7}$ compressive load cycles from zero load to a value $\sim 25 \%$ above the maximum theoretical service load, was also conducted. No cracks or indications were found.

4.17.3.3 Conclusions and Recommendations

4.17.3.3.1 FaAA Conclusions. FaAA concluded that the integrity of the ball-end push rods cannot be ensured or substantially improved. They recommended that all ball-end push rods be replaced with push rods of either the forged-head design or, preferably, the friction-welded design.

The fatigue strength of the plug welds in the forged-head design was determined to be adequate, provided that a liquid penetrant examination is performed to detect any cracks emanating from the plug weld. FaAA recommended that any rods with cracks greater than 0.25 inch long emanating from the edge of the plug weld be removed from service. FaAA concluded that forged-head rods successfully completing 800 hours at full load may be considered qualified for continued service if dye penetrant inspection reveals no cracks exceeding the 0.25-inch criterion. Given the absence of excessive lash (clearance between the rocker arm and the valve stem) in the system, there would be no adverse structural effects on the engine if the plug welds were to fail in shear, because the end fitting would be retained in the tubular rod. 
FaAA concluded that the friction-welded design is the most reliable of the three push rod designs. FaAA predicts that no fabrication crack will propagate, provided that an inspection and sampling plan is developed to meet the following recommended criteria:

- No surface cracks longer than $25 \%$ of the circumference (1 inch) should be allowed along the bond joint between the rod end and the tube.

- A destructive testing technique should be employed on a random sample of friction-welded push rods to examine the interior section for lack of fusion.

FaAA concluded that any friction-welded push rods that successfuliy complete 800 hours of inservice use at full load may be considered qualified for continued use.

4.17.3.3.2 Design Review/Quality Revalidation Reports. The Owners' Group makes no recommendations for routine inspection or maintenance beyond the initial inspections done for all engines in conjunction with the Phase If (OR/QR) component requalification efforts. Generally, this included dye-penetrant examination, sometimes on a sampling basis. For friction-weld push rods, the acceptance criteria allowed for no cracks along the bond line between the rod end and the tube (TOI OG February 1985). The forged-head design push rods are also to be visualiy inspected to ensure full insertion of the forged heads into the tubes (TOI OG January 1985).

\subsubsection{PNL's Review}

The PNL review encompassed primarily the FaAA report cited in Section 4.17.3. In addition, PNL reviewers considered supplementary information provided by the Owners' Group (Ray May 1984; June 1984), as well as calculations provided by FaAA (Coleman une 1984). Field observations by PNL consultants also were considered in PNL's conclusions.

\subsubsection{Reviewers}

The following PNL consultants participated in reviewing the push rod documentation: 
- S. H. Bush, Review and Synthesis Associates

- A. J. Henriksen, A. J. Henriksen, Inc.

- B. J. Kirkwood, Covenant Engineering

- the late A. Sarsten, Norwegian Institute of Technology.

In addition, J. C. Spanner of PNL's Nondestructive Testing Section reviewed nondestructive testing procedures for exalnining the push rods.

4.17.4.2 Results

PNL concurs with FaAA that push rods of the ball-end design are unsuitable for nuclear service because of an inappropriate material and an unfavorable service record. PNL agrees that all such rods in current nuclear service should be replaced with forged-head or, preferably, friction-welded push rods.

The primary concern with the forged-head design is that the resistance to crack growth is marginal for a combination of conditions of an unseated end fitting and a crack in the plug-weld zone. FaAA recognizes the possibility of crack growth early in the life of the push rod, and recommends examination of the push rods with liquid penetrant. Service experience, as evidenced by results of the Owners' Group $D R / Q R$ requalification examinations, has confirmed the presence of cracks in forged-head push rods.

PNL reviewed FaAA's analysis as presented in FaAA-84-3-17 (April 1984) and in handwritten calculations (Coleman June 22, 1984). These calculations support the conclusion that, under the circumstances assumed by FaAA, cracks could propagate in the forged ends. PNL also agrees with FaAA's observation that the end fitting of the forged-head design is contained within the tube and, with proper installation and adjustinent of the push rod and rocker arm components, would not break free unless the crack propagated around the entire rod and through the end fitting.

PNL concurs that FaAA's analysis of the friction-welded design provides a satisfactory basis for the conclusions drawn by FaAR regarding the adequacy of that design. PNL also concurs that the Owners' Group recomnendation, to verify production weld quality of friction-welded push rods by destructive examination on random samples from each future manufacturing lot, is prudent. The basis for the sampling procedure should be documented, as should the results. 


\subsubsection{Conclusions and Recommendations}

Based on a review of FaA's analytical and experimental investigation, and a review of related documents and field observations, PNL concludes that the designs of both the forged-head and the friction-welded push rods are acceptable for use in energency standby diesel engines in nuclear service. On this same basis, PNL concludes that the ball-end design should not be used in nuclear standby engines. To verify that individual push rods of the forgedhead and friction-weided designs are sound, PNL recomends the following inspections:

- Each push rod of the forged-head design should be inspected by liquid penetrant prior to installation or, if installed, at each major (5-year) engine disassembly. This should be repeated until it has been determined by 750 hours of operation at the load level used for surveillance testing that the push rod will not develop serviceinduced cracks. Push rods confirmed in this way need be examined only visually at subsequent major engine disassemblies. Push rods of the forged-head design exhibiting cracks larger than 0.25 inch should be replaced, preferably with push rods of the friction-welded design. Each forged-head rod should also be visually inspected one time to confirm that the head was fully inserted in the tube prior to welding.

- Each push rod of the friction-welded design should be inspected initially by liquid penetrant. If this initial inspection was not done prior to placing the push rods in service, it should be done at the first major (5-year) engine disassembly. If the friction-welded push rod has been previously inspected by liquid penetrant, then visual examination will suffice for future inspections. All friction-welded push rods with cracks should be replaced, preferably with push rods of the same design.

With regard to FaAA's observation that a sound friction weld produces "lips" inside the tube, PNL notes that radiography could be used as a simple and inexpensive method for ensuring the presence of the "lips." Several push rods could be examined simultaneously by placing them in a circular array and 
taking a panoramic radiograph of the friction welds at the center of the array. The friction welds at the opposite ends could be examined by rearranging the rods and taking a second radiograph. This approach is intended only as a suggestion for engine owners to consider when specifying nondestructive examinations for new rods.

\subsubsection{References}

Coleman, W. June 22, 1984. Handwritten calculations of the "Integrity of the Plug Weld Under Shear Loading" (recalculation using new "conservative" loads) by Failure Analysis Associates. The calculations were given to PNL at a meeting with FaAA on June 27, 1984.

Failure Analysis Associates. April 1984. Design Review of Push Rods for Transamerica Delaval Diesel Generators. FaAA-84-3-17, Palo Alto, California.

Ray, C. L., Jr. May 2, 1984. Letter DGTP-16-N-2 to Mr. H. R. Denton (NRC) transmitting sketches of the push rod and valve tappet and valve systern.

Ray, C. L., Jr. June 4, 1984. Letter OGTP-55 to Mr. Carl Berlinger (NRC) transmitting calculations on push rod fatigue behavior.

Ray, C. L., Jr. June 20, 1984. Letter OGTP-85 to Mr. Carl Berlinger (NRC) transmitting answers to questions on push rods.

TDI Diesel Generator Owners' Group (TDI OG). February 1985. TDI Diesel Generator Design Review and Quality Revalidation Report - River Bend Station. Revision 1 .

TDI Diesel Generator Owners' Group. January 1985. TDI Diesel Generator Design Review and Quality Revalidation Report - San Onofre Nuclear Generating Station. Revision 1. 
4.18 ROCKER ARH CAPSCREHS 


\subsection{ROCKER ARM CAPSCREWS}

PNL's review of the Owners' Group effort to evaluate the TOI engine rocker arm capscrews is presented in this section. More detailed documentation of the Owners' Group analyses is contained in PNL-5200-15 issued previously (Pacific Northwest Laboratory March 1985).

\subsubsection{Component Description}

The rocker arm capscrews secure the rocker arm assembly to the cylinder head through the rocker box and transmit the camshaft follower acceleration loads, valve spring loads, and residual cylinder pressure forces from the rocker am shaft to the cylinder heads. To perform these functions, the capscrews must be preloaded with a specified torque that results in sufficient clamping force on the rocker arm.

Transamerica Delaval has used capscrews of two designs on their diesel generators in nuclear service. Of the engines belonging to the Owners'Group member utilities, all but those at the Shoreham plant are fitted with the straight-shanked capscrews of the original design. The three Shoreham EDGs are fitted with capscrews having a narrower, necked-down shank, referred to as the inodified design.

\subsubsection{Fajiure History}

The Owners" Group reported that only a few isolated capscrew failures have occurred in nuclear standby service diesel engines. TDI concluded that these failures were the result of insufficient preload.

\subsubsection{Owners' Group Eyaluation}

Stone \& Webster Engineering Corporation addressed the rocker arin capscrew issue for the Owners' Group. The objective of the SWEC effort was to evaluate the capability of both capscrew designs to withstand the necessary preload and oscillatory loads without fatigue cracking, unacceptable preload relaxation, or thread distortion. 
4.18.3.1 Scope

The scope of the SHEC investigation encompassed four primary activities:

- Evaluate the stresses at the minimum cross-sectional area resulting from capscrew preloads, cam follower acceleration loads, valve spring loads, and residual cylinder pressure forces.

- Compare the total resultant stress to yield and endurance limits for the capscrew.

- Evaluate the thread specification for resistance to distortion and creep.

- Compare the material used in the rocker arm capscrews to the ASTM A-193 Grade B-7 industry standard.

The above analysis is documented in the SWEC report, Emergency Diesel Generator Rocker Arm Capscrew Stress Analysis (March 1984), and in a later supplement (Apri1 1984). Additional details are documented in SWEC calculation 11600.600/245.1-MS (June 1984).

\subsubsection{Conclusions}

SWEC concluded that capscrews of both designs are adequately fatigueresistant for the intended service if they are properly preloaded. SWEC noted that capscrews of the modified design have more margin for fatigue because of their higher endurance strength. Because the rocker arm capscrews are installed in a relatively cool region of the engine, SWEC concluded that creep and stress relaxation would not be experienced. Finally, because the yield stress of the material is not exceeded, SWEC concluded that the threads used in both designs will adequately resist distortion under the anticipated operating conditions and installation procedures.

\subsubsection{PNL's Reyjew}

PNL reviewed the SWEC documents cited in Section 4.18.3. Additional information provided by the Owners' Group (Ray June 1984) was considered also. 


\subsubsection{Reviewers}

Participants in PNL's review included:

- S. H. Bush, Review and Synthesis Associates

- P. J. Louzecky, Engineered Applications Corporation

- the late A. Sarsten, Norwegian Institute of Technology.

In addition, K. I. Johnson and M. C. C. Bampton of PNL's Applied Mechanics and Structures Section reviewed the methods used by SWEC in the stress analyses.

\subsubsection{Results}

PNL's evaluation of the SWEC analyses included a detailed review of the loads on the capscrews and resulting stresses. This review led to the following PNL comments:

- The calculated gas pressure at the exhaust valve opening appears low (78 psi). The pressure used in the force calculation was 100 psi for conservatism. However, based on the experience of PNL's diesel engine consultants, it is still substantially below the 130- to 140-psi pressure expected in a typical engine.

- The polytropic coefficient during expansion used in the caiculation was assumed to be 1.3. A preferable value, according to PNL's diesel engine consultants, would be 1.25 .

- The pressure behind the valve at opening was not considered. However, neglecting backpressure would have a conservative influence on the results.

- The calculations were based upon a theoretical otto cycle (combustion at constant volume), which employs expansion from a point of maximum pressure at top dead center (TDC). A combined Otto-Diesel cycle having expansion from some point after TDC would be more appropriate for a modern diesel engine.

- The rocker arri ratio seens to have been neglected in the calculation of forces on the intermediate push rod.

- The problem is actually three-dimensional rather than two-dimensional. The resultant push rod force is mainly counteracted by the 
nearest capscrew. Furthermore, the resultant force acts at an angle, creating a moment about the edge of the pivot shaft seating flat, which increases the capscrew load. In the SWEC calculations, the resultant force was split evenly between the two capscrews and converted into a purely vertical force.

In consideration of these factors, PNL consultant P. Louzecky recalculated the actual fatigue loads on the capscrews. Both the original design capscrew (8.7-ksi endurance limit) and the modified design capsciew (37.6-ksi endurance limit) show suitable margins to fatigue failure on a Goodman diagram.

Operating experience supports the observation that these capscrew designs are satisfactory. The few reported failures were attributed to inadequate preloads, which, in PNL's opinion, is a reasonable determination of the cause of failure.

\subsubsection{Conclusions and Recomendations}

Based on the evaluation of SWEC's analysis, PNL concluded that the SWEC cdlculations tended to produce nonconservative predictions of dynamic stresses in the rocker arm capscrews. However, PNL estimates that the amount of nonconservatism in these predictions is not sufficient to alter the basic conclusion reached in the SWEC report--that the capscrews of both designs are adequate for their intended service. The operating experience with these capscrews supports the adequacy of the designs, but also emphasizes the need to ensure that the proper preload recomnended by TDI is initially established and maintained. If the rocker arm capscrews are installed with the proper preload, they should not require any maintenance/surveillance until they are removed for other reasons.

\subsubsection{References}

Pacific Northwest Laboratory. March 1985. Review of Emergency Diesel Generator Rocker Arm Capscrews. PNi-5200--15, Richland, washington.

Ray, C. L., Jr. June 2D, 1984. Owners' Group Letter OGTP-85 to C. Berlinger (NRC) forwarding answers to PNL questions regarding the rocker and capscrews.

Stone \& Webster Engineering Corporation. March 1984. Emergency Diesel Generator Rocker Arm Capscrew Stress Analysis. Boston, Massachusetts. 
Stone \& Webster Engineering Corporation. April 1984. Supplement to the Energency Diesel Generator Rocker Arm Capscrew Stress Analysís. Boston, Massachusetts.

Stone \& Webster Engineering Corporation. June 1984. "Rocker Arm Supplemental Calculation." Caiculation 11600.60/245.1-MS. Boston, Massachusetts. 


\subsection{TURBOCHARGERS}




\subsection{TURBOCHARGERS}

This section addresses PNL's review of the Owners' Group actions taken to evaluate the Elliott Model 656 and 906 turbochargers. Two versions of the Model 65G are used in the DSRV-20 engines at the San Onofre Nuclear Generating Station. All other TOI engines owned by Owners' Group utilities employ the Model 90G. Because of the general design and performance similarity of the two models and the model-to-model similarity of the Owners' Group reviews, PNL reviews of both models are presented in this section.

Based on the component failure history, the Owners' Group identified two elements of the turbochargers requiring detailed analysis: 1) the thrust bearing and its lubrication system and 2) the nozzle ring assembly. PNL's review encompasses only these elements.

\subsubsection{Component Description}

The Elliott turbocharger consists of a single-stage gas turbine and a single-stage centrifugal compressor mounted back-to-back on a common shaft. Exhaust gases from the engine cylinders pass through a manjold and nozzle ring to drive the turbine, thereby using some of the exhaust-gas energy that otherwise would be lost. The compressor supplies air at higher-than-atmospheric pressure to the engine cylinders through a manifold system. This permits combustion of a correspondingly greater amount of fuel, thereby increasing the power output of the engine.

The turbocharger nozzle ring assembly is a nonrotating part of the turbine section that directs diesel engine exhaust gases at the proper angle into the turbine stage. It is inanufactured by positioning the guide vanes, which are AlSI type 304 stainless steel, in a fixture and casting the nickel-resistant nub directly around the vane roots. The ring is bolted into the turbine iniet casing shell.

Each 8-cylinder TDI engine at nuclear power plants is equipped with one Model 906 turbocharger, and each 16-cylinder engine is equipped with two. The 20-cylinder TDI engines at San Onofre are each equipped with four Model 65G turbochargers. 


\subsubsection{Failure History}

\subsubsection{Thrust Bearing}

Problems experienced with turbocharger thrust bearings used with TDI engines at nuclear power plants, and corrective action taken to prelubricate the bearings before planned starts, are discussed in two reports: FaAA-84-5-7 (July 1984) and FaAA-84-6-56 (July 1984). These reports address additional details beyond the brief summary that follows.

On December 16, 1980, TDI issued a 10 CFR Part 21 notification informing the NRC of a potential defect associated with the thrust bearing of the Elliott turbochargers installed on nuclear standby diesel generator sets. Turbocharger thrust bearings on the TDI engines at San Onofre had failed due to lack of prelubrication. Because the bearing was lubricated by a pump geared to the engine, it did not receive full oil flow until the engine was at operating speed. TDI recommended that a lube oil drip system be incorporated to provide continuous, but minisal, lubrication whenever an engine was on standby, thereby reducing turbocharger bearing wear associated with nuclear fast start requirements.

The system developed by TDI for this purpose provides lubrication from the standby recirculating oil system [the "before and after" (B\&A) system] through an orifice. Once the engine reaches running speed, lubrication is provided by the gear-driven oil pump. This modification was implemented for all engines in U.S. nuclear power piants subject to the 10 CFR Part 21 notice.

Following two thrust bearing failures in turbochargers at the Shoreham Nuclear Power Station, TDI issued a second 10 CFR Part 21 notification regarding Elliott turbochargers. This notice of February 15, 1984, again cited lack of thrust bearing prelubrication, and recomended an additional modification to permit manual initiation of full oil flow to the bearing via the standby recirculating oil pump (the $B \& A$ pump) prior to planned engine starts.

An alternative full-flow prelubrication system has been used on one TDI engine at the Grand Gulf Nuclear Station. This system provides prelubrication via an auxiliary lube pump that is separate from the $8 \& A$ system. 


\subsubsection{Nozzle Ring}

The failure history of turbocharger nozzle ring components is discussed in FaAA-84-5-7.1 (November 1984). FaAA's examination of a nozzle ring removed from a TOI engine at the Kuosheng (Taiwan). Nuclear Power Station is presented in FaAA-84-11-6 (November 1984). Components that have failed at various installations include vanes, capscrews, washers, and a hub. Some of these failures were discovered after as few as 65 hours of operation. None of the reported failures prevented continued operation of the turbocharger.

\subsubsection{Owners' Group Evaluation}

FaAA evaluated the adequacy of the thrust bearing, lubrication system, and the nozzle ring assembly for the Elliott Model 656 and Model 906 turbochargers used with TDI engines at nuclear power plants. FaAA's evaluations are presented in the four reports referenced in Section 4.19.2, above.

\subsubsection{Scope}

FaAA calculated the thrust bearing axial loads and used them in a bearing performance analysis to evaluate the adequacy of the lubrication systern. A rotor dynamics analysis was performed to determine dynamic modes and to verify the absence of rotor instabilities. FaAA performed a detailed review of the damaged nozzle ring components. This review included inservice inspections and detailed metallurgical analyses of damaged elements, but did not include an examination of missing vanes themselves because none was recovered.

Plant-specific inspections by the Owners' Group included 1) visual inspections of the bearings and nozzle rings for signs of wear or cracks, 2) determination of rotor float to confim that end clearances were within specifications, 3) verification of the presence and correct installation of the proper number of bolts, and 4) examination of the stationary nozzle ring for signs of distress. The Owners' Group also reviewed inaintenance and surveillance procedures and made recommendations for improvements. These efforts are documented in $D R / Q R$ reports for the various power plants. 


\subsubsection{Results}

The results reported by FaAA and the Owners' Group are summarized below.

\subsection{Thrust Bearings.}

- The thrust bearing axial loads were evaluated throughout the entire engine operating range. The maximum loads, occurring at the engine 2-hour overload rating, are about $1200 \mathrm{lb}$ for the Model $65 \mathrm{G}$ and 4750 lb for the Model 90G.

- The lubricating film resulting from the highest loads was found to be consistent with "thick film" lubrication. When this is taken together with lubricant temperature and flow analyses, the loadbearing capacity of the thrust bearing was found to be adequate under steady-state conditions.

- The axial loads during startup are approximately $70 \%$ of the load during the 2-hour overload conditions. With sufficient lubrication the thrust bearing will therefore perform adequately during startup.

- Inservice examinations of bearings from the Shorehain and Comanche Peak engines identified bearing wear from 2 to 25 mils that occurred prior to installation of the improved forced prelubrication systems.

\subsection{Nozzle Ring Components.}

- Vane failures are due to high-cycle fatigue arising from either engine exhaust gas pulsations or vibration during operation. In most cases, crack initiation apparently occurred with no evidence of material defects or pre-existing intergranular cracks. In other cases, crack initiation appeared to be assisted by intergranular corrosion of the vane material. Cracks observed in the trailing edge of one nozzle vane were apparently caused by impacts from foreign objects, possibly separated vanes. However, the separated vanes were never found.

- Capscrew failures are attributed to fatigue or intergranular stress corrosion cracking. Because the former results from improper 
torquing and the latter from improper heat treatment, it was concluded that these failures were due to manufacturing or installation deficiencies.

- Cracked washers occurred in only one installation. No failure analysis was conducted to identify the cause of cracking.

- The hub of one nozzle ring was found to be cracked. Elliott concluded that the nozzle ring was subjected to excessive operating temperatures and that the cracks were caused by thermal fatigue.

- No loss of engine availability has occurred as a result of nozzle ring component failures.

\subsection{Rotor Dynamics.}

- The rotor dynamic analysis has determined that the rotor system's natural modes at the various operating speeds will not be excited by rotor imbalance that falls within Elliott specifications, and that thrust rotor deflection (tilting) sufficient to degrade the performance of the thrust bearing will not occur.

\subsubsection{Conclusions and Recommendations}

The conclusions and recommendations steming from FaAA's evaluations are presented first, followed by those of the Owners" Group based on their DR/QR activities.

\subsection{FaAA Evaluations. FaAA concluded that the Elliott turbo-} charger thrust bearings are adequate for nuclear service, including preoperational testing and up to 40 automatic starts (i.e., starts with drip system prelubrication alone). FaAA also concluded that the Elliott Model 906 nozzle ring is adequate for nuclear standby service, even though isolated vane failures may occur with accumulated service. According to FaAA, the vane failures should not significantly affect turbocharger operation. Capscrew failures were not expected to recur, provided that the installation torque is to specifications and there are no manufacturing defects. 
FaAA's recommendations are as follows:

1. Modifications to permit initiation of full-flow prelubrication of the thrust bearing should be implemented, using either the $B$ \& $A$ or auxiliary lube pumps. Flow should be initiated 1 to 2 minutes prior. to a planned engine start and stopped approximately 30 seconds after the engine reaches full speed.

2. The TDI-recommended drip lubrication system should be retained for minimizing thrust bearing wear associated with automatic fast starts. In addition, the drip system bearing oil flow should be measured on each engine. The quantity of oil passing through the turbocharger should be at least $0.1 \mathrm{gph}$, but flow rates up to $0.35 \mathrm{gph}$ (based on TOI developmental testing) are recominnended to improve the effectiveness of the drip system.

3. Improved confidence in the reliability of the turbocharger thrust bearing can be obtained by inspecting thrust bearings for signs of excessive wear. These inspections should be performed on at least one turbocharger at each nuclear station following an initial 100 engine starts. Results of these inspections will determine whether any additional preventive maintenance inspections are required. These inspections should not be substituted for the current TDI recommendations for checking rotor assembly axial clearance.

4. Because the nuclear standby diesel generator sets may undergo automatic fast starts not associated with a potential LOOP/LOCA event, the turbocharger thrust bearings of any engine experiencing 40 such starts should be inspected for excessive wear and, if necessary, replaced. These starts should be included in the 100-start total discussed above. However, they should also be tabulated separately such that an inspection would oceur should 40 such starts be accrued prior to accumulating 100 total starts.

5. The oil flushing procedures and oil filtration maintenance programs at the individual nuclear stations should be reviewed to verify compliance with Elliott 10-micron filter recominendations. 
6. Turbocharger rotor axial clearance should be monitored to determine not only whether the clearance is within TDI/Elliott specifications, but also to review the trend of any increases, even though the total displacement may be within specification. Trends of increasing clearance could signify thrust bearing degradation.

7. Spectrochemical and ferrographic engine oil analysis should be employed to further expand the preventive monitoring of the turbocharger thrust bearing. Particular attention should be paid to copper level and particulate size, which could signify thrust bearing degradation.

8. During any turbocharger disassembly, the nozzle ring should be visually inspected for any apparent damage, inispositioned vanes, or missing vanes. If such are noted, damaged components should be replaced. During reassembly, capscrews should be torqued to specifications recommended by Elliott.

9. Exhaust gas temperatures should be monitored to ensure that they do not exceed Elliott specifications.

10. Elliott should consider the results of the FaAA study in future nozzle ring design efforts.

4.19.3.3.2 Owners' Group DR/QR. The Owners' Group conclusions and recomendations documented in the DR/QR reports for Shoreham, Comanche Peak, and San Onofre closely parallel those of FaAA for the turbocharger thrust bearings. Publication of these DR/QR reports generally preceded the FaAA evaluations of the nozzle ring components so that FaAA recommendations No. 8 and 9 from section 4.19 .3 .3 .1 were not addressed.

PNL notes that in the above-mentioned DR/QR reports, the Owners' Group states that "Additionally, full flow lubrication can be used through rolldown." This adds a period of bearing lubrication during engine coastdown not identified by FaAA. Further, in the San Onofre DR/QR report, the Owners' Group notes that there has been a reported case (non-nuclear) in which core plugs inside the turbocharger nozzle ring hubs have backed out and caused damage. In response to this, the Owners' Group recommends that, at the next turbocharger 
overhaul, but no later than the fourth refueling outage for any turbocharger, the nozzle ring core plugs be staked to prevent any movement.

\subsubsection{PNL's Review}

PNL and its consultants reviewed the FaAA reports identified in Section 4.19.2, as well as maintenance and surveillance recommendations presented in the Owners' Group $D R / Q R$ reports for Shoreham, Comanche Peak, and San Onofre. The inspection data provided by Southern California Edison Company on the San Onofre turbochargers was also reviewed. PNL representatives also observed partially disassembled turbochargers at the Catawba, Comanche Peak, Grand Gulf, and Shoreham nuclear stations.

PNL believes that the Owners' Group has identified the areas of greatest concern for the reliable operation of the Elliott turbochargers, namely, bearing lubrication and nozzle ring component integrity.

\subsubsection{Reviewers}

The following PNL consultants participated in the review and evaluation:

- S. H. Bush, Review and Synthesis Associates

- A. J. Henriksen, A. J. Henriksen, Inc.

- J. E. Horner, Seaworthy Systems, Inc.

- B. J. Kirkwood, Covenant Engineering

- P. J. Louzecky, Engineered Applications Corporation.

\subsection{9 .4 .2 Results}

4.19.4.2.1 Thrust Bearing Adequacy. PNL notes that the Owners' Group conclusion that the turbocharger thrust bearing will continue to function satisfactorily for at least 40 automatic starts with only drip prelubrication is based on the cited experiences at Shoreham (62 starts without any prelubrication) and Comanche Peak (over 60 starts with drip prelubrication system alone). In both instances the bearings were still serviceable. The basis for the selection of 40 automatic starts is therefore considered reasonable.

PNL has also viewed this from another perspective. On the basis of 1984 Licensee Event Report (LER) data, each operating reactor experiences, on 
average, approximately one automatic diesel-engine start per year. It can then be reasonably concluded that the inspection frequency recomended by the Owners' Group will not interfere unduly with engine availability.

PNL concurs with the Owners' Group recommendation for use of the full-fiow lubrication system during engine coastdown. In first-hand observations of turbocharger bearings in nuclear plants, PNL's consultants have noted at least one instance of discolored thrust bearing surfaces, apparently from high temperatures caused by heat conducted from the turbine after shutdown (NRC/Owners' Group meeting of February 11, 1985).

4.19.4.2.2 Nozzle Ring Component Adequacy. From data provided in FaAA-84-5-7.1 (November 1984), PNL noted that inspections have revealed a significant number of missing inlet nozzle vanes from Elliott turbochargers in nuciear service. Loss of engine operation due to the missing vanes has not been reported. Further, none of these missing blades has been found. FaAA and Dwners" Group representatives provided two explanations for the missing blades: 1) the vanes passed through the turbocharger whole or after being reduced to smaller particles by interaction with the turbine rotor, or 2) the vanes were kicked into the upstream piping where they were not seen during turbocharger maintenance. Noting that no missing blades have been found either upstream or downstream of the turbine, PNL's consultants initially suggested that these vanes may have been removed as part of the turbocharger tuning process. However, FaAA found no evidence that vanes had been purposely removed as part of the tuning process (NRC/Owners' Group meeting of February 11, 1985). Rather, the evidence showed that the vanes had failed in high-cycle fatigue.

To further investigate the argument that these blades can pass through the turbine without damaging the rotor, PNL infomally contacted personnel at General Electric Company, a large manufacturer of stearn turbines, and Phillips Pipeline Company, an owner of large diesel engines with Elliott turbochargers in pipeline pumping service. A member of the General Electric staff cominented that blades can pass through steam turbines without severely damaging them. However, a detached blade has occasionally been observed to damage a turbine. Phillips Pipeline Company reportedly has at least eight Nordberg diesel engines with Elliott turbochargers (model not specified). These turbocharyers have 
given generally satisfactory service in their more than 20 years of operation. However, the Phillips staff member cited one instance in which an inlet vane detached and severely damaged the turbine.

Based on the non-nuclear operating experience described above and the judgment of PNL's consultants, a definite potential exists for severe turbine damage or performance degradation from nozzle vane losses. FaAA's observations of fatigue cracks in inlet vanes of turbochargers that have been examined suggest to PNL that additional vane losses are probable. Accordingly, PNL believes that enhanced maintenance and surveillance of the turbocharger nozzle rings is necessary to reduce the possibility of turbocharger damage or performance degradation. Furthermore, PNL concludes from the available evidence that there is an apparent need for design improvements to get at the root cause of the failures.

In PNL's opinion, intergranular corrosion from the hot exhaust gases may have contributed to the observed capscrew and washer failures. Exposure of these components to the exhaust gases could initiate intergranular cracking. Particularly during rapid start transients, the stress concentration due to such cracking could exceed the strength of these components, thus leading to failure.

PNL notes Elliott's observation reported in FaAA-B4-5-7.1 (November 1984) that cracks found in one hub of a nozzle ring removed from an engine at Grand Gulf were caused by thermal fatigue, and that the nozzle ring was subjected to operating temperatures above those specified by the manufacturer. This reinforces FaAA's recomnendation that exhaust gas temperatures be monitored to ensure that they do not exceed Elliott specifications. However, recognizing that additional chemical reaction takes place between the cylinder head exhaust valves and the inlet to the turbine, PNI. believes that the turbine inlet temperature also should be monitored directly with appropriate instrumentation. This would provide a direct measure of the temperature to which the turbocharger is exposed.

The turbine inlet temperature may also provide diagnostic information on the condition of the turbocharger. If enough vanes are lost to significantly decrease the efficiency of the turbocharger, the engine will receive less air 
to operate at a given load. This will affect the combustion kinetics for that load. One consequence may be a higher temperature of the reacting mixture (due to a slower rate of chemical reaction) when the exhaust valves open, possibly accompanied by a greater level of chemical reaction downstream of the exhaust valves. If so, an upward trend in temperature measured at the turbine iniet could be indicative of nozzle vane distress.

4.19.4.2.3 Other Turbocharger Evaluations. During the PNL evaluation of the adequacy of the turbocharger bearing and nozzle rings, flange and pioing alignment was noted to have been a source of problems (e.g., Grand Gulf and Catawba). This is viewed as a plant-specific problem involving appropriate installation procedures to resolve it.

The question of adequate surge margin was raised by PNL in its evaluation. PNL notes that, although TDI reported that surge is observed in transients, no field experience suggests that steady-state operation involves deleterious surge, or that the transient occurrences have produced turbocharger problems.

\subsubsection{Conclusions and Recomendations}

PNL concludes that the components of the Elliott turbochargers evaluated during ths review are suitable for continued service. This conclusion is subject to the following coments:

- FaAA recommendations (see Section 4.19.3.3.1) regarding the installation of the drip and full-flow prelubrication systems should be implemented.

- FaAA recomendations for maintenance and surveillance, including bearing inspections and preventive maintenance, should be fully implemented. These are identified in Section 4.19.3.3.1.

- The additional maintenance and surveillance recommendations identified by the Owners' Group in their DR/QR reviews and summarized in Section 4.19.3.3.2 should be implemented. These include l) using full-flow lubrication during engine coastdown and 2) staking the nozzle ring core plugs to prevent any movenent. The staking should be performed during the next turbocharger overhaul, but no later than the fourth refueling outage for any turbocharger. 
- The oil analysis, including both spectrochemical and ferrographic analyses identified by FaAA, should be performed quarterly to provide early evidence of bearing degradation.

- The nozzle ring components and inlet guide vanes should be visually inspected at each refueling outage (rather than at times of turbocharger disassembly as recommended by FaAA) for missing parts or parts showing distress. If such are noted, the entire ring assembly should be replaced. The frequency of inspections may be relaxed as appropriate after the causes of earlier failures are firmly established and corrective actions to prevent recurrence are implemented.

- PNL concurs with the FaAA recomnendation that engine exhaust temperature be monitored to ensure that it does not exceed Elliott recommendations. For reasons discussed in Section 4.19.4.2.2, PNL also recommends that the turbine inlet temperature be monitored directly with appropriate instrumentation.

- Considering the potential for turbine blade damage from fractured vanes, PNL recomends that investigations should continue into the cause and consequences of missing stationary vanes. Furthermore, on the basis of the Owners' Group conclusion that the vanes are fracturing from service-induced conditions, PNL recommends that actions leading to design and/or materials improvements be promptly undertaken. (a)

\subsubsection{References}

Failure Analysis Associates (FaAA). July 1984. Design Review of Elliott Model 90G Turbocharger Used on Transamerica Delaval DSR-48 and DSRV-16 Emergency Diesel Generator Sets. FaAA-84-5-7, Palo ATto, California.

(a) Just before this report was printed, PNL learned that at least one turbocharger at the Perry Nuclear Power Plant (PNPP) has been determined to have five or more vanes missing following only 100 hours of operation. Much or all of the operating time was accumulated following installation of the TOI-recomnended bearing prelubrication system, PNL has not received Owners' Group or PNPP reports on this occurrence. However, it reinforces the PNL recomendation that the cause be determined and remedial action be initiated to prevent future vane failures. 
Failure Analysis Associates (FaAA). July 1984. Design Review of Elliott Model 65G Turbocharger Used on Transamerica Delaval DSRV-12-4 and DSRV-20-4 Emergency oiesel Generator Sets. FaAA-84-6-56, Palo ATto, California.

Failure Analysis Associates (FaAA). November 1984. Design Review of El liott Model 90G Turbocharger Used on Transamerica Delaval DSR-48 and DSRV-16-4 Emergency Diesel Generator Sets - Nozzle Ring As Senbly Supplement. FaAA-84-5-7.1, Palo Alto, California.

Failure Analysis Associates (FaAA). November 1984. Examination of Vane Failures of an Elliott Nozzle Ring from Kuosheng (Tajwan) Nuclear Power Station. FaAA-84-11-6, Palo Alto, California.

TDI Diesel Generator Owners' Group. December 1984. TOI Diesel Generator Design Review and Quality Revalidation Report - Shoreham Nuclear Power Station. Revision 1.

TDI Diese1 Generator Owners' Group. January 1985. TDI Diesel Generator Design Review and Quality Revalidation Report - Comanche Peak Steam ETectric Station. Revision 1.

TDI Diese1 Generator Owners' Group. January 1985. TDI Diesel Generator Design Review and Quality Revalidation Report - San Onof re Nuclear Generating Station. Forwarded to NRC (H. R. Denton) as Enclosure 1 of Southern California Edison Company (M. O. Medford) letter dated September 3, 1985.

U.S. Nuclear Regulatory Comission. February 11, 1985. Transcribed proceedings, "Nuclear Regulatory Commission Staff Meeting with TDI Uwners" Group, Bethesda, Maryland." Ace-Federal Reporters, Inc., Washington, D.C. 

DISTR IBUTION

No. of

Copies

OFFSITE

10

$$
\begin{aligned}
& 10 \text { C. Berlinger } \\
& \text { Division of Licensing } \\
& \text { Office of Nuclear Reactor } \\
& \text { Regulation } \\
& \text { I.S. Nuclear Regulatory } \\
& \text { Comission } \\
& \text { Washington, DC } 20555 \\
& \text { M. Carrington } \\
& \text { Division of Licensing } \\
& \text { Dffice of Nuclear Reactor } \\
& \text { Regulation } \\
& \text { U.S. Nuclear Regulatory } \\
& \text { Commission }
\end{aligned}
$$

Washington, DC 20555

D. Crutchfield

Division of Licensing

Office of Nuclear Reactor Regulation

II.S. Nuclear Regulatory Commission

Washington, DC 20555

M. Kaltman

Division of Licensing

Office of Nuclear Reactor Regulation

U.S. Nuclear Regulatory Commission

Washington, DC 20555

H. Thompson

Division of Licensing

Office of Nuclear Reactor Regulation

U.S. Nuclear Regulatory Commission

Washington, DC 20555
No. of

Copies

M. Williams

Division of Licensing

Office of Nuclear Reactor Regulation

U.S. Nuclear Regulatory Commission

Washington, DC 20555

B. Buckley

Division of Licensing

Office of Nuclear Reactor Regulation

U.S. Nuclear Regulatory Comission

Washington, DC 20555

S. Burwell

Division of Licensing

Office of Nuclear Reactor Regulation

U.S. Nuclear Regulatory Comnission

Washington, DC 20555

D. Hood

Division of Licensing

Office of Nuclear Reactor Regulation

U.S. Nuclear Regulatory Commission

Washington, DC 20555

D. Houston

Division of Licensing

Office of Nuclear Reactor Regulation

U.S. Nuclear Regulatory Commission

Washington, DC 20555 
No. of

Copies

K. Jabbour

Division of Licensing

Office of Nuclear Reactor Regulation

U.S. Nuclear Regulatory

Commission

Washington, DC 20555

T. Kenyon

Division of Licensing

Office of Nuclear Reactor

Regulation

U.S. Nuclear Regulatory

Commission

Washington, DC 20555

E. McKenna

Division of Licensing

Office of Nuclear Reactor

Regulation

U.S. Nuclear Regulatory

Commission

Washington, DC 20555

M. Miller

Division of Licensing

Office of Nuclear Reactor

Regulation

U.S. Nuclear Regulatory Cominission

Washington, DC 20555

S. Miner

Division of Licensing

Office of Nuclear Reactor Regulation

U.S. Nuclear Regulatory Commission

Washington, DC 20555

C. Stahle

Division of Licensing

Office of Nuclear Reactor Regulation

U.S. Nuclear Regulatory Commission

Washington, DC 20555
No. of

Copies

\section{J. Stefano}

Division of Licensing

Office of Nuclear Reactor

Regulation

U.S. Nuclear Regulatory

Commission

Washington, DC 20555

E. Weinkam

Division of Licensing

Office of Nuclear Reactor

Regulation

U.S. Nuclear Regulatory

Commission

Washington, DC 20555

2 Public Document Room

Division of Technical

Information and Document Control

U.S. Nuclear Regulatory

Commission

washington, DC 20555

H. M. Hardy

100 Carolina Avenue

Seneca, SC 29678

A. J. Henriksen

A. J. Henriksen, Inc.

7731 N. Fairchild Avenue

Fox Point, WI 53217

J. E. Horner

Seaworthy Systems, Inc.

36 Main Street

Essex, CT 06426

B. J. Kirkwood

Covenant Engineering

17200 County Road 362

Buena Vista, CO 81211

P. J. Louzecky

Engineered Applications Corp.

1674 Witherbee Road

Troy, MI 48084 
No, of

Copies

N. N. Rivera

Designers and Planners, Inc. 1725 Jefferson Davis Highway Arlington, VA 22202

L. Wechsler

Tracor Hydronautics

7210 Pindell School Road

Laure1, MD 20707

A. H. Wende 1

Tracor Hydronautics

7210 Pindell School Road

Laure?, MD 20707

\section{FOREIGN}

\author{
H. Engja \\ Norwegian Marine Technology \\ Research Institute $\mathrm{A} / \mathrm{S}$ \\ Haakon, Haakonsonsgt. 34 \\ P.0. Box 4125 Valentinlyst \\ N-7001 Trondheim, Norway \\ E. Sanberg \\ Oet Norske Veritas \\ Ship Division \\ P.0. Box 300 \\ $\mathrm{N}-1322$ Hovik \\ Dslo, Norway \\ T. W. Spaetgens \\ 6963 Fremlin Street \\ Vancouver, British Columbia \\ Canada V6P $3 W 3$
}

No. of

Copies

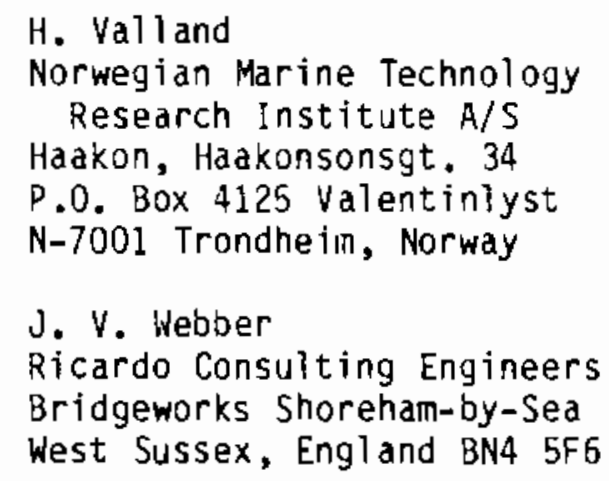

H. Vall and

Norwegian Marine Technology

Research Institute A/S

Haakon, Haakonsonsgt. 34

P.0. Box 4125 valentiniyst

$\mathrm{N}-7001$ Trondheim, Norway

J. V. Webber

Ricardo Consulting Engineers

Bridgeworks Shoreham-by-Sea

West Sussex, England BN4 5F6

\section{ONSITE}

DOE Richland Operations of fice

$$
\text { A. Rizzo/M. Plahuta }
$$

26 Pacific Northwest Laboratory
5. Bush
D. 0ingee
R. Dodge
W. Gintner
W. Laity (10)
d. Nesbitt
W. Richmond
J. Spanner
L. Van Fleet
F. Zaloudek
Technical Information (5)
Publishing Coordination (2) 
